\title{
Critical Communities of Practice in Distance American Sign Language Interpreter Education
}

Danielle South

dsouth@mix.wvu.edu

Follow this and additional works at: https://researchrepository.wvu.edu/etd

\section{Recommended Citation}

South, Danielle, "Critical Communities of Practice in Distance American Sign Language Interpreter Education" (2021). Graduate Theses, Dissertations, and Problem Reports. 8324.

https://researchrepository.wvu.edu/etd/8324

This Dissertation is protected by copyright and/or related rights. It has been brought to you by the The Research Repository @ WVU with permission from the rights-holder(s). You are free to use this Dissertation in any way that is permitted by the copyright and related rights legislation that applies to your use. For other uses you must obtain permission from the rights-holder(s) directly, unless additional rights are indicated by a Creative Commons license in the record and/ or on the work itself. This Dissertation has been accepted for inclusion in WVU Graduate Theses, Dissertations, and Problem Reports collection by an authorized administrator of The Research Repository @ WVU.

For more information, please contact researchrepository@mail.wvu.edu. 
Critical Communities of Practice in Distance American Sign Language Interpreter Education

Danielle V. South

\begin{abstract}
Dissertation submitted
to the College of Education and Human Services

at West Virginia University

in partial fulfillment of the requirements for the degree of
\end{abstract}

Doctor of Philosophy in Education

Melissa Sherfinski, Ph.D., co-chair

Samuel Stack, Ph.D., co-chair

William Beasley, Ed.D

D. Jake Follmer, Ph.D.

Department of Curriculum and Instruction/Literacy Studies

Department of Counseling and Learning Sciences

Morgantown, West Virginia

2021

Keywords: American Sign Language, ASL, ASL interpreter education, distance education, instructional design

Copyright 2021 Danielle South 


\begin{abstract}
Critical Communities of Practice in Distance American Sign Language Interpreter Education
\end{abstract}

Danielle South

American Sign Language interpreter education must center the Deaf community in the learning environment. In a distance-education environment, the task of connecting students with the Deaf community is challenging due to time constraints and geographic separation. In order to facilitate meaningful, engaging, experiential online learning, I developed a critical community of practice (CCoP), similar to Lave \& Wenger's (1991) community of practice (CoP). I facilitate my research through one primary research question and three subquestions: (1) How does integration of the critical community of practice framework impact students' learning in an online languageinterpreting-based learning environment? (a) How does critical discourse analysis enhance students' English-to-American Sign Language interpretations? (b) How does self-reflection influence the development of interpreting skills? (c) How do students perceive and then self-actualize the role of an American Sign Language interpreter?

If interpreter education programs strive to graduate competent interpreters, interpreter educators must focus on the development of critical consciousness, the interpersonal capacity for interpreters to relate the impact of their notions, biases, and perspectives to the interpreting interaction to render messages faithfully. In this study, students analyzed and acted based on their personal experiences through various activities, including self-assessment, reflective vlogs, and peer feedback, aimed at promoting and connecting their usage of critical discourse analysis in interpreting.

This project employs qualitative research methods, digital micro-ethnography and action research. I study the culture of our digital, distance learning environment and study how, in this context, I respond to student progress and challenges. The results demonstrate the benefits of critical discourse analysis, and I analyze and discuss my experiences to yield insight into how future iterations of distance interpreter education courses could be improved to increase critical consciousness. I find that the critical community of practice facilitates meaningful discussions, which leads students (and the instructor) to enhanced insight into interpreting decisions. 


\section{ACKNOWLEDGMENTS}

This work is the summation of hard work, perseverance, and a lot of love.

To my committee members, Dr.s Sherfinski, Stack, Beasley, and Follmer: The sum of your work is immeasurable. You have given me more than I could ever describe in words. Thank you for your patience, your wisdom, and your unwavering faith in me. Together, we made a dream come true. I am honored to know you and to have been able to work together. I am forever grateful to you all. A special thank-you to Dr. Sherfinski for never giving up on me through this process and pushing me to get through this work. I owe my success to you!

To the ASL professor who changed my life: Thank you for giving me a chance, for believing in me. You helped make a dream come true. I am forever grateful for your belief in my capabilities.

To the ASL students who allowed me to study them: Thank you for your patience, support, and tenacity. You have no idea what your time means to me. I cherished our time together in-class and now do so every time we get to catch up.

To my family: Thank you for your love, patience, and demonstrations of support while I conquered this mountainous goal. Here's to a second doctor in the family!

To my Kenney: You are my favorite surprise, and I will always be grateful to Dr. Stack for scheduling his first Nature of Inquiry class at the time he did. Thank you for picking up all of the pieces every day and every night I believed I could not make this dream come true. And, of course, thank you for letting me steal the blankets nearly every night so I could sleep like a baby. The good, the bad, the ugly. I get it now. I love you.

And, to my Jordan: Thank you for being alive and bringing me so much emotion. You inspire me. You are my fuel and my fire. Thank you for your patience and your sacrifice while I accomplish this dream. I love you always. 


\section{DEDICATION}

To the Deaf Community:

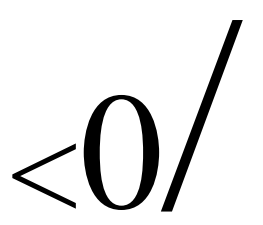


Table of Contents

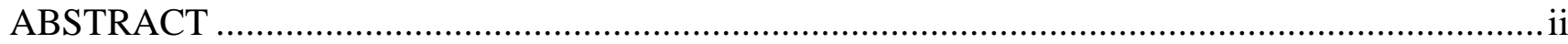

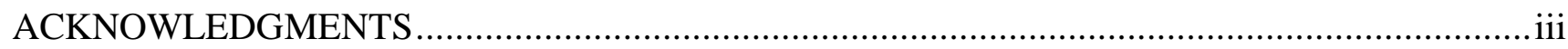

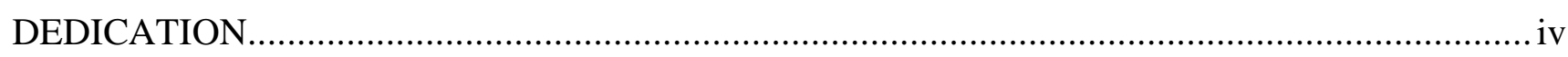

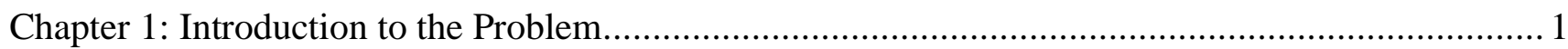

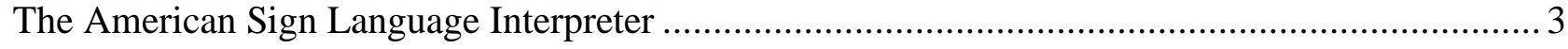

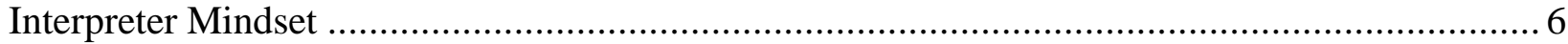

Educating the American Sign Language Interpreter.................................................. 7

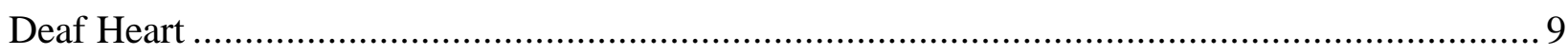

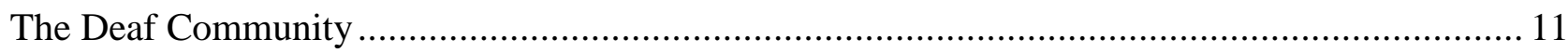

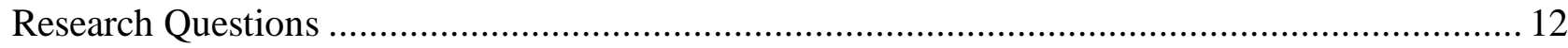

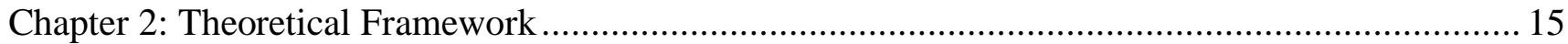

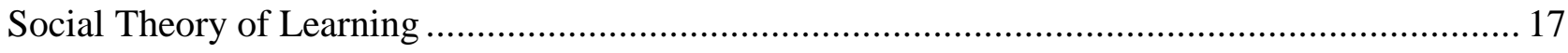

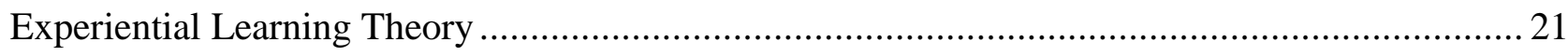

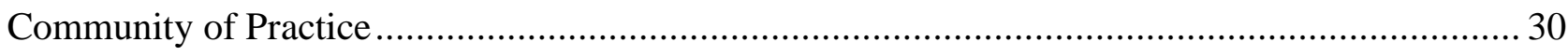

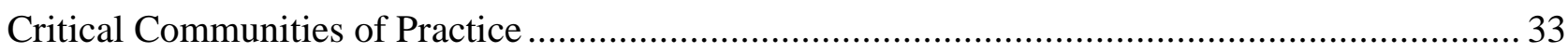

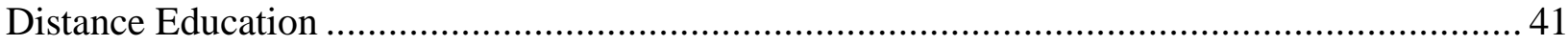

Distance interpreter education .............................................................................. 44

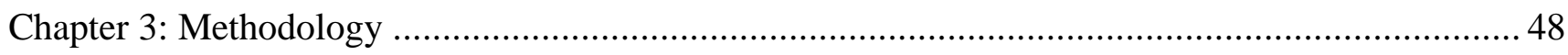

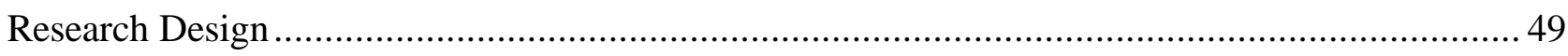

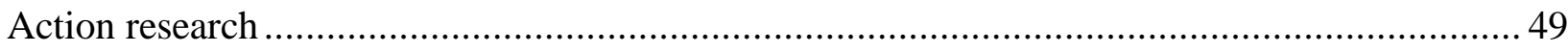

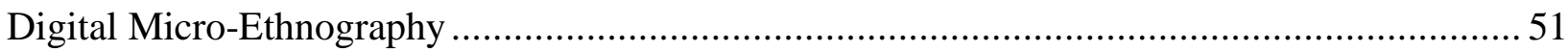

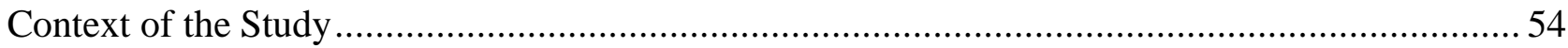

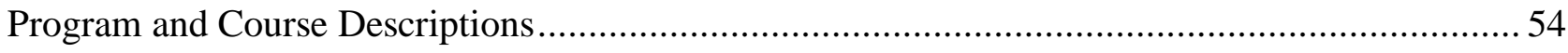

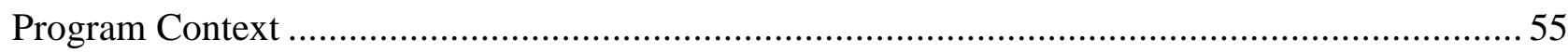

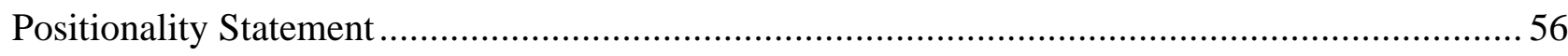

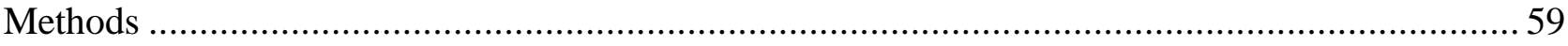

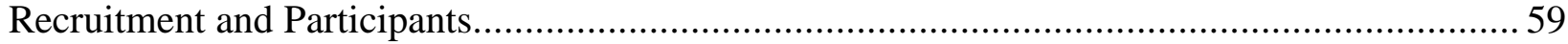

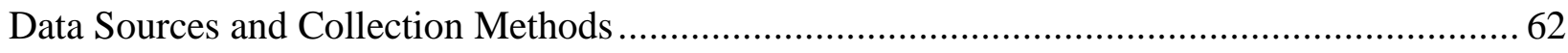

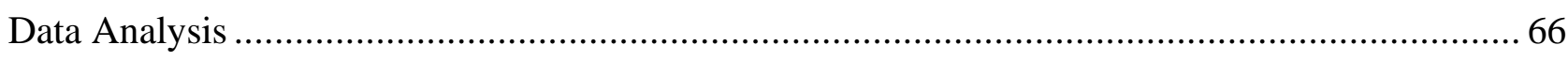

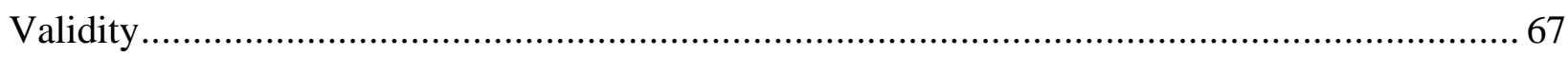

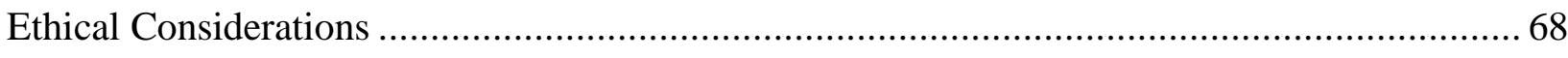

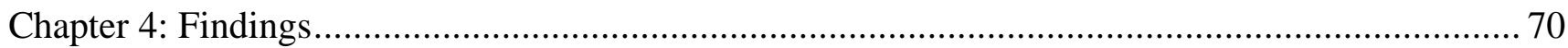


How does the integration of the critical community of practice framework impact students' learning in an online language-interpreting-based environment? .............................................. 70

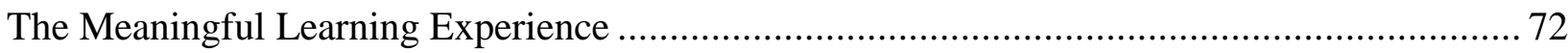

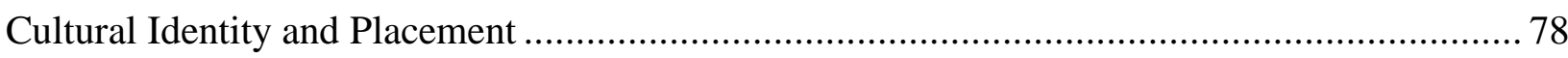

How does individual /group self-reflection influence the development of interpreting skills?.......88

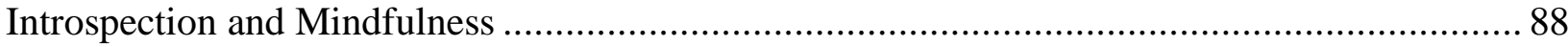

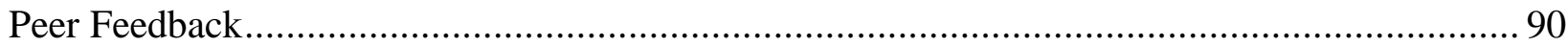

How do students perceive and self-actualize the American Sign Language interpreter role? ........ 94

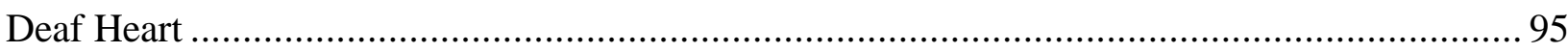

How does critical discourse analysis as a teaching tool enhance students' English-to-American Sign

Language interpretation? ........................................................................... 102

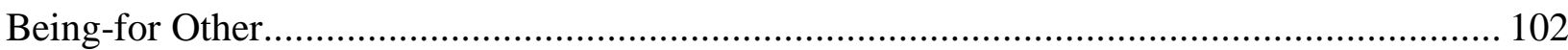

Chapter 5: Discussion, Implications and Conclusion ........................................................ 116

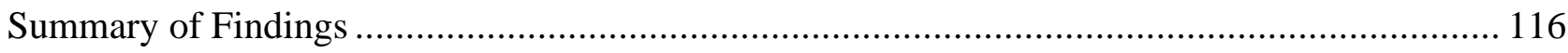

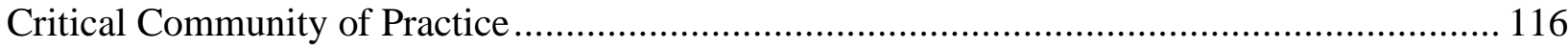

Women in a Critical Communities of Practice................................................................ 117

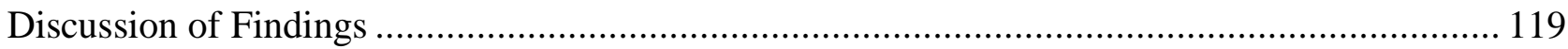

Critical discourse analysis, self-reflection, and peer feedback change interpretation planning.. 119 Students create their interpreter role self-perceptions in the presence of an engaging community.

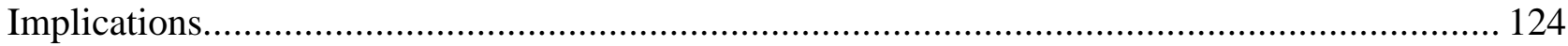

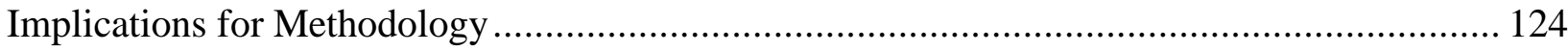

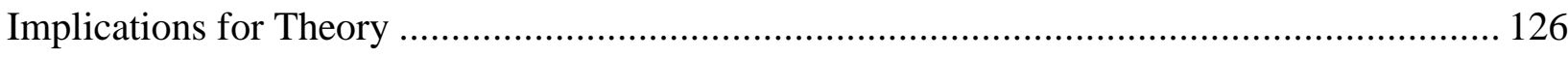

Implications for Practice and Pedagogy ........................................................... 128

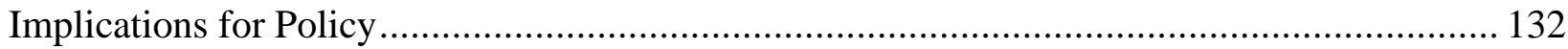

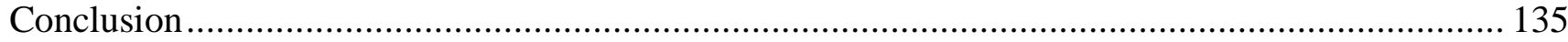

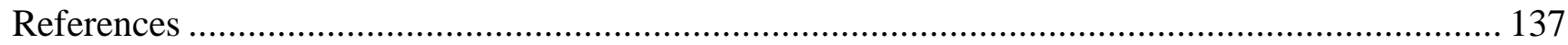




\section{List of Figures}

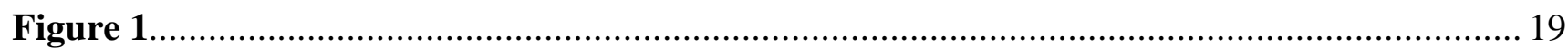

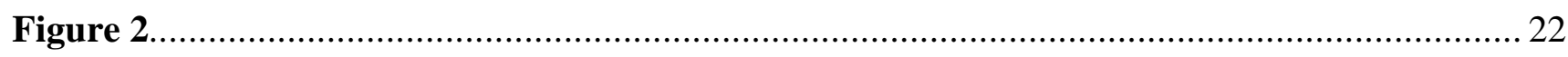

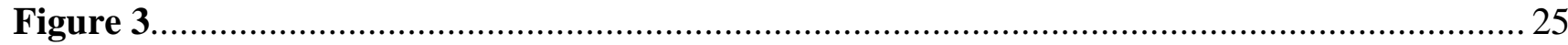

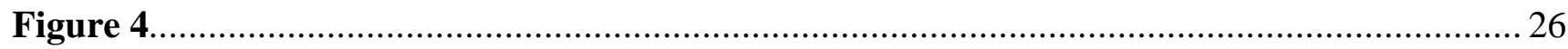

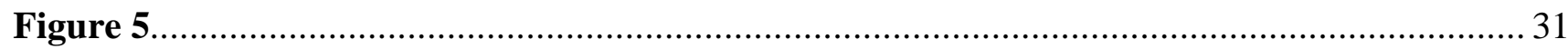

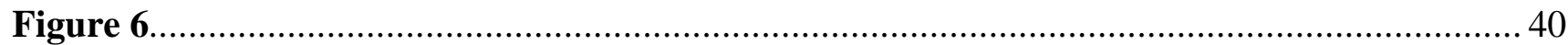

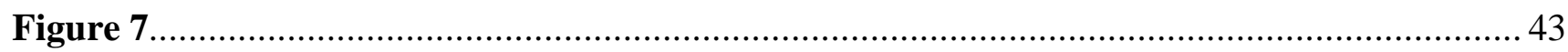

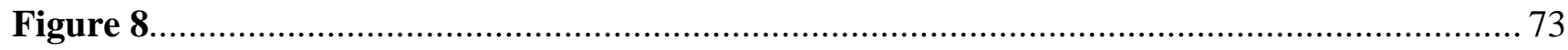

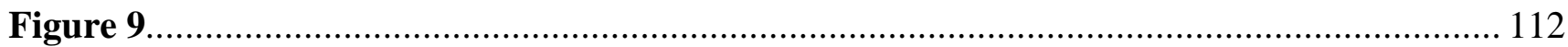




\section{List of Images}

$\begin{array}{lr}\text { Image 1 } & 92 \\ \text { Image 2 } & 104 \\ \text { Image 3 } & 105 \\ \text { Image 4 } & 123\end{array}$




\section{Chapter 1: Introduction to the Problem}

The United States population experienced a drastic shift in public policy in the 1960s and early 1970s that affected people identified as having a disability. The Kennedy (1960-1963) and Johnson (1963-1969) administrations responded to the Civil Rights Movement via expansive national laws and large national government grants (Civil Rights Act, 1964). In 1955, William C. Stokoe published his defense of American Sign Language's (ASL) position as a language, not a gestural system. Stokoe's publication was the catalyst for significant change in the Deaf community. In 1964, the Registry of Interpreters for the Deaf (RID) was established and in 1965, RID published the interpreting handbook, Interpreting for Deaf People. The year 1965 was a sign language-rich year: Stokoe, Casterline, and Croneberg also published A Dictionary of American Sign Language on Linguistic Principles (1965). At this time, American Sign Language instruction practices began to shift, and seven years later, Lou Fant published Ameslan: An Introduction to American Sign Language (1972), which purported a significant distinction between English and ASL. The Deaf community seized the opportunity to demonstrate the viability of ASL as a language and cultural distinction.

Prior to Stokoe's first revolutionary publication, sign language interpreting (SLI) in the United States was not considered full-time employment nor was interpreting done as a professional service (Fant, 1990). Most sign language interpreters were family, friends, or community members who knew the language. These individuals generously volunteered their time. However, during a Vocational Rehabilitation Administration (VR) workshop June 14 to 17, 1964 at Ball State Teachers College, the participants identified that "the major problem was the shortage of competent interpreters, so the recruitment of interpreters and people to become interpreters were priority matters" (Fant, 1990, pp. 1-2). 
Frankly, when I started to outline this chapter, I was immediately inclined to begin with the historical patterns of institutionalized oppression of the Deaf (Morkovin \& Moore, 1960), specifically because the history of the Deaf community has so significantly shaped the accepted practices in the interpreting profession. Until 1964, sign language interpreters were hand-chosen by Deaf community members (Fant, 1990). At this professional shift, the onus of interpreter education fell to formal training institutions, like two- and four-year post-secondary educational systems. This transition disempowered the Deaf community in the interpreter education process. Since that time, it has been the responsibility of the institution to educate sign language interpreting students on cultural compassion, cognitive capacity, and linguistic competence required in the field.

The institutionalization of interpreter education facilitates an accessible location for training for more hearing individuals, but it veers skill development away from an experiential model. The transition has come at a cost (Monikowski \& Peterson, 2005, p. 188). The Deaf community loses its voice in the interpreter training process when interpreter education is controlled by mostly hearing individuals at post-secondary institutions. Some schools, like the National Technical Institute for the Deaf (NTID) in Rochester, New York, have made programmatic adjustments such as service learning to re-center the Deaf community and its members in interpreter education and subsequently, the interpreting profession (ibid.). In 2006, the collaboration between six stakeholder organizations, including Deaf and hearing members, led to the creation of the Commission on Collegiate Interpreter Education (CCIE), which seeks to promote professionalism in the field of sign language interpreter education through the process of accreditation. 
I could deconstruct the ways the neoliberal system disenfranchises the Deaf and interpreting (student and professional) communities, but I focus my energy to determine what steps I can take as a professor of future interpreters to mitigate the gap that has been created in interpreter education, while re-centering the Deaf community in the interpreting profession. I will orient the reader in this chapter by first defining the field of American Sign Language interpreting and move into the definitions of the interpreter mindset and Deaf Heart. I will outline the current field of interpreter education before moving on to a brief background of the Deaf community. Once the groundwork has been set forth, I will present the four research questions that guide this specific study.

\section{The American Sign Language Interpreter}

An interpreter's work, in a spoken or signed language, is "performed in the 'here and now' for the benefit of people who want to engage in communication across barriers of language and culture" (Pochhacker, 2004, pp. 9-10). To many, the immediacy of the process is what distinguishes interpretation from translation. To others, the difference between the two practices is the modality via which language is presented: spoken or written. ASL interpreters may not always orally speak, but their renderings are never written. For example, ASL interpreters provide sight interpretations, the process of interpreting text to ASL, but the target language, the language into which the message is being interpreted, is still dialogical. For this research, the professional field will be referred to as "interpreting," and the professionals as "interpreters," not "translators."

The interpreting field is based on interactive communication, a Deaf participant interacting with a hearing counterpart. The interpreter controls the entire interaction by accounting for cultural and linguistic discrepancies. The interpreter controls turn-taking, conveys 
intention, and decides who has a voice in the interaction. Consequently, interpreters wield tremendous power. The interpreting and Deaf communities have searched to find the appropriate role for the ASL interpreter. At one early point in the interpreting profession, the interpreter was the helper to care for the "poor, sad deaf victim." The field has evolved significantly since then, but professional interpreters continually critically reflect on their positionality. During one Registry of Interpreters for the Deaf (RID) conference, Charlotte Baker-Shenk (1991) revealed some truths about the repercussions of the interpreting profession's "helper" history.

What else is true?

$[\ldots]$

- That Deaf people know we [interpreters] are hearing- by birth, we are members of the class that has hurt them.

- That Deaf people, in certain situations, are relying on us, using [us], to get what they want- information from a doctor, access to a public lecture, the opportunity to ask a question in a classroom or state an opinion at a board meeting, whatever.

In many situations, we stand between the Deaf person and what they want. That gives us great power. In most cases, we are the only ones there who have access to both languages and cultures. And that also gives us great power (BakerShenk, 1991, pp.2-3).

Reflecting on Baker-Shenk's presentation, one can see why the Registry of Interpreters for the Deaf created the Code of Professional Conduct. The Code of Professional Conduct (CPC) for interpreters outlines how an interpreter should behave while working with the Deaf. Interpreters are required to abide by these professional expectations. If not careful, the interpreter 
could be seen as a parasite (Cokely, 2005), benefitting financially off of the legal distinction that deafness is a disability. The National Association of the Deaf (NAD), an advocacy organization, lists an American Sign Language interpreting resource page that defines expectations of interpreters. NAD firmly expresses the need for capable interpreters, those who can receptively and expressively "interpret accurately, effectively, and impartially, using any necessary specialized vocabulary." Clients have a right to interpreters who know what they are doing and do it well. Likewise, other interpreters deserve colleagues who uphold the name of the interpreting profession by practicing, reflecting on, and developing all relevant interpretation skills.

A new interpreter's competence is dependent upon the completed interpreter training experience. How can an interpreter training program prepare a student for the unpredictable nature of the interpreting field? To David A. Kolb (1984), "learning is the process whereby knowledge is created through the transformation of experience" (p. 38). During these experiences, students are exposed to heteroglossia and polyphony, diversity of language and voice (Bakhtin, 1981). Simulating interpreting experiences for American Sign Language interpreting students is often difficult because "users of sign language represent a particularly unusual linguistic community, in that 90-95\% (Schein \& Delk Jr, 1974) of them do not share a primary language with their parents and siblings" (Neidle et al., 2000). In conjunction with the innate fact that all humans are different, interpreting students need exposure to challenging interpreting situations that require significant cultural navigation.

Students must somehow learn to be prepared to accommodate every potential linguistic and cultural nuance from clients who use ASL (and those who speak) while accounting for their own personal biases. Interpreters cannot be neutral, emotionless robots, present in an 
interpersonal interaction without feeling their humanness. Communication is innately personal. Words are drenched in subtextual meaning. This phenomenon is sometimes referred to as linguistic idealism, the concept that language is affected by history and utilized as the manner of thought and motivation (Dilman, 2002), no matter the intent to express oneself in an unbiased manner: "[...] We cannot guarantee neutrality in our interpretations and analyses. This is because our histories and memories are shot through with gendered, classed, racialized and other 'excluding' understandings which give us our particular perspectives on the world" (Blair, 1998, p. 244). The ability for interpreters to perceive others' perspectives of the world and faithfully render the intended message is called the interpreter mindset, a way of thinking I strive to develop in my students.

\section{Interpreter Mindset}

The interpreter mindset consists of four separate acknowledgements. First, the interpreter acknowledges that languages are structured systems used to represent reality. Every region has their method of communication representation with its respective history; one is not superior over another. Second, the interpreter recognizes the significant role of practical reasoning in developing and delivering target language messages. Details are essential to a faithful interpretation, but the relevance of those details is not always obvious. Third, the interpreter is constructive. Interpreting focuses on the portrayal of an original thought from the source language into the target language, accounting for experiential and cultural differences between people and languages. And finally, the interpreter maintains and delivers a standard of highquality services. Many individuals can attempt an interpretation, but a skilled interpreter can produce a clear interpretation for faithful renderings of the source message.

Interpreter knowing, or the interpreter mindset, centers around the tolerance of ambiguity (TA). The second characteristic of knowing, the role of practical reasoning, is a prime example. 
The interpreter must be able to decipher meaning, which often means accepting tangential paths in conversations. The very nature of interpreting requires tolerance of the ambiguous, principally because the interpreter has no idea what either interlocutor is going to say at any point in time (though, there are ways to infer).

It must be noted that TA is a characteristic of a good second language learner. Of course, second language acquisition is a separate field from interpretation studies, but Rubin's (1975) validation of why good guessers make good language learners applies to ASL interpretation. Rubin states that in our native language, "we never comprehend all that the speaker intended and we are always using whatever clues the environment and the discourse may give us" (p. 45). A skilled interpreter is tolerant of ambiguity, is comfortable guessing in both the source and target languages, and commands native-like proficiency of the languages to construct faithful interpretations. The skilled interpreter understands that this interpretation may fall flat, but they are willing to try.

In a high-risk setting where an interpreter is facilitating valuable and meaningful communication, one would not ordinarily suggest guessing. However, these guesses are not random ideas. The interpreter has used contextual clues (i.e. the setting, the cultures involved) to engage in a dialogue with the environment and everything within. So, how does one learn to analyze an interaction for cultural influence and allow it to inform an interpretation? And in the case of interpreter education, how can an educator help students become more tolerant of ambiguity to be able to employ the skill effectively?

\section{Educating the American Sign Language Interpreter}

Educating the American Sign Language interpreter is a complex process that takes experience, pedagogical nuance, and an understanding of the broader social world. To teach 
tolerance of ambiguity, some scholars recommend experience and open, honest discussion and reflection (Huber, 2003; Levitt \& Jacques, 2005). The more ambiguous situations a student experiences, the more tolerant they become of them (Budner, 1962; MacDonald Jr., 1970). Interpreters are typically thrown into situations without much background and expected to provide effective communication services. Consequently, interpreting students should practice navigating ambiguous experiences where decision making and problem solving are required to successfully facilitate cross-cultural interaction.

Sherry Shaw and Len Roberson (2009) take a service-learning approach and outline the functions of service-learning in an interpreter training program at the University of North Florida (UNF). The authors tie Kolb (1984), Lewin (1951), and Dewey (1915; 1938) to interpreting education. When applied to American Sign Language interpretation pedagogy, Kolb’s Model “represents a continuous learning cycle of community engagement that requires interpreting students to (a) observe and reflect upon experience, (b) form abstract concepts of generalization, (c) test the implications of concepts for actual interpreting work, and (d) concretely apply theory to community" (Shaw \& Roberson, 2009, p. 278). Shaw and Roberson never explicitly utilized the terminology, "tolerance of ambiguity," but they presented students with the opportunity to work collaboratively with a culture different from their own. The students at UNF are situated in the middle of the ambiguous relationship between interpreters and the Deaf community and are tasked to accomplish service-learning goals.

The rationale behind the purpose of a service-learning course in interpreter education is simple: Interpreters need to develop more than linguistic skills. Interpreters need to successfully navigate the cultural milieu present in the Deaf community too. Given that post-secondary institutions are now responsible for the education of interpreters, interpreting professionals and 
researchers are responsible for critically analyzing how training programs structure their students' learning.

Programs that primarily structure interpretation learning around language lab work, classroom activities, and occasional Deaf community involvement risk present potential for disconnection, resulting in students lacking the cultural and linguistic skills needed to master the interpreting process by the time they enter the workforce (Shaw \& Roberson, 2009, p. 278).

Since the objective of every interpreter education program is to produce competent and effective interpreters who can faithfully render messages (and secondarily pass certification assessments), program coordinators should avoid structures as outlined by Shaw and Roberson (above) and integrate opportunities to enhance tolerance of ambiguity and Deaf Heart.

\section{Deaf Heart}

The concept of Deaf Heart in American Sign Language is explained most clearly by the signs used to express this concept: HEART-UNDERSTAND (see Image 1). The hands are placed by the heart, right hand close to the chest and left hand slightly in front of the body. With all fingers down, only the pointer fingers pop up to sign UNDERSTAND, as though an idea has magically sprung out. 


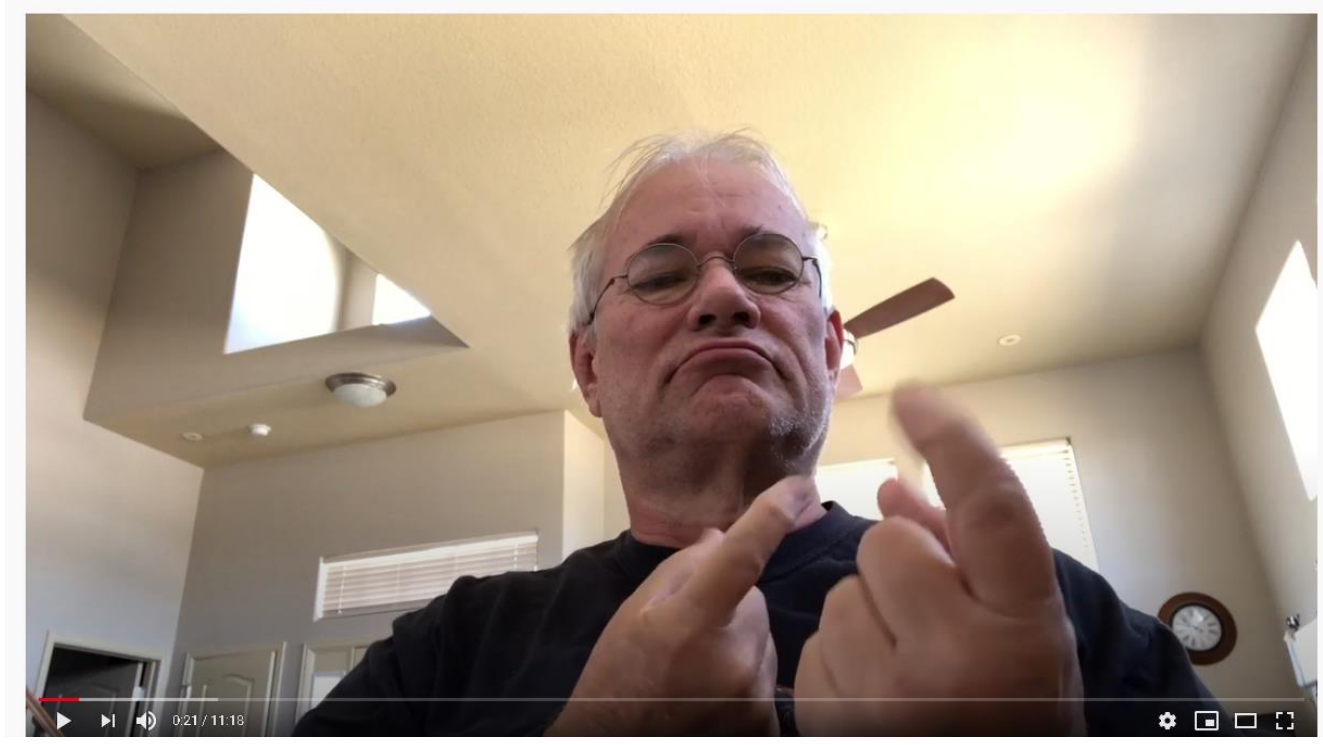

Image 1. HEART-UNDERSTAND sign demonstration (Bridges, 2019)

When I deconstruct this idea, I conceptualize a mutual understanding between individuals that is more than literal; the two (or more) people share an emotive, affective understanding. When ASL interpreters possess this quality, they begin to align with the Deaf community to create an affective economy: "In such affective economies, emotions do things, and they align individuals with communities — or bodily space with social space — through the very intensity of their attachments" (Ahmed, 2004, p.119). The ASL interpreting field might therefore be classified as psychosocial because of this important social and emotional component.

Interpreters who possess Deaf Heart can see the world through the lenses of the clients, which is essential in the profession (Colonomos, 2013), especially when attempting to determine the role of the interpreter in the Deaf community. The presence of Deaf Heart throughout the interpreting profession would combat the affliction, offering agents of change educated to act against audism, the "structural system of exploitative advantage that focuses on and perpetuates 
the subordination of Deaf Communities of origin, language, and culture" (Eckert \& Rowley, 2013, p. 101).

During the transformational time that ignited the professionalization of the interpreting field, the Deaf rightfully fought for their place amongst people who first use spoken languages. Through civil action, the Deaf community had achieved linguistic status. However, with the mandate of communicative access (i.e. Rehabilitation Act of 1973, Individuals with Disabilities Education Act [IDEA], and Americans with Disabilities Act), the Deaf were forced to abandon the movement to be perceived as a cultural and linguistic minority (Cokely, 2005). The Deaf were forced to relinquish linguistic authority because they needed to be classified as "disabled" to receive communication access (i.e. the Americans with Disabilities Act).

\section{The Deaf Community}

The legal labeling of the Deaf as "disabled" spread significantly to the psychology field where deafness was a debilitating condition: "As with virtually all disabled or chronically ill people, many deaf clients have extensive, and often intense, relationships with numbers of professional systems. For each ramification of deafness, there is often a corresponding professional" (Harvey \& Dym, 1988, p. 14). That is to say that according to these professionals, and others (Schroedel \& Schiff, 1972), the Deaf are deeply disturbed and require professional assistance to survive. Most Deaf individuals (and ASL interpreters) would strongly disagree with this notion.

The Deaf are more likely to cite language bigotry and educational failure as the sources of challenges facing the Deaf community (Lane, 1992). In 1973 and 1975 when the United States government enacted the Individuals with Disabilities Educational Act (IDEA) and free appropriate public education (FAPE), respectively, the idea that ASL was subordinate to spoken 
language began to manifest itself in the United States' social and educational culture. Schools were required to teach $\mathrm{d} /$ Deaf $^{1}$ children to a certain academic standard ("Sec. 300.101 Free Appropriate Public Education (FAPE)," n.d.). To accomplish these national goals, the English language became the required form of communication. Students were forced to abandon manual forms of communication and culture for oralism and hearing customs when they were sent to mainstream (public) schools. Some students were even subjected to surgeries (e.g. cochlear implant) (ibid., pp. 132-135).

Language has long been used as "an instrument of empire, used to create homogeneity and fealty to a central power, to minimize or eradicate diversity” (Lane, 1992, p. 105). By removing ASL as a practice in the schools, students were deprived of language exposure, especially since $90 \%$ of Deaf children are born to hearing parents (Boud et al., 1994; Kolb, 2015) (NIH, n.d.), who do not use ASL as their primary mode of communication.

\section{Research Questions}

The ASL interpreter preparatory process is complicated and conflicted with a tumultuous history of oppression. To increase interpreters' capacity to be for the Deaf and make more appropriate language and ethical decisions, there should be more research related to how interpreter program developers, coordinators, and instructors can incorporate professional, transferable skills in the classroom, such as the methods by which individuals develop empathy.

Baker-Shenk (1991) rallies interpreter educators to modify teaching strategies in order to better prepare interpreting students for the profession:

\footnotetext{
${ }^{1}$ I utilize the lowercase " $d$ " in "deaf" to signify those who have hearing loss, but do not identify with the Deaf culture and community.
} 
Do present-day interpreters have the maturity and understanding to do this kind of ethical, decision-making well?? Of course not! Where could we have learned this? What we've been learning is to ignore that there's even a problem! We need to start teaching/facilitating the development of this kind of ethical, decision-making 'skill' (p. 17).

Most students do not expect to critically assess social structure during their formal education experience; they expect to develop their cognitive and linguistic competencies. Interpreting students must learn to do more than memorize patterns; they must confront, analyze, and respond to problems of all kinds and in all contexts, especially given the amoebic nature of interpreting. But when society has not effectively equipped students with critical consciousness, interpreter educators must rise to the challenge to prepare these students for social, dialogic dichotomies. I want to discover the most effective ways of teaching students this essential critical, interpersonal, reflective, introspective skill in a virtual learning environment.

To facilitate this research, I plan to utilize the following research questions:

RQ1 How does integration of the Critical Community of Practice framework impact students' learning in an online languageinterpreting-based environment?

a. How do self-reflection and peer feedback influence the development of interpreting skills?

b. How does critical discourse analysis as a teaching tool enhance students' English-to-American Sign Language interpretation? 
c. How do students perceive and self-actualize the American Sign Language interpreter role?

These questions are designed to assess the teaching methodologies and practices I considered when I designed my course. I utilize these questions to address how students' skill, performance, and mindset transform through this delivery method. 


\section{Chapter 2: Theoretical Framework}

As mentioned in Chapter 1, Deaf Heart is a connective and meaningful understanding the interpreter has of the Deaf community, including the Deaf community's history and struggle for language recognition. In order to achieve Deaf Heart, interpreters must critically consider the role they play in the oppressive system. An introspective interpreter acts as an agent for social change. I liken the interpreter with Deaf Heart to the inside operative, the one who understands both sides, both cultures. Interpreters are cognitively skilled but also cultural workers, able to relate to Deaf and hearing populations.

Thus, this research takes a critical theory approach. Theodor Adorno (1974) wrote about the ways in which critical theory urges us to determine the subjective purpose of our environment, rather than accepting the truths that others impose on our world. To Adorno, the concept of social metaphysics meant "a haven for truth," (Hammer, 2014, p. 63), where experience is not influenced by established societal norms, but can connect with pure, unfiltered meaning.

I do not suggest that the environment is insignificant in interpreter education. Quite the contrary. I want students to perceive the truth of others by first acknowledging, considering, and navigating personal biases. As an interpreter educator, it is my responsibility to help shape future effective American Sign Language interpreters that can be critical. Interpreters must be able to accept the realities of others to effectively convey the messages through critical assessment of language and actions, questioning why reality exists as it does. Then, interpreters must understand how to work to be part of the solution, not the problem. When an interpreter can convey the true intent of a message, they are providing equal access to communication, something that many Deaf citizens have been working to achieve for the entire community. 
I realized how significant it is for interpreters to be able to place themselves in the position of someone else when I interpreted "jihad" into ASL. I chose to spell the word in sign language, given its foreign origins. The Deaf student quickly corrected me and shaped his body to look he was holding a large weapon. He asked, "Oh, you mean JIHAD?" The word, as it stands, means an individual's striving for spiritual self-perfection, but has been distorted by extremist responses. In the context of the interpreted interaction, however, the speaker was speaking about ancient Middle Eastern religious literature so the sign for JIHAD the student showed me would have been conceptually inaccurate given the timeline. I decided to interpret the word by spelling it again in ASL and explained the complex ideologies of the jihad. I culturally adjusted the message for the student to help them understand how such a transformation of meaning could have occurred.

Colloquially, the expression "fall on deaf ears" can be used to characterize when one conversation participant does not heed an incoming message. The expression can also reference when a message does not resonate with the audience. I often relate the skill of the interpreter to pinpoint the personhood experience to that of comedians to deliver humor via messages that connect to human experiences (Thayer, 1968). Skilled interpreters know how to read and understand human intention to embody those characteristics in target language utterances. Interpretations that do not effectively reflect the nature of the intended audience can fall flat; the messages are drenched in literal translation rather than meaningful, relevant concepts.

To prepare these interpreting students appropriately, they need to learn how to perceive and effectively interact with associated languages, cultures, and symbols. Interpreters operate in contentious dynamics, facilitating communication between one's native language and culture, and a second language, arguably one's passion. If interpreters do not reflect on the connotations 
they utilize in interpretations, they are no better than the individuals who forced oral communication on Deaf children for so many years (see E.A.F., 1902). Failing to critically assess the systematic and systemic oppression that continues to place so many Deaf individuals in unfortunate circumstances would be accepting linguistic and cultural injustices, not to mention that it would be contradictory to the purpose of ASL interpreters. ASL interpreters exist to serve the communication needs of the Deaf community amongst the hearing, and that responsibility requires more than cognitive and linguistic competence.

The issues that affect the Deaf directly affect the interpreter community. Students have to be prepared to take on this responsibility and internalize many of the struggles experienced by the Deaf. Interpreter education programs need to focus on maximizing students' potential for sociological and cultural engagement, while also enhancing the cognitive processes of interpreting. To teach students these skills at a distance, I consider social learning theory, experiential learning theory, and communities of practice to lay the groundwork for my teaching decisions, and ultimately, the research method employed in this study. I strive to bring interpreters into their personhood and teach them how to effectively assume the voice of others.

\section{Social Theory of Learning}

I want my interpreting students to be able to perform the essential functions of interpreting and gain the skills to be a proficient interpreter in the future. In order to raise them to that point, I encourage them to interact with their peers through regular dialogue and question their pre-conceived notions. Interpreting knowledge includes the cognitive and affective processes. My goal is to provide students with enough social interaction with peers and Deaf culture to indoctrinate these new interpreters into the field by collectively engaging in meaningful practice that addresses all relevant professional domains. Students cannot interact 
only with hearing peers and expect to achieve even basic interpreting proficiency. The Deaf community is at the center of the profession. However, without extensive exposure to the Deaf community, as was unfortunately the case during the COVID-19 pandemic, it is the responsibility of the interpreter educator to provide opportunities for students to still experience the Deaf World.

Lev Vygotsky (1978) documents the value of language and culture in learning and highlights how a child's speech and behavior work collectively in development. Though Vygotsky refers to children in his study, and the students in this study are at least 18 years of age or older, Vygotsky's idea transfers, nonetheless (see Bakhtin, 1981). As interpreting students speak to others and perform the interpreting role during their learning experience, they shape their professional identities. The process of immersion with the Deaf and interpreting cultures leads to making new meaning and creating new perceptions through diverse, engaging, meaningful, cultural experiences. The unique history of the Deaf community creates heteroglossia and polyphony, variety in language and voice, with which the interpreting students engage to change their realities.

In 1998, Etienne Wenger applied a social theory of learning to communities of practice (discussed later in this chapter), in which social participation facilitates the process of learning and knowing. Like Vygotsky, Wenger (2019) believes that individuals are social creatures who create knowledge through participation and engagement through meaningful experiences. When individuals learn through practice, they "[explore] evolving forms of mutual engagement, [understand] and tune their enterprise, and [develop] their repertoire, styles, and discourses" (Wenger, 2019, p. 95). Learning is the primary objective and Wenger believes that practice, meaning, identity, and community play essential roles in facilitating that learning. Afterall, 
humans are social creatures. Interpreting students gain competence and develop their identity by actively engaging in interpreting and discussing those experiences, reflecting upon development and previous perspectives, all while creating and then maintaining membership in a professional community.

\section{Figure 1}

Social theory of learning (Wenger, 1998)

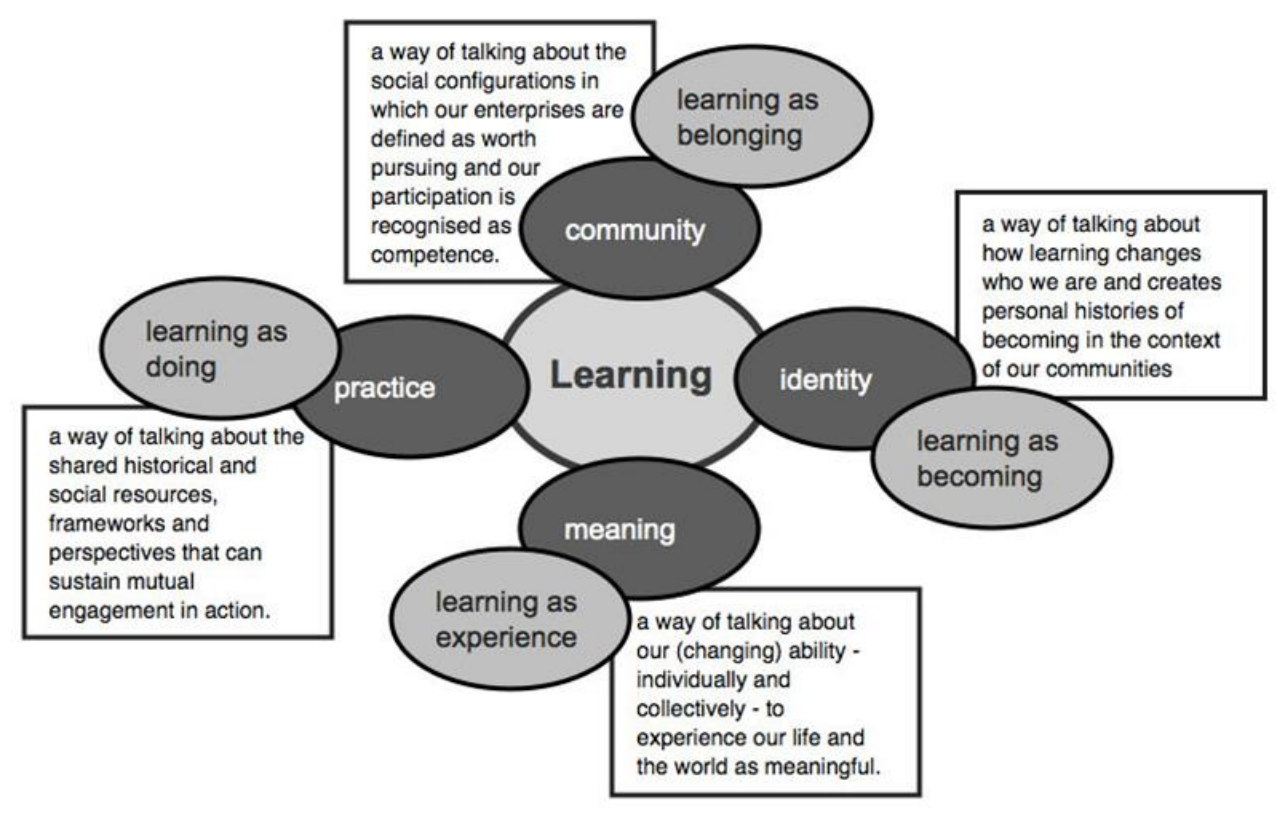

The social theory of learning capitalizes on the outcomes of communication and involvement within a group for the purpose of acquiring new knowledge. In other words, when peers interact, fundamental, systematic change can occur. What kind of change can take place? Well, social, for one. Paolo Freire $(1973,1974)$, whose critical contribution to education will be discussed in further detail later in this chapter, characterized the Western educational system by its unappealing, capitalist characteristics, including social control, systematic oppression, and 
class discrimination. If this is the case, an American Sign Language interpreter will be trapped within oppressive language and biased interpretations. In order to make fundamental social changes, students should be taught the capacity for critical consciousness, the recognition of and actionable methods to confront oppressive realities (Freire, 2000).

Each peer interaction is an opportunity for learning and reflection. During the interaction, members negotiate meaning. The negotiation of meaning is an exchange, though not always a verbal one. Meaning is developed by an interaction with the rest of the world: "Meaning is not pre-existing but neither is it simply made up. Negotiated meaning is at once both historical and dynamic, contextual and unique" (Wenger, 2019, p. 54). That is to say that members are situated within their shared environment and carry with them individual characteristics, traits, and beliefs that contribute to the conversation, just as I did when interpreting JIHAD.

In his literature-focused writing, Mikhail Bakhtin (1981) would describe this trend through the ideas of dialogism, heteroglossia, and polyphony. Dialogism is the interaction an individual has with language, responding according to "an atmosphere of the already spoken, the word is at the same time determined by that which has not yet been said but which is needed and in fact anticipated by the answering word. Such is the situation in any living dialogue" (M. Bakhtin, 1981). Of course, depending on the atmosphere, individuals respond differently, leading to heteroglossia and polyphony, or variety of language and voice, respectively (ibid.).

While Bakhtin might not have initially intended for his ideas to apply to ASL interpretation, his notions directly reflect the goals of this research. All of the students and I have been exposed to an environment that affects how we manifest our professional selves. Given our individual positions, our assigned roles in society, and our real-world experience, we carry a diverse set of perspectives. In order to provide meaningful interpretations that reflect the needs 
of the client, students need to expand their realities, listen to Others' point of view, and consider how to be for someone else.

Dichotomous dialogue serves a mutually beneficial purpose where peers work through new and challenging information together to make meaning. To Wenger (1998), the process of becoming "meaningful" requires negotiation of meaning between community members, new and veteran. Members interact to share information and perspectives. As interpreting students decode and decipher original messages to interpret them in the target language, the discussion of complex concepts, connotations, and potential conflicts becomes crucial.

\section{Experiential Learning Theory}

The experiential learning theory is an applied theory derived from the concept of experiential learning, an educational technique much like problem-based, service, or action learning, via which the person learns directly from life experiences (Kolb, 2015). The truth is not hidden somewhere within experience. The person must reflect on the interaction and respective environment and act ethically in response. Interpreters can learn more effectively by way of minimal-risk practice interpretations and related experiences than they would by reading about the nuanced process of interpreting.

Reflection, sometimes referred to as "experience” (van Manen, 1977) or "learning" (More, 1974), is “"[a]ctive, persistent, and careful consideration of any belief or supposed form of knowledge in the light of the grounds that support it and the further conclusions to which it tends" (Dewey, 1933, p. 9). I not only look at information in regard to the rest of the system, but language and action too. Reflection is inherent in experiential learning and in life, and can bring about various outcomes (Boud et al., 1994; Kolb, 2015). A person can reflect upon behavior, ideas (of which learners are aware), and feelings (ibid., p. 20). The person may find affirmation 
or begin to question preconceptions, and conclude with a "personal synthesis, integration and appropriation of knowledge, the validation of personal knowledge, a new affective state, or the decision to engage in some further activity" (ibid.). Boud, Keogh, and Walker (2005, p. 20) offer a model of the reflection process in learning (Figure 2, below).

\section{Figure 2}

A model of reflection in the learning process

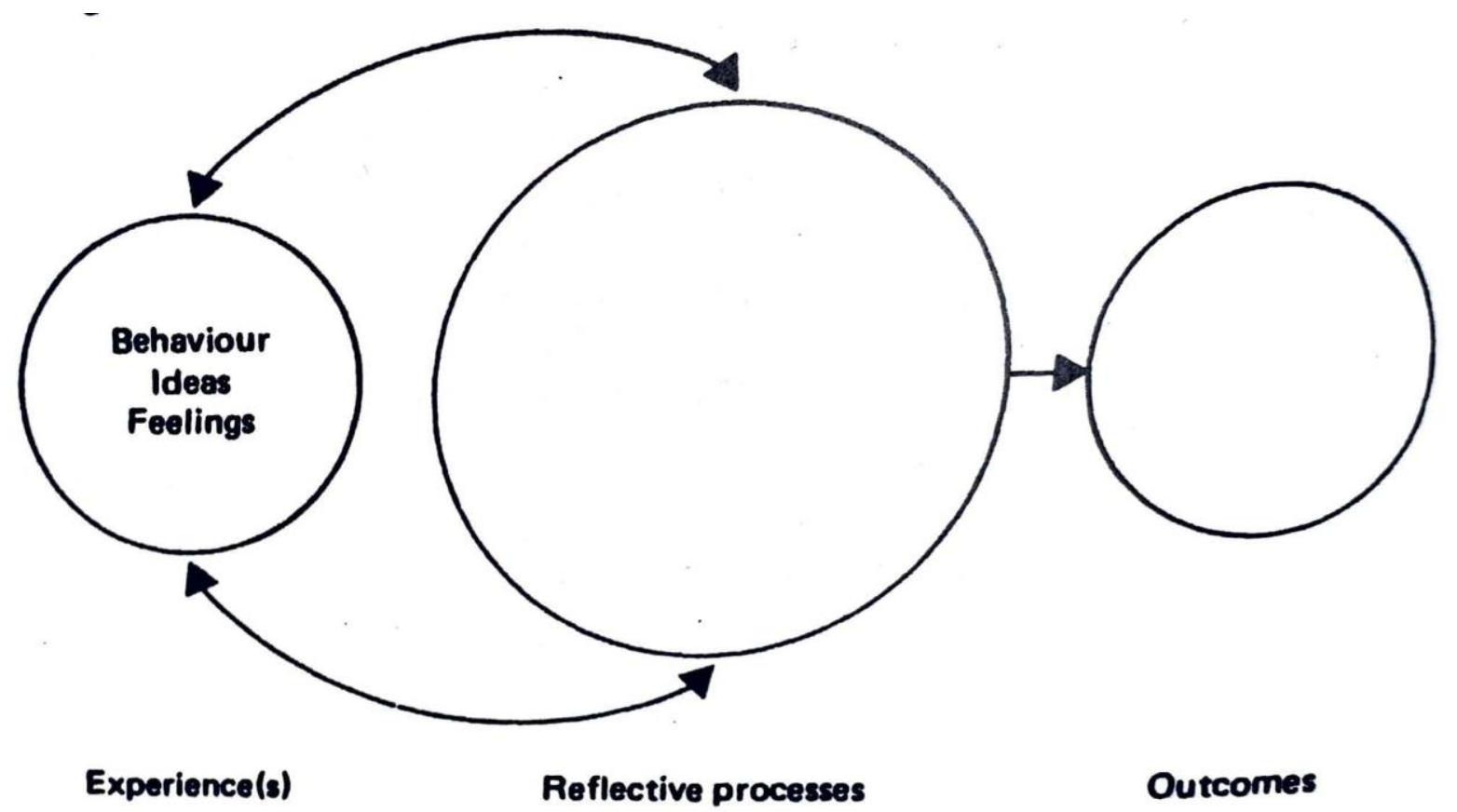

While there is no specific, outlined reflective process, there are three key components shown in the diagram above: (1) students recall salient events; (2) students utilize positive feelings and remove obstructing feelings; and (3) students re-examine the experience, taking intent, goals, and previous knowledge into account. During the semester, I ask my students to 
follow these steps to progress through an (experimental) experiential learning opportunity. This way, students have opportunities to perform their learned cognitive processing skills to later reflect upon their interpreting decisions and development.

In 2004, William M. Synder and Etienne Wenger published their chapter, "Our world as a learning system: a communities-of-practice approach," in which they apply the characteristics of communities of practice to outline identify the three properties of a world learning system that can match the challenges we face: (1) action-learning capacity; (2) cross-boundary representation; and (3) cross-level linkages (pp. 36-37). Action-learning capacity resonates directly with the purpose of this research. Action-learning capacity "address[es] problems while continuously reflecting on what approaches are working and why - and then using these insights to guide future actions" (p. 36). I envision a direct relationship between the driving concept of experiential learning theory and action-learning capacity since both depend on the action and reflection of a given student. I want to investigate the most effective method of guiding students through the reflection process at a distance utilizing action-learning capacity in an experiential learning-based environment.

With distance education students especially, the value of experiential learning increases significantly. I want to develop the most proficient interpreters who can successfully navigate communication across linguistic and cultural barriers. Ultimately, I want students to learn the three basic interactionist assumptions:

1. That human beings act toward things on the basis of the meanings that these things have for them;

2. That the meaning of such things is derived from, and arises out of, the social interaction that one has with one's fellows; 
3. That these meanings are handled in, and modified through, an interpretive process used by the person in dealing with the things he encounters(Chapman Alliance, n.d.) (Blumer, 1969, p. 2).

Meaning, decisions, and perspectives are based on a person's interaction with others and their surrounding environment. While teaching at a distance, I need to provide students with opportunities to interact with meaningful content that incites the appropriate response to help shape a professional interpreter.

To John Dewey (1916), the educational system served a related, elaborate role, a social function (among other functions), via which new members of the community develop the characteristics of the group by way of interacting and immersing with more experienced community members. A student in a social educational system lives with the information long enough to eventually embody it. The environment, which Dewey (1916) dictates, "consists of those conditions that promote or hinder, stimulate or inhibit, the characteristic activities of a living being," is critical to the interaction (p. 13). When a member of a community interacts with their environment, they strive to achieve "continuity of the surroundings with his own active tendencies" [emphasis in original] (ibid.). In other words, the environment influences the behavior of the person and vice versa; the individual behaves in order to be accepted as a member of a community.

Effective interpreter education requires interaction with fellow interpreters and the Deaf community to ensure that the interpreter has acquired necessary cognitive and affective skills, including essential American Sign Language linguistic features like idioms. The ability to utilize and interpret idioms is largely dependent upon an interpreter's exposure to the Deaf community and the exposure to the utilization of idioms. The interaction with others and the perception of 
others' demeanor dictates the language utilized and the persona created in the target language. In the case of this study, interpreting students are tasked with situational interpreting assignments where they learn how to appropriately interact in various settings with the respective symbols. Students adapt their knowledge during active reflections.

Donald Schön (1983) utilizes the term, reflection-in-action, to reference the ability one has to think about doing something while doing that thing. Reflection-in-action is an interactive process where the person focuses on "the outcomes of action, the action itself, and the intuitive knowing implicit in the action" (Schon, 1983, p. 56). An interpreter reflects in-action when they consistently, actively consider linguistic, paralinguistic, syntactical elements, while conveying the tone, or illocutionary force, of the source message. So, if the source message is asking a question, the interpretation should reflect the entire message to clearly convey the question; that message includes all linguistic nuances. The interpreter reflects while interpreting to ensure that message components are integrated ad hoc to match the intent of the original message.

The final founder is Kurt Lewin. Lewin's (1951) work on group dynamics and action research supports the value Dewey placed on the social function of education. Lewin drew on the inspiration of various fields, including electrical engineering for their methods of problem solving (1951). He believed that organizational and individual ineffectiveness can be attributed to an imbalance between research and action. Lewin's model of the experiential learning process (see Figure 3 below) is similar to that of John Dewey (see Figure 4 below).

\section{Figure 3}

Dewey's Model of Experiential Learning (1938) 


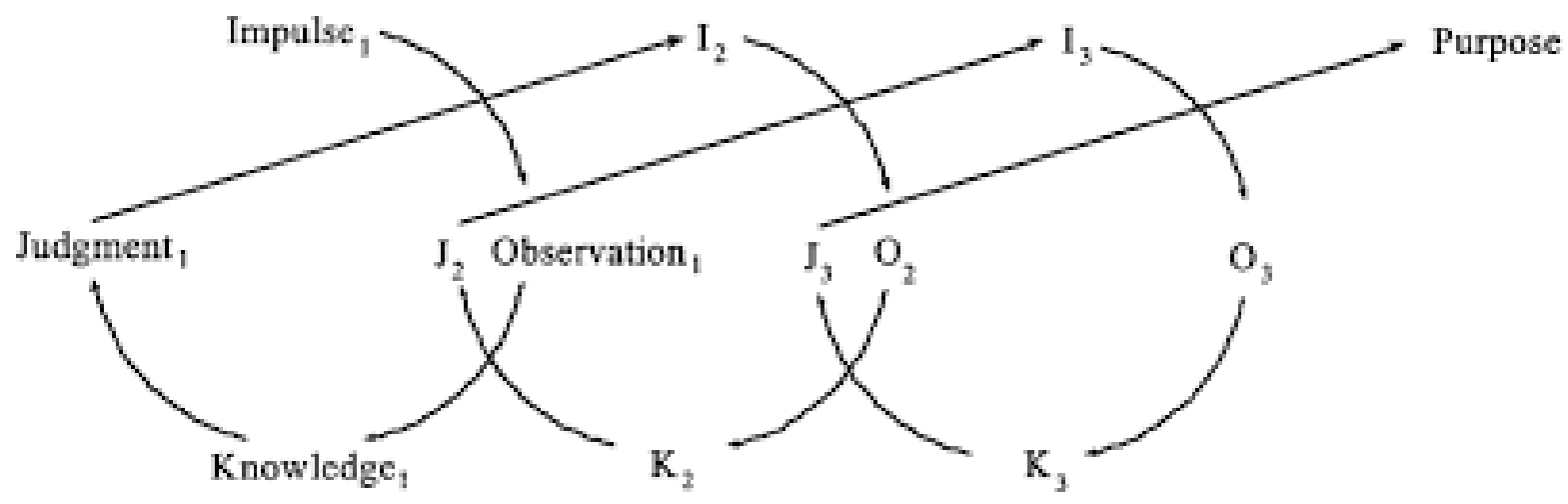

Dewey (1938) proposed a model of experiential learning that demonstrates how impulse, observation, knowledge, and judgment over time lead to a mature purpose. An impulse incites interest, but prior to acting, one must observe and utilize knowledge and judgment. The dichotomous yet symbiotic process yields mature purpose from blind impulse (Kolb, 2015). Lewin (1951) described a four-stage cycle, where "[i]mmediate concrete experience is the basis for observation and reflection. These observations are assimilated into a 'theory' from which new implications for action can be deduced. These implications or hypotheses then serve as guides in acting to create new experiences" (p. 32).

\section{Figure 4}

Kolb’s Lewinian Experiential Learning Model (1978) 


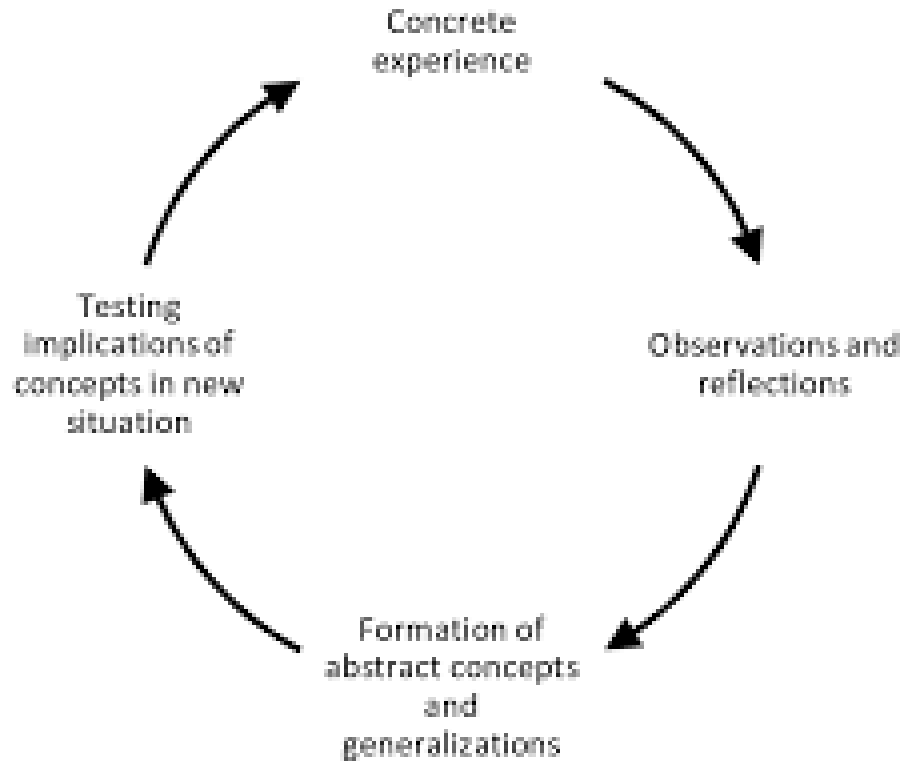

Dewey made explicit the developmental nature of learning, focusing on "how learning transforms the impulses, feelings, and desires of concrete experience into higher-order purposeful action" (Kolb, 2015, p. 33). Lewin emphasized here-and-now concrete experience and feedback processes. Here-and-now concrete experience is immediate personal experience that can be shared (fully, concretely, and abstractly) (p. 32). Feedback processes are the procedures by which an individual assesses the deviation from a desired goal.

Interpreters, interpreting students, and interpreter educators need to experience professional interpreting scenarios and be able to effectively reflect on their decisions and the outcomes of their work. By analyzing decisions and reflecting on the outcomes of the interpretation, the interpretation itself, and the intuitive knowing implicit in the act of interpreting, the interpreter conceptualizes the experience, to then begin actively experimenting with potential changes that enhance interpreting proficiency. 
Not all researchers believe experiential learning, sometimes referred to as "minimal guidance during instruction" is an effective method of instruction (Kirschner et al., 2006; Klahr \& Nigam, 2004). Direct instructional guidance is counter-offered to the experience-based technique. Direct instructional guidance means fully explaining all content, concepts, and learning strategies to support knowledge acquisition (Kirschner et al., 2006). Brown and Campione (1994) observed that when students are asked to discover a topic completely or primarily independently with minimal feedback, they can become lost and frustrated, and their confusion can lead to misconceptions.

If experiential learning is not accompanied by instructor-led guidance through the reflection process, students might also not know how to make sense of (i.e., contextualize) the information presented. If a student is stranded in a sea of information, they will be overwhelmed by the task of navigating all on their own. Wedemeyer (1977) stated that a distance education system places greater responsibility for learning on the student but requires the utilization (where appropriate) for teaching media and methods proven effective. The utilization of experiential learning does not take away from the distance educator's responsibility to guide students through the information. Abandonment does not constitute experiential learning. Dewey and Lewin never advocate for students to be left alone to decode complex information. In experiential learning, the teacher is the learning facilitator. Facilitators should provide students with a social, interaction-based learning environment that encourages collaboration amongst peers (and the instructor) to maximize learning.

This perspective can be connected to Bakhtin's dialogism $(1981,1986)$, where "the speaking self is dynamically situated within both an interactionally and an ideologically complex world" (Dyson, 1995). As humans, we are all situated within culture, and our culture influences 
how we interact with the people and the environment around us. In the Deaf community, for example, music is not given as much reverence as it is in the hearing community, for obvious reasons. Deaf community members do not schedule music-based events nor do they frequently utilize music-based terminology. Individuals' usage of language and voice consequently differs creating heteroglossia (variety in language) and polyphony (variety in voice) (Bakhtin, 1981).

These interpreting students are adults, making interpreting decisions that are influenced by their emotional experiences and responses. An interpreting student with a Deaf family member is likely to possess more strong (positive or negative) feelings toward the Deaf community at-large because of the emotional connection to deafness during their development. Another interpreting student with a passion for American Sign Language could attempt more visual expression and render more proficient interpretations. A similar future interpreter may express more favoritism toward one set of interlocutors over another, which could lead to interference with the target language interpretation. In order to begin to identify, deconstruct, and address any interfering biases, the interpreting student has to live interpreting to understand the process, in addition to analyze previous experiences that inform current perspectives. Through observation, shadowing, reflection, feedback, and supervised experience, just to name a few, an interpreting student can learn the cognitive and affective skills necessary to be a proficient interpreter. The act of interpreting a brief recording can provide a meaningful learning experience only when the interpreter or interpreting student analyzes the work done, identifies areas for improvement, and maps a plan to implement necessary changes.

It is interesting to note that Lev Vygotsky (1994) published a chapter on social education for "deaf and dumb" children. He writes from his perspective as a citizen of Soviet Russia and sheds light on the previous teaching methods utilized in Deaf education. At the time, deafness 
was widely accepted as a disability, especially with the coinciding passage of the Americans with Disabilities Act in 1990 in the United States, which states that the Deaf community falls under these new guidelines. Vygotsky advocates for the Deaf population to receive a practical education "because the child becomes accustomed to take an active part in life from early childhood" (p. 24). The individual should experience the world and learn by exposure. Vygotsky states that children in these academic environments "enjoy company and speech, take an active interest in life and are quite prepared for an independent future" (ibid.).

One could relate Vygotsky's practical education for the Deaf to Simonson, Schlosser, and Hanson's (1999) Equivalency Theory, which states that distance education "should be built on the concept of equivalency of learning experiences. The more equivalent the learning experiences of the distant learners are to those of local learners, the more equivalent will be the outcomes of the educational experiences for all learners" (p. 70). By providing Deaf students with an experiential learning opportunity, equivalence is more attainable between mainstream and Deaf education. Not to mention that students can acquire relevant professional skills and learn by exposure. Interpreter educators should present equivalent, professional interpreter experiences to interpreting students so they can meaningfully engage in this unique professional community of practice.

\section{Community of Practice}

The process of engaging in practice is multifaceted and involves "mutual engagement, a joint enterprise, and a shared repertoire of ways of doing things" (Wenger, 2019, p. 49). When members of a professional field practice together, they communicate thoughts, ideas, and opinions. Wenger marks that participating in a community of practice is not an act of associating oneself with a particular entity or line of work. The community of practice evolves through time. 
Members consistently and collaboratively engage in reification, the process of remembering and forgetting that leads to the renegotiation of meaning (Wenger, 2019).

In the field of American Sign Language interpreting, there is a clear power dynamic between interpreter and Deaf client. Student interpreters need to be given time during their professional training to learn from experienced professionals who have navigated challenging interactions with Deaf clients and between Deaf and hearing clients. By reflecting on the interaction together, the associated actions, and the outcome, students and seasoned professionals can learn about themselves, their role in the interpreting profession, and their role in the Deaf and hearing communities.

Student peers have a remarkable opportunity to learn from each other in this context (Wenger, 2019). When students learn in practice, they participate in forms of mutual engagement, begin to understand and tune their enterprise, and develop their repertoire, styles, and discourses (ibid.). At this point, one can see how social factors influence learning. In 1988, Jean Lave presented cognition as a complex social, anthropological phenomenon that could be studied by addressing three modes of analysis: (1) analysis of semiotic systems with their structural entailments; (2) an analysis of cognition in exploration of the relations among personacting, setting, and activity; and, (3) an interlevel analysis including the dialectical relations between an experienced world and its constitutive order.

\section{Figure 5}

Modes of analysis for a dialectical problematic of practice 


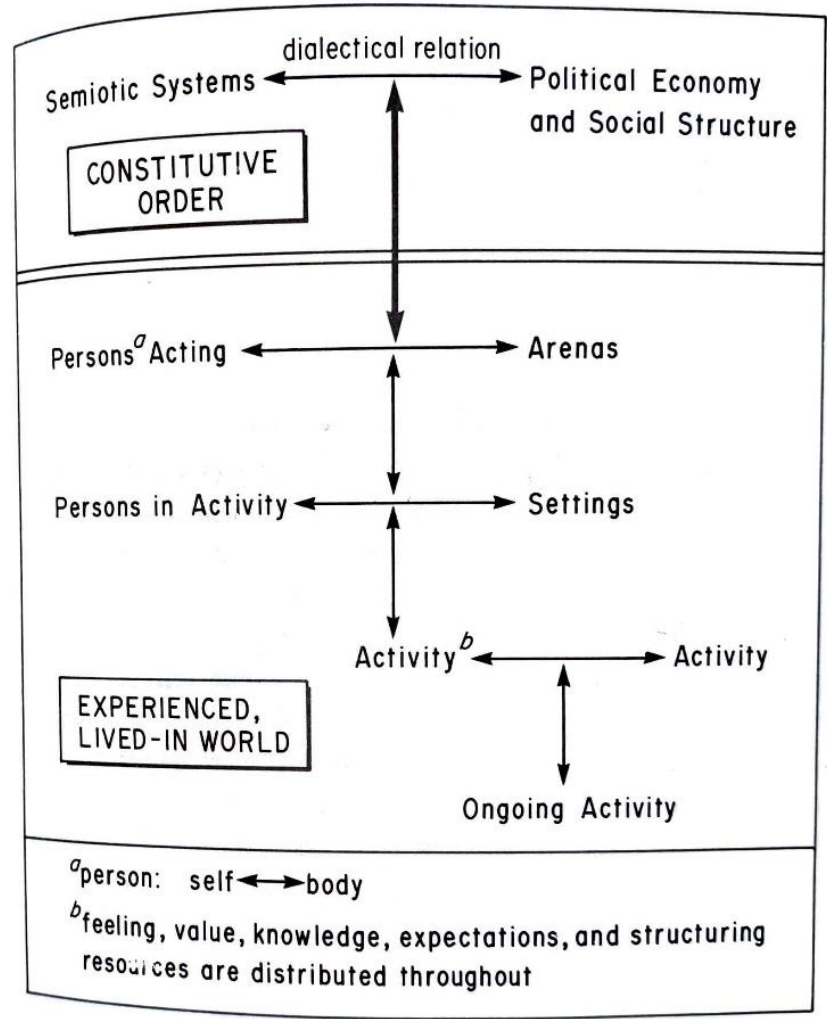

I envision constitutive order and experienced, lived-in world as the sources of contextual information for ASL interpreters. ASL interpreters are constituted to be present for communication access (ADA). Politics, economics, social structure, and culture play a significant role in the interaction dynamic. An ASL interpreter has to critically assess the legal implications of social structure at-large, as well as the day-to-day life experiences to understand register, affect, schema, and make all appropriate subsequent decisions.

Jean Lave and Etienne Wenger (2011) discussed the idea of situated learning, where the situation in which one learns plays a significant role in the learning process. As William J. Clancey (1995) states, "our conception of our activity within a social matrix shapes and constrains what we think, do, and say. That is, our action is situated in our role as a member of a community" (p. 49) [emphasis in original]. Clancey's idea sounds similar to that of Lave (1988), where she outlines how cognition is a social creation. Lave and Wenger (2011) effectively 
exemplify the impact of the environment with a reference to the apprenticeship experience, where learning is governed by the same rules that manage the profession. In apprenticeships, practice is the central pathway for learning.

By the end of the semester, I want my interpreting students to understand how their role and mere presence as an interpreter inherently affects communication. To do so, I will provide an apprentice-like experience where students engage in practice and share information with their peers. I want students to be able to abstractly apply knowledge of their own communities and cultures to render faithful interpretations, while recognizing how culture influences perspective, diction, and consequently, other elements of the interpretation and communication in general. Ultimately, I want students to reflect on their interpreting decisions and develop the skills to critically assess their sign selections and infer the impact those signs might have on the interaction.

People's backgrounds, thoughts, beliefs, ideas, and opinions are going to conflict. The interpreter cannot adjust the original intent of the message, no matter their personal convictions. However, not all interpreters behave ethically. Unfortunately, the idea of "communities of practice" alone does not address power dynamic; a critical component is necessary. When an ethical interpreter understands how their inherent role wields a tremendous amount of power, they more carefully process language during interpretations to exercise professional and social responsibility. The ability to critically assess one's professional practice within and amongst a community of practicing interpreters enhances the competence of the entire field.

\section{Critical Communities of Practice}

When Lave and Wenger outlined communities of practice, they highlighted meaningful engagement and the value of experiential learning. Communities of practice could miss the mark 
on teaching critically conscious thinking if not directly addressed. I do not want students to become more entrenched in their previously held ideals; I want students to challenge what they think they know to determine if, how, and why the reality in which they work is ethically acceptable and how their voice in the interaction affects the communication dynamic. In this study, I specifically utilize critical communities of practice ( $\mathrm{CCoP})$ to bridge the gap between what has been done in communities of practice and the explicit implementation of critical discourse analysis of the social contexts of living and learning in which interpreting is done. $\mathrm{CCoP}$ incorporates more reflection of pre-existing stereotypes to help interpreting students acquire new perspectives and deliver more conceptually accurate interpretations.

When the community assumes a critical function, it challenges uneven power relationships (Anderson \& Irvine, 1993). From within the community, members mutually engage to define their potential impact on their clients with the intention of acting to mitigate any power differential. The community is not hostile; the community is hospitable, addresses the other, accords him, even asks his name, "while keeping this question from becoming a 'condition,' a police inquisition, a blacklist or a simple border control" (Derrida, 2005). The goal is to create camaraderie, where individuals interact as a member of something bigger than themselves to find a solution (Filo et al., 2009). Interact, not transact. In the economic sense, transaction refers to the exchange of goods and services. The transaction is devoid of meaningful connection. If the institution is treated like a business transaction, students come to class to check off the attendance requirement, not to learn.

In 1970, Paulo Freire published Pedagogy of the Oppressed, a book dedicated to the oppressed and those who fight at their side. Freire remarks that "the oppressed" signify a group of people who are victims of injustice, exploitation, and violence, motivated by the idea of social 
liberation and recovering lost humanity. I want interpreting students to understand the plight of the oppressed Deaf community and operate as a vehicle for positive change. Skilled interpreters covertly infiltrate the mainstream population with positive deafness-related rhetoric. Proficient interpreters illustrate and educate others on the competencies, norms, and social expectations of the Deaf. I immediately recall how waving is acceptable in the Deaf community to gain desired attention, but hearing people would likely consider that "rude." An interpreter has the knowledge to explain these cultural nuances to expand the mindset of others. When I consider my student population, I optimistically and creatively envision the great strides in open-mindedness one can make in each respective community. I want to help mold critical, empathetic, and understanding individuals who enhance the quality of life for others.

Freire (1970) discussed the "banking" concept of education that oppresses minorities, and the subsequent importance of dialogue. When the learning processes are like banking, students can be likened to receptacles: "The more completely she [the teacher] fills the receptacles, the better a teacher she is. The more meekly the receptacles permit themselves to be filled, the better students they are" (p. 72). Of course, this process is not really learning. With this perspective, the responsibility of learning falls on the student to accept the knowledge as the teacher provides it. Experiential learning is not a student-only event, just as Freire indicates.

Banking education forces students to independently accept and absorb the information instead of interacting with it to learn it. In order for students to be, they must first become by engaging in praxis (Freire, 2007). Freire (1970) believes praxis, the act of reflecting critically on action often in the form of problem-posing education, is liberating. When a teacher poses problems and offers related discussion, the students and the teacher construct meaning together. Students do not simply accept meaning because some individual with authority told them to do 
so. In a way, the teacher and students equalize; they focus more on discussing the content than power dynamics. The entire group interacts and forms a perspective, just as Dewey (1916) proposed as a function of education. Dewey (1925) characterizes the banking concept of education as well, though he never explicitly labels it: "In ancient science, 'learning' belonged in the realm of inferior being, of becoming, change; it was transitive, and ceased in the actualization of final and fixed objects" (p. 152). As Freire said, knowledge is imposed rather than discovered.

Truthfully, knowledge cannot be imposed. Educators may try but students only learn through their own experiences, trials and failures. To facilitate learning, I post problems to my students and ask them to find solutions. In interpreting and in life, there is no script. I would rather students experience their struggles in a safe environment (like in a class) when an individual's health and safety are not on-the-line than be underprepared in the field and cause harm to the patient, profession, and communities at-large. We will collaboratively develop effective interpretations that incorporate concept representation ideas from more than one perspective. By doing so, we can practice critically analyzing incoming messages for a meaningful learning experience. A lecture about the effective methods of interpreting could never approximate praxis.

Still, banking education grows in post-secondary institutions. Perhaps the need to retain students for financial gain has converted the higher education system from a higher-education institution, meant to train minds to acquire necessary critical thinking skills and one's affective domain via rigorous education, to a factory, an industry, focused more on administrative items like the calendar, the number of credit hours and the development of "verbal skills and deposit of information in storage banks between the ears" (Chickering, 1977, p. 86). Students are treated as 
customers of universities and academic rigor and forming critical communities of practice for problem posing and acting subsequently suffers (Carlson \& Fleisher, 2002).

Students, subsequently, often expect that they will be passed because they paid the registration fees for course. Students do not get to know their peers or their educators. Students fail to experience the profession in the learning environment and cannot effectively interpret after graduation. Students show up for class, listen to an "authority" spout information, and then leave. The environment is not hospitable. Meaningful engagement does not take place and the critical community of practice never forms. There is no physical classroom in an online course so the creation of a connection is even more challenging; however, connection can be created through meaningful dialogue.

Hypothetically, the post-secondary institution provides a potentially safe location for students to engage in critical dialogue. Students are not yet making professional decisions and are expected to still be learning. When students do not possess the mindset of field professionals, educators are present to step in to shape competent people. When a student interpreter is failing to convey underlying connotations in a practice interpretation, the educator (an experienced interpreter) can step in to discuss how to make meaning utilizing the presence of shared meaning and language.

However, not all educators are able to serve this role, even if they may want to. Systemic privilege and neoliberalism plague corners of the educational system in the form of silenced complex inequalities and power relations (Bauman, 2005; Gyamera \& Burke, 2018; Rose, 1999). Some administrators feel restricted by rules handed down from their superiors (Long et al., 2016), while pre-kindergarten teachers, for example, are silenced and censored from speaking with young children about certain topics for which they are "not ready" (Sherfinski, 2017). In 
American Sign Language interpreting, the interpreter must have a critical eye, recognize and acknowledge these issues, and interpret accordingly; there is no option to silence power-laden dynamics in target language interpretations.

At one previous place of employment where I interpreted, I was involved in several conversations regarding the pay rate for interpreters (and transcribers). According to the central human resources office, interpreters are akin to manual laborers; never mind the cognitive skills, tenacity, and empathy one must have to interpret. Interestingly, all of my colleagues at the time were female, save my supervisors who were male. Prior to my departure from this position, I received an approximate $20 \%$ pay reduction when the human resources office discovered that, with my training, I could perform both interpreting and transcribing skills.

Rather than focus on this specific example of workplace inequality, I want students to think critically about the structures that allow for experiences like this to occur. Critical communities of practice provide an environment where students can engage to make (and challenge) meaning (connotation and denotation). Language is created through interaction with the environment and with others (Ellis, 1999). Language bears all components of the world and an interpreter who fails to acknowledge social structure will fail to perform the essential functions of the profession. To develop this skill, the interpreter educator has no choice but to engage students in critical dialogue and to create a critical community of practice, a space where members can deconstruct discrepancies that affect daily interactions.

Joseph Michael Valente (2011) narrated how essential it is for someone to deconstruct speech and consider the personal and subsequent social impacts it has.

Foucault (e.g., 1978, 1992, 1995) tells us that our bodies are a battlefield that forces us to navigate the binary fields determined by normative power/knowledge 
constructs. For each child with deafness, they are interpellated by phonocentric ideologies that see difference as pathology. Epistemically violent phonocentrism/audism works to (de)humanize, (ab)normalize, and discipline the always already failing body. In thinking about how the experience of defending myself manifested feelings of empowerment, I realize this was the beginning of my saying no to 'deaf and dumb.' I wonder how this might reflect who I am today.

Valente's rejection of deaf and dumb validates the notion that word choice and respective connotations influence one's experience in an interaction. As a result, ASL signs have to be visual and drenched in conceptual representations. A word in English that carries a strong connotation will have to embody a proportionate magnitude of meaning.

Provocative ideas can daunt interpreter and conversation participants. Students should be trained to handle these situations through meaningful, critical dialogue that incites emotions to create adherence (connecting individuals with emotions) and coherence (the subsequent creation of a "collective") (Ahmed, 2004). In other words, interpreting students must learn to acknowledge and respond appropriately to their emotional experience to connect with other interpreting students, professional interpreters, and even the Deaf communities. These essential intrinsic and extrinsic connections provide the framework for creating a critical consciousness.

As Freire (2007) saw it, pedagogy is a process of re-creation, where the teacher and student utilize objects in their immediate surroundings to make meaning: "He or she is rather the possessor of $a$ consciousness: an 'empty' mind passively open to the reception of deposits of reality from the world outside" (p. 75). That does not mean, however, that all objects in one's environment penetrate through to consciousness. Simply because American Sign Language 
interpreting students engage in acts of interpretation does not make them conscious of their critical role in the Deaf-hearing interaction. Interpreter educators have to provide students with opportunities to break down stereotypes (via praxis), in part by changing the language of how they view the interpreting profession and themselves as agents of change.

Interpreters need to unite with each other and the Deaf community. Interpreters have a unique role in the Deaf community: interpreters have studied the language and culture of the oppressed (the Deaf) yet are members of the oppressive group (the hearing population). With the decentralization of the Deaf community from the interpreting profession (Shaw \& Roberson, 2009), Deaf Heart is a requirement in the interpreting profession. Deaf Heart is the understanding a hearing individual has of the Deaf community: the language, the culture, and the history. When an interpreter can understand the oppressive experience of the Deaf population, they serve as a peaceful combatant of structural exploitation (Eckert \& Rowley, 2013). When students experience historical reality through praxis, they learn how to respond appropriately and how to act to rectify social mistakes. The interpreter is then awakened to see how the political system, for example, could impede cultural advancement, as it occurred when the Deaf were reduced to a disabled population to receive federally mandated interpreting services (Cokely, 2005).

To me, social learning theory, experiential learning theory, communities of practice, and critical communities of practice nest comfortably inside one another, shown in the diagram below (Figure 6). I envision the social theory of learning as the catalyst for experiential learning since it encourages social participation. We experience the world with others, directly or through

\section{Figure 6}

Relationships and relevance amongst applied theoretical frameworks 


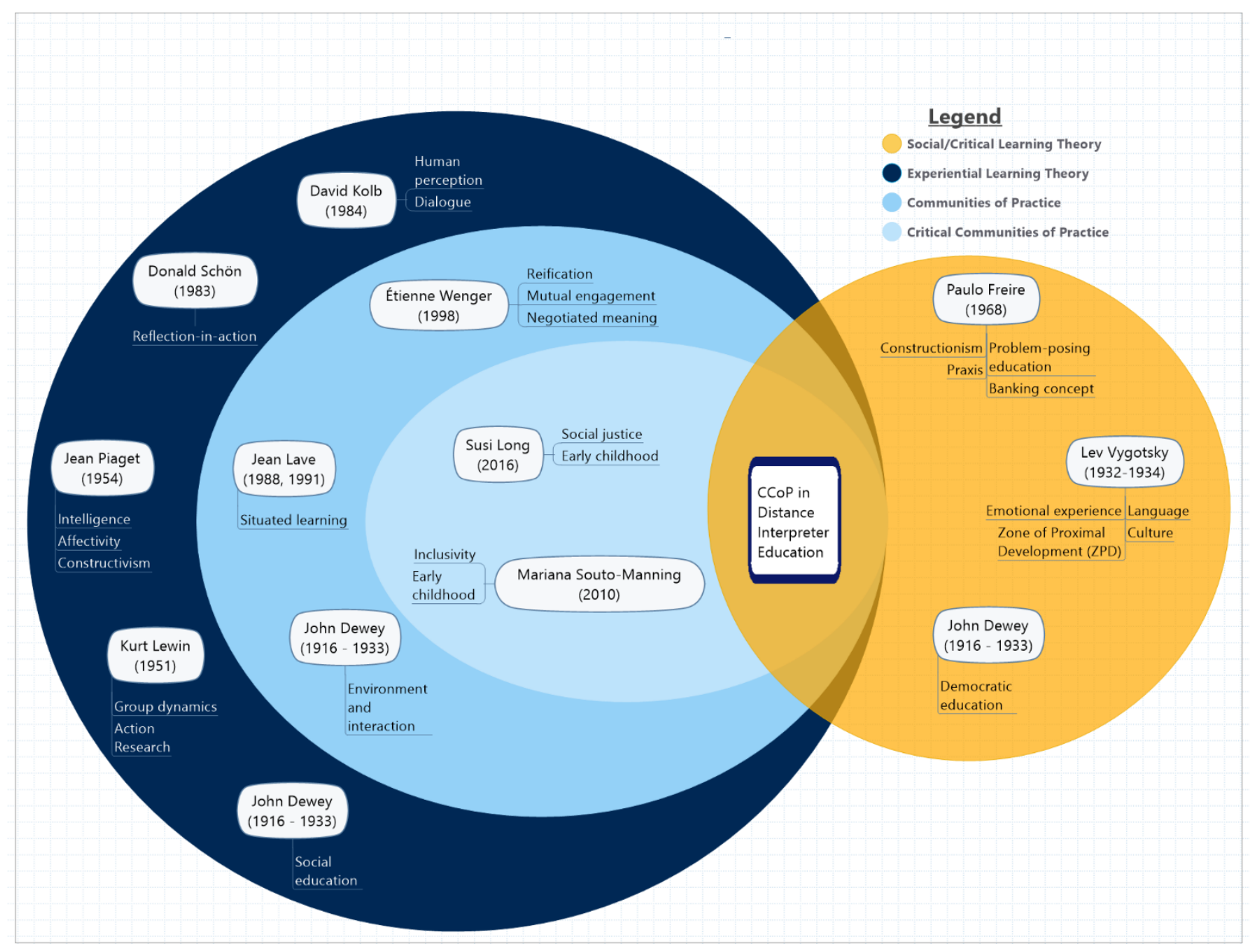

debriefing after-the-fact. By allowing learning to occur through praxis, students are brought into the interpreting community through exposure. This process personifies communities of practice, where current members of the community train incoming professionals to adopt norms. And ultimately, critical communities of practice benefit from the interaction by critically assessing the system within which the community operates. This way, necessary social change may occur.

\section{Distance Education}

The advent of modern technology sparked an educational revolution (J. S. Brown, 2000). The ability to conveniently reach more people and accomplish an equivalent goal as face-to-face teaching made distance education a viable option for post-secondary institutions. The success of 
Britain's Open University incited numerous experiments in higher education (Gerrity, 1976).

During the late 1960s, instructional technology transformed and disassociated from audio-visual devices (Reiser, 2013). In 1970, the Department of Audiovisual Instruction changed its name to the Association for Educational Communication and Technology (AECT) and defined educational technology: "a field involved in the facilitation of human learning through the systematic identification, development, organization, and utilization of a full range of learning resources..." (Silber, 1972, pp. 36-37).

With the increase in utilization of distance education, it is important for the education research community takes a more critical approach to this delivery of learning. Some recent publications (Bektashi, 2018; Morewood et al., 2019) utilize communities of inquiry (CoI) as a framework for active engagement in distance education. $\mathrm{CoI}$ is a constructivist approach to learning which "describes how learning occurs for a group of learners through the educational experience that occurs at the intersection of social, cognitive and teaching presence" (Bektashi, 2018). The CoI has made certain inroads into the online environment research scope (Morewood et al., 2019), but there is little research that approaches distance education and all of its components with a critical eye, especially as it relates to ASL interpreter education. I aim to critically assess the learning experience and its components, including educational technology, two-way communication, myself, and the students' experiences to improve learning for interpreting students.

The more effective utilization of a full range of learning resources, the more likely the students are to acquire required knowledge (Jeffries, 2009). In the scope of distance education, the implementation of educational technology moves learning forward. Students must communicate. John A. Bååth (1979) analyzed teaching models associated with the concept of 
two-way communication (Figure 7 below) in correspondence education, and greatly contributed to the theoretical and empirical underpinnings of current distance systems.

\section{Figure 7}

Bååth's analysis of teaching models (Keegan, 1996)

\begin{tabular}{|c|c|}
\hline Model & Two-way communication \\
\hline $\begin{array}{l}\text { B.K. Skinner's } \\
\text { behaviour control } \\
\text { model }\end{array}$ & $\begin{array}{l}\text { Checking students' achievements; } \\
\text { individualizing functions; assess students' } \\
\text { starting level; consider special abilities; } \\
\text { previous reinforcement patterns }\end{array}$ \\
\hline $\begin{array}{l}\text { E.Z. Rothkopf's } \\
\text { model for written } \\
\text { instruction }\end{array}$ & Helping students get started \\
\hline $\begin{array}{l}\text { D.P. Ausubel's } \\
\text { advance } \\
\text { organizers model }\end{array}$ & $\begin{array}{l}\text { Determine each students' previous knowledge } \\
\text { and cognitive structure; promote positive } \\
\text { transfer to subsequent parts of course }\end{array}$ \\
\hline $\begin{array}{l}\text { K. Egan's model for } \\
\text { structural } \\
\text { communication }\end{array}$ & $\begin{array}{l}\text { Individually devised discussion comments and } \\
\text { 'reverse' assignments }\end{array}$ \\
\hline $\begin{array}{l}\text { J. Bruner's discovery } \\
\text { learning model }\end{array}$ & $\begin{array}{l}\text { Provide individually adapted help; stimulate } \\
\text { students' discovery of knowledge }\end{array}$ \\
\hline $\begin{array}{l}\text { C. Rogers' model for } \\
\text { facilitation of } \\
\text { learning }\end{array}$ & $\begin{array}{l}\text { Check 'open' assignments for submission; } \\
\text { dialogue with each individual student }\end{array}$ \\
\hline $\begin{array}{l}\text { R.M. Gagné's general } \\
\text { teaching model }\end{array}$ & $\begin{array}{l}\text { Activating motivation; stimulating recall; } \\
\text { providing learner guidance; providing } \\
\text { feedback }\end{array}$ \\
\hline
\end{tabular}

However, instructors and designers across all disciplines have struggled to design coursework that effectively facilitates communication, but none more so than in interpreter education. The educators that manage to engage students at a distance do not practice critical discourse analysis of information or reality. Rather than accepting oppressive realities for those with hearing loss who utilize ASL interpreters, interpreters and interpreter educators can pose questions that poke holes in reality for the sake of the entire profession and Deaf communities. Some questions could 
reveal underlying symptoms of oppression, which must be addressed to effectively serve the Deaf community.

Moore and Kearsley (1996) defined distance education as "the planned learning that normally occurs in a different place from teaching and as a result requires special techniques of course design, special instructional techniques, special methods of communication by electronic and other technology." To effectively educate students in distance education, courses must be designed within the structure of the distance learning environment. Some courses implement situation-based learning, for example, to resonate new information with previous experiences (Ariza \& Hancock, 2003; Jeong et al., 2009). Neurologically speaking, the part of the brain that retrieves our first language is close to the part of the brain that retrieves second language learned through situation-based learning (Jeong et al., 2009). If I want interpreting students to be cognitively and critically competent, I need for them to learn from situations, not from reading from a textbook. Engagement in real-life professional situations provide students with opportunities in distance education to be brought up in the professional community while critically assessing the interactions between Deaf and hearing interlocutors.

\section{Distance interpreter education}

The collaborative capacities of technology make it possible to consider distance interpreter education, but not all courses are effectively developed or deployed to utilize such technologies. Some courses attempt to utilize collaborative methods, only to create a "banking" educational system. If Freire were alive to directly address oppressive pedagogical practices in distance education, he would do so by critically questioning reality and implementing the problem-posing structure of education. The vertical, hierarchical structure of the banking- 
education classroom is replaced by discussion, mutual engagement, and a joint responsibility for growth. Students and teachers are critical co-investigators of the educational material.

Interpreters were initially pulled from Deaf communities; they were relatives or friends of a Deaf individual (Lane, 1992). These individuals were hand-selected by the Deaf population to serve the essential communicative function. Now, interpreter education is primarily left to higher education institutions. Unfortunately, students typically begin interpreter education programs (IEPs) with less than fluent ASL skills (Godfrey, 2010). Practitioners enter the interpreting field needing remediation and continued development of ASL proficiency (Humphrey, 2000; C. B. Roy, 2000; Witter-Merithew \& Johnson, 2004).

Even in face-to-face classroom settings, not enough interpreter educators utilize praxis, which could be a result of the difficulty to implement such a practice. Human interaction is so nuanced and unique that it is hard to create an accurate simulated experience. Certainly, a presentation to explain the significance of the experience would be even more challenging to communicate. Unfortunately, even if this course were offered face-to-face, the practicum and out-of-class assignments are limited due to the declared pandemic. Ways of engaging in praxis are generally needed for interpreter education, and even more when in-person interaction rarely takes place.

Especially in a distance-learning environment, praxis is affected by differences in geography and time. Students and instructor are in different locations, working at different moments to study course content. Nevertheless, praxis allows development of a more critical consciousness and should be employed in interpreter education programs no matter how difficult. I find that vignettes offer one opportunity for online interpreting students to engage in praxis. Vignettes have been used in evaluating ethical sensitivity in medical students (Hebert et 
al., 1990). Like medical professionals, interpreters take an oath to do no harm to clients, so it makes sense to utilize vignettes in a similar fashion. The context of interpreting is more volatile than in the medical profession since interpreters are sent to different areas for community interpreting assignments. These contexts hold societal norms on race, gender, sexual orientation, and more, which impact how an interpreter navigates through the situation to make meaning.

Students in this research context will interpret a predetermined situation on their own as they would in the field, but have the chance to share their interpretation, reflect critically, and discuss their cognitive, ethical, and professional decisions with others. Interpreting students should have an opportunity to think about their positionality and their impact on the Deaf community simply by being present as the interpreter. As the interpreter educator, I am not offering answers or solutions. I merely present a unique situation they could one day face in the field and ask them to respond. Then, we collaboratively reflect on their decision and reflect on possibilities for future action and responses.

Steven Johnson (2011) utilized the term liquid network to refer to the capacity for individuals to fluidly engage in meaningful interactions that yield innovation. Interpreting students should be able to comingle with their peers and with their instructor, despite the separation by distance and time. Students should feel that they have a method to collaborate with the members of the course (Skaaden, 2017). By effectively utilizing distance learning techniques and technologies that encourage free-flowing communication, members can exchange and enhance interpreting concepts and practices. I care most about free-flowing communication and question posing. I want students to experience the interpreting field and find ways to connect with their interpreter identity. 
I believe that learning happens when presented with authentic situations to which individuals must respond. I attempt to simulate real world events so that students can engage in praxis with different voices, different language, and different ideas to emerge proficient interpreters. We critically analyze and reflect upon interpretations and course experiences to enhance our capacity as humans and as interpreters. Teachers should create learning environments where students can engage in relevant practices that reflect analogous real-life problems or activities faced by citizens, consumers, or professionals in the field (Wiggins, 1993). I believe that time inhibits the success of praxis implementation in distance education. New content generation takes a significant amount of time (Chapman Alliance, n.d.). If a more robust approach were employed in interpreter education, perhaps instructors and instructional designers could spend less time creating, and instructors could spend more time problem-posing and communicating with their students.

This exchange and discussion of ideas is essential to interpreting students, interpreting educators, and the education community at-large. We need a critical approach to distance education in communities of practice, a la critical communities of practice. Even though this study is small, the theory applies to a myriad of contexts throughout the higher education system. All instructors need to teach critical thinking and information literacy. Students need to question the information provided to them in this terrifying age of information-entertainment hybridization. 


\section{Chapter 3: Methodology}

This study used qualitative research methods. As is inherent to qualitative research, this study sought to find "how people interpret their experiences, how they construct their world, and what meaning they attribute to their experiences" (Merriam \& Tisdell, 2016, p. 6). Interpreting students first situated themselves within the interpreting role and community and assessed how their positionality may affect interactive communication. Then, interpreting students applied their understanding of positionality to interlocutors in order to formulate and deliver conceptually accurate target language utterances. I experimentally move-tested (Schön, 1983) to examine how my teaching practices influenced students' ability to accomplish these tasks. I developed the following four research questions to guide me through this study:

RQ1: How does integration of the Community of Practice framework impact students' learning in an online language-interpreting-based environment?

RQ2: How does critical discourse analysis as a teaching tool enhance students' English-to-American Sign Language interpretation?

RQ3: How does self-reflection influence the development of the Interpreter Mindset?

RQ4: How do students perceive and then self-actualize the role of an American Sign Language interpreter?

These research questions needed to be answered qualitatively. Like the ability to perform critical discourse analysis, interpreting requires finesse and the navigation of cultural nuances; the research of the development of such skills could only be done faithfully through qualitative research practices. 


\section{Research Design}

To collect this qualitative data, I utilized action research in a digital micro-ethnographic setting. I documented the events within the course, including my teaching decisions, to monitor how my own teaching praxis affected students' learning. I experimentally move-tested (Schön, 1983) to establish a community of practice where students and I collaboratively discussed, developed, and demonstrated cognitive and critical competencies applied to the interpreting profession.

\section{Action research}

In order to best document, reflect upon, and leverage my role in this enculturation process, I conducted action research. I made teaching decisions with specific course goals in mind, but I consistently reflected and imagined how I could take transformative action to bring students into an experiential learning environment. Action research is "a social practice, a practice-changing practice, which cannot ignore the theoretical terrain that might help participants to work from a critically informed perspective on social life" (Kemmis et al., 2014, p. 2). Because I wanted to focus on creating a critical community of practice in my online classroom I treated action research as ethnography where I sought to learn more about the culture of the classroom community and of the individual members of our community in and out of the online classroom (Gregory, Long, \& Volk. 2004) in order to improve classroom practices and support the students' trajectories to becoming interpreters. In Mariana Souto-Manning and Christina Hanson Mitchell's (Souto-Manning \& Mitchell, 2010) article, “The Role of Action Research in Fostering Culturally-Responsive Practices in a Preschool Classroom”, the authors utilized a responsive teaching style which allowed them to document events, frame contextually, and "collectively (re)imagine spaces for transformative action" (p. 271). These researchers anecdotally and systematically collected data through journaling, interpreted the notes 
narratively (Hankins, 2003), and made instructional decisions based on observations and interpretations.

This research study aimed to do exactly what Souto-Manning and Mitchell did, but in a post-secondary institution instead of a primary classroom. I utilized the current teaching and learning situation as an opportunity to develop effective and efficient online interpreting (and other disciplines') pedagogical methods. Throughout the semester, I documented the moments of the course by journaling about significant events that impacted the course of student learning.

As previously discussed, experiential learning opportunities should appropriately and accurately reflect the nature of the interpreting profession in situ (Brown, 2000). Providing students with realistic experiential learning opportunities is challenging in an online program, especially during a pandemic (WHO Director-General's Opening Remarks at the Media Briefing on COVID-19 - 11 March 2020, 2020). Students were limited in opportunities to interact with the Deaf community due to physical distancing guidelines ("Social Distancing," 2020). Consequently, I had to develop methods of providing students with alternative experiences that yielded similar outcomes.

This action research was designed to evaluate how I utilized the methods, technology, and systems to provide students with authentic interpreter training experiences, adjusting to appropriately accommodate students' learning needs. The action research design specifically captured my work building and navigating a critical community of practice for and with my students by provoking me to recursively question, develop, implement, reflect, and refine. As the instructor of this course, I provided students with another rite of enculturation, training them to perform the essential functions of a professional interpreter. The action research design encourages consistent self-assessment and realignment with goals. 


\section{Digital Micro-Ethnography}

A micro-ethnography is the study of a small social system. Smith and Geoffrey, two educational researchers, first utilized the micro-ethnographic structure in 1968 in the study of the "complexities of an urban classroom" (p. 3). In this 1968 seminal work, Smith and Geoffrey assumed E.T. Hall's concept of a "silent language" meant to "describe the silent language of a culture, a classroom in a slum school, so that those who have not lived it will appreciate its subtleties and complexities" (Smith \& Geoffrey, 1968, p. 2). The micro-ethnographic structure facilitates the potential for rich contextual and situational information (Harry \& Rippey, 2009). At the heart of the micro-ethnographic procedure is "the study of moment-by-moment interaction in classrooms [that] ultimately explains how the social institution of school is constituted" (Streeck \& Mehus, 2004, p. 817). Where an ethnography focuses on an entire system, such as an entire town population, a micro-ethnography is the day-in, day-out study and documentation of an individual classroom or even one entire school to understand how students generate the concept of "school" (ibid.).

To answer my research questions, I facilitated a digital micro-ethnography: the documentation of the day-to-day operations and interactions on a small social system online. The distance education classroom is really the world. There are an infinite number of factors that can influence a student. Without a shared physical space, I created a digital, engaging, interactive community where students considered their interpreting development in their reality and critically assessed the implications of other realities on meaning. I considered the impact of my work as an instructor, specifically how guiding the students through the objectives of the course influenced students' professional and personal progress, including content knowledge, skills, and more generalized meaning making. As described in the first two chapters of this prospectus, this process was socially situated and both constructivist as well as constructionist, located in 
communities of practice that constituted and were constituted by multiple social worlds of both the online environment, and chains of discourses linking to broader social worlds of interpreter practices within Deaf communities.

As previously discussed, communities of practice provided spaces in which novice members were brought into new communities, otherwise known as legitimate peripheral participation (Lave \& Wenger, 2011). Community members interacted to help each other and share information (Wenger, 2011). In the case of my course, students strove to become interpreters, a role that is professional yet personally meaningful, and co-constructed in social worlds both in and outside the classroom, and encompassing knowledge and experiences from not only the present teaching and learning experiences but past experiences and suppositions of future experiences as well (Hale, 2007; Pochhacker \& Shlesinger, 2002; Wadensjo, 2013)

Effective interpreting involves an affective side. Learning to employ empathy, for example, can only be done by doing: "much of knowing is brought forth in action, through participation - in the world, with other people, around real problems" (Brown, 2000, p. 14). The finesse of interpreter education involves integration of reality-driven scenarios, allowing the student to learn the facts, concepts, and genres of a particular profession:

Returning to Bruner's notion of learning to be, recall that it always involves processes of enculturation. Enculturation lies at the heart of learning. It also lies at the heart of knowing. Knowing has as much to do with picking up the genres of a particular profession as it does with learning its fact and concepts. (Brown, 2000, p. 15).

To provide interpreting students with an authentic learning experience where they could "learn to be," the University of North Florida created a service-learning course, wherein they 
collaborated with the Deaf community (Shaw \& Roberson, 2009). As is characteristic of servicelearning, both communities benefitted from the cooperative effort. Unfortunately, I did not teach a service-learning course and focused specifically on interpreting processes. Professional interpreters practice intrinsic and extrinsic situational analysis to assess the positionality of each participant to effectively accommodate for communicative nuance. To teach students this capacity, I exposed them to critical discourse analysis (CDA) early in the semester. CDA is “discourse analytical research that primarily studies the way social-power abuse and inequality are enacted, reproduced, legitimated, and resisted by text and talk in the social and political context" (van Dijk, 2015). The analytical social research of the dichotomous relationship between the Deaf and hearing communities is an applied example of CDA.

In American Sign Language interpretation education, CDA is applied to discourse as a socially analytical process so interpreters might "comprehend the full meaning of the message and the speaker's intent" (Pollitt, 2000, p. 70). As CDA guides, discourse is "an act of identity, of social action. It should be possible, therefore, to pick apart what we say and the way we say it to reveal some of the influences and beliefs that shape our lives, frame our perspectives and characterize our speech" (ibid.). By engaging in critical discourse analysis, I believe that students can develop their critical consciousness. If critical consciousness is the recognition of society's "essence" (Freire, 2000), CDA is the method by which this recognizing can begin.

Everyone has their own petits recits, a unique mixture of influences, ideas, ways of using language, etc. By employing critical discourse analysis, I can situate students in the context of each interpreting passage. Throughout the semester, I enculturate students and ask them to hypothesize about the potential influence of individuals' petits recits on the interaction. After this reflection, students share their interpretations with their classmates for others to view and to 
provide feedback. I would subsequently situate this research in a critical community of practice, a community where people engage in critical discourse analysis-focused activities and discussion around a shared domain of interest.

\section{Context of the Study}

Clear Point College (CPC) offers more than 40 Associate of Arts, Associate of Applied Science, and Certificate of Applied Science degree programs. The school is accredited by the community college system. The Interpreter Education Program (IEP) is over 15 years old. When it was initially created, the courses were delivered mostly on-campus, save perhaps one class online. The delivery transitioned to all-online within the last two years.

\section{Program and Course Descriptions}

The program information in the College catalog outlines the program's purpose, the student learning outcomes, employment opportunities, program requirements, required course list, and a potential two-year course schedule. The course schedule for the 2-Year Interpreting Program at CPC is presented below.

\section{Table 1: 2-Year Interpreting Program Associate Degree Course Schedule}

Fall first year (16 Deaf Studies and Culture, ASL Linguistics, American Sign Language 1, hours) American Sign Language 2, Written English

Spring first year American Sign Language 3, American Sign Language 4, Technical

(17 hours) Report Writing, Written English 2, Computer Concepts and Applications, Fundamental Concepts of Mathematics 
Fall second year

(16 hours)

Interpreting 2, Simultaneous and Consecutive Interpreting,

Interpreting Observation, Introduction to Sociology

Spring second year

(14 hours)

American Sign Language 5, Sign-to-Voice Interpreting 1, Voice-to-Sign

American Sign Language 6, Sign-to-Voice Interpreting II, Voice-to-Sign

Interpreting 2, Educational Interpreting, Interpreting as Private Practice

The class I taught that was the focus of this project is titled: Simultaneous and

Consecutive Interpreting (bolded in the schedule in Table 1 above). This class is typically taken

during the second year of the program. Students completed programmatic general requirements, including the passage of English and Mathematics courses. I was fortunate enough to have the freedom to determine and write the course objectives. They are as follows:

1. Perceive incoming source language and analyze for content.

2. Deconstruct incoming source message for meaning and connotation.

3. Reconstruct meaning utilizing target language and grammatical and syntactical structures to plan interpretation.

4. Render interpretation in target language maintaining integrity of original message's (source language) meaning, affect, and register.

5. Reflect on impact of interpreter presence on Deaf-hearing client interaction and interpretation.

6. Assess client feedback to identify and acknowledge limitations and develop strategies for improvement.

\section{Program Context}

There are two interpreter training programs in the state of West Virginia. Both are twoyear programs that prepare interpreters to take the Virginia Quality Assurance Screening (VQAS) or the Educational Interpreter Performance Assessment (EIPA). Because a bachelor's degree (in any field) is required for national certification (RID, 2012), the students in these community college programs will not be eligible for national certification after graduation; they 
would have to pursue additional education. Looking more broadly, there are 56 Interpreter

Training Programs (ITPs) in the United States but only 15 are fully accredited (CCIE, 2018). CPCC's program is not accredited.

In West Virginia, the West Virginia Invests Grant "is a state-funded grant program that pays toward the full cost of basic tuition and mandatory fees for select certificate and associate degree programs at a West Virginia public two- or four-year institution” (West Virginia Invests, n.d.). The creation of this program opens the door to higher education for individuals who would otherwise not be able to afford the cost. The ability for CPCC to receive state funding is greatly beneficial. In recent years, and especially through the pandemic, two- and four-year higher education institutions struggled financially (Friga, 2020). Schools have begun searching for alternative methods of funding and making decisions in the name of the bottom line. In my experience, $\mathrm{CPCC}$ is no exception.

\section{Positionality Statement}

I was the instructor for the course, Simultaneous and Consecutive Interpreting at Clear Point Community College as part of an interpreter training program. I am a graduate of this same program, which has both added to and possibly constrained my ability to create a critical community of practice in my classroom. Fortunately, I remembered many of the skills I struggled to master. I structured the enculturation process and design necessary lessons to teach cognitive interpreting skills.

On the flipside, I had preconceived notions of how I believed students should behave in an interpreter training program since I was a successful graduate of this same one. The programmatic structure is very different now, beginning with the online delivery format. When I started my undergraduate career in the interpreting program, it was on-campus, compared to the 
online format under which the program currently operates. I believe I was offered only one course (Deaf Culture, interestingly enough) online. Otherwise, each of my interpreting courses were face-to-face delivery.

I must remind myself of the potential impact of distance education and work to minimize the perceived communication barrier it creates. I must also continually situate students in their learning contexts, not mine, remembering that these students do not have the same multilingual background I do. Additionally, during my time in the program, there were only two instructors: Mae and Jamie. Mae taught interpreting; Jamie taught American Sign Language and served as the Program Coordinator. Jamie is still at the institution in her same roles, but there are three different interpreting professors, including myself, all of whom have a different approach, perspective, and set of professional experiences. I have never formally met the other interpreting instructors.

When my high school offered American Sign Language, I got into the class as soon as I could. I felt at home in the class, like I was a novice member of a community, and that I was being cultivated into a new and exciting community of practice. I enjoyed learning the language and being in the Deaf culture environment. I spent time with the instructor at Deaf events (like bowling) and in class, hung out with an older classmate (who also went on to be an interpreter, receiving her training at Gallaudet University). I decided during high school (because of my classroom experiences) that I would attend an interpreter training program.

During my interpreter training, I was asked to interpret several times for my sign language instructor, Jamie. I gained cognitive and situational knowledge during these experiences. I interpreted mostly in open house settings, where Jamie was interacting with prospective students. I was facilitating communication between Jamie and others, but I served as 
an ambassador of the Program. I needed to utilize everything I had learned to faithfully render the source messages.

I completed majors in American Sign Language interpretation and Spanish, simultaneously. My spoken language learning experience taught me how to approach second language learning in general. The structural knowledge of Spanish, a romance language, helped me grasp parallel syntactical elements of American Sign Language, a visual language inspired by romance language structure (Pizzuto et al., 2006).

Upon successful completion of the interpreter training program in 2012 and national certification in 2016, I began seeking more community work. While actively interpreting in the community, I worked in various settings ranging from elementary education to medical appointments; I worked with various numbers of clients; I worked in video remote and on-site settings. My experiences have been vast.

During one of my interpreting roles, I was able to work with Certified Deaf Interpreters (CDIs). CDIs are deaf or hard of hearing and have a demonstrated knowledge and understanding of interpreting, deafness, the Deaf community, and Deaf culture. CDI certification holders have specialized training and/or experience in the use of gesture, mime, props, drawings and other tools to enhance communication. CDIs are a unique community of practice. These individuals are interpreters who capitalize on the minimal language skills of deprived Deaf individuals, yet they are members of the Deaf community.

Through my interactions with CDIs, I learned about the ability to express thoughts and ideas more clearly. Hearing interpreters (HIs) are accustomed to utilizing language drenched in connotative meaning. CDIs, however, are trained to express meaning using more than signs. Individuals in high risk situations, like medical contexts, benefit greatly from the utilization of a 
CDI. Both CDIs and HIs are trained to visually present information. However, American Sign Language is typically a second language for HIs, whereas it is native to many CDIs. Even if ASL is not the CDI's native language, it is expected that these individuals have a more comprehensive understanding of interpreting, deafness, Deaf community, and Deaf culture because they live these experiences as members of the Deaf community and culture.

The "Deaf Heart" trait is the closest an HI can come to being Deaf. I was not born Deaf; I will never have the comprehensive Deaf understanding of the Deaf experience that the Deaf possess. However, as a result of my experiences with the Deaf community (as a member and as a professional), my personal and professional identities center around Deaf language and culture. Consequently, I maintain high-level expectations of students. As the interpreter for palliative care appointments, immigration law, and more, I know that an interpreter's failure to faithfully render a source message in the target language can be life-shattering.

I know that I cannot force the wisdom my experiences afforded me upon my students. Each of them, at their own time, must live their profession. However, I do understand that my experiences shaped and honed my interpreting skills until I was a sought-after talent in the field. I want to mimic those experiences for my students so that they may hone their skills and provide their clients with clear, correct, and concise interpretations.

\section{Methods}

\section{Recruitment and Participants}

There are four students enrolled in the course: Christina, Maggie, Reba, and Willow (see Table 2 for brief profiles of each student). Students' names have been replaced with pseudonyms to protect their identities. Because I am the students' instructor, I wanted to be sure that students had a way to safely exit the study if they so choose. Thus, I offered an opt-out option: students 
may contact the Program Coordinator, Jamie, if they are no longer comfortable participating in the study. To date, all students have remained a part of the study.

Table 2: Participant demographics and characteristics

\begin{tabular}{|c|c|c|c|c|c|c|c|}
\hline Student & $\begin{array}{l}\text { Age } \\
\text { range }\end{array}$ & Background & $\begin{array}{c}\text { In- or out- } \\
\text { of-state? }\end{array}$ & $\begin{array}{c}\text { Relationship } \\
\text { to Deaf } \\
\text { community }\end{array}$ & $\begin{array}{l}\text { Year in } \\
\text { school }\end{array}$ & $\begin{array}{l}\text { Course } \\
\text { attempt }\end{array}$ & $\begin{array}{c}\text { Additional } \\
\text { foreign } \\
\text { languages } \\
\text { spoken? }\end{array}$ \\
\hline Christina & $18-21$ & $\begin{array}{l}\text { California- } \\
\text { born; moved } \\
\text { every two } \\
\text { years }\end{array}$ & In-state & Hearing & $3^{\text {rd }}$ year & Second & No \\
\hline Maggie & $22-25$ & $\begin{array}{l}\text { Several } \\
\text { counties } \\
\text { within state }\end{array}$ & In-state & CODA & $2^{\text {nd }}$ year & First & No \\
\hline Reba & $28+$ & $\begin{array}{l}\text { Born in state } \\
\text { but raised } \\
\text { elsewhere. } \\
\text { Moved back } \\
\text { about } 6 \text { years } \\
\text { ago }\end{array}$ & In-state & $\begin{array}{l}\text { Family } \\
\text { member of } \\
\text { deaf }\end{array}$ & $3^{\text {rd }}$ year & Second & No \\
\hline
\end{tabular}

Willow 18-21 $\begin{aligned} & \text { State-born } \\ & \text { and raised } \quad \text { In-state }\end{aligned} \quad \begin{aligned} & \text { Other: Deaf } \\ & \text { friends and } \\ & \text { Deaf camp } \\ & \text { counselor }\end{aligned} 3^{\text {rd }}$ year Second No

Christina is a young, quiet, shy student. She was born in California but moved to the same state as the College for her father's job. Christina does not have any direct ties to the Deaf community but is passionate about the language. During our first meeting, I asked her why she chose to be an interpreter. She told me the story of her Deaf friend and how the little knowledge of sign language she had at the time granted her a new friend. Christina was taking this course for the second time. 
Maggie is a non-traditional student, resident of the state, and a Child of a Deaf Adult (CODA). The CODA title is well-respected in the Deaf and interpreting community. For many interpreters, ASL is acquired outside of the home. As a child, Maggie was able to interact daily with Deaf language and culture. Consequently, she was able to develop strong ties to the Deaf community and ultimately identify as a community member. Maggie wants to become a better interpreter and recognizes that she must break some of the ingrained CODA habits to transition appropriately into the interpreter role. Maggie was taking this course for the first time.

Reba is another non-traditional student. Unlike Maggie, Reba has lived outside of the state, though she returned within the last 10 years. She is outspoken about her struggles as an individual with multiple disabilities (including mobility limitations). Reba effectively communicated her understanding of the oppression against people with disabilities. As an interpreter, Reba feels that she could advocate strongly for Deaf people. At times, she struggles to ambulate or perform daily essential tasks. However, Reba is passionate about potential work with wrestling organizations to provide interpreting services to individuals who use ASL. Reba is taking this course for the second time.

Willow is a positive, upbeat student. She speaks positively about the interpreting profession. She maintains contact with current interpreting professionals and seems genuinely excited to interpret in the field. Willow is hesitant to ask for help but focuses when afforded opportunities to learn. Willow is socially active in the Deaf community, which makes her a conscientious participant in the course. Willow is taking this course for the second time.

Each student has a unique backstory with the Deaf community with varying ascribed and prescribed roles. In spite of this discrepancy, all students are impassioned about their future careers as interpreters. But they are all were the infancy stages of their work at the time of this 
study. I felt especially at the outset of the course that their interpreting mindsets were not fully developed. I wanted to grow their mindsets, so I focused on experiential development and critical discourse analysis when designing and teaching this course.

\section{Data Sources and Collection Methods}

Weekly assignments, vlogs ${ }^{2}$, journal entries, and interviews serve as opportunities for students to increase their ability to accurately frame source language messages into the target language and develop their interpreting mindset. Data sources were chosen to most authentically represent the progress of student development throughout the semester, focusing like all good interpreters do on the meaning and implications of the language used. I actively respond to learning needs by documenting course experiences and adjusting teaching to maximize learning effectiveness. As Souto-Manning and Mitchell did (2010), I journal anecdotally to later analyze narratively.

The following table (see Table 3) represents the triangulation of research questions to data sources. I created this matrix to plan from where I would target sources to provide answers to my research questions. Interviews, assignments, vlog posts, and journal entries are the four main categories of data sources. Below, I mark which sources are utilized to respond to the four research questions. Assignments inform all four research questions, while interviews, vlogs, and journals provide varying relevant responses to the questions.

Table 3: Triangulation Matrix: Data Sources and Research Questions

\section{$\begin{array}{llll}\text { Data Source Interviews Assignments Vlog Journal } & \text { Nog }\end{array}$}

\footnotetext{
${ }^{2}$ A vlog is a website made up primarily of videos that contains personal reflections and comments.
} 


\section{Research Questions}

RQ1: How does integration of $\mathrm{X} \quad \mathrm{X}$

the Critical Community of

Practice framework impact

students' learning in an online

language-interpreting-based

learning environment?

How does self-

$\mathrm{X}$

$\mathrm{X}$

reflection influence the

development of

interpreting skills?

discourse analysis

enhance students'

English-to-American

Sign Language

interpretations?

How do students

X

X

perceive and then self-

actualize the role of an 

American Sign
Language interpreter?

\section{Interviews.}

I conducted interviews with each of the students, once at the beginning of the semester and once at the end of the study via Zoom. The first interview was seven (7) questions (see Appendix A) long and the second interview was eight (8) (see Appendix B). I transcribed both sets of interviews verbatim with discourse cues. The interviews followed a five-stage interview structure (Chrobak-Munoz, 2000). that allowed me to learn how the student perceives their interpreting capacity and role during both interview collection timepoints. The interview questions for both interviews were strategically designed to respond to the four research questions and determine how their course experience influenced their Interpreter Mindset (see Appendix D for triangulation matrix of research questions to both sets of interview questions).

The discussions were informative and formal, but I capitalized on opportunities for humor (Seidman, 2006). I responded to the all-women group composition by referencing power dynamics between men and women to relate the experience to the Deaf community. By making this connection, I hoped to place students in a comfortable, relaxed setting so they might respond most truthfully to interview questions. If words included historic experiences as previously discussed, I could utilize language to help place students in the frame of mind to provide honest responses and help them transform into effective professional interpreters.

\section{Assignments.}

Students completed a pre-assessment where they were asked to interpret two passages at the beginning of the semester. From that point forward, students are assigned different passages 
to interpret. Throughout the semester, students complete weekly assignments with various components (Appendix E) related to the part of the Interpreting Process (see Appendix F) on which we were focusing at that time.

For the first two weeks of the semester, students were guided through the course on a week-by-week basis, rather than a goal-oriented approach to understand and practice the Interpreting Process. Starting on the third week, I shifted the focus of each content area to match the components of the Process. This way, activities would be aligned with the interpreting practice, rather than focused on where students were in the completion of the semester.

Students submitted their activities via Blackboard, the learning and content management system (LMS and CMS) at the college. Students utilized other tools to record their submissions, including YouTube and Flipgrid, a video discussion application. While YouTube has outstanding storage capacity, I was concerned for students' privacy due to the ease of access of videos and personal information, even when content is uploaded and unlisted. I made the decision to transition us to posting English-to-Sign-Language interpretations, peer feedback, and vlogs on Flipgrid $^{3}$ as much as possible. Students still had the opportunity to post to YouTube, if they chose to do so.

\section{Vlog/Journal.}

Students were asked to keep a weekly vlog, responding to specific questions or prompts (Appendix G). These prompts were designed to get students thinking about their careers in ASL interpreting and about themselves as future cultural mediators. Students submitted vlogs for

\footnotetext{
${ }^{3}$ Students were allowed and encouraged to utilize Flipgrid to post questions to each other and to me.
} 
classmates to see via Flipgrid or semi-privately via a shared YouTube video link sent to me to complete the assignment.

I maintained a regular, semi-private journal to document ideas and events on Google Sites. This journal was shared with my committee members, to keep everyone abreast of my data collection progress. All names were changed in the journal to protect students' identities.

This journal served two purposes: (1) for myself as a teacher to organize my thoughts and (2) as a memorandum and audit trail to support my analysis. In this journal, I wrote about course plans and the events that inspired changes, such as the course framework adjustment to focus on the interpreting process.

\section{Data Analysis}

The structure of this research project afforded me a plethora of data. To appropriately focus and funnel the data to answer the proposed research questions, I focused on the pieces of data which I believed most acutely responded to the research questions. To begin, I transcribed the interviews I conducted at the beginning and end of the semester with each student verbatim (Appendix I-L). After completing necessary verbatim transcriptions, I dramaturgically coded the first and second interviews and compared the coding results. I also coded students' critical discourse analysis (CDA) assignment responses in the same way.

The interview conversations provided a direct source for students' perceived positionality within and amongst the Deaf while the CDA assignment showed me how their individual perspective influences their membership in the Deaf and interpreting communities. Dramaturgical coding helped me understand and analyze students' perceived power relationship in their role as an interpreter amongst the Deaf community and how that perception changed over time, for example. I explored themes throughout both sets of interviews and made note of any 
value, attitudinal, belief, or performance changes and patterns over time for all study participants, including myself.

I used in vivo coding and themes to analyze my teaching journal (Appendix M) accompanied by integrative memos. The codes were organic and the themes summative based on patterns. My journal served as a written record of teaching decisions throughout the semester, so I relied on the verbiage in the journal to situate the analysis procedures. I also employed value coding (values [V], attitudes [A], and beliefs [B]) (Saldana, 2011, p. 106) to analyze students' vlogs. The vlogs were designated venues for students to express their thoughts and feelings throughout the semester as they pertained to their interpreting-skill and identity development. Values coding allowed me to gain further insight into their value system as it related to their roles in the Deaf community.

Then, I descriptively coded the students' pre- and post-assessment interpretations conducted at the beginning and end of the semester, respectively. The descriptive codes (sign production and vocabulary, grammar, use of space, affect, pacing and pausing) for the interpretations come from the NCIEC ASL Performance Interpreting Rubric (see Appendix H). These descriptive codes were categorized by frequency. I summarized each student's interpretation results (pre- and post-assessment) utilizing the rubric (Appendix N-Q).

\section{Validity}

To promote research validity, I utilized my reflective notes on my teaching to narrate my decisions. As Merriam (2015) states, these notes are my audit trail: "written reflections, questions, decisions made to problems, issues, or ideas encountered in collecting data" (pp. 252253). Rather than try to remember my perspective, I have written documentation of my thought 
processes and the actions taken throughout the semester to provide students with an authentic interpreter education experience.

Each week of the semester, students interpreted a different piece ranging from primary education to politics. The variance was designed to provide students with a range of experiences in register, signs, and forms. While I feel like I provided students with a breadth of content, I found it challenging to simulate a realistic interpreting interaction. The text required the utilization of a CD and many students did not have a CD player. Many students completed their text-based interpretation by reading the transcript. Their interpretations were filled with movements as they read their books that distracted from the quality of the interpretation.

To ensure validity for this research analysis, I utilized crystallization to look at more than three components to validate the study (Richardson, 2000). For this study, I employed assignments to be utilized for specific analytic functions. Consequently, I utilized my journal, the

pre- and post-assessments, and the weekly assignments to check learning; I used vlogs, interviews, and correspondence to validate the growth of the Interpreter Mindset. Of course, I am with these students for the entire semester, so I have adequate engagement in data collection, which is another strategy for ensuring internal validity or credibility (Merriam \& Tisdell, 2016).

\section{Ethical Considerations}

I understood how students might feel pressured to participate in my data collection because I was their instructor and their grade could be influenced by their participation status. I did not want students to feel that they were pressured to continue their participation in my data collection. Consequently, I provided students with a third-party opt-out since I was the instructor of the class. This way, students could reach out to a neutral individual in case they were not comfortable with me including their data in my dissertation research. 
In order to protect students' and colleagues' identities, all names have been changed to pseudonyms, including the name of the college. These students' names were kept confidential to protect students from receiving criticism and judgment from the Deaf, hearing, and interpreting communities. Students' future professional careers should not be negatively affected by their apprenticeship in learning through a critical community of practice. 


\section{Chapter 4: Findings}

In this chapter, I will outline the research questions and the recurrent, emerging themes that answer each question. In this research, I focused on how a more critical approach to distance interpreter education increased students' awareness of their positionality as an interpreter, their role in the Deaf-hearing interaction, and their ethical decision-making skills. I found that students' introspection and mindfulness contributed greatly to learning. I identified the components of this meaningful learning experience and witnessed significant shifts of some students' cultural identities.

I tracked how my teaching decisions, centered around the development of critical consciousness, influenced the interpreter mindset and interpreting competencies. As ASL interpreters, we are precariously positioned in a myriad of settings. We must be prepared to perform the functions of the interpreter at a high standard while acknowledging and appropriately responding to etymological, cultural, sociological, and anthropological discrepancies. Thus, interpreting educators must provide opportunities for students to experience the field in the learning environment.

\section{How does the integration of the critical community of practice framework impact students' learning in an online language-interpreting-based environment?}

The semester was built around group discussion and collaboration. Each week, students completed a first-draft interpretation, and were then required to offer concrete feedback to each of their peers before completing their second draft of their interpretation. I witnessed a significant increase in the utilization of affective and cultural components in interpretations, as well as enhanced sign production, grammatical, and syntactical use of ASL.

Providing and receiving feedback was not easy for students, as I will demonstrate in the themes and examples below. In spite of their struggle, when students actively engaged in peer 
feedback, they exhibited a significant, positive shift in their overall approach to the interpreting process. For example, these students demonstrated how to plan interpretations that matched the speaker's intentions, rather than formulate a word-for-word translation. The work they put into this process also gifted them with connections to their peers, through which they sorted out various questions and strengthened their community ties.

My involvement in their learning manifested itself in various ways, but I avoided scenarios where I was simply a "talking head" (Smaldino, 1999). Instead, I situated myself as the praxis facilitator. As a hearing interpreter, I cannot implant Deaf culture and language knowledge into students' minds. I must provide opportunities for students to explore the oppressive realities of the Deaf World and realize their precarious hearing person-hearing interpreter position in fighting to change it. Additionally, the more time they spent amongst the Deaf World while planning and constructing their interpretations, the more they gained an understanding of the world in which they were working and the people who inhabit it.

In 1970, Paulo Freire published Pedagogy of the Oppressed where he wrote about how the oppressed community and their allies must liberate themselves and their oppressors from oppression.

This lesson and this apprenticeship must come, however, from the oppressed themselves and from those who are truly solidary with them. As individuals or as peoples, by fighting for the restoration of their humanity they will be attempting the restoration of true generosity. Who are better prepared than the oppressed to understand the terrible significance of an oppressive society? Who suffer the effects of oppression more than the oppressed? Who can better understand the necessity of liberation? They will not gain this liberation by chance but through 
the praxis of their quest for it, through their recognition of the necessity to fight for it. And this fight, because of the purpose given it by the oppressed, will actually constitute an act of love opposing the lovelessness which lies at the heart of the oppressors' violence, lovelessness even when clothed in false generosity. (p. 45)

In any other semester, I would have assigned various Deaf Club events throughout the course as assignments so students could mingle with the Deaf and experience their traditions. When students could not attend Deaf Club events due to COVID-19, for example, I attempted to provide similar experiences to these interpreting students from which they could learn. I hoped that by allowing interpreting students to experience Deaf World through interpreting scenarios and critical discourse analysis, they would still gain an understanding of the Deaf experience.

\section{The Meaningful Learning Experience}

When I spoke with each student during our first interview, they seemed to have all been deprived of meaningful learning in their interpreter education experience. In our interviews together, the students individually and without prompting mentioned a lack of communication with their other interpreting professors. While I never missed a correspondence, I found biases in my language in my teaching journal. I would argue that the presence of these ideas in my writing indicates their existence in my course decisions at the beginning of the semester. In my second journal entry, I reflected on my first impressions of two students. I later returned on September 3, 2020 to write a reflection. As I read my entry (Figure 8), I witness my own transformation and language-shift from a business- to a student-centered approach after spending a little time with the group. 


\section{Figure 8}

Journal Entry from August 18, 2020

August 18, 2020

I spoke with two of my students today! It was nice to see their faces. My, how their personalities differ. I wonder how their personality test results impact the students' perception of who they are as people and as interpreters.

It was interesting: my students today mentioned two things. (1) Their previous instructors were terrible communicators. (2) They both stated how they "lost their way" last semester.

Each of these students is a unique case. They truly are.

Both students today told me that previous instructors have failed to reply to communication. One would return correspondence about an assignment after the assignment was due. While I assured the student that I would never delay to respond to an email, I also informed her that she should not expect a reply from me at 11:58 PM for an assignment due at 11:59 PM. The other student told me that previous instructors refused to answer her emails, and she ultimately had to escalate to the Dean to get a response.

While I was not there for the Instructor's side of this situation, I really do hope that I never miss an email for more than 24 hours. I hope that I am able to maintain access to my computer, internet, and the web to facilitate quick communication (email or otherwise!) throughout the entire semester. I hope I never have to leave a student for that long.

Additionally, both students stated how they "fell off" at the end of the Fall 2019 semester. These students stated that they stopped working on coursework altogether. One stated that now she has a planner to write down her tasks, since she did such a poor job at staying abreast of her work during that semester.

Initial assessments:

- Christina: Very shy. It was very painstaking to interview this student. I would ask a question hoping for more information. Or, share a little more about myself in hopes of getting her to open up. She never did. I perceive a lack of self-confidence and self-efficacy. I do not know if she feels that she should interpret. She believes interpreting in elementary or secondary (middle school, specifically) will be easiest for her because she is not comfortable when information comes at her quickly. I fear that she does not understand the amount of creativity required for interpreting at those younger levels. I hope to shed light on her internal conversation and help determine if she is capable of handling such a position. She mentioned that her last semester, she stopped working on all of her courses. She bought a planner and seemed motivated to utilize it to organize her semester. I hope she utilizes it to its full potential! I will be sure to follow-up with her in a few weeks and see how she is doing with it. Perhaps we can work together if she is struggling.

- Reba: Very outgoing and perceptive. Frankly, the antithesis of Christina. We spoke at length about her disability, her experiences, her perspective, her goals, and her struggles (for nearly two hours, compared to less than 45 minutes with Christina). She is very insightful about the Deaf community, as she is an individual with a unique-ability. I took a minute to 


\section{(Figure 8, continued)}

inform her that as an interpreter, there is a need for self-advocacy for presence. She shared some of the mistreatment and discrimination she experienced, such as her dismissal from her previous internship experience, for what she believes was due to her disability. She seemed very interested in helping herself--until she got uncomfortable! When I suggested additional research (in speech-to-text options, for example), she shirked the idea and did not pay it much mind. In fact, she seemed vehemently opposed to utilizing anything related to technology like that, something that would allow her to add speech-to-text features to nurture her academic and professional careers. She seems to need additional support and self-advocacy encouragement. I communicated to this student that while I am willing to work with her to adjust assignments (e.g. responding via voice rather than typing or handwriting), the essential functions of the course will not change. I do hope that she understands how true this fact is. Throughout the semester, I am interested to see how she approaches her work. I was told by the Program Coordinator that she should not be an interpreter. I do not know what to expect.

REFLECTION: I feel very disheartened by the approach taken by the College. This student has been identified as one who should not be an interpreter, but I am supposed to encourage her through the program. I feel like I am in a very difficult situation, one where I am set up to be the hatchet man, but I don't want to get cut (Thanks, Dr. B, for the verbiage here). I also acknowledge the drive to keep as many dollars in the College system as possible. But, by allowing a student who may not meet the essential functions of the course to continue in the program, are we setting her up for failure? I was told by the _College Psychologist_that I was only supposed to tell the student if she passed the class, not if she would be successful in the professional field. This statement is heartbreaking to me! Is this the future of education? Take their money, but don't help them find their passion? Push them through the system. Don't help them find their internal motivators. Just add them to the Conveyor Belt of Non-Thinkers. (Date: September 3, 2020)

Additionally, the students did not fail for the reasons to which I was previously alluded. These students struggled with time management, self-discovery, and self- actualizations. These students seemed to struggle more with their identity than they did with their coursework, at least by their own description.

I speak with one other student tomorrow. I speak with my final student on Thursday morning. I am excited to meet them both! :) 
The main theme in my writing is communication and I believe I focused on communication in the interviews, too. After all, interpreters are professional communicators. However, I temporarily fell into a business-approach to education. As an employee at the college, I felt obligated to move with the overall flow of the program. Unfortunately, the flow in the Clear Point College system is disconnected and disjointed, characterized by weak communication infrastructures and delayed support responses, even to essential inquiries like learning management system support. At the end of the semester, Jamie (program coordinator) contacted me to confirm the textbooks I use for the class. It turns out the College was being audited because some professors in various departments had not updated their textbooks in over 30 years.

In spite of the obstacles that affect education in the community college system, I was compelled to provide an experiential learning environment that taught, demonstrated, and facilitated relevant knowledge acquisition. On September 3, I returned to write my reflection after I scrapped my initial course organization. I saw a shift in my language that supported the development of practical and applicable knowledge instead of implanting information in apparently separated units. Instead of laterally structuring the course by week, I transformed it into a developmental process where interpreting was explained by its parts, down to the smallest parts, and practiced consistently. This transition occurred starting the third week of the semester, a few days after my reflection was posted.

I aligned myself to provide opportunities for each individual to expand their skill set and their mindset. Jamie indicated that these students would never thrive in the interpreting field because they were "lazy people who never unwrapped their books." But books should not be the basis of learning. I decided to more deliberately orchestrate experiential learning to enhance their 
core competencies. I quickly recognized (though I wish I had sooner) students' issues to situationally relate their experiential and structural interpreting knowledge to the act of interpreting.

During a conversation with a colleague of mine who is Deaf, he told me about an experience in a mainstream education, or public school, classroom. He narrated the boredom on Deaf and hearing students' faces and their passive presence in the intended learning environment. He said, “The hearing world focuses on discussion. Deaf people don't learn by talking about it. We learn by doing it." I, too, find that active, collaborative participation in critical discourse analysis alongside a professional community yields greater introspective and interpersonal understanding than listening to others spout their analyses and interpretation ideas. I do not learn how to create a nuanced message with a particular voice by observing others do it; I must practice, fail, and receive feedback on how I can improve from those who understand the Deaf and interpreting communities.

I want students to learn how to read their audience and understand people, relate to them, even when there is seemingly nothing in common. Students learn how to decipher meaning by interacting with others. Lave and Wenger (1991) believed that when people interact, they negotiate meaning based on the situation they are in. I wanted students to interact and make meaning together in both English and ASL. I organized weekly interpretations where students had to employ various registers and understand the schema. I selected interpreting material based on the students' need to conduct additional research to understand the situation. I believe that gaining more situational details, as I did in the case of these students, provides a more holistic perspective of the speaker's intent during the planning process of an interpretation. I learned that these students have had very drab, gray learning experiences in the program thus far, which has 
stunted their ability to think critically in interpretations. Similarly, I want students to reflect upon how one's experiences might influence energy, speech, and actions, which impact how the interpreter presents information and controls the dynamic of communication.

I trivialized the amount of work that went into this adjustment and the significant impact this change had on my instruction when I documented it in my journal: "I restructured a bit of my course. Instead of organizing my course by weeks, I am going to organize my course by interpreting process.” I said a “bit,” but I did not mean I adjusted portions of my class; I changed the entire thing. By incorporating interpersonal components into the teaching structure and relating those events to the entire interpreting process, I was able to parcel time to discuss critical discourse analysis and engage with students to explain the relevance of this work.

Students also had time to consider and share personal thoughts and opinions through their vlogs. They concentrated their discussions around how those habits might shape interpreting and ethical decisions. For example, vlog 8 asked students to respond to the following four questions:

1. What is my ideal definition of success?

2. Is this definition well-rounded, to include all of the important aspects of my life?

3. What are my top three values and how do they apply to my interpreting?

4. Do I factor in these values when I make interpreting and personal decisions?

Even though I did not require students to discuss their responses with at least one classmate, I allowed their answers to be public. In doing so, students could listen to their peers reflect on the same prompt with personal reactions. This weekly activity seemed to produce more critical thought when applied to the interpretation assignments since the students were not expressing themselves in a vacuum with no potential for dialogue.

Christina summed up the problem in our first interview when she said, "I don't feel like I'm learning as much—like, I'm learning what I'm being taught but I don't feel like I'm 
processing it and able to go and talk to the Deaf community." I created and assigned pragmatic activities so students could witness their own skill development and discuss it with others, as it

directly related to their future work in the field. Students had a community with which they could interact and ask appropriate, engaging, meaningful questions. It was this significant structural shift in the course outline and in student experience that facilitated student development.

\section{Cultural Identity and Placement}

One student, Maggie, is a Child of a Deaf Adult, a CODA, who consistently mentions how she feels her identity amongst other Deaf individuals, rather than with her hearing peers, despite her reverence of one essential hearing-world custom: "For me, I'm more comfortable in the Deaf World. I like signing. I love the language. I'm a very blunt, up-front person. [...] If you get offended, that's how I am, but at the same time, I go in with the hearing world, too because I like my music. I can't live without my music. I would die. My music is my savior. It really is." Of all of the students, Maggie has had access to more individuals who can serve as key informants than anyone else because of her role in the Deaf community, no matter her ties to her hearing life. It is safe to say that Maggie's cultural identity is clear and unwavering.

I should note that not all of Maggie's deafness-related experiences have been positive, so I do not suggest idealizing the "CODA Life." She endured painful bullying during her childhood at the hands of young hearing peers who picked on her for having a Deaf parent.

I came home from school one day and I was so upset because like, at one point, my oldest brother got into drugs. And, it was really bad for a while. And, at the same time, like, me and my other brother, Jared, me and him were like sticks and stones together. Everywhere I went, he went. We were, hands down, best friends. We also fought like cats and dogs every day. If I knew I needed 
someone or something, he was the first person I called, every time. And, he heard one day this chick picking on me.

Since it was, at the same time... Jared had a temper. He was always in fights. Justin had just gotten arrested. Mom was stressed out in both ways. I decided not to do anything. I kept my mouth shut and dealt with it until I can't. I didn't want to stress my mom out and make it worse. And, it just kept on, and kept on, and kept on. Every single day. And then, one day, I got home off the bus and I just refused to talk to her. I went in my room and I bawled. I was so aggravated and stressed out. I was so upset.

Nevertheless, Maggie is connected to her local Deaf community and plans to help a Deaf friend of her mom's who wants to organize camping trips and other adventures for young, often neglected Deaf children:

That's why my plan is to work with my mom's friend before I go into the, like, trying to get a job in the school system. His plan is to work with them on weekends, taking them on camping trips and stuff like that from where most of them are either too poor or they can't do anything. And, there is no Deaf community around here for them. And, on top of that, if they're not incredibly poor, then they have really, really bad homes. So, his idea is to kind of help give them like a sense of a Deaf community, even though there isn't one here and to work with them, helping them, teaching them, stuff like that. Things that they're not normally going to be able to do, which is why my goal is to kind of help him build that up first while working on getting my experience. 
Maggie is a fascinating case because she has felt audism from various sources throughout her life as a result of her love of and early life access to the Deaf World. She is connected to ASL, the Deaf community, and the Deaf World. Her family experiences created for her a viewpoint, through which she plans, constructs, and delivers interpretations: "And out of my two older brothers, I was the only one that really adapted to sign language. [...] I looked forward to going to Deaf events with Mom: The pig roast, the [school] reunions. I loved going."

Maggie was fortunate. As a CODA, she had consistent access to the Deaf World, including opportunities to serve in the interpreting role at a young age. It was this access that set her on a path to pursue a formal career in ASL interpreting.

Then, what really set me to become an interpreter was one of my mom's best friends had a college graduation. I was only 13 or 14 at the time and her interpreter never showed up. So, she was down there, and she was bawling because she couldn't understand anything they were saying at her own graduation. And, the person who was in charge of hiring the interpreter [...] kept trying to get her daughter to go down and sign.

$[\ldots]$

And then, they looked at me. At first, I just looked around at how full the gym was and then I was like, "Eh, oh well. I will try." So, I walked down there and I did it. $[\ldots]$

Once I walked off that stage, or the gym floor, and the dude who hired the interpreter talked to my mom to make sure this was okay, but he took what the 
interpreter's pay was supposed to be and gave it to me. And, then told me that even though I was the youngest he had ever met, that I was one of the best that he had seen. I was like 13 or 14 at the time so that meant the world to me.

Interestingly, she never mentioned having an interpreter community to influence her desire to entire into the field. She did not mention friends or acquaintances who are also CODAs. She said that her influence to become an interpreter was solely in her experiences with her mom. There were no interpreting experts to facilitate situational and experiential knowledge to her during her beginner stages, though some might believe that the access to the Deaf community is sufficient for this type of learning.

I feel that the absence of the community in her life greatly contributed to the need for a critical community in this learning environment; Maggie did not learn how to interpret messages from varying points of view. Maggie is clearly different than the rest of the other students in this course. She grew up with ASL and approached interpreting from a unique vantage point: a Deaf community member. Unlike the other students who required linguistic confidence, Maggie was in search of a professional interpreter to mentor her in the field. Her definition of meaningful was differentiated from her peers.

During our second interview, Maggie indicated that our learning over the semester changed her interpreting approach: "Um, for one, actually looking at the message, as you know. I've never done that before. I always just listened to the words and just kind of winged it and went with what I thought. I never paid attention to, like, getting across the other person's message, which I should have.” I was taken aback, then, when Maggie told me during our second interview that an interpreter could be a [psychopath]. Maggie said, "Therefore, someone who feels nothing is able to do that and fool a good amount of people along the way, why can't a 
person who regularly experiences feelings be able to translate a message even though they have no connection to the message whatsoever?"

Maggie's comments are intriguing because she believes that the connection is to the message, rather than to the person communicating the message. While content knowledge is helpful, it is not everything to an interpretation. Being able to understand and relate to a person is vital to an effective message rendering. This process involves being very vulnerable and open to experiencing a wide range of emotions depending on the environment. Some people are more prepared than others to handle emotionally-charged situations; Reba was one of those people.

Reba, Willow, and Christina are markedly different than Maggie because they do not have direct ties to the Deaf community. Reba does not have any community-member connections to Deaf culture, but she does empathize with the Deaf community's "fight for existence," as she called it. During our first interview, Reba detailed her recent, traumatic confrontation with ableism.

I think the biggest thing for me, and I think this goes back to what happened to me last semester when I had my breakdown. I was in the interpreting internship for last semester. And I got kicked out because of my disability. They asked me to leave. Because of my disability and my religious views, I was asked to leave. Because I answered a question that I knew because of my religion and apparently it made people uncomfortable and I was asked to leave and they tried to mask it as because I could not go to bathroom on my own, I was an issue, I needed to leave.

First and foremost, I acknowledge this narrative as a turning point for myself. It was at this time that I began to realize how my perspective of Reba from information previously shared by college faculty was influencing my teaching decisions. 
Through previous experiences, even traumatic ones, Reba learned. She learned where she does not want to be professionally: "And, I know, I learned through doing the internship over the summer and the internship last semester... I cannot do educational interpreting. [...] I am too emotional a person." Reba decided that interpreting wrestling promotions was her calling, given her love for wrestling and pre-established connection to fight sponsors in the field:

I started looking into interpreting at wrestling events because, again, my biggest thing is wrestling. I actually talked to someone who owns one of my favorite companies, and he was telling me, 'I always have interpreters when I do stand-up comedy. I don't know why there's not interpreters at these events for when the guys are giving promos and things like that, you know? Why is there not somebody here, interpreting these things for people?' And I went, wait, maybe this is my door into the business that I love so much.

I want to also draw attention to Reba's self-declared (in our first interview) second greatest passion in life, theater (after wrestling). This fact is relevant because while speaking with a friend of mine who is a Certified Deaf Interpreter (CDI), I asked about how to help interpreting students utilize ASL more naturally. He suggested practicing through acting, so students can learn how to communicate thoughts and emotions through body language, facial expressions, and vocal inflection (when appropriate). These traits are essential in interpreting and I believe that Reba has the ability to employ them.

Unfortunately, Reba expressed how she felt discouraged on her path to becoming an interpreter, even at the beginning of her time in school.

In the beginning, I struggled. I literally almost dropped out on day one because I was the only person in the beginning of my program when I started in 2018 who 
had no sign language experience in the beginning whatsoever. Everyone else in my class was communicating really easy with Jamie, they could at least fingerspell to tell her things. I had nothing and I had a mental breakdown outside Rockward Hall, and was like "Wait, maybe I made a mistake here." You know? I still have my moments. I do feel like I'm slower at picking things up than everyone else; I do feel like I'm struggling.

I see a strong connection between Maggie and Reba because they both demonstrate a passion for standing up for the Deaf community. Their experiences growing up, however, were largely different. Nevertheless, because of their life experiences around individuals who have been marginalized, they both are passionate about positively impacting the lives of Deaf community members. Reba outlined her defining moment when she began to relate more strongly to the Deaf World.

I think for me when we did Deaf culture in my first semester, that was something that really helped me click as far as, like, I've never known another person with CP. But, going through the Deaf culture textbook and things like that, I was like, wait. I've been in this exact situation, just slightly different.

So, like, having the life experiences that I've had, being able to bring that to the table and, like, not even necessarily have to tell the other person, but just kind of knowing sort of what it's like to be there, then you kind of know, like, what you might have to do to advocate for that person because you've had to advocate for yourself. $[\ldots]$ 
It's one of those things that like got me started in the beginning because it was, like, when it comes to able-bodied people in general, whether it be hearing people, ambulatory people, whatever, a lot of times they don't fight for people with a disability or whatever and it's like, if those of us with $\mathrm{CP}$ or some other condition don't fight for other people in the community with other conditions, nobody is going to fight for us because nobody has.

Throughout the semester, I tried to tap into Reba's powerful connection to helping others and shed light on her invaluable experiences and their application to her interpreter professional development. During one informal conversation at mid-term, Reba told me about how overwhelmed she felt as a novice amongst classmates with more experience in the Deaf World. I reminded her that unlike her peers, she, unfortunately (though it turned out wonderfully!) has years of overcoming disability-related oppression. During our second interview when she related her advocacy experience to that of the Deaf, Reba demonstrated how she shifted her behavior from responding to the Deaf as Others whom she should serve to fellow community members. She planned and delivered interpretations that sought to provide as much information access as she possibly could.

Willow was involved in the Deaf and interpreter communities more than anyone even though she does not have Deaf family members. She told me about knowing 7 Deaf people, one of whom is her best friend: "In sixth grade, I actually wanted to learn sign language to communicate with one of my peers. Then we became best friends and since sixth grade until now, I've been best friends with her." She told me about the interpreters she knows, one of whom is a CODA. Not that knowing a CODA makes someone knowledgeable about interpreting, but she is surrounding herself with people who are experienced in Deaf culture. At the very least, she 
hears more stories about Deaf people than others might. I regularly questioned Willow (and Maggie, too) during group conversations and other interactions we had about Deaf Club events and was able to share those activities with others too. Unfortunately, due to COVID-19, the events were all virtual and many students did not feel comfortable attending, especially since they were connected to the program coordinator, Jamie's, social media account.

Willow's active involvement with the culture and community tells me that she has a personal connection to the Deaf. I would argue that Willow has been enculturated into the Deaf World. When I asked her if she could ever imagine herself not interpreting, she assured me that she was meant to be in this profession: "Probably not, [I would not quit.] I like interpreting too much. I would get aggravated. I might take a little bit off," but she would not quit.

Willow talked about issues that many people with hearing loss experience, such as facial hair when depending on reading lips: "A lot of times, if they have a beard or mustache, [my friend] has a harder time [understanding]." It seems to me, through Willow's actions and statements, that she feels at-home in her interpreting role: "Maybe [someone would quit after an argument] with a client or something, maybe they got into it, and [the interpreter] might want to go into another field. I don't know how they would. I love interpreting."

I think Christina was the most interesting and challenging case during the semester. First and foremost, she did not have any Deaf community ties and expressed her interest in communicating more organically in ASL. In the midterm vlog post, she asked for "time to chat with each other about a specific topic.” During a group conversation and in a one-on-one interview, she stated how difficult it was to be involved in the Deaf community at this time due to COVID-19. 
During our second interview, she said, "I mean, this year was kind of hard because of COVID and you can't go nowhere, so it was hard to get out into the community." Christina wanted to engage with the Deaf community. She asked me once during a group call about opportunities to sign more. I told her about virtual events, to which Maggie replied, "I just sat in the living room with my mom the other day and played bingo with a bunch of Deaf people. It was really fun. Jamie [program coordinator] organized it." I encouraged Christina to connect with Jamie on social media, a fixture in the local Deaf community so that she could become more involved with ASL and the Deaf World, even if it was online.

Until the end of the semester, I did not realize that she moved every two years with her family due to her father's line of work. Consequently, Christina had to learn how to adapt to her new environment and communicate with others. I am sure Christina has felt trapped during the pandemic, not being able to hone the skills she desperately wants to. Christina strives for proficiency and expresses some frustration that she is not yet ready to work in an interpreting position.

Interviewer: If you could, or not, would you pick interpreting all over again?

Christina: I would... I would still pick it, but I would double major in something else like vet.

Interviewer: Okay. How come?

Christina: Because I knew that going into interpreting, not knowing anything besides the $\mathrm{ABCs}$, it was going to be very difficult and it is. And, I knew that. And, I've always wanted to be a vet. I grew up and wanted to be a vet. I wanted to help animals. 
And then, I was like I want to help people too, but I don't want to be a nurse because I can't do blood. I can't do human blood on me. Animal blood doesn't really matter, but so, I knew I didn't want to do nursing and wanted to help people and also wanted to help animals.

And then, I was like, do I really want to spend all this money just so I can cry over an animal that's not mine dying? But, there's also, just, not just the animals dying, I'm also saving an animal so I would like to do that, so I would double major in both.

I probably confused you.

I sense that Christina feels a bit of regret that she did not double major to be a veterinarian, but given her choice, she wants to be a proficient interpreter. I admire the acknowledgment she has of her own limitations and the steps necessary to get there.

\section{How does individual /group self-reflection influence the development of interpreting skills? Introspection and Mindfulness}

Humans learn by doing, and in the case of this ASL interpreting course, these students engaged in interpreting assignments that involved critical self- and peer-assessment. The interpretations, vlog assignments, and peer feedback connected students more meaningfully to the course content while providing me with insight into how individual self-reflection and group collaboration yields growth in interpreting.

I started the semester by asking students to complete a mindfulness questionnaire (Appendix J) to inform their self-perception as an interpreting professional. Truthfully, I was less concerned about students' interpretation of these results and more focused on setting the appropriate tone for the semester. I wanted students to take the time to consider their 
positionality as a hearing interpreter amongst other hearing individuals and the Deaf community. I initiated this insightful investigation by taking stock of daily interaction through the introspective questions in this survey. I utilized consistent themes to create vlog prompts so that I could help all students address various challenges as they relate to interpreting. I hoped that by utilizing the survey I could narrow down my focus to create vlog prompts that were more than busy work.

The remaining vlog prompts (Appendix G) incited self-reflection as it related to interpreting-skill development. For example, vlog 7, the semester's mid-point posed the question:

How have you developed your skills as an interpreter? Please provide at least three examples of how you have improved over the past 7 weeks (because we all know you have). *If you do not believe you have improved, please contact me ASAP.*

What more do you want to work on? How can I help? How can we work together as a class to help you become the interpreter you want to be?

Christina provided a telling learning experience in her vlog submission. She has noticed an improvement in her ability to utilize non-manual signals (e.g. facial expressions and body language), which are essential grammatical and affective components of the language. She has made comments about her typical "blank" expression, referring to it as "the b-word face." In response to what else she would like to learn, she said, "So, like, I would like to work more on the conversational piece, if that makes sense. Like, I don't know how that would be or anything 
or how it would work at all because we all live in different places, but like signing with each other randomly on a certain topic."

I believe Christina is referring to her need for native and natural engagement with the Deaf, during which she would navigate the features of American Sign Language and learn from her interlocutor. Her ability to speak the language with native-like proficiency could increase her comfort in rendering more faithful interpretations. Nevertheless, Christina has acknowledged a performance deficiency and seeks regular interaction and engagement in ASL to obtain it.

\section{Peer Feedback}

Despite the lack of time spent in the Deaf World this semester, students were able to meaningfully engage with each other. Part of what made the learning experience so valuable was the collaborative discussion throughout the semester. Students were tasked with weekly assignments, submitted on Flipgrid, so they could post drafts of their weekly interpretations and provide feedback to their peers. Students gave feedback with audio and video, which increased how meaningful the discussion was. On one of Christina's first draft interpretations, a month into

the semester, Reba commented, "I think you improved a lot on the last three interpretations, but I do think it's a lot easier to not think so hard on what you're signing on when you're given something and you have time to memorize it and think about what you're going to sign. You don't have to on-the-fly think of facial expressions and sign at the same time. I do think that you definitely improved there."

Student discussions were honest and real, and even made some students uncomfortable. During one of our one-on-one conversations, Reba mentioned that the style of feedback I required during students' weekly interpretations was uncomfortable for her, at first. She said, 'I think a lot of the things that challenged me most were doing the feedback for others because I 
have a hard time criticizing other people unless you really screw up and upset me." Reba is the only student who openly stated that the feedback was uncomfortable for her because of the nature of the conversation.

I asked students to provide more than agreeance on the decisions that were made. Students were required to provide actionable items to their peers on which they could work and improve their skills. Students needed to do more than commend others' work, especially given the fact that three of the four students have once before taken and failed this course. I provided the following 14 guidelines to giving constructive feedback (Image 1). Reba confirmed my suspicion that students had not been asked to provide peer feedback in this same way in the past or in other courses.

Not only giving the criticism, but there were definitely times in the beginning, and I think you and I talked about it, where I would get the same criticism for one everybody, over and over and over again, and I'm like, I'm trying my best to fix it but I don't know what else to do because that was something that yeah, in other classes, we were required to respond to our peers but it was more like, talking about the subject and agreeing on thoughts and adding to conversation. It was not feedback in the sense that we were doing. 


\section{Guidelines for Giving Constructive Feedback}

\section{Allows for receiver readiness}

Has the receiver indicated he is ready to listen and accept the feedback as it is intended?

There is little point to giving feedback that won't be heard or will be misunderstood.

\section{Is descriptive, not interpretive}

Feedback is a description of your perceptions and reactions. Interpreting meanings of another's behavior is often a guessing game, which the other resents. Let him share his own meaning if he's so inclined. If you want to check your perception of his meaning, be very clear that is what you are doing.

\section{Covers recent happenings}

Generally, the closer the feedback is to the time the behavior occurred, the more helpful it is. When feedback is given immediately, all know exactly what it refers to and feelings about the situation are most valid.

\section{Comes at appropriate times}

Don't for example, share negative reactions when there are others present who would not understand the constructive intent of your remarks.

\section{Includes things that are new}

Consider whether the reactions you are sharing are new information to the other. If they are so obvious that he is already aware of them, they won't help much. Telling another what you saw him doing is often not news. Often, what is news is the sharing of how you reacted to what you saw.

\section{Is on changeable things}

The value of feedback to the other is in being able to modify his behavior if he wants to. Reactions to things that can't be changed are not usually helpful.

\section{Is given to be helpful}

Consider your own motivation in sharing the reactions. Are you really trying to help the other person gain a useful view of himself? If you are simply angry and wish to express it, say so, but don't present such feelings as feedback. 


\section{(Image 1 continued)}

14 Guidelines for Giving Constructive Feedback (continued)

\section{Does not demand a change}

Feedback is sharing reactions. It's up to the receiver if he wishes to make a change in his behavior based on the feedback. If you want to ask the person to change, say so, but don't consider such a request as feedback.

\section{Is not an overload}

If you give another too much feedback or too many things all at once it may be more than he can deal with. He may lose track of all you are saying.

\section{Shares something of the giver}

Giving feedback can create a sense of imbalance in the relationship. It generally helps the receiver to feel more comfortable and be more active if the giver can share some of his own feelings and concerns as he gives his reactions.

11. Is specific, not general

Be specific by quoting and giving examples of what you are referring to.

\section{Checks understanding}

Use such behavior as paraphrasing to be sure you understand the meaning of the other's reactions. Watch out for becoming argumentative or taking a lot of time giving the rationale for your behavior, rather than working to understand the other's feedback to you.

\section{Asks for feedback about specific things}

You can help the giver provide useful reactions by asking for feedback about specific things. This indicates your areas of readiness to receive feedback and helps him be specific rather than general.

\section{Shares reactions to feed back}

Sharing your reactions to the feedback you have received can help the giver improve his skills at giving useful feedback. It also lets him know where he stands with you on a feeling basis so that the relationship can continue to grow. If he goes off uncertain about your reactions to this feedback, he may feel less inclined to risk sharing them with you in the future. 
I understand how difficult feedback can be to both deliver and accept. Socially and culturally, criticism is seen as a negative action that yields only hurt and disappointment. Reba remarked that the feedback from her peers was, at times, disheartening: "I really came into this semester because of what happened last semester and some of the feedback from my peers and things like that really shaken as to whether I could do this anymore, shaken as to whether or not this was the right path for me, whether I was making the right decision $[\ldots]$ in choosing this major." I found that setting the tone for feedback and discussions greatly enhanced students' understanding of the expectations I held for them, as well as those I hoped they possessed of themselves.

She consistently used the term "broken" to describe how she entered this semester. She remarked that it was her discussions with me and her peers that seem to have changed her mindset: "But having sat down with you and with my fellow classmates and things like that, I'm starting to realize now that the issues that I have are not the issues that I thought I had." Since we, as humans, cannot actually see ourselves through our own eyes, we must utilize our community to help us improve. In this case, I employed students' knowledge of and experience in interpreting to encourage interpreting skill perception, development, and personal growth.

\section{How do students perceive and self-actualize the American Sign Language interpreter role?}

I documented students' perception of the American Sign Language interpreter role during the initial and final interviews and supported this data with vlog entries, my journal entries, and informal conversations with the students throughout the semester. I asked students at the beginning and end of the semester what it means to be an American Sign Language interpreter and how the students feel they fit that title. 
The students in this program are diverse. One student was raised by a Deaf parent who utilizes ASL to communicate while another did not formally study the language until she entered this interpreting program as a non-traditional student. I started the semester by asking students what the role is of an American Sign Language interpreter and how well they believe they fit that role.

\section{Deaf Heart}

During our initial interview, Reba indicated that her status as an individual with a disability helps her better satisfy the needs of the interpreter role. She stated, "I think for me I have a different perspective because I am a person with a disability myself. I know what my own needs are and how I would feel comfortable with somebody being able to help me, so I can kind of look at it as, if I were this Deaf person that they want me to interpret for, would I want myself to interpret for me?" She continued,

I think being absolutely perfect at the language is $100 \%$ essential because you can still get your point across without being absolutely perfect. The language is constantly changing; all languages are constantly changing. So, you are not going to know every single thing, every single minute. It's not going to happen. But, if you're able to get your point across without too many stumbling blocks, I think then at least you are ready to start at like a base level.

Reba connected her disability status to the Deaf experience and her interpreter role, an impressive connection and ethical milestone for an interpreter.

Since the start of the semester, Reba embodied Deaf Heart by caring about doing well by her future clients. During our second interview, Reba impressed me by demonstrating a shift toward praxis. 
I think empathy is a really important thing, at least in my mind. If you can't empathize with the situation someone is in when you're interpreting for them, then you can't understand the exact message because something somebody says out of anger, you're going to interpret differently than something that they're going to say while they're sitting there, bawling their eyes out.

By the end of the semester, she showed me how she would serve her clients, not only that she wanted to. She does not have many (if any) mentors in the interpreting field, nor direct connections to the community or language, but she is impassioned to do right by her future audiences. When Reba and I first discussed why she was retaking this course, she told me, "I had to look at it, again, my grandparents being hard of hearing, I was like if they needed an interpreter, would I want somebody that barely passed? That barely made it through and was not ready to be interpreting for my family? No, no I would not."

Reba might not have any community-interpreter connections, but she was the most willing to put herself out there and try. During the weekly feedback activities, she worked on enhancing the quality of her comments and increasing her competence. She even noted, in our second interview,

I can remember doing my summer internship and our student wasn't there. So, the interpreter I was working with, we sat, and we looked at the book we would have been interpreting and talked about how we would have interpreted it had he been there. And, I think that's something that like, at the time, I was able to do a little bit because I knew the story, but now I'd be able to look at it a little bit differently and maybe provide a little bit more than I could at the time having not taken this course yet. 
Willow seemed to describe a similar relationship between the role of the interpreter and the Deaf and hearing clients when she said, "[An interpreter helps] the Deaf and the hearing connect with each other. With the Deaf, like if they don't know something, they can ask the interpreter to ask in English to the person that is hearing." I do perceive Willow's remark to be more focused on the language-facilitation aspect of interpretation rather than the humanistic component given how she concluded her response. Regardless, her understanding of a need for connection is essential to take note of here.

When I asked Maggie about the role of an ASL interpreter, she stated, "It's sign language. It's speaking ASL and translating to the person beside you who can't hear." This interpreter definition is simple, but I take note of Maggie's idea of being "beside" an individual who cannot hear. Typically, a hearing interlocutor and the hearing interpreter would be in front of the Deaf person so that the Deaf person could see the speaker and the interpreter at the same time. However, Maggie places the Deaf person next to her, leading me to believe that she has a meaningful allyship with the Deaf and understands that the purpose of her presence is for the Deaf client.

Christina responded the most literally to my question, "What does it mean to be an American Sign Language interpreter?" She said, "Not having any trouble communicating. Not having any trouble knowing signs or any of that" and "Being able to translate, in-time, English to a Deaf person." I immediately noticed Christina's use of the word "translate" to respond to this question since it seemed to focus on the delivery of English-equivalence to Deaf people. I felt that asking about the difference between interpreting and translating would provide meaningful insightful into her perspective on her role as an interpreter, her field experience, and her ability to use appropriate diction. I asked Christina about the difference between an interpreter and a 
translator and she replied, "I know there's a difference, but I don't know the difference. [...] I feel like interpreters are bigger. They're more known."

As time progressed, Christina's comments on the role and responsibility of interpreters shifted. Most notably in my second interview with her, she said, "The role for the first part, interpreting, would be language. Like, um, I don't want to say language bridge, but that's the first thing that comes to my head. I know that's kind of correct but not really correct." So, I asked her what was missing out of the "language bridge" concept and she replied, "the human part that can bring more... I don't want to say awareness, more knowledge about the community to those who don't understand it."

One of the students' assignments was to interpret the 1999 speech, "Perils of Indifference" by Elie Wiesel during which he reflects on the joint decision of the United States and NATO to intervene in Kosovo (American Rhetoric: Elie Wiesel - The Perils of Indifference, n.d.). He remarks that

Indifference can be tempting -- more than that, seductive. It is so much easier to look away from victims. It is so much easier to avoid such rude interruptions to our work, our dreams, our hopes. It is, after all, awkward, troublesome, to be involved in another person's pain and despair. Yet, for the person who is indifferent, his or her neighbor are of no consequence. And, therefore, their lives are meaningless. Their hidden or even visible anguish is of no interest. Indifference reduces the Other to an abstraction.

By asking students to interpret this passage through critical discourse analysis, they engage with the speaker's original ideas and plan a faithful signed interpretation. More glaringly obvious in 
this passage is the reiteration of my intentions this semester, which are to decrease the barriers that impede communication amongst Deaf-hearing cultural divides.

Christina also demonstrated an interest in collaborating more with other interpreters in the future. When I asked if she wanted to be an active member in the interpreting community, she said,

I want to be an active member because they do help other interpreters. I don't know how to word it. So, the interpreter that I worked with in the spring at the elementary, I still have her number and throughout the summer, we had stayed in contact. We had FaceTimed and gone over signs and just talked sometimes.

So, I stuck with her. She helped me with my interpreting and that might not be with all interpreters, not all interpreters want to help others. I understand that. So, with my experience, interpreters help others. With the one in the school system right now with multiple students, she could reach out to other interpreters and say, 'Hey, this subject. I don't know how to interpret it. How would you interpret it?'

Even though, like Reba, Christina does not have a significant Deaf community connection, she is dedicated to being active in the profession and helping others succeed in the field, like her mentors have done for her in the past. Throughout the semester, Maggie mentioned that she and Christina worked together. In our second interview, Maggie said, "Like, the only person I could ask for help from was Christina. Even though we weren't necessarily on the same level, she, from where we worked together and had classes together before, I don't know, she kind of understood some of my [interpreting] issues." 
Willow unfortunately seemed to regress during our final interview. I asked, "What human-related skills do interpreters need to be good?" She replied, "I didn't know it wasn't just the words." I later asked her to explain why empathy was an important skill for interpreters to have. She responded, "To, like, make sure that the people you're working for gets the message." She focused on how the individual comprehends what is happening rather than the positionality of the interpreter and/or the interlocutors involved in the interaction.

Maggie was a unique case study in regard to her perspective on interpreting. There are two facts regarding her CODA status that should first be outlined. Maggie was an active member in the Deaf community at a young age and consistently communicated with her Deaf mother through sign language. Second, she had several opportunities to interpret before she was formally trained to interpret, starting in her early teenage years: "Yeah. Well, I have been interpreting my entire life. My mom is Deaf. I grew up interpreting for her. I grew up interpreting for her friends. A lot of this I already know. [...] My mom started teaching me sign language when I was 3, so I grew up doing it.”

Like the rest of us, Maggie was born into a set of family circumstances, only Maggie's afforded her professional experiences that would ultimately tie into her career. During our first interview, she narrated a traumatic experience in the public-school system, where she had acquired a substitute interpreting position before attending this interpreting program.

A couple years ago. I got a substitute interpreting position for this little Deaf boy in a hearing school. He was in seventh grade. I have never been so heartbroken and so infuriated at a school system in my life. $[\ldots]$ 
I mean, I did [want to work in a school system] at first, but after that experience, I'm a little bit iffy about interpreting in a hearing school for a Deaf child because that just ... when I went in for the interview, this Communications Specialist, is what she called herself; she was a Guidance Counselor. She had a piece of paper, so she thought she was hoity-toity.

I went outside and met a sweet, funny boy. He was a kid! After we were done and we walked out, she asked me how it went. I said I think it went well. I said he seemed like a good, sweet kid.

Then, she had the nerve to turn around and look at me and say, 'it's really heartbreaking watching him.' I asked her why.

She said, 'Because he's deaf. He's never going to amount to anything. He's never going to be able to achieve anything until doctors or scientists come up with a way for this beast that we call deafness. He will never achieve anything in his life. [...] You know what I mean. I mean, your mother is deaf. Obviously, you think that if your mother wasn't deaf, she would have achieved so much more if she was hearing.'

We discussed whether an interpreter should step in at this point to address the audistic, disrespectful comments from the counselor. She reflected on what an interpreter might otherwise do, instead of excusing herself as she did.

I feel like I should have a place to step in and look and them, and say, "This is not okay. This is still your client. You have no right to insult them," but with that job territory you are not allowed to do that, and I don't think that's fair. Regardless of 
whether that Deaf person will stand up for themselves, they've heard that their entire life. They might not feel like arguing or dealing with it. I don't think that's fair. They [hearing people] are all about bullying. "You can't bully your kids. Bullying is not tolerated in school." But, that's exactly what they're doing to this whole [Deaf] community that they have no knowledge about, and I think if they did actually have the knowledge, then maybe they would open their eyes. Like, I wanted to throw my Deaf culture book at that woman and just tell her she is wrong.

\section{How does critical discourse analysis as a teaching tool enhance students' English-to- American Sign Language interpretation?}

\section{Being-for Other}

As Lévinas would purport, the ability to be-for the Other is more than empathy; it is the capacity to deeply understand an individual from a difficult culture. In order to accomplish this level of emotional relationship, I assigned weekly critical discourse analysis assignments to all of the students throughout the semester (see Appendix E). The majority of the assignments were interpretations. These assignments required extra research and critical discourse analysis to determine the context of the interaction and the potential resulting connotations. Since ASL signs are not meant to be used for their literal meaning, critical discourse analysis allowed students to understand the purpose of an individual's message, even if the goal is not clear.

The students learned about other people and other perspectives; they read, contemplated, and applied the situational factors that influence an interaction. Students were able to hypothesize how these people might react and interact with their surroundings through language; not to mention, students began to consider how their own perspectives influence their language. 
Students talked about their interpretations and learned how their peers and future colleagues might perceive the information.

From panim, the always-plural Hebrew word for face, Emmanuel Lévinas gave new, precise meaning to the notion of “face.” In Lévinas's Totality and Infinity (1994) he writes, “The face is present in its refusal to be contained" (p. 194). I can think of no better application of this idea than to American Sign Language interpreting, a language and profession based on the utilization of the face (and body) to communicate meaning. In ASL, a shift in eye gaze, a turn of the shoulders both indicate meaning and demand recognition. Furthermore, with such attention to the face, it's no wonder that ASL interpreters cannot help but feel connected to their Deaf clients. Interpreters internalize, process, and vocalize signed utterances, making them seem, at times, as though they are self-directed statements. This intermingling of identities requires the interpreter to wear many faces.

Perhaps the interpreter is in the classroom of the student one day, and a school administrator's office with the student the next. The language register is going to be different in these two contexts because of the people involved and the topics discussed in these two locations. The interpreter has to be able to match the speaker's intention, including their register, no matter where they are. During the semester, I asked students to interpret a children's story and the brief monologue of a counselor. The children's story was a brief written passage (below) (Richards \& Rudser, 1988).

When Donkey gives his friends their new backpacks, his friends thank him profusely, and make plans to take their lunches in their new backpacks. They invite Donkey along, and this is when he realizes he had forgotten to make a 
backpack for himself. He goes back home, and works all night making a backpack for himself. In the end, they all enjoy their new backpacks.

In this assignment, I challenged students to interpret the entire story in all classifiers, which are handshapes and other physical embodiments that represent movements more clearly than signs. In the context of interpreting in primary education, gestural actions resound more with Deaf children than words because they are illustrative, rather than abstract.

Christina's interpretation of this short story was arguably the turning point in her performance this semester. One of the performance rubric categories is the use of space. To receive a score of "Excellent Control," the rubric describes: "signing space is appropriate; clear establishment and use of referents; excellent use of spatial aspects of expansion features." That is exactly what Christina accomplished in this interpretation. When Donkey realizes he does not have a backpack for himself, Christina pats her shoulders and arms down, looking for the backpack. She looks away, as if she is Donkey, realizing that he did not make his own backpack. She shifts her gaze up (Image 2) toward Donkey's friends who have been established on her right, and raises her hands as he tells them he does not have a backpack, before venturing off to make one. Christina makes it easy for her (young) audience to visualize what it would look like to be Donkey in this moment.

\section{Image 2}

Christina, eye gaze, role shift during Donkey story interpretation 


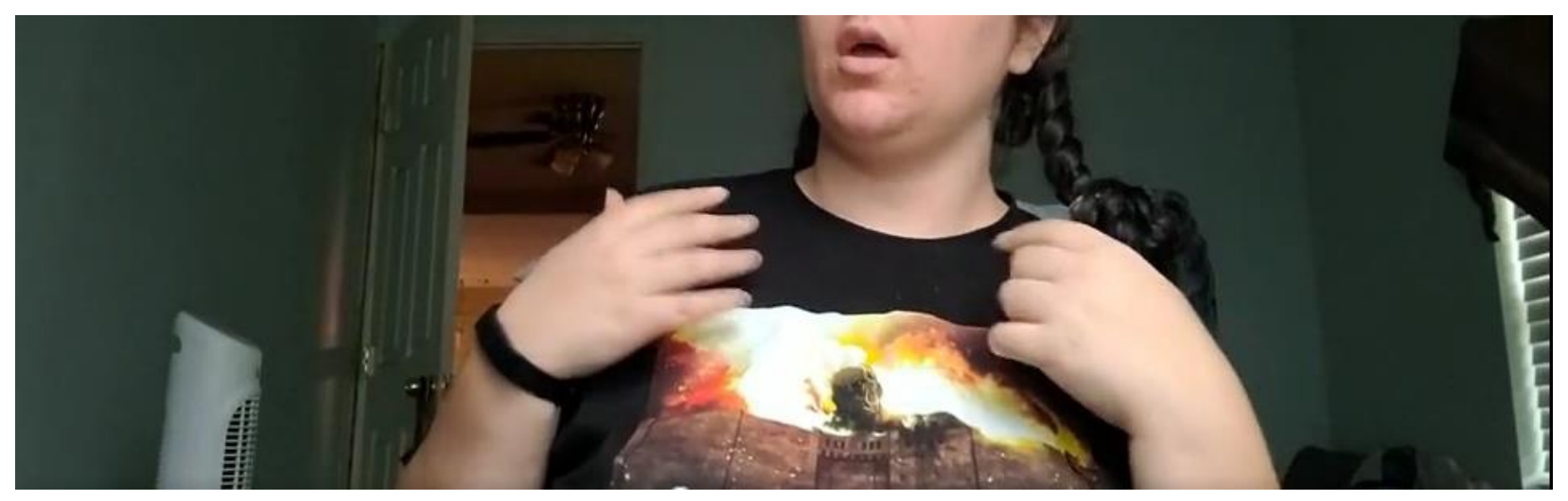

To the outward observer, this interpretation characteristic might seem trite. I would agree that the detail is slight, but never trite. Christina is demonstrating her ability to put aside her selfconsciousness and act for the sake of the meaning of the passage.

Reba increased her role shifting capabilities. ASL structure incorporates dialogue more vividly than English does. So, when there are multiple speakers in a story, Deaf signers turn their bodies and shift their eye gaze to designate the location of subjects. Reba did not initially incorporate this language feature at the beginning of the semester. While the image below (Image 3) is blurry (to protect her identity), you can still make out the shoulder shift to her left, slight head tilt back, and lifted eye gaze. Reba is utilizing 3D space (an expansion technique) that transforms spoken English into actions. Sometimes, these actions are small shifts while others are more noticeable.

\section{Image 3}

Reba and role shifting, eye gaze, head tilt in her "Donkey" interpretation 


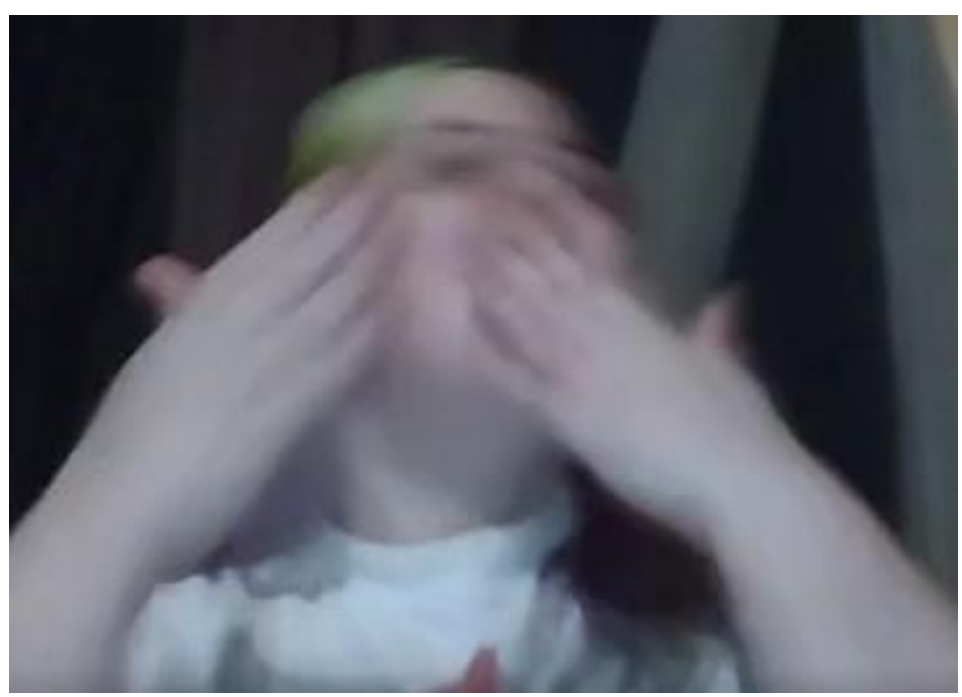

During my own interpreter education experience, my interpreting professor told me of a story of a teamed assignment she worked where she told an adventurous mountain climbing story filled with trials, tribulations, and powerful messages. The Deaf client made it clear that her interpretations were more understandable and more enjoyable to watch than those of her team interpreter, principally because she utilized more actions and movement than signs. It was as though my interpreting professor embodied the speaker and she, herself climbed the mountain and later narrated the whole story.

When I think back to this conversation, I am overwhelmingly grateful because at this moment I received license to do whatever I needed to communicate meaning. My interpreting professor was my idol; she was nationally certified and appeared in several interpreter training videos that sell globally. She was a name in the interpreting field, and I was in awe of her interpreting skills. I wanted to be her. So, I took her word when she told me that Deaf people expect visual communication and the more visual, the better. So, acting out a story and perhaps drawing laughter from the hearing crowd was okay; I was embodying the message, as long as I was not being excessive. 
After the semester, I chatted with Maggie about her insecurity of showing emotion during interpretations. She said that she felt "dumb" and "ridiculous." I assured her that these feelings meant she was doing her job well. During my interpreter education, I was told that if I took a pretty, smiling picture while interpreting that I was not doing my job to convey meaning. In a debriefing with a Deaf colleague of mine, he confirmed how essential it is for signers (Deaf or hearing or in-between) to step outside of their comfort zone and experience the language. I giggled a little that these discussions occurred when I reflected on them. I, too, felt uncomfortable like Maggie when I began actually interpreting and portraying meaning, not relying on words to be understood based on my intentions. It seems like a rite that interpreters must pass to overcome the constraints of mainstream, hearing society.

To provide a clear example of how non-manual and affective features are utilized in American Sign Language, I have glossed (Table 4) the Donkey story interpretation from Maggie and from Willow. Glossing is a written English translation of ASL signs. There is a transcript of a gestural (left) and non-gestural (right) interpretation performed by these two students. In the table, you will see capitalized letters. These are used to represent ASL ideas in English. You will also see +++ , which corresponds to the sign in front of it and indicates that the sign was repeated. Any writing in parentheses is not a sign, but a movement, gesture, or classifier. With each role shift, please note that I add a new line to help differentiate between speakers.

\begin{tabular}{l|l} 
Gestural & Non-gestural \\
\hline GIVE+++ & WHEN HORSE* OFFER FRIENDS NEW \\
& BACKPACK, FRIENDS THANK-YOU+++.
\end{tabular}




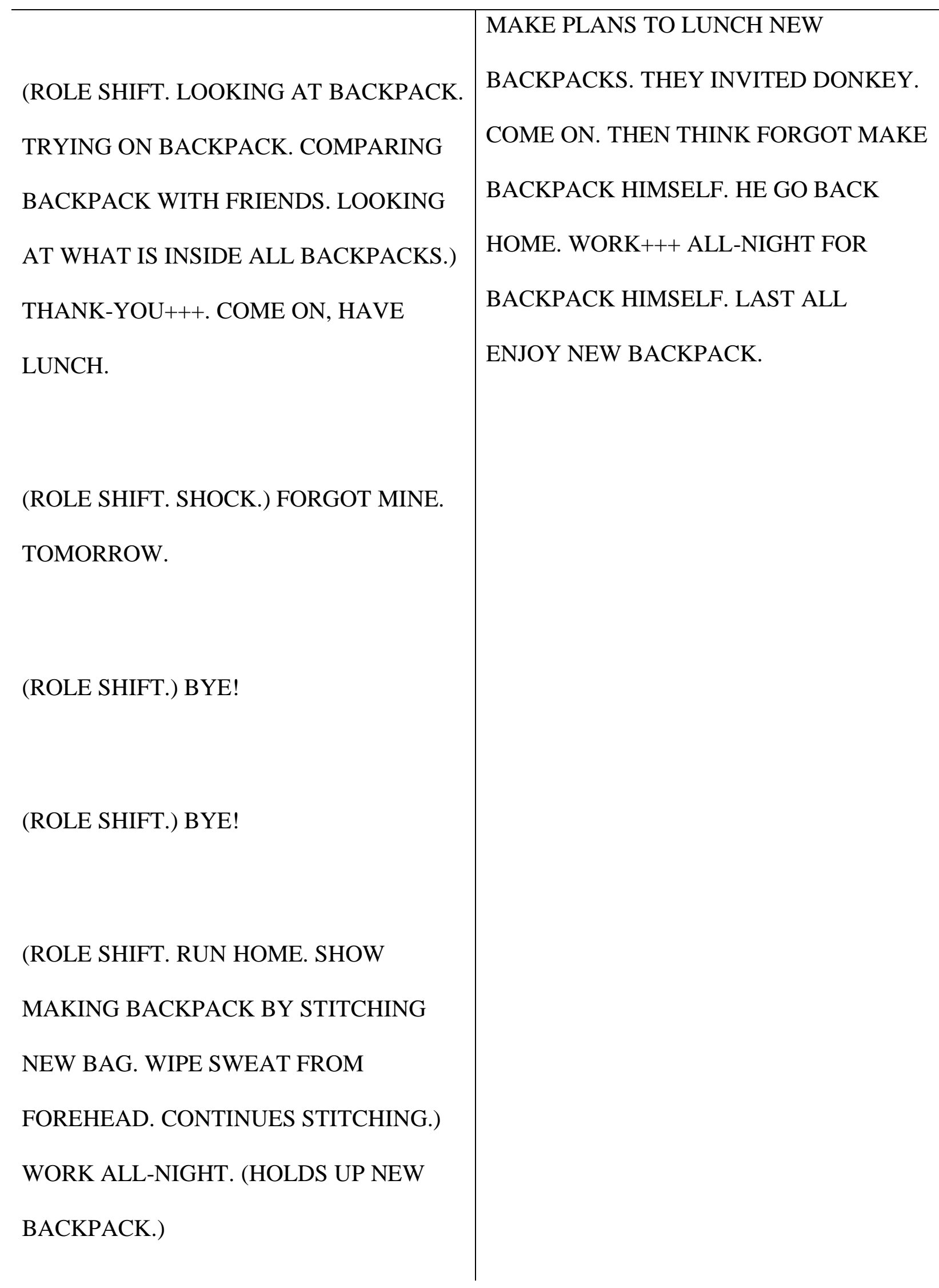




\author{
FINISH. (TRIES BACKPACK ON, \\ CHECKS IT FITS, AND WALKS. WAVES \\ TO FRIENDS.)
}

(ROLE SHIFT.) COME ON! (PACK LUNCH+++. PUT ON BACKPACK. WAVE OVER TO DONKEY.)

(ROLE SHIFT. DONKEY JOINS.)

\title{
FINISH ALL ENJOY BACKPACK FINISH
}

Table 4: Gestural and non-gestural interpretation glossing transcripts

As you can see, the transfer of ASL to English is not an easy feat and can get confusing when trying to write it out. Teaching students how to process this information and deliver a cohesive, spoken English utterance in an interpretation is nearly as challenging, if not more so. I clearly witness a distinction between showing the story and telling the story.

In English, we must depend on the connotations of words to communicate our true meaning. Often, the greater the vocabulary, the more effective the communicator; but in ASL, those constraints disappear. Yes, English-speakers could move about and theatrically during English conversations, demonstrating their message like native and proficient ASL-users do. 
Their behavior would probably raise more questions than provide answers; it is just not socially expected. When an interpreting student decides to demonstrate more actions like a Deaf person and diverges from the English path toward an overtly expressive one, the individual steps outside of the comfort zone of their native language in the name of communication access for the Other.

At another point in the semester, during a synchronous class meeting, we discussed the following CDA passage

Hello, come in. Nice to meet you. I understand that you wish to talk to me about your daughter's schooling. Now she's hearing impaired, too, isn't she? And she's currently at Cherry Tree Juniors, and you want her to be transferred to the old Deaf and Dumb school? Actually, you know, my great aunt was hard of hearing, and I learned some of the sign language myself when I was in the Brownies. Of course, that's quite a few years ago now, but I still remember a bit of it... That's A, isn't it? Yes, very good. Can you lipread me all right?

The discussion that followed this reading was intriguing because most of the students saw this speaker as ignorant and offensive. She utilized outdated language like "hearing impaired" and "deaf and dumb" while discussing a child's educational future. These students immediately perceived the speaker as a threat to Deaf culture. I borrowed this assignment from Kyra Pollitt (2000). In this chapter of Innovative Practices for Teaching Sign Language Interpreters, she wrote about how her own students had a similar negative initial reaction to the speaker. Without critically analyzing the speaker, Pollitt cites that the result would have likely been different.

At the conclusion of the analysis, students have changed their opinion about the education official; she is now perceived as an older professional who lacks modern Deaf awareness but who was making an effort to bring her experiences 
and resources to bear on this situation. It became obvious to the group that as interpreters, their original assessments of the official's intent would have greatly affected their interpretation, perhaps leading to conflict. After analysis, however, their interpretation would reflect the official's good intentions along with her lack of information, potentially leading to a different outcome (p. 75).

I utilized a similar framework to her study and, as she suggested, guided these students through the critical discourse analysis process by asking them two questions: What do they believe the text means? What do they know about the speaker of the text? To these questions I provided little to no guidance to elicit the widest range of comments.

Like Pollitt's students, Maggie, Christina, Reba, and Willow all perceived this speaker as rude and disrespectful given her language. Interestingly, they continuously referred to the speaker as "he," which I addressed. Based on the speaker's reference to her involvement in the Girl Scouts of America, I cited that as a primary indicator that this individual would be female. Maggie replied, "That makes it worse. Women are bitches, always out to get you." We also considered how her body language and voice inflection, neither one of which was given here, might also impact word processing. In the image below, I have included my annotation of the passage as it relates to critical discourse analysis. I discussed these same ideas with the students and then asked them to independently consider how they can implement critical discourse analysis.

In Figure 9 below, I provide my notes from this critical discourse analysis assignment. In green, you see the comments that we (the students and me) believed were positive in regard to addressing audism. The one orange comment could be perceived as negative, depending on the tone. Some students said that this woman might be in disbelief that this parent wants to send her 
child to the Deaf school, in which case her comment would also be seen as threatening to Deaf culture. Finally, the red statements are those that students and I blatantly pointed to as offensive to Deaf culture, and potentially interfering to the conversation as a whole.

\section{Figure 9}

Critical discourse analysis mark-up 
Hello, come in. Nice to meet you. I understand that you wish to talk to me about your daughter's schooling. Now she's hearing impaired, too, isn't she? And she's currently at Cherry Tree Juniors, and you want her to be transferred to the old Deaf and Dumb school? Actually, you know, my great aunt was hard of hearing, and I learned some of the sign language myself when I was in the Brownies. Of course, that's quite a few years ago now, but I still remember a bit of it... That's A, isn't it? Yes, very good. $\underline{\text { Can }}$ you lipread me all right? 
Lévinas's definition of "face" immediately comes to mind here, primarily because of all of the ways the word can be understood and applied to this context. Most prominent is the idea that students have to analyze the person and the situation before they can understand it. Immediately, students wanted to regurgitate classroom lectures, identified "buzz words" like hearing impaired and deaf and dumb as legitimate reasons for dismissing this individual as audistic. When we critically analyzed her speech and her position in this interaction, we ended up with more questions than answers. Her genuine interest in ASL contradicted her usage of oppressive terms like "deaf and dumb." So, together, we faced the reality that speaker intent really does matter and why understanding o/Others' objective is so essential to developing a critically, culturally, and conceptually appropriate interpretation. This shows the complex ways in which critical communities of practice must be enacted in this context; CDA and related critical pedagogies must engage nuanced readings of power that are specific to interpreter education and working with Deaf communities.

Bakhtin would say, in the context of literature, that this speaker's meaning is defined and influenced by her surroundings through dialogism. Her exposure to the Deaf World might have only taken place while terms like "hearing impaired" and "deaf and dumb" were culturally appropriate and she is a result of that time period. By taking the time to critically analyze the speaker, including hypothesizing about her age, students gained a different perspective than the one with which they initially started. They were still skeptical, though. When I made a comment about the speaker's old age, Maggie immediately replied, "Then, why is she working if she is too old to learn about Deaf people?" Reba supported this notion and replied, "Regardless, you should 
keep up with the populations you are serving. At some point, she should have learned not to say 'deaf and dumb."”

I reminded students that some professionals do not have access to development opportunities related to deafness, the way these interpreters were provided at least two professional development interpreting workshops throughout the semester. During these sessions, the interpreters attended various breakout sessions that discussed message comprehension and conceptualization. Although they did not define the conceptualization process through an explicitly critical lens during these workshops, ASL embodies cultural and critical components, so conceptualization, in this case, is innately critical. For a whole host of reasons, this female speaker might not have been surrounded by the heteroglossia that challenged her pre-conceived notions and vocabulary related to deafness. It is critical dialogism, the analytical relationship between polyphony, heteroglossia, and the society in which we live, that forces individuals to consider the message they share with others. 


\section{Chapter 5: Discussion, Implications and Conclusion}

Preparing American Sign Language interpreters falls on the shoulders of the higher education institutions that employ the faculty to teach students. Faculty approach this responsibility differently. Some interpreter educators believe that field experience is the only way to gain the knowledge required to be successful. Other educators believe that experiential learning can take place in the classroom, as long as the activities develop and enhance the competencies necessary to become a professional interpreter. In this study, I focused on how students develop their critical consciousness, the awakening to and acknowledgment of an oppressive situation, by taking steps to create a critical community of practice $(\mathrm{CCoP})$ in this distance learning environment.

Interpreters must increase their capacity for cultural analysis when they begin learning how to interpret. Cultural analysis applies to various studied elements in an interpretation, including context of the interaction, the language used, the speaker's inflection, and/or the nonverbal cues witnessed on both the hearing and Deaf interlocutors. Without the capacity to understand and relate to Deaf and hearing people, interpreters' interpretations lack emotion, the human trait that connects speakers.

\section{Summary of Findings}

\section{Critical Community of Practice}

Branching off Lave \& Wenger's (1991) community of practice, I used some critical pedagogies in my teaching. First and foremost, I recognized the unique challenge that a distance learning environment presents: students are typically at-a-distance from each other and the instructor. Not to mention in the middle of the COVID-19 pandemic, students are more isolated and alone than before, without many opportunities to mingle with the Deaf. Advanced educational technologies aid in the facilitation of dialogue because they allow face-to-face 
interaction, but these exchanges cannot always be in real-time; synchronous meeting times are not scheduled for this specific course.

The students in this study were isolated from each other and the Deaf community they serve due to their siloed learning environments. The pandemic and the remote nature of the program made the negotiation of meaning more difficult. This harsh reality meant that I needed the course content to relate to their everyday activities, and for their coursework and social interactions to emphasize the benefit of expanding their critical consciousness. If I could not consistently engage with them face-to-face, I had to engage their curiosities and allow them to explore the various realities they could construct for Others' messages in ASL. I hoped that by providing guidance and support to students (as they ended up with more questions than answers), I would increase their interest in solving concept-representation puzzles. I wanted them to imagine the process of deciphering meaning in an interpretation as a challenge that could be navigated with reflective expressions of the human experience. I hoped that their sense of connection and relationship to the small digital community they formed in this class would transfer over into the professional interpreter community after graduation and as they further developed their careers. In the future, when they seek answers, I hope they will look to their interpreting peers for professional support and guidance.

\section{Women in a Critical Communities of Practice}

In this context, all of us are women. In fact, most of the interpreting profession is female (RID FY2019 Annual Report, 2019). Our womanhood directly influences how we are positioned in interpreting scenarios. For example, I have been in many medical interpreting situations, working with other females in caregiving professions, like nursing. These women were not always the friendliest. Honestly, I understand why they are frustrated. The technology would fail 
and they could not communicate. However, I was treated like a floating head. There is a meaningful comparison here of the social expectation of women to care for others in the background, and be seen, not heard. Somehow in the video remote interpreting realm, though, the woman is neither seen nor heard (on video with typically little-to-no volume). In the field, many interpreters say that a successful day of interpreting work is one in which the interpreter seems invisible and communication flows smoothly and naturally.

On the one hand, interpreters should not be ignored because we are dynamic humans, not robots. Interpreters deserve validation of their work for what they contribute. On the other hand, interpreters are encouraged to avoid attention-seeking behavior during an assignment, like holding personal or private conversations with an interlocutor. While I want my female students to be advocating for language access, I also want them to acknowledge their situational reality. Like the Deaf, interpreters are positioned neither in the Deaf World, nor the hearing. We strive to make ourselves as invisible in the interaction as possible, but filter experiences through our eyes as we convey others' meaning. This blurred identity is frustrating.

While going through my undergraduate education, I was chatting with a family friend, who happened to be the Dean of a community college in my hometown. She asked me how Deaf people could see themselves as a culture: “They're Deaf, right? That's a disability." I responded that there is a collective history in the Deaf community and at the center is American Sign Language, rife with meaning and the ability to communicate abstract concepts. She is an intelligent woman who perceived deafness as a pathology, not a community. To her, an interpreter would be provided to accommodate the individual's needs, not empower them to think and act for themselves because to her, deafness is a pathology meant to be treated and cured. 
To some, deafness is an illness. My students were forced to face the cultural-pathological dichotomy of deafness in my critical discourse analysis assignments. These interpreting students will have to understand how to professionally navigate interactions where someone undervalues the profession because the Deaf World is misunderstood. As women, these students have to learn how to appropriately situate themselves in the interaction and account for any interference from their own personal identity, including their womanhood, that might derail the Deaf community's quest for freedom from marginalization.

\section{Discussion of Findings}

To guide this study on how a critical community of practice can impact interpreting students' learning, I asked the following primary research question and three sub-questions:

$$
\begin{aligned}
& \text { RQ1 How does integration of the critical community of practice (CCoP) } \\
& \text { framework impact students' learning in an online language- } \\
& \text { interpreting-based environment? } \\
& \text { a. How do self-reflection and peer feedback influence the } \\
& \text { development of interpreting skills? } \\
& \text { b. How does critical discourse analysis as a teaching tool } \\
& \text { enhance students' English-to-American Sign Language } \\
& \text { interpretation? } \\
& \text { c. How do students perceive and self-actualize the } \\
& \text { American Sign Language interpreter role? }
\end{aligned}
$$

My research data answered my questions and ultimately, I came to two conclusions: (1) critical discourse analysis, self-reflection, and peer feedback change interpretation planning; (2) students create their interpreter role self-perceptions in the presence of an engaging community.

\section{Critical discourse analysis, self-reflection, and peer feedback change interpretation planning.}

This statement may seem obvious because when people engage with Others, their actions, including their interpretations, are affected. Students are impacted by polyphony and heteroglossia. Through weekly assignments, students learned how to assess an interpreting situation and process the incoming information accordingly. Information processing in 
interpreting is not cut-and-dry because people are not clear-cut either. The outlined process of critical discourse analysis (CDA) helped students plan culturally-responsible ASL interpretations. By the end of the semester, most students could understand how to listen to an utterance and glean meaning beyond the words to facilitate communication access.

This newly learned capability seemed largely due in part to their exposure to diverse, hypothetical settings in their assignments, where they worked with individuals in situations they might not otherwise encounter if not as an interpreter. In these scenarios, students were sometimes forced to put themselves in a foreign voice, concept, and/or ideology and interpret it. Instead of just "listening to the words and winging it," as Maggie once said, students considered how the speaker situated their utterance within the specific context.

After some practice with CDA, students began demonstrating more physical embodiment when interpreting a message into ASL, as they did in the Donkey story interpretation. In this instance, the story's author did not write this narrative to be told in monotone. They wrote it to be told expressively; the story was written for children. Students also increased their openmindedness when they looked at the short monologue of the counselor. They were faced with the reality that their judgments of others will impact their interpretations. CDA helped them navigate and identify the speaker's voice in this context to be able to accurately represent the speaker's intentions by understanding the o/Other's personal identity. No matter their interpretation assignment results, working through the process changed their approach to interpreting.

In this study, I hoped that as interpreting students engaged with their peers, they would develop more confidence utilizing critical discourse analysis and consequently, deconstructing source language messages. I see a direct relationship between critical discourse analysis and an increase in expression. If an interpreter understands the client (e.g. as a member of a professional 
community, a member of a family, etc.), they know what words to select to convey the speaker's intended meaning. When interpreting students hone these skills, they learn ways to succinctly communicate thoughts and ideas, which is critical to do because inaccurate conceptual representations can lead to unintended conflict.

One of the most effective methods I found for honing these skills was discussion. When students talked about their own work and provided peer feedback to others, I witnessed a change in perspective and approach to interpretations. Students were more attuned to conceptual representations of meaning after negotiating with their peers. Sometimes, students were not sure how to create a culturally-responsible interpretation, but they understood that they were experiencing a shift in their approach to the practice of interpreting. They spoke with their peers about this change during peer feedback opportunities and their vlog assignments, which then incited even more personal and professional development, including more effective cultural adjustments in interpretations. The interaction with the content, one's own perspective, and the stance of others served as a catalyst for student development.

\section{Students create their interpreter role self-perceptions in the presence of an engaging community.}

The more I worked with this group of students, the more I realized that they had been missing support from their other interpreting professors. Unfortunately, it seems that some interpreter education programs are more focused on the "bottom line" than they are on teaching fundamental skills to interpreting students. The stature of community colleges in the state also seems to be rapidly decreasing, with one recent community college closure. Students commented throughout the semester that they felt disconnected from their professors and were not learning how to apply their knowledge to interpreting. 
I have witnessed and experienced similar disconnects between the content taught and the application of the information. This discordance runs systematically. In speaking with an Army soldier once, he said, "Basic training is nothing like the Army." One could then argue over the point of Basic then, if not to simulate the Army. However, like in the interpreting profession, there is no way to prepare a soldier for all of the battles they will face in the future. Instead, the Army must train soldiers to have the character to fight through obstacles, no matter the setting. That is exactly what I aimed to do by making students experience and respond to diverse interpreting environments.

The students had a difficult time navigating my course expectations at first because I expected them to utilize critical discourse analysis, a new procedure for them, and proof of their improvement. Both the college and the program failed to prepare the students for cultural navigation in interpreting by approaching the interaction like a business-owner, rather than a novice-expert relationship. I did not have too much difficulty teaching them the critical skills necessary to be successful interpreters, though they each learned them to varying degrees. All of the students are intrinsically motivated to work as interpreters. They even have connections with their peers, especially since three of the four students in the class were in face-to-face classes together before the program shifted to all-remote delivery.

I spoke to them from an experiential (Dewey, 1925, 1938; Kolb, 2015; Skaaden, 2017) point-of-view, so their assignments were framed in an applied context. Their coursework reflected the types of situations I have been in. Then, we discussed their decisions together. Their interpreter education experience failed to provide them with someone in the interpreting community to guide them into and then through the profession. All of the students mentioned that their other interpreting professors were poor communicators and did not provide necessary 
support. I felt the frustrations of the students when they vented to me. So, even though I was not present in these disadvantaged situations, students consistently mentioned the lack of support from other instructors and I understood more about the disconnect between content and professional practice (including the development of the critical consciousness) that these students have previously experienced.

Lave and Wenger (1991) make it clear that collaborative work in a professional learning community strengthens the ties between individuals. By making my experiences real and making students respond critically to them as assignments throughout the semester, students began to "feel" for Others. Of course, my mind immediately thinks of the ASL sign for FEEL because of how much the sign conceptually communicates. The sign is located on the chest, near the heart (Image 4).

\section{Image 4}

Sign for FEEL in ASL

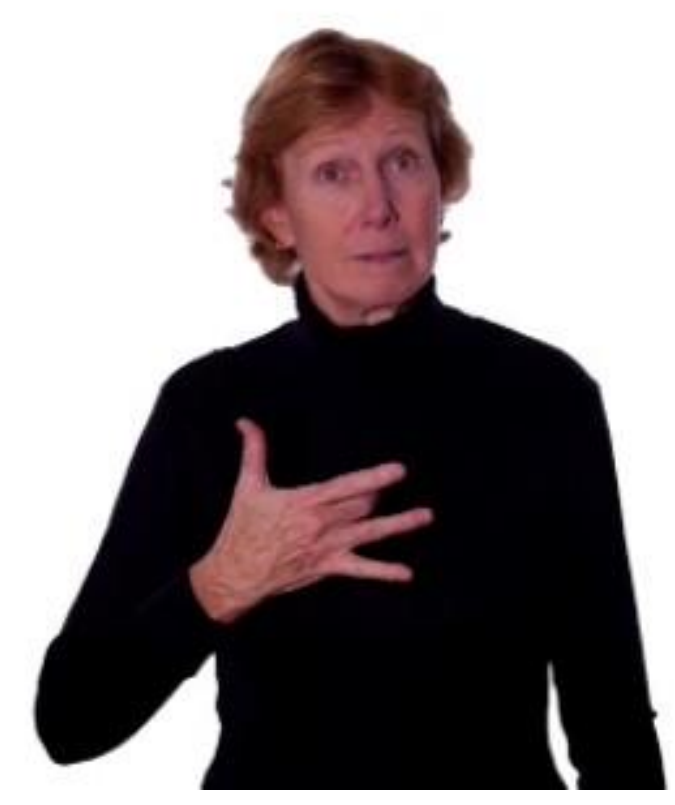


When students can FEEL for the Deaf and interpreting communities through real experiences that make them feel like members of the interpreting community, they expand their already burgeoning Deaf Hearts, and connect with Others' voices (and their own).

\section{Implications}

\section{Implications for Methodology}

My digital micro-ethnographic and action research methodologies afforded me a plethora of data that responded to my research questions in this project. I was fortunate enough to have a small class of four students where I could focus overtly on the collective traits of our small community while learning about each of the individuals within. Ethnographically speaking, I was able to observe how interpreting students begin to come into their role as professional interpreters by way of a critical community of practice. The ethnographic structure allowed me to study the people as they are in this context of distance interpreter education.

Because of the class's geographic separation, I quickly realized that every interaction I had with a student was noteworthy for this research. Perhaps not for primary data sources, but certainly for validity and ethical considerations. For example, many students mentioned my willingness to help answer questions. During these one-on-one tutor-like conversations, I learned more about the areas of their interpreting skills that still require additional development. Consequently, I could more critically reason through an interpreting student's sign choice because I better understood who they were as people. I was also then better able to assist students again later when they returned with more questions.

If I reconducted this investigation, I would scaffold my interview questions at the beginning of the semester to decipher the different levels of learning of each individual. I made inaccurate assumptions about students' learning, which took time to remedy. I will approach 
another iteration of this course with a closer lens on knowledge, skills, and abilities from the outset so I can more effectively differentiate instruction for future students. I will scaffold learning and development through progressive activities that build competencies and the critical consciousness at a fundamental level. During the semester, when students inevitably disagreed with each other, I tried not to impose any of my own ideas or perspectives on them. Unfortunately, I noticed that some group members remained silent during these disagreements, as if uncomfortable to dispute a counter perspective. In future course iterations, I will do my best to elicit and facilitate better dichotomous discussions by offering rationale to both perspectives to enhance overall learning and divergent thinking.

One of the most challenging aspects of implementing these research methodologies was the amount of data I managed to collect. I collected hours' worth of meaningful discourse and really wanted to critically analyze it all. I had to first focus on the most significant interactions. Not to mention that there is a mountain of influences in a distance-learning environment. Students are impacted by many factors over which I have no control that could shift their approach to critical discourse analysis. By incorporating most of the communication I had with my students as a source of secondary data, I learned about the students" "identity delta" or the students' overall change in develop of the critical consciousness.

While I was providing students with opportunities to critically analyze language, to become critically conscious interpreters, I also critically analyzed their language during the process. I learned about the students' interpreter voices, their vocabulary, and the way they interacted with others. Of course, all of these behavioral, attitudinal, and linguistic manifestations are a result of their experiences, as Bakhtin (1981) would also purport. As a result of this data collection and analysis, I responded accordingly (as best as I could with realistic expectations) 
and attempted to address the issues and concerns in the structure and dynamic of the course that might have interfered with the development of the critical consciousness, the awakening to the oppressive structures that serve to bring down communities. In instructional design, one might refer to my action research approach as evaluation, a key component of determining overall teaching effectiveness and learning progress. However, unlike most evaluation that takes place formatively or summatively, I utilize action research to consistently guide and reflect upon my teaching decisions as they are made. Truthfully, every educator should actively assess and adjust their teaching to address student-learning concerns. Yes, the adjustments I made took time, but in a class of four, they were more manageable than they might have been with more students. Nevertheless, if course structure or lesson plans are not meeting the desired outcomes, there is no reason to continue on a tangential trajectory.

\section{Implications for Theory}

As I told my students throughout the semester, interpreters do more than search for oneto-one word equivalents in the target language; they look for meaning and represent it in a way that the intended audience would culturally and linguistically understand. To facilitate students' learning of how to do this, I could have implemented the community of practice framework (Lave, 1991), so long as it was clear to the students that the community and profession are both deeply contextual and saturated in power, so those skills will be developed. By emphasizing the critical nature of the community, I believe that a critical community of practice framework keeps the mindset that interpreters are consistently analyzing and deconstructing social realities to embody concepts and intentions. This mindset is positioned to disrupt audism and audistic tendencies, in favor of more effective communication that acknowledges cultural diversity. 
In this study, one of those harsh social realities was that the students in this course were all disadvantaged economically, socially, and linguistically. As students of Clear Point, they are subject to the tightening budget in community colleges, especially given their major which does not garner much public attention or notoriety. Because it does not receive news attention, it often is the recipient of the short end of the stick, like when it went from a full-time interpreting faculty member to separate (and independent) instructors. The students, too, are geographically challenged and cannot as readily collaborate with classmates. Their time together is now a scheduled via a video call. Due to COVID-19 these students were separated more than they otherwise might have been when gathering at statewide Deaf Club functions. Even though I have tried to provide meaningful learning experiences for these students without their in-person events, I am only one instructor. Without the support of the other professors, these students have stalled in their interpreter development.

I witnessed several demonstrations of how their negative experiences in the interpreter education program has changed how they see the interpreting community. Some students made negative comments about classmates' proficiency levels, which threatened the critical nature of the CCoP. On the other hand, some interactions between classmates were most positive because they were not face-to-face or real-time, so people could organize their responses, especially in the case of the peer feedback for interpretations.

I do find strong similarities between overcoming the fear of utilizing non-manual signals in interpretations and novice interpreters' experiences in relating to other professionals and individuals in the field. I see interpreter development the same way butterflies metamorphosize. After undergoing a significant change, we are never the same. Our human changes may not always be physically noticeable, but they are significant, nonetheless. They are fundamentally, 
internally life-altering because they shifted our internal processing of the world and the reality we create for ourselves and our respective communities.

Like Bakhtin, I believe that situated dialogue informs our view on the world, which in turn affects the way we utilize language. I had an internal dialogue with myself that yielded a shocking and painful realization: students' focus on improving vocabulary skills rather than the understanding of speaker intent could limit their ability to perform essential functions of interpreting. If students languish in linear language and do not expand their usage of the word "critical" past the idea of judgment, for example, they will not be able to catch potential misinterpretations and disrupt audism, like the example we deconstructed with the woman who was previously in the Brownies (Pollitt, 2000). To connect more interpreters to speaker intent, I conceptualize a theory of relational critical identity development. I envision this process as a critical approach to dialogue where interpreters are critically conscious of their interactions and keenly aware of their surroundings. Ultimately, the interpreter would engage with the critical community of practice as a practicing professional and advance their identity development.

\section{Implications for Practice and Pedagogy}

The implementation of the $\mathrm{CCOP}$ in distance interpreter education demonstrated that students learn from critical discussions and analyses of experiences. I provided students simulated, novel experiences and utilized the CCoP framework to show them how to navigate these moments appropriately in their future interpreter role. Ultimately, students learned how to think critically about someone's message and plan an ASL interpretation that carries an equivalent meaning.

If an interpreter time and time again is changing the core intention of a message, then the Deaf individual is disenfranchised. The Deaf person's message is not getting to the hearing 
individual and the hearing individual does not know the Deaf person's true goal(s). The hearing person may also be portrayed differently than they actually are. Even though a Deaf person's attention to facial expressions can help illuminate some glaring differences between original spoken words and their interpretation, adjustments to intent, not affect, can go undetected. The original spoken message cannot be confirmed to have been interpreted effectively. The Deaf community is left without any recourse to learn what was actually said, putting them at the mercy of the hearing population to take care of them.

Of course, all of the experiences I offered students were hypothetical and did not provide some essential elements of the interpreting process, like consumer feedback. Unfortunately, due to a host of reasons (e.g. the pandemic, scarcity of interpreting internship placements, supervision of clinical practice in Deaf communities, etc.), it was difficult to expand their critical consciousness to its greatest potential. After all, it is an interpreter's immersion into the Deaf community that fuels their capacity to create critically and conceptually accurate interpretations. Being surrounded by the Deaf sparks creative ways of communication given the heteroglossia throughout the community. The inconsistent language skills that plague the Deaf community yield a shiny, silvery lining of diversity of thought and expression. These interactions force interpreters to adapt their way of communicating to be understood, likely expanding their capacity for other forms of creative expression of a concept or idea.

During this semester, I could not easily send students out into the Deaf World and make them mingle with each other and the Deaf in ASL, something that most interpreter education programs depend on for language and cultural development in interpreters. While I provided students with the interpreting vignettes (Appendix E), they really experienced no direct 
connection to the Deaf community by the coursework alone. I honestly do not believe there is a learning substitute for cultural interaction, immersion, and experience.

At the beginning of the semester, I tried to establish common knowledge amongst the members of this critical community of practice, including myself. Together, we engaged in "working out a common understanding of events, or a common language for describing [our] experience" (Edwards \& Mercer, 2013, p. 84). As Edwards and Mercer (2013) suggest, we engaged in dialogue about the mental processes involved in interpreting, and about the interpreting interaction itself, "at precisely those points where there appear to be disagreements, mismatches, or incongruities in the different participants' understandings" (ibid.). I elicited knowledge from students and responded by questioning their realities and the innate power of the interpreter to create reality for others. Then, we discussed our learning at the end of each activity to investigate how it applies to field-based interpreting work, a situational practice central to the contemporary notion of dialogic teaching (Alexander, 2008).

After reading Shaw and Roberson (2009) during the semester, I decided that I will likely create service-learning opportunities for my students as part of their regular coursework, no matter the courses I teach in the field of ASL interpreting. Students learn more by living the Deaf experience than being told about it (Shaw \& Roberson, 2009). I will utilize a relatable problem (one to which I have not yet found a satisfactory response). For example, due to the pandemic, many interpreting students have not been able to use ASL with native signers at Deaf Club events. I will present this obstacle to the interpreting students and ask them to solve the problem in teams. The teams will then come together and share their ideas on the best way to approach the challenge at-hand. I will do my best to support the students with my access to and understanding of the Deaf World. 
I would hope that students would schedule virtual events for the Deaf to attend so they could experience heteroglossia and polyphony through dialogue. In order to tie this semesterlong project into the course, I will ask students to submit weekly journals in which they reflect on their meaningful project-related experiences, both while working on the project with interpreting colleagues and during Deaf Club events with Deaf individuals. With this information, I will create interpreting situations that are realistic and make great use of students' understanding of their environment and the people within this context.

I have two goals: (1) I want to empower women in the interpreting field to see how they can solve problems; (2) I want these interpreting students to put themselves in ambiguous and uncomfortable situations. Rather than telling a female interpreter how to solve the problem, I ask them for their opinion. This action-based approach will likely challenge some students, but the time investment is worth the reward. Interpreters need to feel confident in their decisions and utilize relative social, cultural, and contextual clues to quickly inform their processes.

Second, I want interpreters to take risks and be willing to try something different. Many interpreting students and professional interpreters struggle with non-manual signals. I believe that this systemic challenge is due to an internalized sociocultural difference. Spoken English does not encourage "funny faces" because they are seen as rude, but American Sign Language demands them because they demonstrate affect. Spoken English also discourages pointing, but American Sign Language encourages it to establish referents in a story with more than one person. Despite these cultural differences, I want to find ways to teach students how to step outside of their comfort zone, drop English form, and show true HEART-UNDERSTAND (Deaf Heart).

For educators of interpreters, key pedagogical insights. 


\section{Implications for Policy}

I notice a lack of compassion in this higher education institution's policy that oppresses the students' potential for reaching their full interpreter mindset. At the highest levels, the interpreter education program is not supported with new course development. At the grassroots, interpreting students are placed into distance learning environments where some instructors provide no meaningful context for learning. I will provide detailed examples to support these claims.

I am disheartened by the neglect, but believe there are reasonable, actionable steps that can be taken in this situation. First, adjunct instructors need to be more closely evaluated. My understanding is that the students have complained about the lack of support they receive from their other instructors, but yet they are still employed at the college. Second, adjunct instructors need to be given more course development support to utilize available technologies to support complex learning outcomes, especially in given the rigor and level of accomplishment expected in an interpreting program. Three adjunct instructors teach all of the required courses to graduate with a degree in ASL interpretation. If our teaching is fundamental to students' program completion (and impacts the beloved bottom line) then we need the resources to prepare students.

I immediately think of how the other instructors would benefit from instructional design support, especially given the distance learning setup. However, the Distance Learning office at the college is run by one instructional design professional who provides support to the entire college by herself. The struggles that students experience in this college fuel the self-fulfilling prophecy: in order to better their lives, they went to college. Once in college, they realized that the world is no kinder to them in academia than it is in the workforce and they are sometimes 
preyed on financially without opportunities for learning or advancement. Students enroll in these community college programs to be "career-ready" in a short amount of time, only the college does not provide students with the necessary access to essential resources because they require money. Rather than spend the money to maintain the physical space of the ASL interpreting program, they allow students to fail the course(s) over and over again without direct apprenticeship support (or any other kind) because they continue to collect tuition dollars. The ultimate motivator is the bottom line, not the students' success.

This truth is bleak. I, frankly, do not want to think or write about these facts because they anger me to my core. If higher education institutions fulfilled their purpose, which I understand to be to educate, then how do some colleges and universities fail to facilitate and assess learning? Rather than provide students with tutors, stipends, clinical practice opportunities (online for faceto-face), job placement assistance, relationships and guidance in the Deaf and interpreting communities, connecting graduates to new communities, follow-up support and professional development as alumnae, the college established a program that requires the same amount of field experience (maybe even more) than other technical professions taught at the college, yet it does not support the program's development of services to facilitate such professional involvement.

Perhaps the college's administrators have internal biases toward individuals who are Deaf, leading them to believe that federal money will support individuals who are Deaf, so they do not need to. Perhaps the administrators are audistic and believe that Deaf people will never become meaningful contributors to society, so they do not see the purpose of the role of the interpreter. Maybe the administrators see this program filled with women instructors and students and believe that their caretaking role is "natural," so they do not need formal assistance 
to develop those skills. Perhaps they forgot about the interpreting program altogether after they developed it. Perhaps they would love to contribute money to the program's success and continually look for ways to support the program, but do not have the funds to do so. The rationale for programmatic neglect cannot be confirmed in this case. Like in the case of message planning in an interpretation, I must focus on responding to the concept I perceive to be at-hand, which in this case is the lack of support the program, instructors, and students receive from the institution.

College is a time of self-discovery and people do not discover their identities by only reading a textbook. They must be provided opportunities to engage with their personal identities, their respective communities, Others' communities, and their learning. Especially given the majority female population in the interpreter community, colleges should yield more to the needs of interpreter education programs to create meaningful experiences for women to learn their individual voices, while solving complex communication challenges. Interpreters can be positive influences in all communities because of their far-reaching range and access to diverse populations through their work. By teaching interpreters to be critical, they become voices of critical consciousness, problem solving, and reasoning in many communities. In this case, interpreters become "super spreaders" of awareness.

The effort for recognition of the interpreting profession within the college continues and strengthens with involvement by people from different linguistic and cultural communities. When administrators hear polyphony and heteroglossia in shared social justice efforts, they are more likely to validate the concern. Unique voices that share common goals may motivate institutions to feel more accountable to answer for their misdeeds. This answerability (M. M. Bakhtin \& Brostrom, 1990) can be strengthened by asking questions of administrators. Paolo 
Freire might have referred to this as "problem posing." Instead of telling administrators what to do and shaming them for not already doing it, I suggest explaining the problem and ask them for a reasonable solution. Perhaps in the dialogue, both parties will learn about the Other and gain the ability to be-for them and together they can develop reasonable solutions to policy-related obstructions.

Moving forward, I have not given up my efforts to help transform the culture of the interpreter program at Clear Point College. I recognize that the shift will take time and I will have to plant seeds of change, not try to bulldoze years of structure. To that point, I will collaborate with Deaf colleagues to help students overcome internalized cultural barriers that prevent them from matching the cultural expectations of native signers in the Deaf community. If I want the college to see that interpreters are multifaceted, intelligent, and worthwhile professionals, then we must develop a pragmatic approach to approach interpreting obstacles. Second, when I am able to implement my service-learning project into the course, I want to conduct similar research to this study where I observe the development of students' critical consciousness after working more closely with the Deaf, interpreting students, and professional interpreter communities.

\section{Conclusion}

I could not help but notice again and again during this research that institutional context comes to bear on students' experience and identities as professionals in the interpreting field. By utilizing a micro-ethnography, I was able to observe how students operated within their environment, how they interacted with each other, and how they engaged in the course as future interpreters. By observing their behaviors, I was able to make teaching decisions that addressed opportunities for development. Most notably was the implementation of critical discourse 
analysis (CDA), which is widely used in ASL interpretations to deconstruct an incoming message.

CDA proved to be an essential feature of this course because students could live the role of others without being offered the opportunity to formally work in that role. In this way, CDA was like acting, which causes some people to experience perspective and role changes (see Brown et al., 2019). During this time, it was essential for students to self-assess and take stock of their internal shifts and note how those changes might impact their work and interactions with others. Students worked together and provided feedback to each other to help them work through questions they might have during the development of their interpreter mindset and identities. 


\section{References}

Adorno, T. (1974). Minima Moralia: Reflections from Damaged Life. NLB.

Ahmed, S. (2004). Affective Economies. Social Text, 22(2).

Alexander, R. (2008). Exploring Talk in School: Inspired by the Work of Douglas Barnes (N. Mercer \& S. Hodgkinson, Eds.). SAGE.

American Rhetoric: Elie Wiesel-The Perils of Indifference. (n.d.). Retrieved April 8, 2021, from https://www.americanrhetoric.com/speeches/ewieselperilsofindifference.html

Anderson, G., \& Irvine, P. (1993). Informing critical literacy with ethnography. In Critical literacy: Politics, praxis, and the postmodern (pp. 81-104).

Ariza, E., \& Hancock, S. (2003). Second language acquisition theories as a framework for creating distance learning courses. International Review of Research in Open and Distance Learning, 4(2), 1-9.

Baath, J. A. (1979). Correspondence Education in the Light of a Number of Contemporary Teaching Models.

Bakhtin, M. (1981). Discourse in the novel. In C. Emerson \& M. Holquist (Eds.), The dialogic imagination: Four essays by M. Bakhtin (pp. 259-422). University of Texas Press.

Bakhtin, M. (1986). Speech genres and other late essays. University of Texas Press.

Bakhtin, M. M., \& Brostrom, K. (1990). Art and Answerability. University of Texas Press. https://www.jstor.org/stable/10.7560/704114

Bauman, Z. (2005). Education in Liquid Modernity. Review of Education, Pedagogy and Cultural Studies, 27(4), 303-317. 
Bektashi, L. (2018). Community of Inquiry Framework in Online Learning: Use of Technology. In Technology and the Curriculum: Summer 2018. Power Learning Solutions. https://techandcurriculum.pressbooks.com/chapter/coi-and-online-learning/

Boud, D., Keogh, R., \& Walker, D. (1994). Reflection: Turning Experience into Learning. Nichols Publishing Company.

Bridges, B. (2019, April 7). Deaf heart [YouTube]. https://www.youtube.com/watch?v=XH6vd3Fs6Ac

Brown, A. L., \& Campione, J. C. (1994). Guided discovery in a community of learners. In K. McGilly (Ed.), Classroom lessons: Integrating cognitive theory and classroom practice. MIT Press/Bradford Books.

Brown, J. S. (2000). Growing up Digital: How the Web Changes Work, Education, and the Ways People Learn.

Brown, S., Cockett, P., \& Yuan, Y. (2019). The neuroscience of Romeo and Juliet: An fMRI study of acting | Royal Society Open Science. R. Soc. Open Sci., 6(181908), 1-20. http://dx.doi.org/10.1098/rsos.181908

Carlson, P. M., \& Fleisher, M. S. (2002). Shifting Realities in Higher Education: Today's Business Model Threatens Our Academic Excellence. International Journal of Public Administration, 25(9-10), 1097-1111. https://doi.org/10.1081/PAD-120006127

Chapman Alliance: LMS Selection Services, Learning Technology Consulting, Choosing an LMS - How Long Does it Take to Create Learning? (n.d.). Retrieved January 5, 2021, from http://www.chapmanalliance.com/howlong/ 
Chickering, A. W. (1977). Experience and Learning: An Introduction to Experiential Learning. Change Magazine Press.

Chrobak-Munoz, E. (2000). A Five-Stage Model To Facilitate Critical Reflection Using Interviewing Skills. https://eric.ed.gov/?id=ED442996

Clancey, W. J. (1995). A tutorial on situated learning. In J. Self (Ed.), A tutorial on situated learning (pp. 49-70). AACE.

Cokely, D. (2005). Shifting positionality: A critical examination of the turning point in the relationship of interpreters and the Deaf community. In M. Marschark, R. Peterson, E. A. Winston, P. Sapere, C. M. Convertino, R. Seewagen, \& C. Monikowski (Eds.), Sign Language Interpreting and Interpreter Education: Directions for Research and Practice (pp. 3-27). Oxford University Press.

Colonomos, B. (2013, February 26). Sign Language Interpreters and the Quest for a Deaf Heart. StreetLeverage. https://streetleverage.com/2013/02/sign-language-interpreters-and-thequest-for-a-deaf-heart/

Derrida, J. (2005). The principle of hospitality. Parallax, 11(1), 6-9.

Dewey, J. (1916). Democracy and Education: An Introduction to the Philosophy of Education. The Free Press.

Dewey, J. (1925). Experience and nature (1st ed.). Open Court Publishing Company.

Dewey, J. (1933). How we think. D.C. Heath and Company.

Dewey, J. (1938). Education and Experience. Simon \& Schuster. 
Dyson, A. H. (1995). Writing Children: Reinventing the Development of Childhood Literacy. Sage Publications, 12(1), 4-46.

Eckert, R., \& Rowley, A. (2013). Audism: A Theory and Practice of Audiocentric Privilege". Humanity and Society, 37(2), 101. https://doi.org/10.1177/0160597613481731

Edwards, D., \& Mercer, N. (2013). Common Knowledge: The Development of Understanding in the Classroom. Routledge.

Ellis, R. (1999). Learning a second language through interaction (Vol. 17). John Benjamins Publishing Company.

F., E. A. (1902). MR. FORCHHAMMER'S MANUAL-ORAL METHOD OF INSTRUCTION AND COMMUNICATION FOR THE DEAF. American Annals of the Deaf, 47(4), 363370.

Fant, L. (1990). Silver threads: A personal look at the first twenty-five years of the Registry of Interpreters for the Deaf. RID Publ.

Freire, P. (2000). Pedagogy of the oppressed (30th anniversary ed). Continuum.

Freire, P. (2007). Pedagogy of the oppressed (M. B. Ramos, Trans.). Continuum.

Friga, P. (2020, April 20). Under Covid-19, University Budgets Like We've Never Seen Before. The Chronicle.

Gerrity, T. W. (1976). College-sponsored correspondence instruction in the United States: A comparative history of its origin (1873-1915) and its recent development (1960-1975). [Dissertation]. 
Godfrey, L. A. B. (2010). Characteristics of effective interpreter education programs in the United States [Dissertation].

Gregory, E., Long, S., \& Volk, D. (2004). Many pathways to literacy: Young children learning with siblings, grandparents, peers and communities. London: RoutledgeFalmer.

Gyamera, G. O., \& Burke, P. J. (2018). Neoliberalism and curriculum in higher education: A post-colonial analyses. Teaching in Higher Education, 23(4), 450-467. https://doi.org/10.1080/13562517.2017.1414782

Hale, S. B. (2007). Community Interpreting. Palgrave Macmillan.

Hammer, E. (2014). Metaphysics. In D. Cook, Theodor Adorno: Key Concepts. Taylor \& Francis Group. http://ebookcentral.proquest.com/lib/wvu/detail.action?docID=1886855

Hankins, K. H. (2003). Teaching Through the Storm: A Journal of Hope. Teachers College Press.

Harry, E., \& Rippey, M. (2009). Achieving a balance: Ethnography or ethnographic methods? Qualitative Research Methods in Special Education, 15-32.

Harvey, M., \& Dym, B. (1988). An Ecological Perspective on Deafness. 21(3). https://repository.wcsu.edu/jadara/vol21/iss3/6

Hebert, P., Meslin, E. M., Dunn, E. V., Byrne, N., \& Reid, S. R. (1990). Evaluating ethical sensitivity in medical students: Using vignettes as an instrument. Journal of Medical Ethics, 16, 141-145. 
Huber, N. (2003). An Experiential Leadership Approach for Teaching Tolerance for Ambiguity. Journal of Education for Business, 79(1), 52-55. https://doi.org/10.1080/08832320309599088

Humphrey, J. H. (2000). Portfolios: One answer to the challenge of assessment and the "readiness to work" gap. In C. B. Roy (Ed.), Innovative practices for teaching sign language interpreters (pp. 153-175). Gallaudet University Press.

Jeffries, M. (2009). Research in distance education. MA Distributed Learning. http://cmapspublic.ihmc.us/rid=1HZXXGY8W-1ZZ4DLF137T/Research\%20in\%20Distance\%20Education.docx

Jeong, H., Sugiura, M., Sassa, Y., Wakusawa, K., \& Horie, K. (2009). Learning second language vocabulary: Neural dissociation of situation-based learning and text-based learning. NeuroImage.

Johnson, S. (2011). Where Good Ideas Come from: The Natural History of Innovation. Penguin.

Keegan, D. (1996). Foundations of Distance Education. Psychology Press.

Kirschner, P., Sweller, J., \& Clark, R. (2006). Why Minimal Guidance During Instruction Does Not Work: An Analysis of the Failure of Constructivist, Discovery, Problem-Based, Experiential, and Inquiry-Based Teaching. 41(2), 75-86. https://doi.org/10.1207/s15326985ep4102_1

Klahr, D., \& Nigam, M. (2004). The Equivalence of Learning Paths in Early Science Instruction: Effects of Direct Instruction and Discovery Learning. Association for Psychological Science, 15(10), 661-667. https://doi.org/10.1111/j.0956-7976.2004.00737.x 
Kolb, D. A. (1984). Experiential learning: Experience as the source of learning and development. Prentice-Hall, Inc.

Kolb, D. A. (2015). Experiential Learning: Experience as the source of learning and development (Second).

Lane, H. (1992). The Mask of Benevolence. https://www.goodreads.com/work/best_book/266072-the-mask-of-benevolencedisabling-the-deaf-community

Lave, J. (1988). Cognition in Practice: Mind, Mathematics, and Culture in Everyday Life (1st ed.). University Press.

Lave, J. (1991). Situating Learning in Communities of Practice. In L. B. Resnick, J. M. Levine, \& S. Teasley (Eds.), Perspectives on Socially Shared Cognition (pp. 63-82). American Psychological Association.

Lave, J., \& Wenger, E. (2011). Situated learning: Legitimate peripheral participation.

Lévinas, Emmanuel. (1994). Totality and infinity: An essay on exteriority. Duquesne University Press.

Levitt, D. H., \& Jacques, J. (2005). Promoting tolerance for ambiguity in counselor training programs. Education and Development, 44(1), 46-54.

Lewin, K. (1951). Action Research and Minority Problems. Journal of Social Issues, 2(4), 3446.

Long, S., Souto-Manning, M., \& Vasquez, V. (2016). Courageous Leadership in Early Childhood Education: Taking a Stand for Social Justice. Teachers College Press. 
Merriam, S., \& Tisdell, E. (2016). Qualitative research: A guide to design and implementation (4th ed.). John Wiley \& Sons.

Monikowski, C., \& Peterson, R. (2005). Service Learning in Interpreter Education: Living and Learning. Sign Language Interpreting and Interpreter Education, 188-207.

Moore, M., \& Kearsley, G. (1996). Distance education: A systems view. Wadsworth.

Morewood, A. L., Ankrum, J. W., \& Dagen, A. S. (2019). Conceptualizing Characteristics of Professional Learning in an Online Environment. In Handbook of Research on Educator Preparation and Professional Learning. EBSCO Publishing.

Morkovin, B. V., \& Moore, L. M. (1960). Through the barriers of deafness and isolation; oral communication of the hearing-impaired child in life situations (pp. xvii, 178 pages). Macmillan.

Neidle, C. J., Kegl, J., Bahan, B., MacLaughlin, D., \& Lee, R. G. (2000). The Syntax of American Sign Language: Functional Categories and Hierarchical Structure. MIT Press. https://books.google.com/books?hl=en\&lr=\&id=MqzBc7eYyLsC\&oi=fnd\&pg=IA2\&dq $=$ C.+Neidle+et+al.,+2000\&ots=3fBBQ2zDrG\&sig=pyFWNDrnbAAkYDWPt1UcnlaR9

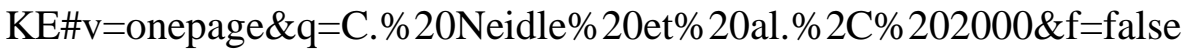

Pizzuto, E. A., Rossini, P., Sallandre, M. A., \& Wilkinson, E. (2006). Deixis, anaphora and highly iconic structures: Cross-linguistic evidence on American (ASL), French (LSF) and Italian (LIS) signed languages. Theoretical Issues in Sign Language Research Conference, 475-495.

Pochhacker, F. (2004). Introducing Interpreting Studies. Routledge.

Pochhacker, F., \& Shlesinger, M. (2002). The Interpreting Studies Reader. Routledge. 
Pollitt, K. (2000). Critical Linguistic and Cultural Awareness: Essential Tools in the Interpreter's Kit Bag. In C. Roy (Ed.), Innovative Practices for Teaching Sign Language Interpreters. Gallaudet University Press.

Reiser, R. A. (2013). Instructional technology: A history. In R. M. Gagne (Ed.), Instructional technology: Foundations (2nd ed., pp. 11-48). Routledge. https://books.google.com/books?hl=en\&lr=\&id=PTtdAgAAQBAJ\&oi=fnd\&pg=PA11\& $\mathrm{dq}=$ reiser+1987\&ots $=\mathrm{TSA} 4 \mathrm{~m} 5 \mathrm{cYcD} \& \mathrm{sig}=\mathrm{Nh} 6 \mathrm{~Eb} 8 \mathrm{eFw}-$ scNzXZGhkBk9Tfalo\#v=onepage \&q\&f=false

Richards, J. C., \& Rudser, S. F. (1988). Sign language instruction and its implications for the Deaf. In Language Learning and Deafness. Cambridge University Press.

RID FY2019 Annual Report. (2019). [Financial]. Registry of Interpreters for the Deaf. https://documentcloud.adobe.com/link/track?uri=urn\%3Aaaid\%3Ascds\%3AUS\%3A228f ae3e-eb75-477f-87c3-eda18257ed11\#pageNum=23

Rose, N. (1999). Powers of Freedom. Reframing Political Thought. Cambridge University Press.

Roy, C. B. (2000). Training interpreters-Past, present, and future. In C. B. Roy (Ed.), Innovative practices for teaching sign language interpreters (pp. 1-14). Gallaudet University Press.

Rubin, J. (1975). What the "good language learner" can teach us. TESOL Quarterly, 41-51.

Saldana, J. (2011). Fundamentals of qualitative research.

Schein, J. D., \& Delk Jr, M. T. (1974). The deaf population of the United States. New York University: 
Schön, D. (1983). The Reflective Practitioner: How Professionals Think in Action. Basic Books, Inc.

Schroedel, J. G., \& Schiff, W. (1972). Attitudes towards deafness among several deaf and hearing populations. Rehabilitation Psychology, 19(2), 59-70. https://doi.org/10.1037/h0090872

Sec. 300.101 Free appropriate public education (FAPE). (n.d.). Individuals with Disabilities Education Act. Retrieved June 16, 2021, from https://sites.ed.gov/idea/regs/b/b/300.101

Seidman, I. (2006). Interviewing as Qualitative Research. https://www.google.com/books/edition/Interviewing_as_Qualitative_Research/pk1RmqY15QC?hl=en\&gbpv=1\&dq=seidman+2006+interview \&printsec=frontcover

Shaw, \& Roberson. (2009). Service Learning Recentering the Deaf Community in Interpreter Education. American Annals of the Deaf, 154(3), 277-283. https://doi.org/10.1353/aad.0.0105

Sherfinski, M. (2017). Becoming Critical Communities of Practice in Pre-Kindergarten. Journal of Family Diversity in Education, 2(3), 71-93.

Silber, K. (1972). The field of Educational Technology: A statement of definition. Audiovisual Instruction, 17(8), 36-43.

Skaaden, H. (2017). An experiential-dialogic approach to interpreter education and online learning. In Teaching Dialogue Interpreting (pp. 324-240). Teaching Dialogue Interpreting.

Smaldino, S. (1999). Instructional design for distance education. TechTrends, 43(5), 9-13. https://doi.org/10.1007/BF02818158 
Smith, L. M., \& Geoffrey, W. (1968). The Complexities of an Urban Classroom; An Analysis Toward a General Theory of Teaching.

Social Distancing. (2020, July 15). Centers for Disease Control and Prevention. https://www.cdc.gov/coronavirus/2019-ncov/prevent-getting-sick/social-distancing.html

Souto-Manning, M., \& Mitchell, C. H. (2010). The role of action research in fostering culturallresponsive practices in a preschool classroom. 37(4).

Stokoe, W., Casterline, D., \& Croneberg, C. (1965). A dictionary of ASL on linguistic principles. Gallaudet College Press Washington, DC.

Streeck, \& Mehus. (2004). Microethnography: The study of practices. In Handbook of Language and Social Interaction (pp. 816-870). Lawrence Erlbaum Associates, Inc., Publishers.

Thayer, H. S. (1968). Meaning and Action: A Critical History of Pragmatism. Bobbs-Merrill.

van Dijk, T. A. (2015). Critical Discourse Analysis. In D. Tannen, H. E. Hamilton, \& D. Schiffrin, The Handbook of Discourse Analysis.

Vygotsky, L. S. (1978). Mind in Society: The Development of Higher Psychological Processes (M. Cole, V. John-Steiner, S. Scribner, \& E. Souberman, Eds.). Harvard University Press.

Vygotsky, L. S. (1994). The Vygotsky Reader (R. van der Veer \& J. Valsiner, Eds.). Basil Blackwood, Ltd.

Wadensjo, C. (2013). Interpreting as Interaction. Routledge; Taylor and Francis.

Wedemeyer, C. A. (1977). Independent Study. In A. S. Knowles (Ed.), The international encyclopaedia of higher education. CIHED.

Wenger, E. (2011). Communities of practice: A brief introduction. National Science Foundation. 
Wenger, E. (2019). Communities of Practice: Learning, meaning, and identity. Cambridge University Press.

WHO Director-General's opening remarks at the media briefing on COVID-19-11 March 2020. (2020, March 11). https://www.who.int/director-general/speeches/detail/whodirector-general-s-opening-remarks-at-the-media-briefing-on-covid-19---11-march-2020

Wiggins, G. (1993). Assessment: Authenticity, context, and validity. Phi Delta Kappan, 75, 200214.

Witter-Merithew, A., \& Johnson, L. (2004). Market disorder within the field of sign language interpreting: Professionalization implications. Journal of Interpretation, 19-41. 
Appendix A: Interview Protocol for Interview \#1

1. Why did you decide to major in American Sign Language interpretation?

a. Are you confident in your decision?

2. What does it mean to be an "American Sign Language Interpreter?"

a. How do you feel you fit that title?

3. What do you perceive your role is in the Deaf community?

4. What challenges do you foresee in your interpreting career?

a. How will you address these challenges?

b. What resources will you utilize to overcome future obstacles?

c. Why do you believe people leave the interpreting profession?

i. Would you ever leave for the same reason(s)?

5. How do you feel about interpreting for Deaf individuals?

a. Is there a context in which you feel most confident or comfortable? Why?

b. Is there a context in which you would never interpret? Why?

6. What previous Simultaneous-Consecutive Interpreting course experiences contributed to your success?

a. What experiences challenged you?

7. What would you like to see happen in this course to ensure your success? 
Appendix B: Interview Protocol for Interview \#2

1. Do you feel you have experienced growth as an interpreter? How so?

2. How can you continue to grow your empathy as an interpreter?

a. Is empathy important to have as an interpreter? Why or why not?

3. Do you enjoy the process of interpreting? Why?

a. What do you enjoy the most? Why?

b. What do you enjoy the least? Why?

4. Demographic/background questions (Appendix C)

5. What are your plans after graduation?

a. Do you plan to interpret in a school system? If so, where?

b. Do you plan to pursue a bachelor's degree? If so, in what?

i. Will you try to earn your National Interpreter Certification?

Why or why not?

c. What work would you like to pursue in your professional career?

d. Given the choice, would you choose interpreting work all over again?

6. What does it mean to be an "American Sign Language Interpreter?"

a. How do you feel you fit that title?

7. How do you feel this course structure impacted your learning in the course?

a. Was there something that you found helpful?

b. Anything you felt to be a challenge?

i. How was it challenging to you?

ii. How did it challenge you?

8. How do you expect other interpreting professionals to influence your work in the future? 
Appendix C: Demographic or background questions

1. Age range: (select one)
a. $18-21$
b. $22-27$
c. $28+$

2. Background: Where were you born and raised?

3. In or out of state? (select one)

4. Relationship to Deaf community: (select one)
a. Hearing
b. Hard of hearing
c. Child of Deaf Adult (CODA)
d. Family member of d/Deaf
e. Other

5. Year in school?

6. Course attempt?

7. Additional foreign languages spoken? (Yes or no; if yes, list name) 


\section{Appendix D: Triangulation matrix of research questions to both sets interview questions}

\begin{tabular}{|c|c|c|c|c|c|}
\hline Research Questions & & $\begin{array}{l}\text { RQ1: How does integration of } \\
\text { the Critical Community of } \\
\text { Practice framework impact } \\
\text { students' learning in an online } \\
\text { language-interpreting-based } \\
\text { learning environment? }\end{array}$ & $\begin{array}{l}\text { a: How does critical } \\
\text { discourse analysis enhance } \\
\text { students' English-to- } \\
\text { American Sign Language } \\
\text { interpretations? }\end{array}$ & $\begin{array}{l}\text { b: How does self- } \\
\text { reflection influence the } \\
\text { development of } \\
\text { interpreting skills? }\end{array}$ & $\begin{array}{l}\text { c: How do students perceive and } \\
\text { then self-actualize the role of an } \\
\text { American Sign Language } \\
\text { interpreter? }\end{array}$ \\
\hline \multicolumn{6}{|l|}{ Interview 1 Questions } \\
\hline & $\begin{array}{l}\text { Why did you decide to major in } \\
\text { American Sign Language } \\
\text { interpretation? Are you confident } \\
1 \text { in your decision? }\end{array}$ & & & & $\mathrm{X}$ \\
\hline & $\begin{array}{l}\text { What does it mean to be an } \\
\text { "American Sign Language } \\
\text { interpreter?" How do you feel you } \\
2 \text { fit that title? }\end{array}$ & $\mathrm{X}$ & $\mathrm{X}$ & $\mathrm{X}$ & $\mathrm{X}$ \\
\hline & $\begin{array}{l}\text { What do you perceive your role is } \\
3 \text { in the Deaf community? }\end{array}$ & $\mathrm{X}$ & & & $\mathrm{X}$ \\
\hline & $\begin{array}{l}\text { What challenges do you foresee in } \\
\text { your interpreting career? How will } \\
\text { you address these challenges? } \\
\text { What resources will you utilize to } \\
\text { overcome future obstacles? Why } \\
\text { do you believe people leave the } \\
\text { interpreting profession? Would } \\
\text { you ever leave for the same } \\
4 \text { reason(s)? }\end{array}$ & $X$ & & & $X$ \\
\hline & $\begin{array}{l}\text { How do you feel about } \\
\text { interpreting for Deaf individuals? } \\
\text { Is there a context in which you feel } \\
\text { most confident or comfortable? } \\
\text { Why? Is there a context in which } \\
5 \text { you would never interpret? Why? }\end{array}$ & & $\mathrm{X}$ & $\mathrm{X}$ & $\mathrm{X}$ \\
\hline & $\begin{array}{l}\text { What previous Simultaneous- } \\
\text { Consecutive Interpreting course } \\
\text { experiences contributed to your } \\
\text { success? What experiences } \\
6 \text { challenged you? }\end{array}$ & $\mathrm{X}$ & $\mathrm{X}$ & $\mathrm{X}$ & \\
\hline & $\begin{array}{l}\text { What would you like to see } \\
\text { happen in this course to ensure } \\
7 \text { your success? }\end{array}$ & $\mathrm{X}$ & $\mathrm{X}$ & $\mathrm{X}$ & \\
\hline
\end{tabular}




\section{Appendix D (continued)}

\begin{tabular}{|c|c|c|c|c|c|}
\hline \multirow[t]{4}{*}{ Interview 2 Questions } & & $\begin{array}{l}\text { RQ1: How does integration of } \\
\text { the Critical Community of } \\
\text { Practice framework impact } \\
\text { students' learning in an online } \\
\text { language-interpreting-based } \\
\text { learning environment? }\end{array}$ & $\begin{array}{l}\text { a: How does critical } \\
\text { discourse analysis enhance } \\
\text { students' English-to- } \\
\text { American Sign Language } \\
\text { interpretations? }\end{array}$ & $\begin{array}{l}\text { b: How does self- } \\
\text { reflection influence the } \\
\text { development of } \\
\text { interpreting skills? }\end{array}$ & $\begin{array}{l}\text { c: How do students perceive and } \\
\text { then self-actualize the role of an } \\
\text { American Sign Language } \\
\text { interpreter? }\end{array}$ \\
\hline & $\begin{array}{l}\text { Do you feel you have experienced } \\
\text { growth as an interpreter? How } \\
\text { so? }\end{array}$ & $\mathrm{X}$ & $X$ & X & $X$ \\
\hline & $\begin{array}{l}\text { How can you continue to grow } \\
\text { your empathy as an interpreter? Is } \\
\text { empathy important to have as an } \\
\text { interpreter? Why or why not? }\end{array}$ & $X$ & $X$ & $X$ & $X$ \\
\hline & $\begin{array}{l}\text { Do you enjoy the process of } \\
\text { interpreting? Why? What do you } \\
\text { enjoy the most? Why? What do } \\
\text { you enjoy the least? Why? }\end{array}$ & X & $X$ & $X$ & \\
\hline & $\begin{array}{l}\text { What are your plans after } \\
\text { graduation? Do you plan to } \\
\text { interpret in a school system? If so, } \\
\text { where? Do you plan to pursue a } \\
\text { bachelor's degree? If so, in what? } \\
\text { Will you try to earn your National } \\
\text { Interpreter Certification? Why or } \\
\text { why not? What would would you } \\
\text { like to pursue in your professional } \\
\text { career? Given the choice, would } \\
\text { you choose interpreting work all } \\
\text { over again? }\end{array}$ & & & $X$ & $X$ \\
\hline & $\begin{array}{l}\text { What does it mean to be an } \\
\text { "American Sign Language } \\
\text { interpreter?" How do you feel you } \\
\text { fit that title? }\end{array}$ & X & $X$ & $X$ & $X$ \\
\hline & $\begin{array}{l}\text { How do you feel this course } \\
\text { structure impacted your learning in } \\
\text { the course? Was there something } \\
\text { you found helpful? Anything you } \\
\text { felt to be a challenge? How was it } \\
\text { challenging to you? How did it } \\
\text { challenge you? }\end{array}$ & $X$ & $X$ & & \\
\hline & $\begin{array}{l}\text { How do you expect other } \\
\text { interpreting professionals to } \\
\text { influence your work in the future? }\end{array}$ & $X$ & $X$ & & $X$ \\
\hline
\end{tabular}


Appendix E: Assignments

Week 8 Activity

\section{$\underline{\text { Reconstruction and Planning Activity }}$}

Speech: The Perils of Indifference

Deconstruct

1. What is the speaker's message?

2. What cultures are involved in this environment?

3. Who is physically present? 
Appendix E (continued)

a. What impact do all individuals have on the interaction?

4. What are the historical references surrounding this speech?

Reconstruct \& Plan

INSTRUCTIONS: List any of the following elements present in this speech.

SOURCE LANGUAGE

Idioms, expressions

Speech differences (i.e. non-native English

speaker) 
Now, gloss the idiom(s).

Appendix E (continued)

Finally, head to Flipgrid to post your interpretation. This week, you will comment to your peers by Friday, October 9, 2020 11:59 PM. Your final draft of your interpretation is due on Sunday, October 11, 2020 11:59 PM. No late assignments will be accepted without prior approval.

\section{End of Assignment}


Appendix E (continued)

\section{CDA Questions}

Now that we have talked about CDA a bit, let's synthesize this information:

- What is CDA?

- What are the components of CDA?

○ HINT: Provide examples from the text.

- How can we use it when we interpret?

- What are the opportunities and challenges to using CDA?

- How does one conduct CDA? 
Appendix E (continued)

Meeting Notes and Questions for analysis

More in-depth analysis

- Topic range: What are they talking about?

- Background information: Is there anything we already know?

- Turn taking/interrupting strategies: Do we see any interruptions in conversation? If so, how might we interpret them? If not, how is conversation being managed?

- Hedging: Do you witness any examples of what might be hedging?

- Pausing: Do you witness any examples of what might be a pause?

- Terms of address/relational markers: What terms of address or relational markers (i.e. how does the speaker refer to his/her audience or others) are present? Does the speaker shift his/her terms of address to his/her audience? If so, where?

○ Conjecture: Why might an individual make this adjustment?

- Register shifts: Are there shifts in register? If so, where?

○ Conjecture: Why might an individual make this "shift?" 
Appendix E (continued)

- Gender markers: Are there clear gender markers in this passage? What are they?

- The use of interrogatives versus declaratives: What examples of interrogatives or declaratives do you see?

- The use of definite versus indefinite articles: Do you see any distinguishes in word choice? If so, where? How does this subtle word choice change meaning? 
Appendix E (continued)

Resources

PHILOSOPHY: Jacques Derrida

https://www.youtube.com/watch?v=H0tnHr2dqTs

A Teacher's Introduction to Deconstruction

https://files.eric.ed.gov/fulltext/ED305652.pdf 
Appendix E (continued)

Construction assignment

\section{Construction Assignment}

Trip to Hong Kong (Exercise 4.1)

This is a collaborative assignment.

Individually, watch each of the posted YouTube videos in the "Trip to Hong Kong" Discussion Board.

Note any opportunities for improvement and areas of success.

Share your feedback with your peers on the "Trip to Hong Kong" Discussion

Board. Pose three meaningful questions to all of your colleagues. [See additional attachment for more information]

Reflect on your own original interpretation.

Reconstruct your interpretation, considering your exposure to other methods of interpreting the same content.

Post your "final" interpretation to the same "Trip to Hong Kong" Discussion Board. The link to the discussion board is below. 
Appendix E (continued)

ITTP 2203 Post-Test

This test is not for a grade, meaning your interpretation will not be assessed for accuracy; you will receive points for submitting a completed assignment. Please note that I will not award full credit to work that appears sloppy and is not given an honest attempt.

I want to know how far you have grown this semester. Like the pre-assessment, you will interpret two videos:

- Simultaneous Interpreting from English, Page 34, Exercise 1.1, "My Big Move” by Lorraine Oldham

- Consecutive Interpreting from English, Page 52, Exercise 2.1, "Newspaper Layout” by Amber Lewnes

Like we did for the pre-test, please record your videos on Youtube. You will submit the links to

\section{Blackboard.}

Even though this assignment is not graded, I am assessing you on how you interpret. If you spend the entire interpretation STARING at a piece of paper for the words, you will not receive full credit. I want to know how you interpret and staring down isn't involved in the process. 
Additionally, you are required to respond to the accompanying vlog to reflect on your semester. You are to respond to the questions on YouTube, so that you may speak for more than the maximum 10 minutes allowed on Flipgrid.

INSTRUCTIONS: Think about it this way: When we interpret a message, there's more involved than just words. So, how do you intuit (as in intuition) what people mean? The message is in more than the words. So, we need to acknowledge your development in these non-cognitive (and equally, if not more, important) interpreting abilities.

1. Describe the impact of empathy on being an interpreter. Are you empathetic? How so? How can you increase your empathy for your potential clients (hearing AND Deaf)?

2. Describe your role in the Deaf community. Consider the following possible situations:

What is your role in settling communication conflict between a Deaf person and

- Non-native English speakers

- Deaf clients

- White clients

- Clients of Color **Yes, your role will differ in some situations based on the needs of the clients

3. You are interpreting an Individualized Education Plan (IEP) meeting for a Deaf student and her parents. The school system is refusing to listen to the parents request to have the child receive 
ASL interpreting. The school board demands the interpretation of English, citing evidence that English interpreting is "better" for English-language acquisition. You have worked with the student before. You have been with the student for some time and you acknowledge that their language preference is American Sign Language.

Write out a monologue (in a sense) citing why you believe the student should receive American Sign Language interpretation. Cite your previous training, including the word structure of American Sign Language to illustrate that you are competent in the linguistic features of American Sign Language. Additionally, demonstrate that you understand that development of one solid language (like a Deaf child learning American Sign Language) can enhance the child's ability to learn other languages, like English.

Note: This situation is adapted from a real-life event.

You will submit all links to the Blackboard submission location by November 20, 2020 at 23:59

EST. 
Appendix E (continued)

\section{Final Project}

\section{Final project}

PURPOSE: The purpose of this project is to test your interpreter self development. This project is not being graded as an interpretation skill evaluation.

SAMPLE

1. If you choose, you may redo each of the interpretations we have done this semester. Doing so will give you an opportunity to earn up to 1.5 points on each "final" draft.

2. Select your favorite interpretation and your most challenging interpretation.

3. complete the analysis outlined in the SAMPLE.

a. You will delete what I have as an example and directly insert your responses. Your responses should be complete and accurately represent your work to receive full credit.

4. Once complete, save the document: FinalProject (ITTP 2203)_Lastname

5. Submit to Blackboard. Assignments > SUBMISSION: Final Project 
Appendix E (continued)

Sample Final Project Response

INTERPRETATION ANALYSIS: SAMPLE VIDEO

Sources of Error $\mid \begin{aligned} & \text { Literal Translation } \\ & \text { Brief definition of error } \\ & \text { Example: "Machine runs" signed literally } \\ & \text { Rate: Probable effect of error on } \\ & \text { communicative function (1 = no negative } \\ & \text { consequences to participants; } 5=\text { errors } \\ & \text { cause grave consequences) } \\ & \text { Example: } 3 . \text { I fixed my sign right after; I } \\ & \text { was thinking about the word, rather than } \\ & \text { the concept or intent of the message. }\end{aligned}$


Example: Interpreted "afraid of death" instead of "scared to death"

Rate: Probable effect of error on communicative function $(1=$ no negative consequences to participants; $5=$ errors cause grave consequences)

Example: 4. Even though the words around the idea are communicated, the strength of the expression is not relayed.

\section{Omission}

Brief definition of error

Example: I missed the fingerspelling around [minute mark; topic]

Rate: Probable effect of error on communicative function $(1=$ no negative 


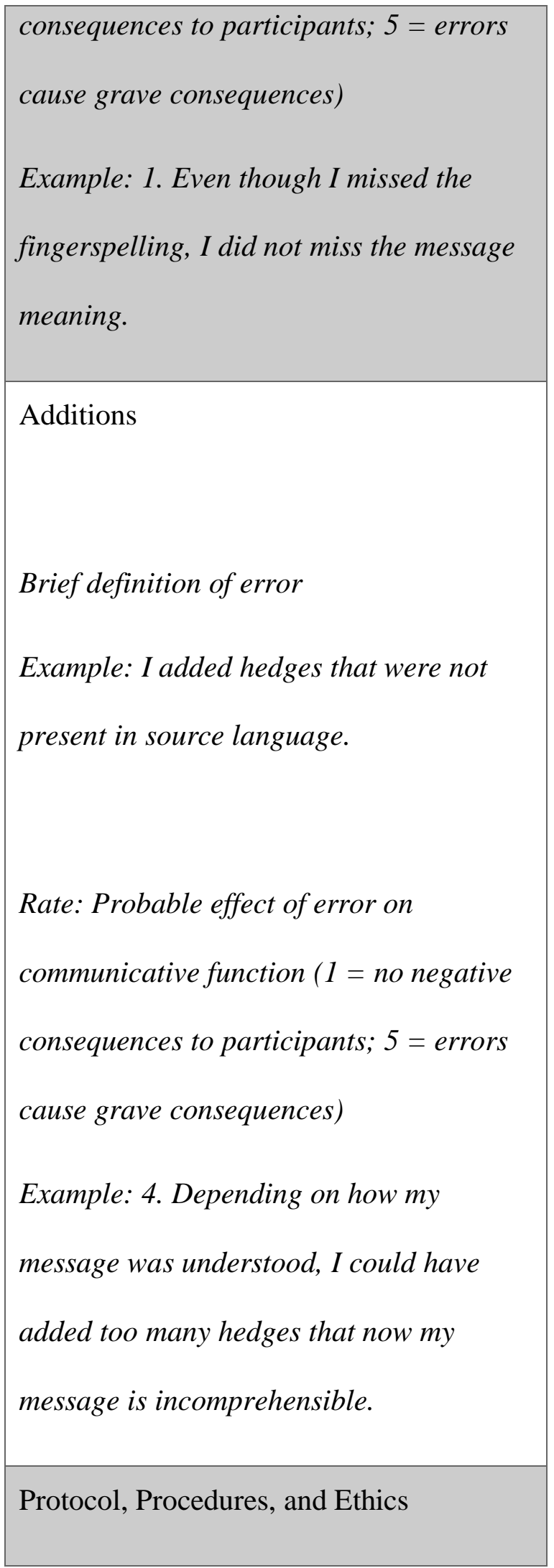




\section{Brief definition of error}

Example: I did not sign profanity because

I do not believe in those words.

Rate: Probable effect of error on

communicative function $(1=$ no negative

consequences to participants; 5 = errors

cause grave consequences)

Example: 5. I changed the affect (feeling)

of the message.

Non-conservation of paralinguistic

elements, hedges, and fillers

Brief definition of error

Example: Eliminated natural pauses to sign less and get straight to the point of the message 


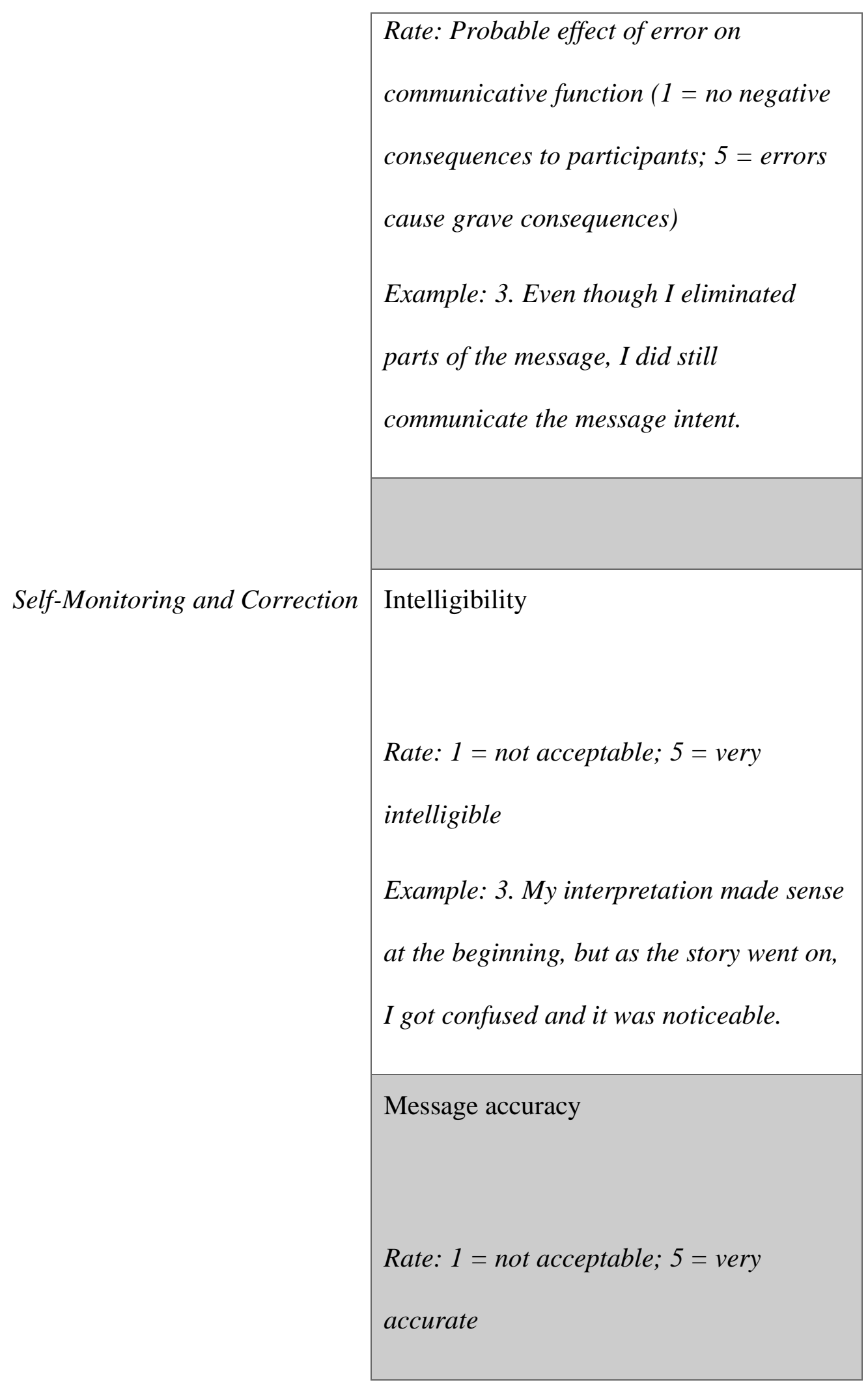


Example: 2. I understood the concept and used signs to communicate the speaker intent. However, I know I have areas where I can improve.

Illocutionary force

Rate: $1=$ not acceptable $; 5=$ very clear Example: 4. I matched the source message's intonation with my facial expressions and signs.

Fillers and repetitions

Provide examples. Did they greatly affect the meaning of the message?

Irrelevant comments

Did you add any comments or information that was not present in the source language? If so, what did you add? Why 
INSTRUCTIONS: Place (click and drag) the following circles around how you feel you have

done on the following five areas: sign production \& vocabulary, grammar, use of space, affect,

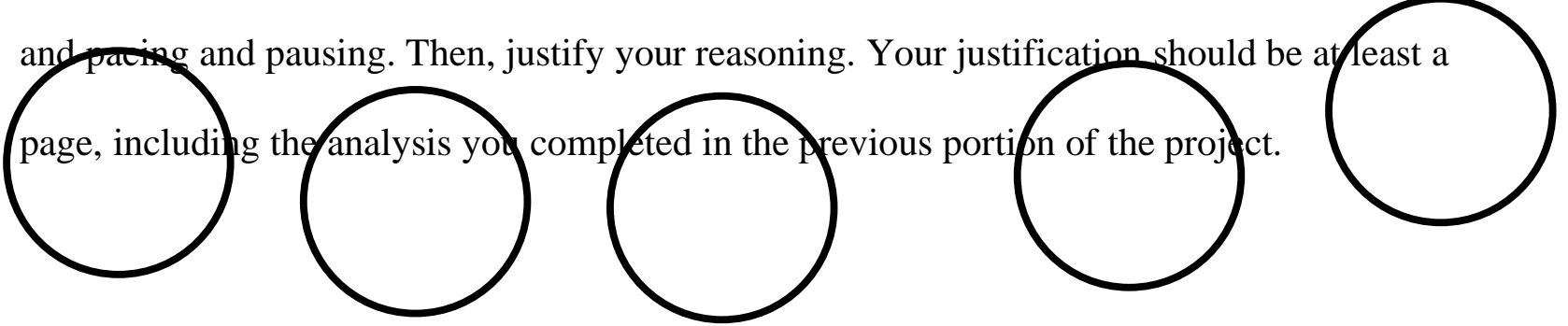

\section{Performance Rubric for ASL Interpreting}

\begin{tabular}{|c|c|c|c|c|c|}
\hline CATEGORY & $\begin{array}{l}\text { Sign } \\
\text { production \& } \\
\text { vocabulary }\end{array}$ & Grammar & Use of Space & Affect & \begin{tabular}{|l|} 
Pacing and \\
Pausing
\end{tabular} \\
\hline $\begin{array}{l}\text { Excellent } \\
\text { control }\end{array}$ & $\begin{array}{l}\text { High level of } \\
\text { equivalence between } \\
\text { SL and TL; produces } \\
\text { signs accurately, both } \\
\text { structurally and } \\
\text { conceptually; wide } \\
\text { range of well-chosen } \\
\text { vocab }\end{array}$ & $\begin{array}{l}\text { ASL syntax } \\
\text { successfully conveys a } \\
\text { wide range of } \\
\text { grammatical structures } \\
\text { (T/C, conditionals, } \\
\text { RHQs, etc.); ability to } \\
\text { use complete and } \\
\text { complex sentences }\end{array}$ & $\begin{array}{l}\text { Signing space is } \\
\text { appropriate; clear } \\
\text { establishment and use } \\
\text { of referents; excellent } \\
\text { use of spatial aspects } \\
\text { of expansion features }\end{array}$ & $\begin{array}{l}\text { High level of } \\
\text { equivalence between } \\
\text { source text and target } \\
\text { text }\end{array}$ & $\begin{array}{l}\text { Smooth and fluid } \\
\text { production; few to no } \\
\text { hesitations; pausing } \\
\text { where appropriate }\end{array}$ \\
\hline Good control & $\begin{array}{l}\text { Produces most signs } \\
\text { accurately, both } \\
\text { structurally and } \\
\text { conceptually; good } \\
\text { range of vocabulary }\end{array}$ & $\begin{array}{l}\text { ASL syntax conveys a } \\
\text { range of grammatical } \\
\text { structures (T/C, } \\
\text { conditional, RHQs, } \\
\text { etc.); mostly complete } \\
\text { sentences that are } \\
\text { complex, with few } \\
\text { errors }\end{array}$ & $\begin{array}{l}\text { Clear establishment } \\
\text { and use of referents } \\
\text { with few errors; } \\
\text { limited command of } \\
\text { spatial aspects of } \\
\text { expansion features }\end{array}$ & $\begin{array}{l}\text { Mostly successful } \\
\text { representation of } \\
\text { source text affect }\end{array}$ & $\begin{array}{l}\text { Production is relatively } \\
\text { smooth but contains } \\
\text { some hesitation and } \\
\text { unevenness. }\end{array}$ \\
\hline $\begin{array}{l}\text { Adequate } \\
\text { control }\end{array}$ & $\begin{array}{l}\text { Produces signs } \\
\text { inaccurately, } \\
\text { structurally and/or } \\
\text { conceptually; limited } \\
\text { range of vocabulary; } \\
\text { source text is } \\
\text { retrievable }\end{array}$ & $\begin{array}{l}\text { Source text rendered } \\
\text { faithfully with } \\
\text { occasional lapses and } \\
\text { elisions }\end{array}$ & $\begin{array}{l}\text { Establishment and use } \\
\text { of referents are not } \\
\text { clear, but meaning of } \\
\text { source text is } \\
\text { retrievable }\end{array}$ & $\begin{array}{l}\text { Offers fair } \\
\text { representation of } \\
\text { source text }\end{array}$ & $\begin{array}{l}\text { Production is } \\
\text { frequently besitant and } \\
\text { jerky }\end{array}$ \\
\hline $\begin{array}{l}\text { Weak (or no) } \\
\text { control }\end{array}$ & $\begin{array}{l}\text { Structural and/or } \\
\text { conceptual clarity of } \\
\text { signs is lacking; } \\
\text { limited } \\
\text { vocabulary...rendering } \\
\text { the source text } \\
\text { iretrievable }\end{array}$ & $\begin{array}{l}\text { Limited range of } \\
\text { grammatical } \\
\text { structures; incomplete } \\
\text { sentences that obscure } \\
\text { meaning }\end{array}$ & $\begin{array}{l}\text { Establishment and use } \\
\text { of referents are not } \\
\text { clear and rendered } \\
\text { message is not } \\
\text { retrievable }\end{array}$ & Affect is largely absent & $\begin{array}{l}\text { Production is slow and } \\
\text { choppy; excessive } \\
\text { pauses make } \\
\text { comprehension of the } \\
\text { source text difficult }\end{array}$ \\
\hline
\end{tabular}


Appendix E (continued)

Justification

During this interpretation, I committed [insert number] different errors. They were... I interpreted things like [insert glossing] when the speaker said [insert quote.] I attribute these errors to [insert source of error]. I believe that this error would affect my interpretation [nominally, mild, moderately, significantly, gravely] because... I found that I was good at [insert positive reflection] but need to focus on [insert constructive improvement suggestion]. 
Appendix E (continued)

Introductory assignment

Trip to Hong Kong (Exercise 4.1)

Please complete Exercise 4.1 on page 112 of your Simultaneous Interpreting from English text. Complete the Study Questions and Five-Step Follow-Up on pages 112-116.

Please utilize YouTube to record and post your video. You may list the video as "Unlisted" to keep your information private. Please share your video on the “Trip to Hong Kong (Exercise 4.1)" Discussion Board.

Then, proceed to the CONSTRUCTION assignment in this week's folder. 
Appendix E (continued)

Week 6 Assignment

\section{SPEECH}

In this grave hour, perhaps the most fateful in history, I send to every household of my peoples, both at home and overseas, this message, spoken with the same depth of feeling for each one of you as if I were able to cross your threshold and speak to you myself.

For the second time in the lives of most of us, we are at war.

Over and over again, we have tried to find a peaceful way out of the differences between ourselves and those who are now our enemies, but it has been in vain.

Now, it is time to answer some questions (and get some search engine practice!).

- Who made this speech?

- What is the context?

- How does the context inform the speaker? $\bigcirc$ In other words, think about why the speaker might have chosen the words that he did.

- About what is this speech?

- This speech is considered "great" (by some). What makes this a "great" speech?

Let's start our interpreting process.

INSTRUCTIONS

1. GLOSS: Take time to gloss this speech into ASL. This glossing assignment is due by Wednesday, September 23, 2020 at 11:59 PM. You will submit this assignment via Blackboard. Failure to submit this assignment on time will result in a $10 \%$ grade deduction.

2. FIRST DRAFT: Give it a whirl. This draft is due by Wednesday, September 23, 2020 at 11:59

PM. You will submit the assignment via Flipgrid. Failure to submit this assignment on time will result in an additional 10\% grade deduction.

3. SELF-INTERPRETATION. Voice for yourself. If it doesn't make sense, you probably should adjust your plan. You will submit this voicing assignment on Blackboard. This self-interpretation is due by

Friday, September 25, 2020 at 11:59 PM. Failure to submit this assignment on time will result in an additional $10 \%$ grade deduction.

4. FEEDBACK: You know the drill. You will submit your feedback on Flipgrid. Feedback is due by

Friday, September 25, 2020 at 11:59 PM. Failure to submit this assignment on time will result in an additional $10 \%$ grade deduction. 
Appendix E (continued)

5. FINAL DRAFT: Submit it. This final draft is due by Sunday, September 27, 2020 at 11:59 PM.

Failure to submit this assignment on time will result in an additional 10\% grade deduction. 
Appendix E (continued)

\section{ASSIGNMENT: Critical Discourse Analysis (CDA)}

This week, we are going to put a name to this process we have been working on all along, a process called Critical Discourse Analysis (CDA).

Please be sure to read this article on Critical Discourse Analysis to better understand what you are doing.

Your understanding of CDA will be assessed in this assignment.

Hello, come in. Nice to meet you. I understand that you wish to talk to me about your daughter's schooling. Now she's hearing impaired, too, isn't she? And she's currently at Cherry Tree Juniors, and you want her to be transferred to the old Deaf and Dumb school/ Actually, you know, my great aunt was hard of hearing, and I learned some of the sign language myself when I was in the Brownies. Of course, that's quite a few years ago now, but I still remember a bit of it... That's A, isn't it? Yes, very good. Can you lipread me all right?

I would like you to answer the following two questions:

1. What does the text mean?

2. What do you know about the speaker of the text?

\section{Your response should be at least a page in length and should reference the CDA article attached here.}

Note: I am providing you with as little guidance here on purpose. I want to know what you think. 
Appendix E (continued)

\section{Week 5 Assignment}

This week, we are going to analyze a passage with a much different audience than our last two assignments. Let's try working with elementary educational-level content. This passage is a children's story.

Here's the text:

When Donkey gives his friends their new backpacks, his friends thank him profusely, and make plans to take their lunches in their new backpacks. They invite Donkey along, and this is when he realizes he had forgotten to make a backpack for himself. He goes back home, and works all night making a backpack for himself. In the end, they all enjoy their new backpacks.

Now, I know it is really short. That means that I am expecting you to use a lot of descriptive signs and take your time preparing this interpretation.

EXTRA CREDIT OPPORTUNITY: If you can interpret this short story in all classifiers, I will give you an extra $10 \%$ on your first project, coming up 
shortly! Your projects are worth $40 \%$ of your total grade! An extra $10 \%$ on your project would be very helpful.

Things to turn in:

Appendix E (continued)

1. Glossing of passage: Please gloss the entire passage. You will submit a .docx or a .pdf to Blackboard.

2. First draft of interpretation: Please interpret the prompt. You will submit a video on Flipgrid.

3. Feedback: Please provide feedback of your peers' interpretations. You will submit your feedback on Flipgrid.

4. Final draft of interpretation: Please record your final interpretation of the prompt. You will submit this video again on Flipgrid.

Each of these assignments is due no later than Sunday, September 20, 2020. However, remember that your delay to post your initial interpretation, for example, affects you and your peers. No late assignments will be accepted. 
Appendix E (continued)

Flipgrid Instructions (week 3)

Hey, y'all!

I wanted to send you better instructions on how to join the Flipgrid section for our ITTP 2203 course this fall.

As I told you in my announcement email, we will be utilizing Flipgrid to submit our assignments (including our vlogs) rather than YouTube. While I know we started out with YouTube, I do not want your information to be as easily accessible by others. Even when a video is "unlisted," it can be found. Flipgrid provides us an extra layer of personal protection and I think that is important for all of us.

"Flipgrid? Professor South, what is this?"

I got you. () Flipgrid course registration link: click here

To register for Flipgrid:

1. Click this link

2. Click "Join with Google."

3. Enter your Pierpont.edu email address

4. Voila! Welcome! 
Appendix E (continued)

\section{Concept Map Assignment}

This week, I want us to take a moment to look at comprehension from the perspective of analysis. You are tasked to create a concept map.

Not sure what a concept map is? Check this out.

For this concept map, you will be mapping the following sentence:

$$
\text { Been there, done that. }
$$

You know the phrase in English. We use it often. How does this concept get conveyed to a Deaf individual? Here are some questions to get your brain buzzing about how this statement could be interpreted. These questions are written to help you make sense of the true meaning of the statement:

- Why do people use this expression?

- In what contexts do you use this expression?

- Do you have to have physically visited a place to make this expression applicable? Why?

- Do you know of other ways of saying this same message, but with different words? Make a list.

- What are these expressions? 
- What do they mean?

Appendix E (continued)

Be sure to look at and comment on at least two of your peers' concept maps. Provide helpful feedback. Utilize the following guidelines to understand how to provide constructive feedback to your classmates. 
Appendix E (continued)

\section{Vlog 2 Prompt}

Before we get started into really interpreting, I wanted us to take a moment to think about the process of simultaneous interpreting. Now that we understand more about what it is, let's take some time to reflect.

What are your initial takeaways from your newly gained insight?

$\circ$ Maybe the article seemed to *exaggerate ${ }^{\star}$ the process of interpreting. You don't think it's really that hard.

O Or maybe you were intimidated by the article and question your decision to make a career out of interpreting.

Either one of these reactions is perfectly fine. I am not here to judge you. But please, don't give up without talking to me first.

$>$ How do you think you need to develop your simultaneous interpreting skills this semester?

What steps will you take to support your learning? Map out at least three things you will do to support your growth as an interpreter.

Record your video in YouTube. Please mark the video as "Unlisted," to protect your privacy. Please share the link with me under SUBMISSION: Vlog 2. 
Appendix E (continued)

Introductory video

Welcome to ITTP 2203! I cannot wait to work with all of you this semester and to learn more about each of you.

To start this semester off right, l'd like for you all to record your very first introductory video! You are welcome to talk about whatever you'd like, but l'm including some prompts, in case you get stuck:

- What is your name?

Do you have a sign name? If so, what is it?

- Where are you from?

- What do you like to do for fun?

- Is there a topic you really like studying (not directly related to interpreting)?

If so, what is it? Why do you like this topic?

- How do you think this knowledge base will assist you in your interpreting profession?

- What do you like the most about interpreting?

- What is your greatest interpreting challenge?

- What questions do you have for your instructor?

- What questions do you have for your classmates?

Please utilize YouTube to record and post your video. You may list the video as "Unlisted" to keep your information private. Please share your video on the "Introductory Video" Discussion Board. 
If you have issues, please use the resources here! They are meant to guide you through the process. 
Appendix E (continued)

One-on-one with Professor South

We are all busy. I know throughout the semester we will have obligations that take us away from our schoolwork (hopefully, not for too long!). So, I want to take the time to talk with you now!

Before we are able to do this, please take a look at the following document:

Cover Letter. Keep this information.

I have the following dates and times available.

\begin{tabular}{|l|l|l|}
\hline $\begin{array}{l}\text { Tuesday, August 18, } 2020 \\
\text { at 10:00 AM }\end{array}$ & $\begin{array}{l}\text { Tuesday, August 18, } 2020 \\
\text { at 11:00 AM }\end{array}$ & $\begin{array}{l}\text { Tuesday, August 18, } 2020 \\
\text { at 12:00 PM }\end{array}$ \\
\hline $\begin{array}{l}\text { Wednesday, August 19, } \\
2020 \text { at 10:00 AM }\end{array}$ & $\begin{array}{l}\text { Wednesday, August 19, } \\
2020 \text { at 11:00 AM }\end{array}$ & $\begin{array}{l}\text { Wednesday, August 19, } \\
2020 \text { at 12:00 PM }\end{array}$ \\
\hline $\begin{array}{l}\text { at 10:00 AM } \\
\text { Friday, August 21, 2020 } \\
\text { special appointment }\end{array}$ & $\begin{array}{l}\text { Friday, August 21, 2020 } \\
\text { special appointment }\end{array}$ & $\begin{array}{l}\text { Friday, August 21, 2020 } \\
\text { special appointment }\end{array}$ \\
\hline
\end{tabular}

Please email me with your date and time selection. This meeting is mandatory. Even if you decide not to have your information documented for research, I still need to meet with you to discuss what challenges, concerns, or prowess you have. I want to make this course an effective learning experience!

Of course, if you have any questions, please contact me. I'm here to help you! 
Appendix E (continued)

Simultaneous and Consecutive Pre-Test

This test is not for a grade. Rather, I want to understand where you are in your interpreting skill so that we may build on your established abilities and develop those ready to be honed.

- Simultaneous interpreting: Simultaneous Interpreting from English, Page 34, Exercise 1.1, "My Big Move" by Lorraine Oldham

- Consecutive interpreting: Consecutive interpreting from English,

Page 52, Exercise 2.1, "Newspaper Layout" by Amber Lewnes

Please utilize YouTube to record your video. You may list this as

"Unlisted" to protect your information. Please submit your YouTube video link the SUBMISSION: Simultaneous and Consecutive Pre-Test Assessment location.

Refer to the included instructions for help with any of the processes required to submit your assignments. 
Appendix E (continued)

Survey

In hopes of helping all of us learn a little more about ourselves, I want you to complete the following survey. https://wvu.qualtrics.com/jfe/form/SV cUwOp5a0m9B4QiV The completion of this survey should take no more than 30 minutes to complete.

You will be utilizing this feedback and information to help shape your first Vlog assignment. 
Appendix F: Interpreting Process Diagram
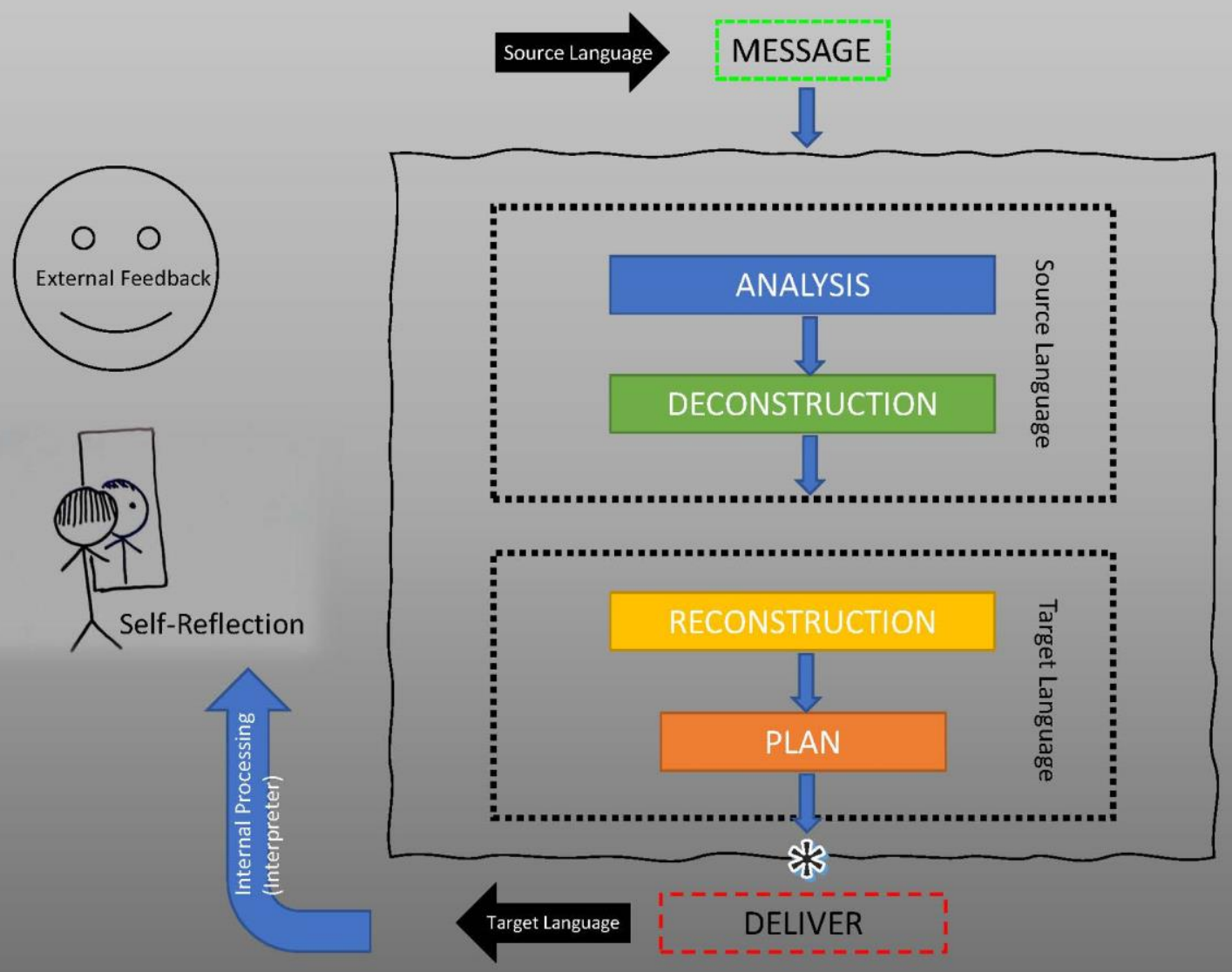

At this point, new incoming source
language message can begin processing.

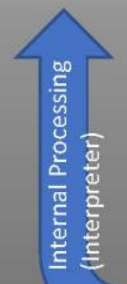


Appendix G: Vlog questions/prompts

Vlog Prompt

$1 \quad$ How do your results affect your self-perception as an interpreting professional?

What are your initial takeaways from your newly gained insight? How do you think you need to develop your simultaneous interpreting skills this semester?

What steps will you take to support your learning? Map out at least three things

2 you will do to support your growth as an interpreter.

You completed your first interpretation. What did you think? How did you do? What did your colleagues point out? Do you agree with them? If you do, how are you taking advantage of these opportunities for improvement? If you disagree with your classmates' feedback, why? What do you think you need to work on? Why?

3 How will you address these issues?

Why would someone (like an agency owner) pick you over another interpreter to work on an interpreting assignment, like this one? Even if you do not want to interpret in this assignment, imagine you do. Over all of the other interpreters, why

$4 \quad$ should an agency owner choose you?

What do you think about your progress thus far? What have you really excelled on? Have your peers brought up valid concerns? If so, how will you address those concerns? If not, what do you believe you have an opportunity to improve on? How will you take steps to improve your skills as an American Sign Language

5 interpreter?

What is something that no one would guess about you? What do you believe in? (NOTE: The response to this question is open to wide interpretations and should not be perceived in any specific light, other than the vast spectrum of the world of "things.") If you could be doing anything, anywhere right now, what and where would it be? What do you wish you had done differently in your life? What are you doing to improve yourself? What is one thing you've had to overcome in your life? What is the most important thing to you? What is your life motto or philosophy you live by? What is your biggest dream? What was the best time of

6 your life?

How have you developed your skills as an interpreter? Provide at least three examples of how you have improved over the past 7 weeks. What more do you want to work on? How can I help? How can we work together as a class to help

7 you become the interpreter you want to be?

What is my ideal definition of success? Is this definition well-rounded to include all the important aspects of my life? What are my top three values and how do they apply to my interpreting? Do I factor in these values when I make interpreting and

8 personal decisions?

Using 10 words, describe yourself in English. Using 10 signs, describe yourself in American Sign Language. Reflect. Do your signs change how you are

9 "represented?" How so? 
Write a list of questions to which you urgently need answers. Come up with at least five (5) questions. These questions can be related to the interpreting field, professional development, school (in general), or anything you want! If you're looking for inspiration, think about what you feel is your biggest challenge in 10 interpreting. Go from there!

What is vicarious trauma? How does an interpreter experience vicarious trauma? Do you believe vicarious trauma could affect you as an interpreter? What will you 11 do to take care of yourself? 
Appendix H: NCIEC ASL Performance Interpreting Rubric

\section{Performance Rubric for ASL Interpreting}

\begin{tabular}{|c|c|c|c|c|c|}
\hline CATEGORY & $\begin{array}{l}\text { Sign } \\
\text { production \& } \\
\text { vocabulary }\end{array}$ & Grammar & Use of Space & Affect & $\begin{array}{l}\text { Pacing and } \\
\text { Pausing }\end{array}$ \\
\hline $\begin{array}{l}\text { Excellent } \\
\text { control }\end{array}$ & $\begin{array}{l}\text { High level of } \\
\text { equivalence between } \\
\text { SL and TL; produces } \\
\text { signs accurately, both } \\
\text { structurally and } \\
\text { conceptually; wide } \\
\text { range of well-chosen } \\
\text { vocab }\end{array}$ & $\begin{array}{l}\text { ASL syntax } \\
\text { successfully conveys a } \\
\text { wide range of } \\
\text { grammatical structures } \\
\text { (T/C, conditionals, } \\
\text { RHQs, etc.); ability to } \\
\text { use complete and } \\
\text { complex sentences }\end{array}$ & $\begin{array}{l}\text { Signing space is } \\
\text { appropriate; clear } \\
\text { establishment and use } \\
\text { of referents; excellent } \\
\text { use of spatial aspects } \\
\text { of expansion features }\end{array}$ & $\begin{array}{l}\text { High level of } \\
\text { equivalence between } \\
\text { source text and target } \\
\text { text }\end{array}$ & $\begin{array}{l}\text { Smooth and fluid } \\
\text { production; few to no } \\
\text { hesitations; pausing } \\
\text { where appropriate }\end{array}$ \\
\hline Good control & $\begin{array}{l}\text { Produces most signs } \\
\text { accurately, both } \\
\text { structurally and } \\
\text { conceptually; good } \\
\text { range of vocabulary }\end{array}$ & $\begin{array}{l}\text { ASL syntax conveys a } \\
\text { range of grammatical } \\
\text { structures }(\mathrm{T} / \mathrm{C} \text {, } \\
\text { conditional, } \mathrm{RHQ} \text {, } \\
\text { etc.); mostly complete } \\
\text { sentences that are } \\
\text { complex, with few } \\
\text { errors }\end{array}$ & $\begin{array}{l}\text { Clear establishment } \\
\text { and use of referents } \\
\text { with few errors; } \\
\text { limited command of } \\
\text { spatial aspects of } \\
\text { expansion features }\end{array}$ & $\begin{array}{l}\text { Mostly successful } \\
\text { representation of } \\
\text { source text affect }\end{array}$ & $\begin{array}{l}\text { Production is relatively } \\
\text { smooth but contains } \\
\text { some hesitation and } \\
\text { unevenness. }\end{array}$ \\
\hline $\begin{array}{l}\text { Adequate } \\
\text { control }\end{array}$ & $\begin{array}{l}\text { Produces signs } \\
\text { inaccurately, } \\
\text { structurally and/or } \\
\text { conceptually; limited } \\
\text { range of vocabulary; } \\
\text { source text is } \\
\text { retrievable }\end{array}$ & $\begin{array}{l}\text { Source text rendered } \\
\text { faithfully with } \\
\text { occasional lapses and } \\
\text { elisions }\end{array}$ & $\begin{array}{l}\text { Establishment and use } \\
\text { of referents are not } \\
\text { clear, but meaning of } \\
\text { source text is } \\
\text { retrievable }\end{array}$ & $\begin{array}{l}\text { Offers fair } \\
\text { representation of } \\
\text { source text }\end{array}$ & $\begin{array}{l}\text { Production is } \\
\text { frequently hesitant and } \\
\text { jerky }\end{array}$ \\
\hline $\begin{array}{l}\text { Weak (or no) } \\
\text { control }\end{array}$ & $\begin{array}{l}\text { Structural and/or } \\
\text { conceptual clarity of } \\
\text { signs is lacking; } \\
\text { limited } \\
\text { vocabulary...rendering } \\
\text { the source text } \\
\text { irretrievable }\end{array}$ & $\begin{array}{l}\text { Limited range of } \\
\text { grammatical } \\
\text { structures; incomplete } \\
\text { sentences that obscure } \\
\text { meaning }\end{array}$ & $\begin{array}{l}\text { Establishment and use } \\
\text { of referents are not } \\
\text { clear and rendered } \\
\text { message is not } \\
\text { retrievable }\end{array}$ & Affect is largely absent & $\begin{array}{l}\text { Production is slow and } \\
\text { choppy; excessive } \\
\text { pauses make } \\
\text { comprehension of the } \\
\text { source text difficult }\end{array}$ \\
\hline
\end{tabular}




\section{Appendix I}

Interview 1 with Maggie

Danielle: Hey, I think I can hear you now.

Maggie: Oh, I can hear you now.

Danielle: Yay. You did it. There we go. Oh my gosh. I know what you mean because the call over internet makes no sense. I'm like, why are you talking about it like that? I'm so glad you got it. Thank you for not giving up.

Maggie: I was struggling.

Danielle: That's okay. It's okay. It's been a semester. It's day three and I'm already panicking.

Maggie: I am like that every semester. The first start of every semester stresses me out to no end. It takes me forever to figure out Blackboard and differentiate what has to be actually done and what they are posting for later assignments and it confuses the crap out of me.

Danielle: That was going to be my first question for ya is just making sure that you don't have any questions about the way our Blackboard is currently set up. My goal is to not give you access to too much. So, right now, you should see Week 1 and only material for Week 1. I don't want to confuse anyone. I know what you mean. It can get very confusing. It is too much. So, I am going to try really hard to keep everything just based on the week so that no one gets confused like that.

Maggie: Oh, that's amazing.

Danielle: Hopefully. We will see what happens, right? Any other questions about the way Blackboard is currently set up? Does everything look okay?

Maggie: I have used Blackboard before, but when all the assignments get posted, I get overloaded. I have to go through every single one to figure out which ones to do and it just stresses me out.

Danielle: You will always see the folder for me. I will do a folder and assignment. I will 
basically try to enumerate as best as I can. You have four for this first week. So, I will do the first and second. Inside each of those is a submission link to keep you from getting confused. I am trying really hard to make it as clear as possible. If you get confused, please let me know. I know exactly what you mean. I had an all-online program, too, and it was, it was an experience. You learn quickly that people don't know how to organize stuff online and you're like, "I need help! This is not okay."

Maggie: Yeah. I went through that last semester. Last semester, I ended up overloading myself.

Danielle: Okay.

Maggie: I took ten classes.

Danielle: Maggie!

Maggie: That was a bad idea.

I got it all done with As and Bs, but oh my god. I was so stressed from the beginning of the semester to the end of the semester trying to keep up with everything.

Danielle: Ten?

Maggie: It was a bad idea.

Danielle: I took 21 credits one time, one semester because I'm an alum of the same program you are in. It was like, it was too much. It was too much. I couldn't handle it. Thank goodness Ruby let me test out of some of the classes. She let me test out of fingerspelling class. So, thank goodness she let me test because I would have cried the entire time. It would have been awful. 21 credits is too many. 30 is unimaginable.

Maggie: There was a bunch of classes I could have tested out of but I'm so far away so I'd spend more money going down there to test out of the course than I would just taking the course.

Danielle: Just take the class. 
Maggie: Yeah, but at the same time, last semester, I sat down with my cousin and I was ready to rip my hair out. I didn't know what I was doing. I had too many assignments and was so lost.

Danielle: That's what happens. I hope we can avoid that in simultaneous and consecutive because this is like the bread-and-butter of interpreting. I mean, sign-to-voice and voice-to-sign, the pre-requisites are pretty, don't get me wrong, that's really breaking it down, but doing the simultaneous and consecutive process is teaching your brain to do what you need to do for everything. That's how these all work together, so hopefully we don't overload you again. How many classes do you have this semester? Hopefully not ten.

Maggie: This semester I only have four.

Danielle: So, you decided to come back to normalcy.

Maggie: Yes. I am living with my cousin. I went through a big schpeal a year or two ago. Everything was a nightmare. That's when I decided I was going back to college to get my life in order.

Danielle: Good for you.

Maggie: I broke down and told my cousin everything. I was living in my car. I lost my trailer. I had a psycho ex that was stalking and harassing me. It was bad, so I broke down and told her everything, so she let me move in and that's when I went back to college.

Danielle: Good for you.

Maggie: But I am living in someone else's house. I want my own place, but I can't do that until I get money saved up. I am trying to get it done as fast as possible and it did not work.

Danielle: It did though. I am sure you did learn. That's a lot. Your cognitive load, the amount your brain could handle is limited but you got As and Bs. You are no slacker. You can make it work. That should have shown you what you can handle. That's a good place to be. Not a lot of people can say that. Not a lot of people can take 10 classes and pull As and Bs. Some of the classmates you have can't take four classes and get As and Bs, so you taking 10 - that's definitely a win. You are definitely going to pull through on all this stuff it's just a function of doing it.

Maggie: Yeah. Well, I have been interpreting my entire life. My mom is deaf. I grew up 
interpreting for her. I grew up interpreting for her friends. A lot of this I already know. The main thing that I ever struggled with ...

Danielle: You just need the piece of paper?

Maggie: I struggled with translating ASL to English and sign. I can talk ASL. I can talk English and sign, but I cannot translate it. I get so confused trying to process it and talk it at the same time. That I switch back and forth.

Danielle: That's what our job is. That's what we are going to work on this semester. And that's actually one of my questions. I will let you know, I want to preface this, I am utilizing this opportunity and experience in speaking with you guys as part of my dissertation research, so I am -- just a little bit about me. I am a Ph.D. student at WVU, West Virginia. I don't know where you are. Are you in the state?

Maggie: Yeah, I live in Beckley, WV.

Danielle: Okay. I was not sure where you were. You said you were far away, so I didn't know if you were out of state or still here.

I am working currently on collecting data. That's part of what we are doing right now. In terms of really understanding the way that I can help students online, first of all, the process of interpreting is not easy in-person. It is certainly not easy online so really my background is in instructional design and languages and that's how I ended up where I'm at right now. So, we are going to work on how I can best teach it, how you guys respond to it, if it is helpful, not helpful.

What that means is at any point during the semester, if something happens, then please let me know that it does not work. If you feel like you are being overloaded, you have colleagues who have told me that in the past, some professors didn't answer emails until three days later after the assignment was due. Things like that.

First of all, I'm sorry that it happened because that's not okay. But, second of all, if that's happening I need to know that my timing is not okay. I will not wait three days; I don't do that, but I need to know that you need quicker feedback. We can find ways to do that. The beauty of teaching online is how much technology we have access to. The struggle with teaching online is how much technology we have access to. Sometimes, it's too much. So, what's good is also bad. I want to make sure that you know, too.

If something happens and something pops up and you think something is not going how you 
think, let's change it. I am open to that. I know you and I had our initial email, but I'm also obviously not holding it against anybody. I am a very upfront person. You know because you grew up with Deaf people. They are very upfront people. I ascribe to the same thing. I think hearing people get uncomfortable with that. I don't do it to hold a grudge.

Maggie: I just get my point across firsthand. I'm the same way.

Danielle: Then I can just move on. I definitely want you to know if at any point during the semester something is not working, please tell me. That is my job, but it is also my research. I want and need to know so that I can fix it and we can make this better.

\section{Maggie: Okay.}

Danielle: The same thing goes for, if you are not comfortable with, I will make sure that all of your information is anonymous. So, that said, that means that your name, the name of the institution, the program, all of it will be removed. When I am publishing anything, my goal is to make it untraceable that someone would look at the information and not know it is Pierpont. No one has a clue, so you don't have a tie to it.

If you don't feel comfortable, you can always reach out to Jamie so, if you don't feel comfortable reaching out to me about it, you can always reach out to her and let her know you don't want your information to be included anymore. I will get rid of it. You are not obligated by any means. If you ever get uncomfortable, you can always tell Jamie that you are not comfortable anymore. So, that's definitely an option.

Maggie: Okay.

Danielle: Okay.

Maggie: I had a quick question. I was reading over your syllabus last night. It popped up that I had to have two different books for this class.

Danielle: The texts that are listed there are ones that other classmates have, people who have taken the course. So, truthfully, you could get away with just having the simultaneous book, the green one.

Maggie: I have that one. I just wanted to make sure I didn't need to order another one. I was halfway there. 
Danielle: No. For the second one, we will only use two chapters, I will get you those pages. We will do it that way. Especially after looking through what we are really doing, there's no reason for you to do that. The simultaneous one is bigger. That's the more frequent process and I would argue the more difficult process. The consecutive, we are going to do and go through and in what context, but really, it's not, they're not so different. We can bridge the gap and keep talking. I will give you those pages.

Maggie: Thank you.

Danielle: Of course.

I know this will be a silly question, especially since you told me you are a CODA, so I know that is a big reason for this question, but why did you decide to major to be an interpreter? What made you decide that this is where you wanted to be just in general?

Maggie: I don't know. My mom started teaching me sign language when I was 3, so I grew up doing it. And, out of my two older brothers, I was the only one that really adapted to sign language. They were always fingerspelling. My one brother that I used to be really close to before he passed, he would fingerspell a word and then do a keyboard thing for space in between the words.

Danielle: Oh my gosh, stop. That's so funny. That's so cute. I love that.

Maggie: It made him so hard to understand when he was signing. I could not help but laugh.

Danielle: That's the Rochester Method. That stuff will exhaust you. That's something else. That's so funny. The space bar, though. That has me dying. Space bar. [Laughs.] That's a new one. I have never heard that but that's funny.

Maggie: Yeah, watching him sign was hilarious. You would have to struggle to understand him because of that space. We were like, wait a minute? What are you doing?

Danielle: So, you were comfortable with sign from the beginning though? That wasn't a difficult thing for you. You started at 3 and adapted pretty quickly to that.

Maggie: Yeah. I fell in love with the language. I looked forward to going to Deaf events with 
Mom: The pig roast, the WVSD reunions. I loved going. I grew up with Ruby and it is weird now because she's my teacher. I have known her since I was little. Then, what really set me to become an interpreter was one of my mom's best friends had a college graduation. I was only 13 or 14 at the time and her interpreter never showed up.

So, she was down there and she was bawling because she couldn't understand anything they were saying at her own graduation. And, the person who was in charge of hiring the interpreter. I was here and my mom was next to me. He was there. They kept trying to get her daughter to go down and sign. She was older and technically a little better at signing than I was at that time.

They were pushing her to go down there but she refused because there was so many people.

[Dog barking]

[Shut up.]

[Laughs]

I'm sorry.

Danielle: No, it's okay. Don't you love when they sass you back just one more time and they have something small back to say? What butts.

Maggie: That's my dog.

Danielle: [Laughs]

Maggie: She is like a kid. She has to have the last word.

Danielle: I have a large puppy, she is a year ish. She is a rescue. Who knows how old she actually is, but she's a 75 pound puppy and when she lays on my lap. When I want to get her to stop doing something, she's like, "I don't want to." She uses her whole body as a weapon. They're sassy.

Maggie: We have a pit-lab mix who does the exact same thing. 
Danielle: Yeah. She's a Doberman, Mastiff thing so she's goofy so she's just a wiggle butt and so sassy. I think it's a female dog thing. They have way more to say than male dogs do. Male dogs just calm down. Female dogs just have something to tell ya. Like women, right? We always have something to say back.

So, did you get to interpret? Was that your life changer?

Maggie: Yeah, pretty much. They spent about 10-15 minutes trying to get her to go down. And then, they looked at me. At first, I just looked around at how full the gym was and then I was like, "Eh, oh well. I will try." So, I walked down there and I did it. And then at the end of it, when they started doing the names, after the speeches and everyone was walking, that was when her interpreter showed up. Yeah ... they were mad.

Danielle: They should have been. That's so messed up. Especially too, why not give someone a heads up about what's going on? I've been late to assignments before and interpreted while driving on FaceTime. That's not suggested. I'm not saying that's the best plan of action, but I don't leave clients without interpreters. If I'm late, that's on me, but I won't leave you without communication access. You can't do that to somebody.

Maggie: That's the way it should be.

Danielle: I don't suggest driving while interpreting.

Maggie: But I've done it before.

Danielle: But, that's so critical. I mean, kudos to you for getting up and doing it anyway. That's intimidating. When you have all those people staring at you, it's intimidating.

Maggie: Oh, yeah. My mom has a video of me standing up there. You can see my knees shaking. And, whenever there was a pause in someone's speech, I would apologize for messing things up.

Danielle: I hope you learned not to do that now. I hope you don't apologize now. I hope you understand now how much you probably capture and can communicate because you grew up with the language. You have been doing this for so long. We have to start somewhere. I hope you got through that.

Maggie: I've gotten better at it. I wouldn't say I don't still do it. I still kind of do, but I'm as bad 
at it.

Danielle: That's okay. It's different when it's your own words. I appreciate that. I'm guessing that you're pretty confident in your decision to be an interpreter? You feel like this is where you're supposed to be.

Maggie: Once I walked off that stage, or the gym floor, and the dude who hired the interpreter talked to my mom to make sure this was okay, but he took what the interpreter's pay was supposed to be and gave it to me. And, then told me that even though I was the youngest he had ever met, that I was one of the best that he had seen. I was like 13 or 14 at the time so that meant the world to me.

Danielle: So, when you think about the definition of a sign language interpreter, that's the kind of impact you're supposed to make. It's funny though when you think about how many people come up to you after you're done interpreting and tell you how great of a job you did. Like, man, you have no idea what I said. I could have been signing Spongebob Squarepants. You have no clue. You just think it looks great so you say something, but when you have people who mean it because they've been involved for a while, and they congratulate you, that changes everything.

Maggie: It does.

Danielle: It means so much. So, how would you define the title of being a sign language interpreter? Or, if someone said, "What does a sign language interpreter do?" what would you say?

Maggie: I have never thought of that question, even though I've been asked that a million times.

Danielle: So, what do you tell people? So, you are majoring in sign language interpretation. What is that? What's your answer?

Maggie: It's sign language. It's speaking ASL and translating to the person beside you who can't hear.

Danielle: Okay. And then what about the role then that you play in that dynamic? In between a hearing person and a Deaf person? Or multiple Deaf people if I have a Certified Deaf Interpreter with me, what's your spot in the middle of that? Why are you there? What's your role?

Maggie: My spot is to make sure that the Deaf community doesn't get left out. Like, it would 
be no different than a bunch of hearing people going to a concert and having all the sound equipment mess up but all the lights still work. Then, the interpreter can stand there and all the Deaf community can see everything. They know what's being said, but all the hearing people in the back, they don't have any sound. They don't know what's going on. It's the same thing with the roles reversed.

Danielle: Yep. Okay. Alright, so it's bridging communication to make sure everybody has access to the same information. Whatever that person decides to do with that information is their own thing, but they at least have that information. I hear that.

Do you feel like you're an interpreter? Like, if someone said, are you an interpreter? You are going through this program but aren't you already since you've been interpreting since you were three? I mean not really three, but you know what I mean.

Maggie: Pretty much, yeah.

Danielle: Okay, so would you say you're an interpreter?

Maggie: Yeah, I'm just not certified.

Danielle: Is that because you have done it? What makes you feel like you've gotten to that point in your life because not everyone is there? What have you gone through to get you there?

Maggie: I feel like after watching, because at one point, my mom decided she didn't want to put that stress on me for interpreting all of her doctor's appointments, and the school meetings, and everything else. She was just going to go through companies and get interpreters. And, I met this one interpreter at one of my mom's doctor's appointments up in Maryland and I have never been so disappointed in someone who is certified.

Danielle: Isn't that heartbreaking?

Maggie: It is and it is so infuriating because you just want to yell at them. What are you doing here?

Danielle: Yeah.

Maggie: You are not even trying and I can see that you're not even trying. 
Danielle: Yeah, and shame on them for still being in the community, for still being involved. Shame on you. Pick a different thing. If you don't care, you should go somewhere else. If you care about something else, that's great but you clearly don't care about this.

Maggie: I feel like interpreting is something you have to love. You either have to be in love with the Deaf community and the Deaf World or everything, or you have to be physically in love and have that passion for the language.

Danielle: Yes. Or both.

Maggie: You either have to have one, or the other, or both. Otherwise, you just don't do your job, I feel like.

Danielle: Yeah. So, for me, for example, so I have been in so many contexts, right? I have interpreted VRI-legal, VRI-medical. I've interpreted in-person medical; never done in-person legal. I've done on-site post-secondary education. I've done remote post-secondary education. I've done, goodness, you think of it, I've done it. Social security administration: I've done it. Presidential speeches: I've done it. I interpreted for Bernie Sanders; I've done it. Anything you can think of, I've probably done it and interpreted it, but I got to a point where I could no longer take the oppression and frustration that Deaf people experience on a day-to-day basis and do nothing. I couldn't do it anymore. I was interpreting for 15 years; I started around 14. At some point, you just say, "Okay. I'm exhausted. I need to be in this but I can't interpret anymore. I can't be part of it" because it gets heartbreaking, especially when you can do nothing. Because as an interpreter, you are not supposed to do anything but communication access. You are not supposed to step in.

Maggie: You are not supposed to say or do anything other than relay the information being said.

Danielle: That's hard. Being an advocate is not where I want to be either. That's also difficult and exhausting, but at least I'm in the role in that advocacy position to speak up, but as an interpreter, I can't do it. I am not an advocate. That's not my goal. My goal is to teach interpreters. I love talking about interpreting. I geek out about it. It's the best thing ever but doing it is a whole other thing. That passion in some way for the language, for the culture, or both has to be there in order to give that fire when you are geeking out to actually care about what you're doing. You get not good interpretations.

Maggie: Exactly. 
Danielle: What would you define your role in the Deaf community? How would you define yourself?

Maggie: I would say I'm a little bit of all.

Danielle: That's fair.

Maggie: In one way, I grew up in the hearing world, but I grew up in the Deaf world. I was explaining this to my mom the other day. For the first time, she has to be a part of the hearing world she is in. She hates it.

Danielle: [Laughs]

Maggie: I keep telling her that she's never tried. She's never given that . . or tried. She's never tried to make hearing friends. She's never tried to go to hearing people cookouts and stuff like that. I get it but at the same time, there's a lot of a lack of communication. I understand it, but at the same time, you're in it. You kind of gotta learn how to be in it.

Danielle: Yes.

Danielle: You're right. That's something a lot of people don't give a chance to.

Maggie: I've been a part of both. I don't know. For me, I'm more comfortable in the Deaf world. I like signing. I love the language. I'm a very blunt, up-front person. You make me mad; I'm going to tell you the first thing on my mind. You ask my opinion? I'm going to give it to you as honest as you want it. I'm sorry. If you get offended that's how I am, but at the same time, I go in with the hearing world, too because I like my music. I can't live without my music. I would die. My music is my savior. It really is.

Danielle: You make a good point. I agree with you completely. I am way more myself when I'm signing. My identity comes out. I speak four different languages but my identity comes out when I get to sign. My body becomes more-- I get to use it the way I want to instead of having to follow hearing rules where I'm supposed to smile all the time and look a certain way. When I'm signing, I can tell you how I feel. My face should show you how I feel because how else would you know how I feel? You're not going to hear it in my inflection. You're not going to get it from the little hints and clues I leave in my language, I mean you can, but it's significantly easier for me to match my sign with my facial expression, whereas in hearing world you're not supposed to do that. I totally understand that. Do you think it will ever be a challenge to work with hearing clients, maybe it's a barrier because you do have this Deaf Heart? You have a "me 
too" thing. Do you think that could be a road block for you?

Maggie: Yes.

Danielle: Okay. To what extent?

Maggie: A couple years ago. I got a substitute interpreting position for this little Deaf boy in a hearing school. He was in seventh grade. I have never been so heartbroken and so infuriated at a school system in my life.

Danielle: Do you want to interpret in a school system?

Maggie: Yes and no.

Danielle: Okay. Fair enough.

Maggie: Yes and no. I mean, I did at first, but after that experience, I'm a little bit iffy about interpreting in a hearing school for a Deaf child because that just ... when I went in for the interview, this Communications Specialist, is what she called herself; she was a guidance counselor. She had a piece of paper so she thought she was houghty-towty. I went outside and met a sweet, funny boy. He was a kid! After we were done and we walked out, she asked me how it went. I said I think it went well. I said he seemed like a good, sweet kid. Then, she had the nerve to turn around and look at me and say, "it's really heartbreaking watching him." I asked her why. She said, "because he's Deaf. He's never going to amount to anything. He's never going to be able to achieve anything until doctors or scientists come up with a way for this beast that we call deafness"

Danielle: [Gasp]

Maggie: He will never achieve anything in his life.

Danielle: How did you not punch her?

Maggie: I wanted to. I had to walk away because her next sentence was, "you know what I mean. I mean, your mother is Deaf. Obviously, you think that if your mother wasn't Deaf, she would have achieved so much more if she was hearing." 
Danielle: No.

Maggie: I just looked at her, smiled, and said, "I hope you have a good day." And, I left.

Danielle: First of all, kudos to you for not smacking her. I don't know if I could have controlled myself. I think I would have gone ballistic. I'm Italian, right? I talk with my hands anyway. It was always a joke when I was a kid: "Danielle has to be an interpreter because she talks with her hands anyway." But, that part, the fire in me, right, the fire would have just taken over. Kudos to you for not saying anything and keeping yourself professional, but that's, and I hate to say it, but I can't tell you how many times I heard that in VRI settings when I'm doing medical appointments. I'm listening to these people say, "Oh, but if they weren't Deaf ..." So, do you think as an interpreter that you have any position to say something? How do you feel, other than being professional, smiling, and excusing yourself, what if it's in the middle of a conversation? You can't just walk off and say deuces. So, what's your plan for situations like that? Because it'll happen. What do you think you can do for that?

Maggie: I feel like if you're not done with the job yet, and they're insulting them, it is your place and your job to tell them what's being said.

Danielle: Okay. So what happens if the Deaf person doesn't say anything. You tell them. You communicate the information. You are relaying that, but they don't stand up for themselves. Maybe it's even inhibiting communication;. Maybe at that point, it's inhibiting communication. Maybe the hearing person isn't listening to you anymore, or the Deaf person isn't paying attention anymore because the whole interaction just got kerfuffled over those kinds of comments. What's your game plan? Do you see that as a time to step in? Do you see that as a this is still not my place? What's your role in that interacting?

Maggie: I mean, yes and no. I feel like I should have a place to step in and look and them, and say, "This is not okay. This is still your client. You have no right to insult them," but with that job territory you are not allowed to do that and I don't think that's fair. Regardless of whether that Deaf person will stand up for themselves, they've heard that their entire life. They might not feel like arguing or dealing with it. I don't think that's fair. They are all about bullying. You can't bully your kids. Bullying is not tolerated in school, but that's exactly what they're doing to this whole community that they have no knowledge about and I think if they did actually have the knowledge, then maybe they would open their eyes. Like, I wanted to throw my Deaf culture book at that women and just tell her she is wrong.

Danielle: I think you made a good point. It is ignorance. You want to tell them you read something. You are so proud of this piece of paper but you have never read about this community, though these are the people you are serving. Things like that, I understand, but I do 
think that in certain contexts, especially if it is inhibiting communication, there are times when as along as you are not outside of your role. Your role is to provide communication access. If you get so high on your soap box and you can't see your Deaf client anymore because you are so high up here, talking on your soap box, then yeah, you got a problem right? But if you are communicating, and you are trying to facilitate communication, sometimes those comments become helpful. Sometimes those comments are necessary and allow additional communication to happen. So, I definitely think that's where interpreting gets so complicated. Talk about a sticky situation. I love this sign. It's sticky, it would be what we did. "Not sure yet." It is a weird interaction and context. You have to be able to respond but also know that your role is kind of on this fence and being on the fence, is a hard place to be. It's not gentle.

Maggie: It's hard to be on the fence for me. I don't know. I went to high school. I grew up with people picking on me because my mom was Deaf. I have heard all of the jokes. Only problem is now I'm not really allowed to punch people in the face.

Danielle: [Laughs] Were you ever? Were you allowed to punch them in the face before?

Maggie: Sometimes. I mean, yeah. It depended on the situation. I mean, I came home from school one day and I was so upset because like, at one point, my oldest brother got into drugs. And, it was really bad for a while. And, at the same time, like, me and my other brother, Jared, me and him were like sticks and stones together. Everywhere I went, he went. We were, hands down, best friends. We also fought like cats and dogs every day. If I knew I needed someone or something, he was the first person I called, every time. And, he heard one day this chick picking on me. Since it was the same time, Jared had a temper. He was always in fights. Justin had just gotten arrested. Mom was stressed out in both ways. I decided not to do anything. I kept my mouth shut and dealt with it until I can't. I didn't want to stress my mom out and make it worse. And, it just kept on, and kept on, and kept on. Every single day. And then, one day, I got home off the bus and I just refused to talk to her. I went in my room and I bawled. I was so aggravated and stressed out. I was so upset.

Danielle: I don't blame you.

Maggie: So, Jared came in and talked to me. Then, he made me go tell Mom everything. I went in and told her. She looked at me and said, "Maggie, I love you. I appreciate you not trying to get into trouble. Maggie, go to school in the morning and knock that bitch the fuck out."

Danielle: Good. Good. You got permission.

Maggie: And that's exactly what I did. 
Danielle: Good for you. In a lot of ways, one of my goals this semester, especially with you will be to hone your ability to say things without the other person realizing you just insulted them until after the fact. I think that's going to be such a good skill; it is such a great skill. Every interpreter should harness that skill. We have to be able to set people right, sit them down, and say, "Listen. This is not okay. It will not continue," without us stepping out of our roles, right?

Maggie: Yeah.

Danielle: There's a line that you don't want it to border along me stepping across and doing too much, or stepping in and fighting for them and making the Deaf person look bad in the meantime. It is a sticky thing; however, making sure that people understand about the Deaf community is part of what we do. Not to say I'm going to sit you down and teach you all about it because I am an expert, but I am going to help you culturally adjust your tiny, little brain in order to be able to work with this population, or this community. And, at that point, you are doing a service to the hearing population, which you should be doing, when you have an opportunity. Typically, we only have a chance in that interaction. So, there are ways, especially if people are being disrespectful, to make sure communication does not get inhibited because they are being ignorant. And, you can address it in the right ways, especially if people are being disrespectful to make sure that the communication does not get inhibited because they're being ignorant and that you can address it in the right ways so that you can continue to do your job. My big thing, I've always said, I don't like when people are in my way of accomplishing my goal. Maybe it's in that interpreting, but I'm certainly not going to get in the way of what I know how to do. I'm a nationally certified interpreter. $20 \%$ of people who take that test, pass it. That means that I am darn good at what I do. There's no question. Yes, I make mistakes, I'm not saying I'm so good, but there's a reason I'm good at what I do.

Maggie: There's a reason you're where you are.

Danielle: So, there's a lot of things and a lot of interactions that when you leave them you should try to leave them better than you found them. Maybe the person will be stubborn about it but they'll hear you in the interaction. I can't tell you how many times I've said, goodness grief, you'll repeat yourself, you don't have to tell me to tell her. Tell her. I can't tell you I have interpreted tell her, tell her, until the Deaf person finally says "can you stop?" TELL HER. Deaf person is like, that's enough. So, I get to say, okay, that's enough. There are little ways that I can throw that into my interpretation to fodder for the Deaf person to get them to say something.

They need to know that's happening. There's things we can do but I definitely want it to be something that we can address in a lot of ways because I want you to feel comfortable and confident that you're able to mitigate that communication because that's your job. Your job is to make sure that communication is not interfered with by anything else. You have to manage that, understand it is there, and figure out what you can do about it to make communication effective. 
I'm starting to get into lectures now. I geek out. This is what happens. You're seeing it happen.

Maggie: I do the same.

Danielle: It's a passion.

So, we've talked about some challenges. You talked about having this split feeling about educational interpreting. Is there any place that you really feel is your home? Any place you really want to interpret? And then a place that you would never interpret in your whole life?

Maggie: I've never really experienced anything that I never want to interpret. If I have to guess, I'm going to go with that's the politics in interpreting, like for presidents. That's not my forte.

Danielle: [Laughs.] It's hard to do.

Maggie: I can only keep my mouth shut for so long.

Danielle: I can't tell you how many times I rolled my eyes and I only did it once. I know what you mean.

Maggie: I don't know. I've always wanted to work in a completely Deaf-cultured place, like a Deaf school. After I graduate, I plan to move down to Nashville. My mom is friends with one of the principals or presidents of the school down there. I'm hoping to send my resume in after I graduate and get a job down there.

Danielle: Awesome, good. Good. I definitely ... that immersion is, so, you have the language skill, you have the language skill, but that's where you can make an impact the most. You are working with people, speaking their language, in "their world because it's not a hearing school with a Deaf child. It's Deaf school, Deaf child. Just prepare yourself for a mismatch in resource availability. What public schools get is not what the Deaf kids get. It's messed up but that's a piece of the game. It's very heartbreaking to see but that's something that if you go in with your eyes open, you can address those things and look for ways to get money and resources for them. There are ways around it but it's something you should go in with your eyes open. There's a different set of challenges when you go that route.

Maggie: I've always felt more at home. I can go to a Deaf event. I just went camping with my mom's friends and all of them are at least 5 to 15 years older than me. And I fit more in and feel more comfortable with that crowd than I ever have being around people my age, or just hearing 
people in general.

Danielle: Preach. I feel ya. I have that Deaf Heart. I don't have any family members who are Deaf, sadly. I would love one, but I understand how you feel. You find your identity in the language, the culture, the people. I get that. So, how do you feel about being online? Do you feel like that makes it so difficult to connect with the information?

Maggie: Yes and no. I feel like it is harder because I'm one of those, I learn hands-on.

Danielle: Okay.

Maggie: Whether it is through video and I'm signing. I learn more doing it than studying it.

Danielle: I think that's everyone.

Maggie: Online, it is all about studying it because there's not really the hands-on contact with the teacher. Last semester I went through one of those classes and I was just so confused. I kept emailing and emailing and emailing this teacher like, I'm lost. The assignment is due. I have no idea what I'm doing. I feel like that makes it so much harder because when you reach a spot that you're that confused and you have no idea what you're doing, you're relying on them to do something as simple as check their email.

Danielle: And then when they don't, then you still have no idea what you're doing.

Maggie: Yeah.

Danielle: Yeah. So, I'll say this because I feel like ... just so you know, those were my last questions. I have my other meeting at 12:30. I'm sorry for the rush but thank you for your flexibility but I think one of the big things I want you to know is there's three types of, what I would call, presence that I'm focusing on. It's what we call in instructional design: Social presence, cognitive presence, and teacher presence. Right? So, social presence means you guys interact with each other. Cognitive presence is you think about the content, you work with the content. Instructor presence is me actually having some kind of involvement. Really, I should be the last of it. That's why I listed it the way I did. This really should be, as far as importance goes, we have CHAMP up here, we can call these two tied. This is definitely in second place. No question. These are same level. These first two. This one is definitely underneath. My big thing will not be to study the theory of it. Just because you are online does not mean that you cannot have hands-on experience. It is a little clunkier as far as that experience as it gets put together, but I promise everything you will do will be the construction of meaning. You will 
create meaning from an English text into sign, or a sign language passage into English. You will spend your time doing exactly what you will be doing in the field. You will process those parts of your brain. I need you to know the process. I need you to at least read a chapter, yes. Everything after that is not, let's talk about theory. Let's apply it. I need you to be able to do it. This kind of program especially is based on the student's ability to do it.

Maggie: That's what I struggle the most with. Like, I can read ASL. I can talk ASL. I can sign ASL. That's not a problem. Same thing in English. I am terrible at translating it. So, trying to do it simultaneously ...

Danielle: Let's cut out the terrible. The "I can't." I'm terrible. My first assignment for you is to cut that word out. I'm sorry for interrupting you. Cut that word out right now. We're not focusing on that. We're focusing on the fact that you have an opportunity to do great things and learn. We are just going to do that. I don't expect you to know. There's a difference between knowing a language and knowing how to interpret the language. My job is to teach you the second part. So I will. That's fine. I don't want you to think that you have to be really great at it already, but unless someone has broken it down for you before and said, Maggie, here's what the process looks like. Here's what the textbook tells you to do. Then, you wouldn't know. But you are not bad at it. The fact that your mom can understand you tells me that you can do it. You just need someone to tell you to try something, adjust something else, focus on this. That's my job. Just wipe out that "terrible" word. We are going to focus on learning. "I'm learning how to do it," right? That's a way better perspective and I know you can do it. I have talked to Ruby. I have a feel for who my students are. I wanted to have some background but I also wanted to speak with you guys. You can do it. I don't have any question in my mind. You can do it. Ruby was like, "She's a CODA." That was the end of the conversation. Got it. Noted, thanks. I want you to know that not all CODAs are created equally. Just because you are a CODA doesn't mean you are proficient in sign or that you should be an interpreter, but given everything you can accomplish, I have no question. We can get there. We just need the semester to do it. We will do that. If anything happens throughout the semester and you need something, you know how to find me. We will do at least one more of these talks. I am not going to push it. I know we are busy. I am available, but I just mean required ones. I will probably do other things so we can see each other instead of a one-on-one like this.

Maggie: Before we end this, what is the vlog?

Danielle: What's what?

Maggie: Vlog? Vlog 1 assignment?

Danielle: Yes, it is posted. I have it posted now on Blackboard. The instructions are there. There's a prompt. That was my fault. I made it hidden from you guys so you couldn't see it. I 
just fixed it. The prompt is there and the submission link is there, too.

Maggie: Awesome. Okay.

Danielle: If you can't find it, let me know. If you look but it's not there, just shoot me a quick message. I will either send you a screenshot or I will double check.

Maggie: Awesome.

Danielle: Keep me posted.

Maggie: Thank you.

Danielle: Talk soon.

Maggie: Bye.

Danielle: Bye. 
Interview 2 with Maggie

Danielle: This is a great question to start with, though. So, my first question on my list was (is), how do you feel you've experienced growth as an interpreter? Which, is a perfect question for you. Right?

Maggie: It is. Um, alright, I've experienced growth in some ways, I want to say. Like, I can definitely feel that I've improved. I've opened my mind up to more than just my way of doing it, which is pretty much what I've done for so long.

Danielle: [Laughs.] Okay, good.

Maggie: In other ways, I feel like it's running full speed, making two steps at a time and I feel like I'm still going six steps backwards.

Danielle: So, how have you improved? So, you said there's certain things you do better where you think about other ways to do it. Like what? Do you have any examples? Maybe not?

Maggie: Um, for one, actually looking at the message, as you know.

Danielle: Yeah.

Maggie: I've never done that before. I always just listened to the words and just kind of winged it and went with what I thought. I never paid attention to, like, getting across the other person's message, which I should have.

Danielle: Gotcha, yeah.

Maggie: And now, I'm starting to pay more attention to that.

Danielle: Love that, good.

Maggie: And trying to figure out how to get that message across.

Danielle: That's good, okay. 
Maggie: Without putting my own opinion in that.

Danielle: Which is really hard to do, especially if what someone is saying sounds absurd. So, we talked about this before and I used the word empathy, which now I don't love that word anymore but I used it, so it is what it is. That sounds a lot like you have to have empathy. You have to understand where someone else is coming from. Should all interpreters be like that where they can have that empathetic, maybe, connection with the Deaf or hearing person that they're working with?

Maggie: Yes and no.

Danielle: Oooooh, okay.

Maggie: I don't feel like you have to have it to be a good interpreter.

Danielle: Why not?

Maggie: Regardless of whether you understand or feel what they're feeling, as long as you can get their message across, then you've done their job.

Danielle: Got it.

Maggie: I don't feel like you have to connect with someone on some level to do that. I feel like if you do have it, then you're going to do a better job of getting that message across because you're actually going to take on the feeling, you're going to relate to it, and you're going to be able to interpret it that much better than a person who's like "whatever. I don't care. I don't understand."

Danielle: Yeah, and there's something about like brushing it off.

Maggie: I don't think you have to have it.

Danielle: It's not necessary, but it's not brushing off the person's feelings. So, what happens though if you're not empathetic? So, I guess my question would be can you really embody a message if you don't understand where the person is coming from, which a lot of times is what 
people call empathy? Can you truly understand what they're talking about if you can't "walk a mile in their shoes?" Whatever that expression.

Maggie: [Laughs.] Yeah, I'd say you can.

Danielle: Okay, how do you do that?

Maggie: I mean, this is going to be like a little bit of a far-fetched stretch, but I'm going to attempt to explain it the way it is in my head.

Danielle: Okay.

Maggie: Okay, there's a word for it but it's not popping up in my head, for a person who has no emotions. Is it sociopath?

Danielle: Yes.

Maggie: [Laughs.] Okay, that person who has absolutely no feeling whatsoever is able to watch people's reactions, watch people's facial expressions, and take on their emotion even though they have no idea what it is whatsoever, but they're able to mimic it.

Danielle: Okay.

Maggie: Therefore, someone who feels nothing is able to do that and fool a good amount of people along the way, why can't a person who regularly experiences feelings be able to translate a message even though they have no connection to the message whatsoever?

Danielle: That makes perfect sense. I think the big concern with it-- not concern. The takeaway is it's still a skill of matching somebody's feelings. Honestly, sociopaths are usually brilliant. That ability to mirror or mimic someone else's feeling, or expression, or whatever, usually is-that's not easy to do, especially when you don't feel it but you can copy it and do what they're doing. So, I think it still requires a skill but I think you're right. That skill doesn't have to be empathy. So, are you a sociopath or empathetic?

Maggie: I'm in the middle. 
Danielle: [Laughs.] Uhhh ... okay. I think? Okay. But, do you feel like you can embody somebody's message still, even though you're like in the middle? Can you still embody a message?

Maggie: Yes and no.

Danielle: Okay.

Maggie: I feel like there would be certain messages that I would struggle more with and others where I'm not.

Danielle: Yeah. No, that makes sense. Okay.

Maggie: Like, okay.

Danielle: Yeah. Okay, so I'm guessing, despite all the issues that we're having right now in class, you still like interpreting? Do you still enjoy the process when you actually get to do the process?

Maggie: Yes, I do.

Danielle: Why do you like it?

Maggie: I enjoy the job more than I enjoy the process. I enjoy being able to do it out in the field more.

Danielle: What's the difference?

Maggie: The process and the job goes hand-in-hand, but, like, with school has nothing to do -like, it has to do with learning the process, but it doesn't have to do with doing it in the field.

Danielle: Right, right.

Maggie: And, when you're doing it, if you're just learning the process, or you're just doing it for school, you don't really get the same kind of satisfaction, at least I don't. 
Danielle: Not when it's set up like it's been set up.

Maggie: Like, I enjoy--

Danielle: Not like that.

Maggie: Yeah. [Laughs.] I get more, like, for example, when I interpreted my mom's best friend's college graduation, granted I was 14 and was in no way, shape, or form whatsoever had any goddamn clue what I was doing.

Danielle: [Laughs.] Fair enough. I appreciate the honesty.

Maggie: But, I was able to do it to a point and be successful at it, like, looking back on it now, I could've and should've done so much better, but at the time, like, knowing that I was able to do it and succeed at it to a certain point, at being only 14 and seeing how someone I knew and cared about went from bawling her eyes out, completely upset because she had no idea what was going on, it was her graduation, to at least understanding bits and pieces of it and being grateful and thankful that I at least attempted it and she understood some of it compared to nothing.

Danielle: Right.

Maggie: I like that gratification. I like that feeling.

Danielle: Yeah, which is totally logical, but the process of actually, well, your educational experience has been different than that. We'll just put it that way.

Maggie: Yes.

Danielle: Yeah. Okay. That makes sense. And then, after graduation, do you still want to go into the-- do you still want to go to Nashville? Is that still your plan?

Maggie: Yes.

Danielle: Cool! Have you talked to them yet? 
Maggie: I talked to someone from Sorenson in Nashville and they said that when I get everything situated to let them know.

Danielle: Sweet.

Maggie: And they'll go ahead with the interview process, or if I wanted, I could go ahead and do the interview process online via Zoom and they would let me know whether I got the job or not.

Danielle: Sweet. Okay. Do you still want to be in the school? Because you had talked about that? Do you still want to do that or not so much?

Maggie: I still want to.

Danielle: Okay.

Maggie: I want to do-- I have more of a passion to do both. I don't want to just do one and get stuck at it.

Danielle: Yeah.

Maggie: And I know the ups and downs of working in the school system. And, I feel like if I only worked in the school system then I'm going to lose the passion that I have for interpreting.

Danielle: Oh yeah, then don't do that. [Laughs.] Yeah, that makes sense. If you're not-- if you feel like you might get burnt out from it then it's not something, it's not something you want to do. That's not a good idea. Okay.

Are you planning on getting your bachelors for national certification?

Maggie: Yes.

Danielle: Are you waiting a little bit? 
Maggie: Um, well, at first my plan was to move down to Nashville and get everything situated first and then go back to school.

Danielle: Okay.

Maggie: But seeing as how I needed to buy a new car and drain my savings, I was talking to Mom about staying here until I finish school completely. That way, I have enough time to build my savings back up and then move.

Danielle: Gotcha. Yeah. And, where would you go back to school?

Maggie: I haven't decided which yet though.

I don't know where I would go back to school. I want to do another online program just because it would be easier for me.

Danielle: Okay.

Maggie: But, finding an online bachelor's program is proving to be a little more difficult than I thought.

Danielle: In interpreting or in something else?

Maggie: In interpreting.

Danielle: Okay. Yeah, there's some of them. They're going to probably ask for more field work, which is a good thing because then you have more experience as you're earning your bachelors. I think Troy University offers one. They're in Alabama, something like that. They have an online one. Okay.

Maggie: Well, with that being said, I also found out that southern West Virginia, there's probably only like 2 or 3 interpreters in this entire bottom half of West Virginia and in Greenbrier County, there's none. So, I'm supposed to take my EIPA certification in April, which I have been consistently freaking out about.

Danielle: [Laughs.] Yeah, that'll do it to ya. That'll freak anybody out a little bit, yep. 
Maggie: Oh, it has. But, since I found that out, I've been planning on once I get my certification to try to get set up as a community interpreter for, like, Greenbrier and Raleigh County. That way, I can get my degree and have a job.

Danielle: Yeah.

Maggie: And, that way help out people around here because, like, when Mom goes to the doctor, she has no interpreter whatsoever. And because I'm not certified her insurance company won't pay me. And then, on top of that, one of Mom's friends found out, or well, he's taking classes in DC.

Danielle: Okay.

Maggie: For the Deaf kids around here because they're all, honestly, like 15 and younger. And, they all go to school here, but he was explaining to me how a bunch of them come from bad homes and they're poor and blah blah blah. And he wants to set up doing like a community thing for them, like taking them camping.

Danielle: That's cute.

Maggie: Taking them on fieldtrips and doing stuff like that with them.

Danielle: I love that.

Maggie: And he asked if I would be interested in it, and I am.

Danielle: That's awesome.

Maggie: But I figured if I could do that, I could get semi-setup with the school and be an interpreter for the community itself.

Danielle: Yeah, okay. So, first of all, that sounds awesome.

Okay, so that's actually really cool. I was just thinking about that. You have me stuck now on that. So, I always think about how small the Deaf community is in West Virginia. Which, most 
people think, why go to West Virginia because there's no Deaf community there, but you have a chicken and an egg problem. There's no Deaf community because there are no interpreters. If there are more interpreters, at least then they know they have communication access. They could go in somewhere and get a certified interpreter, or at least a qualified interpreter, to do their work. You know, to do that assignment, whatever it is. So, at least if you're putting yourself into that community and getting that experience-- the only thing I would say is if it comes to education, just be careful because of how difficult it can be to interpret that kind of information for really young kids. Not that it's-- a lot of people think it's easier because they're young. They think that -- they worry about the words and they're like, little kids are stupid and they can interpret for a little kid, but they don't have the language skills.

Maggie: It makes it harder to give them input.

Danielle: Yes. It does. So, you don't have the same ability to just grab the sign that first pops into your head. They won't know what you're saying. It doesn't mean anything to them. You have to give it meaning. So, the only thing I would say is, especially starting out, I would recommend more like, like, like social security administration assignments. Other types of community work. I know you weren't talking about going into the school system only. I understand that. I'm not saying that you would do any of this, but I would just be very aware of what your ability is to be gestural. Like, if you feel like you're kind of stuck in the word thing and you're like, breaking out of it, which to me is what it sounds like, that you've started to make that transition away from just the words, more into the meaning, which is what you're supposed to do, but if you're still going through that learning process, until you really feel confident, like you do only that, just be careful because you don't want to mess with some kid's education and you're their language model. So, if you're not comfortable being that expressive person that they're ready to-- that they need, you're not maybe at that point just in your career, which I don't have any doubt that you'll get there, then focus on the stuff that will build those skills, like getting to work with children one-on-one and being expressive but not being responsible for their education. Like, I think working with kids is a great idea for you because then you can develop that and talk about getting good at being expressive! You work with kids? You will be so much more than a word. You will. You'll be a great interpreter because your language skills will develop, which means your brain will think about it differently. So, I think that's a perfect fit for you. I just don't want you to be responsible for somebody's education while you're still developing that skill because you'll feel terrible when it's like "Oh my god."

Maggie: Right. That's why my plan is to work with my mom's friend before I go into the, like, trying to get a job in the school system. His plan is to work with them on weekends, taking them on camping trips and stuff like that from where most of them are either too poor and they can't do anything. And, there is no Deaf community around here for them. And, on top of that, if they're not incredibly poor, then they have really, really bad homes. So, his idea is to kind of help give them like a sense of a Deaf community, even though there isn't one here and to work with them, helping them, teaching them, stuff like that. Things that they're not normally going to be able to do, which is why my goal is to kind of help him build that up first while working on getting my experience. 
Danielle: Yeah.

Maggie: Before I go into the school system.

Danielle: Yeah. I think that's awesome.

Maggie: Because I already know I'm not going to do that.

Danielle: Yeah. We had talked about that before, how you were not a big fan of that after some of your experiences. Yeah. I don't blame you. I totally get that. So, do you think that you'll go into, like, working with your mom's friend, do you think you'll go into that as an interpreter? Or will you be different than an interpreter?

Maggie: I think it's going to be a little bit of both.

Danielle: Okay.

Maggie: Because, I don't know. Everyone that he's planning to set up to work with the kids is Deaf. I'll be the only hearing person, so I feel like it's kind of going to be like a half-and-half role for me because for one, I'm not going to just strictly be the interpreter, but I'm going to help work with the kids, help him achieve whatever his goal is, and how to set it up.

Danielle: So, what does that mean? When you said, "just be the interpreter?" What's an interpreter do? Like, can we just make that clear? What's that definition to you?

Maggie: To relay whatever message or communication that needs across, across, accurately.

Danielle: Okay. And, you probably won't have to because if everybody is Deaf, and everybody is signing, there's probably not a lot of you necessary then because they can all talk to each other.

Maggie: Right, but this will also help better me with my signs and the gesturing because that's . .. still needs work.

Danielle: Yeah. I don't think ... okay, so sometimes I think it's a really great thing to be a CODA and other times, I think it's like breaking a really deeply rooted habit. So, it's great 
because you always have access, you always have exposure and that's awesome. But, I think at the same time, then you spend, if you do have a habit, like not gesturing as much, then it's hard to get out of that habit. Keep in mind, though, that no matter what, Deaf people in general, your mom included, all of her friends, included, the community that you know, Jamie included, right, everybody that we know, did not-- the language was not developed by design. It was developed by use. So, people didn't go, "Hmm . . . how do I want to sign FOOD? Well, let's make this shape and we should probably put it like, I don't know, let's just put it here. [On face.] This just seems right." No. It's what it looks like, right? As they're feeding themselves, as they're putting the food into their mouth. So, I think part of what will help too is when you stop feeling so selfconscious about being in the words itself, right? When we can get you through the who, what, when, where, why, how, get you really comfortable with that, you'll start playing with it because you'll know that your brain can do it. You don't have to panic yourself. Your brain can do it and what you can do is then take that on. Sometimes, like, I interpreted for a teenager one time, she must have been like 15 or 16 . She was with her mom. And, the doctor goes, "So, what brings you in today?" And the girl went [shrugs shoulders, hems, haws.] What would you voice? If you see someone do that, what would you say? She didn't sign anything?

\section{Maggie: Kind of like, "Uhmmm ..."}

Danielle: Yes! "Well . . ." I saw like a drawn-out "well," especially a teenager. When someone asks a question, and especially when it's kind of weird, I think at the time she was asking for birth control or something, so it was like a weird discussion anyway, so you could kind of see she was awkward, right? But, the "uhmm" that's not ... she didn't say UHMM. Right? But, you knew by what she was doing, you could see, you could pick that out. You know that she's doing the "Uhmmm ..." "Sooo ..." That's the kind of thing that Deaf people do and what the dream is for you is to get you out of your head, to just see what people are doing, as well as being able to embody that. When someone goes, "Well . . " instead of you signing W-E-L-L. You don't need the letters. How many times as Jamie said that you don't need the letters? You can just say no [shakes head.] You don't say DON'T UNDERSTAND. You just say UNDERSTAND [head shake.] That kind of thing. The language wasn't made because someone said, "You have to put the don't with the understand." They said, "This looks like 'understand,' and if I shake my head 'no,' you say DON'T UNDERSTAND." It's what it looks like. Hearing people weren't in the middle of it; Deaf people had to make it work. There wasn't any hearing person saying, "This is the structure. This is what you're going to do." There's just Deaf people being Deaf people and talking, and figuring things out and communicating, adding words, right? We joked about there being a big committee, right, when someone is adding a new sign.

Maggie: Yeah.

Danielle: How does that happen? It's just discussion. It's just by use, by the way things develop, by the way they grow. So, that's kind of my goal for you would be for you to finally see that it's not just the word and the sign, and that the way that the language was created was more like just what they do, like non-manuals. Right? No one sat there and said, "well, if 
something's really far..."

Maggie: Yeah, it's more like, it's not what they say, it's what they do.

Danielle: Yeah.

Maggie: Type deal?

Danielle: Yeah. And a lot of what Deaf people have developed is based on, like, the difference in classifiers, right? Some classifiers, you become the thing. This is me still flipping something, right? That's what it looks like, but then, I can also make my hand look like a pancake-- like a spatula, itself. And here's my hand being the spatula, flipping a pancake. Okay, but it's very clear because it's what it looks like. I would hope, and I believe it will happen, that in working with younger people, you'll just start doing that kind of stuff because it's more like, I don't want to call it Charades, but it's more like Charades than it is like regular English speech where it is just all about the words. Sweet.

Maggie: Yeah.

Danielle: Okay, so did you-- and you can tell me the truth, it's okay, so the way that our class, 2203 was structured, did you like it? Did you like that setup?

Maggie: Yes and no.

Danielle: What was good and what was bad?

Maggie: Alright, um, I liked that you had office hours. That way, if questions or concerns or anything like that were to happen, you were available to actually talk to and reach out to you, and that you gave us contact information for us to reach out and contact you. That was extremely helpful.

Danielle: Okay.

Maggie: I liked the one-on-one. It was more of the group calls that I'm not a fan of.

Danielle: [Laughs.] 
Maggie: But, me, personally, I felt like in the group calls you couldn't say as much without saying something you weren't supposed to say, or saying something and hurting someone's feelings.

Danielle: [Laughs.]

Maggie: Or something along that nature.

Danielle: Yeah. Yeah, I get that. Okay, the times when you got to do the first draft of the interpretation, the analysis, and then the second draft, did you like that setup? Or did that just seem like busy work?

Maggie: It was a little bit of both.

Danielle: Okay.

Maggie: At the time, it just kind of seemed like busy work but looking back on it now, it was actually helpful.

Danielle: Okay. Yeah, I appreciate that. Was it because-- you and I had this conversation before because you said some of the feedback from your peers wasn't very helpful because you are at a much different level than many of your colleagues, especially at the beginning. Like, there was no comparison. So, I totally get that. Is that what made the group work seem like busy work and the group calls seem a little less helpful?

Maggie: Yes.

Danielle: Okay. That makes sense. If you're not talking to people who are really an equal, it's hard to work together on that. It's hard for you to get any assistance because they can't really help you. And, you have nobody above you, except for me, no other student above you to say, "Hey, here's what you can do" because you're up here and there's nobody else near you. So, yeah.

Maggie: Like, the only person I could ask for help from was Christina. Even though we weren't necessarily on the same level, she, from where we worked together and had classes together before, I don't know, she kind of understood some of my issues, but when it came time for her to 
looking and reviewing my work, it was the same as everyone else: Your signs look great. You did really good. Blah blah blah. And I'm watching it like, no, I didn't, which made that kind of not helpful at all.

Danielle: It makes it seem like busy work because you're like, this is not very constructive. Saying you did a good job, you know you didn't do it perfect. I don't do it perfect. No one does it perfect. There's always something we can work on, but you have to have people who can identify those things. And if they can't identify it in others, that also says what their skills are for themselves. I mean, and you're right, even though you're at a different level, if you have someone who can understand, even the idea of it, then there's something to discuss, but like you said, when you've interpreted and they're trying to figure out what you just did, they're like "looked good." I don't know. Having some random hearing person telling the interpreter they did a good job. You know they don't know what you're saying. That makes sense. I totally get that. I am sorry that it felt like busy work. I tried not to interject but when you and I finally had that conversation, going forward there needs to be a good balance between what's all students and where I come in. I want you guys to ask the questions and then find the answers instead of looking for someone to answer your question, but at the same time if you, Maggie, do not have help from your peers, you can't do that, so it only works if the rest of the people are able to do that. And, if they're not then it doesn't work and that's kind of what happened in some ways. I definitely see that too.

Maggie: Well, when it came to do the actual work, the book work itself, it felt like peer-wise, all of us were on the same level. It was when it came to the videos and the discussions and the replies, where you could kind of just see the difference, or at least to me it felt kind of obvious.

Danielle: Yes, definitely. Definitely.

Maggie: But, I feel like that was where, like you had a really good plan and concept but it backfired because we were not all on the same level.

Danielle: Exactly, and you can't know that kind of stuff until it backfires, you know what I mean? Until it explodes all over you, you have no way of knowing that's going to happen, but yeah. I agree. I appreciate that because it definitely-- I know that feeling because when I walked into this program, I was having full-blown conversations with Jamie and people were asking me to interpret for her. Like, my classmates were like, "Danielle, can you ask her this question?" Jamie was finally like, "Stop asking Danielle. Learn how to sign. You and I are talking. Let's talk. Stop asking Danielle to interpret." So, I totally know what you mean because from the time I started, I was interpreting for people, which I'm not trying to say I'm so awesome, but it can be weird because how can they help me. If I'm doing all of this help for them-- what you do learn, and I'll tell you this: You learn from people how to be and how not to be. You can always learn something from somebody else. So, maybe for example, like in your donkey interpretation, do you remember that one? Because that was amazing. In that interpretation, you had this very 
gestural, let's do it kind of thing, you know what I mean? Your body just showed everything. When you see other interpretations of that same thing, some people might have done things really well. Some people might have done things absolutely horribly in comparison, but you can still pick something up. It might be, "Okay, I'll never do that." Maybe you were never going to do it in the first place, right? That's probably true, but at least now that you have seen it, I feel like it's a lot easier to say to yourself, "That's one thing I can point to and say never, ever, ever." You watched someone else do it and failed. By that way, yes you can learn from other people. Maybe they did something really great, even if it was one sign, one time. You can still figure that out, but again, if people are not giving you the pointers, as far as to say, "you're not breaking things down," or "you're focusing on the words," which happens with every interpreter ever, if no one is there to tell you that and to help you break out of that, then yes, it's going to be like just watching people who are flopping their hands around, getting no message across, and you're like, I would never do that. My signs would never look close to that and that's not very helpful. I get that.

So, what do you think about working with other interpreters in the future? Like, one day you might have to team with somebody, what if they're really bad? By bad, I don't mean that they just sign differently. What if they are missing significant chunks of the message? And then, let's imagine this: They're missing chunks and then while you guys are working together, they try to give you advice on what you should be doing? How do you respond to that?

Maggie: [Laughs.]

Danielle: Yeah, I know, right.

[Child in background.]

Aw. I heard that small person.

Maggie: I am trying to think of the best way to answer this. And, that's my nephew.

Danielle: So cute.

Maggie: He's a stinker. It sounded like he was running for a minute. I just had to make sure.

Danielle: Not into your room. [Laughs.]

Maggie: I'm really not sure how to answer that, like professional brain function part says to, 
like, I don't know, nicely be like, "Hey, maybe we should not work together."

Danielle: [laughs.] Fair enough, okay.

Maggie: Or maybe recommend maybe going to some interpreting seminars, all the while letting the person ahead of me know that hey, this is a problem.

Danielle: Yeah. For sure.

Maggie: But, then the confrontational side of me kind of just wants to be blunt. And there's a fine line between the two.

Danielle: Yes, and there totally is. You are going to find people like we had in class where you're at a totally different level. I hate to say that, but that is going to happen. So, I feel like, I feel like you should be prepared in a lot of ways for those kinds of situations because you are going to work with other interpreters in the future, good and bad. It will run the gamut with what you will deal with, but you just have to be ready mentally for people who might not be where you are with interpreting, but like I said before you can still learn something, even if that's learning how not to be. That's still learning something.

Maggie: Well, that was going to be the next thing out of my mouth.

Danielle: Yeah.

Maggie: Because I think one thing, especially, to always remember for your class, for example, was even though this might sound a little wrong, but even though out of the classmates in that one I was the more experienced and better in a way, I was still also not the best. Like, I still had my own struggles and there were certain parts where Christina does better at certain things than I do. And I do certain things better than Christina does, and the same thing with the other two that I can't remember their names.

Danielle: Yes, yes. I see how much of an impact they had. Yes, I see that.

Maggie: [Laughs.] My point of it is even though you're on different levels, it's still, like you said, there's still some things to learn whether it's how to do it or how not to do it, but it's also a humbling lesson to learn that you're not the best and that you're not perfect. Like, I still have my own issues. They have their own issues. Even though we are still on different levels, there are certain things they could surpass me on and things I can surpass them on. 
Danielle: Yeah.

Maggie: And I think that's a key thing for anyone to remember because the moment you start letting your ego get ahead of your skill set, it's all downhill.

Danielle: Also, the reason that you're there. Also, the reason that you're there is not for your own self because if it was, you'd be in a different profession. Like, people don't interpret to be selfish. We're interpreting because we care about somebody else, most of the time.

Maggie: That's true. If you're there for yourself, that doesn't make sense. If you're there for selfish reasons then you're kind of contradicting yourself and waiting for, I don't know, your career suicide, pretty much.

Danielle: You are setting yourself up. If you're not thinking about somebody else while you are there to interpret, the fact that you're interpreting for Deaf people, then, yeah, 100\%. I think, I feel like that's what most people forget, is like the reason they actually start doing the job, but yeah. I think that's why it always makes me so mad when I hear about instructors who forget why they interpret. We interpret for other people and we don't teach interpreting for ourselves. We teach people so that other people can learn how to do it because I can't always do it. I think my abilities are bomb diggity, not perfect, but pretty damn good. I've spent so much time in the field getting experience. I think I've done a good job at that, but I also know I want to look at it more in-depth and the best way for me to do it is to learn from people who are developing their skills too, identifying where they have problems, that makes me better. By seeing other people struggle, whatever level, you included, then that helps me see, okay here's how I can be better, or a better teacher, or a better interpreter, or explain something more clearly. Whatever the problem is in the context, that's why it always frustrates me when I think about instructors who don't have that mentality or practice that mentality because then what are you doing. Like you said, that's carer suicide. You are doing it for yourself. That's like the opposite of the whole field, literally.

Maggie: Especially in this field.

Danielle: Yes. Completely.

Okay. Those were all of my questions. So, done. Done. 


\section{Appendix $\mathbf{J}$}

Interview 1 with Christina

Danielle: Hey! How are you?

Christina: I'm good. How are you?

Danielle: Good. I am glad we get to talk. Sorry about that. Let me just get the . . there we go!

So, how are you? Just, in general: for real, for real, how are you handling school work? The new semester during COVID and everything else? You handling it okay?

Christina: I had to quit my job because of all the scheduling because of Zoom meetings. That all happened on the weekend.

Danielle: Okay.

Christina: I work part time, which is weekends and holidays.

Danielle: Okay.

Christina: This semester, I got a planner. Last fall I have taken these classes before. There were some personal family issues that happened and I just got in a weird place and didn't plan for my classes or assignments. I kinda just stopped with them. So, I just got a planner. I hope that helps.

Danielle: I don't know if you have seen yet on our Blackboard page, but I did want to show you this cover letter. I will share my screen. Let me know if you don't see it after I do this. Did that work? Do you see that.

Christina: Yes.

Danielle: Us doing these conversations as I stated in the description, this is part of my dissertation research. I am a Ph.D. in education, so I am an educator studying education, but specifically in interpretation. Especially given my love of interpretation, this is an awesome fit. 
So, I do want you to know and I want to make sure this is stated before anything else. We were going to have these conversations anyway but this conversation is being recorded. I will have a transcript. If at any point in time you are uncomfortable, you can always reach out to Ruby that you don't want to do this anymore. It will not impact your grade as far as not using the data. At the time I am ready to analyze everything, I am going to make everything anonymous. It is not like I am not going to use your first and last name. I will not use anything that identifies you or the program. It is about this experience. I have some questions about it and I am trying to address some things. I think this is a perfect spot to do it.

Given that, do you have any questions?

Christina: I saw on Blackboard that there's a vlog 1.

Danielle: Yes.

Christina: I can't find that.

Danielle: That's something you create. That first vlog that's a video blog. You make that on Youtube. Does that make sense?

Christina: Do I post it somewhere?

Danielle: Yes, those instructions should be on Ecampus-- I'm sorry, on Blackboard. Let me stop my share and go look while we are talking, while we are thinking about it. It should be there that it'll tell you where to post it and everything. I should have created one of those. Let me check. I believe you that it is not there, but I just thought I put it there.

Christina: It says it is there, but I couldn't figure out where to post it.

Danielle: Okay. I got you. If I do have it, I will share my screen with you again, so that when you do it for yourself, you know what you are looking for. It was never created, that's why. Thank you for telling me. I will put that in an assignment right now. That will be there. When you have that link, that's where you can post that. I apologize for that. Thanks for letting me know. It should be there now under "Assignments." That's where you should see that first vlog.

Those are not shared publicly. I don't want them in a discussion board. I want that to be something you can share. I will look at them, I want to know your feedback, but really, I am not focused as much on if you say, "Professor South, your decision, this is crazy, this doesn't make 
any sense." I want you to be able to tell me what you really think in those videos. No harsh feelings. I want pure reflection when you are doing those kinds of recordings.

Christina: Okay.

Danielle: Okay.

Let's get into these questions. If anything else pops up, please feel free to stop me and ask or add something. Whatever. Okay?

First, why did you decide to major in ASL interpretation?

Christina: [Chuckles.] So, well, all throughout middle school and up until my senior year, I had wanted to be a vet. Then, my senior year I was in band and [inaudible.] We had gotten the freshmen in. There was a girl with cochlear implants. She played saxophone. Not many people talked to her. So, I knew basic sign language: HELLO, THANK-YOU, the alphabet. I went up to her and asked if she knew sign language. She got cochlear implants when she was young so she did not learn sign language. I just thought-- I don't know. At the very last minute, I changed my major.

Danielle: Are you confident in your decision? Are you glad you changed your major? How do you feel about the change?

Christina: I feel alright with my decision.

Danielle: Okay.

Christina: I don't feel like I'm learning as much -- like, I'm learning what I'm being taught but I don't feel like I'm processing it and able to go and talk to the Deaf community.

Danielle: Okay. You're not going to insult me by saying what you think or how you feel about anything. If you are not feeling like you are getting a full experience, that's part of what I am trying to fix. You don't have to feel like you need to caveat. It is what it is. I understand that completely. I think you have a good description of talking to the Deaf community and integrating yourself in that does require certain level. You can feel that level and sometimes that level is something that you grow into. It is something you just learn how to do. 
So, what does it mean then to be an Amercan Sign Language interpreter? At what point do you feel like you'll be ready? What does that look like in your mind?

Christina: Not having any trouble communicating. Not having any trouble knowing signs or any of that.

Danielle: Okay. So, the actual sign piece itself. What about the interpretation part?

Christina: Being able to translate an in-time English to a Deaf person, hearing to a Deaf person, being able to do that.

Danielle: Do you feel like you can do that?

Christina: I was able to do it at the preschool where my intern was. It was a little sign.

Danielle: Okay. It depends on the context then.

Christina: I feel so.

Danielle: Okay. So, given that, what do you think your role is then in the Deaf community?

Christina: Not necessarily to help them because they can be on their own and everything, but trying to-- it's hard to put in words because I have seen hearing people be rude to Deaf people because they can't understand each other. I feel like an interpreter can ease the anger.

Danielle: Yes. Yeah. In what way? How do they ease that?

Christina: By translating.

Danielle: Okay.

So, let me ask you a question: Do you think there's a difference between translation and interpretation? You keep saying translate. I'm not saying you're wrong, but I'm an interpreter, too. So, how do you interpret the difference between those two words? Do you interpret a difference between them? 
Christina: I know there's a difference but I don't know the difference.

Danielle: I'm not saying you are wrong. I am just curious because you keep throwing that in there. I was curious if you see a difference. Because obviously word choice matters because we are interpreters. I was just curious how you saw it.

Christina: I feel like interpreters are bigger. They're more "known."

Danielle: Okay.

Christina: Like, on TV, through this whole pandemic there's a box with an interpreter in it.

Danielle: [Laughs.] Right.

Christina: A translator, I feel like, is not in that little box; in person, though.

Danielle: Okay. So, actually, translation happens on paper and interpretation happens out-loud with spoken language. Just so you know the difference, the "official" definition difference. Translation is something that happens-- they're talking more from like an English-Spanish or Spanish-English kind of thing. In our context it is different because we don't have a written form, but that's kind of what we are getting at. I see the confusion, too, because we don't have that written form. We don't use translation.

Does that mean then, would you see yourself as an interpreter? Where you are currently in your education? Post-graduation? Do you see yourself as an interpreter? Would you self-identify that way?

Christina: I feel like after graduation I would be able to, but where I am right now, I don't feel like I would be able to.

Danielle: How come?

Christina: It is hard for me to go from English-- I sign English. I don't know how to put it in ASL. I know it is subject-verb-object. I have never been good at that in English. I just, I don't know. 
Danielle: Okay. That makes sense. So, there's a little bit of a language thing here, too, for language structure and understanding what it should look like. It seems like there's a lack of confidence in your ability to do that. I mean, would you agree with that?

Christina: Mm-hmm.

Danielle: Okay. Given that, what challenges do you see as an interpreter going through your career? Not just through schooling piece but in the actual career itself, when you get into the field, what kind of challenges do you think you might face?

Christina: It being too fast-paced.

Danielle: Okay.

Christina: Getting confused a lot. I get confused a lot, so ...

Danielle: About what?

Christina: When it gets too fast and I get lost. I will focus on that part where I got lost and I won't know the rest of what's going on.

Danielle: I get that. I used to do the same thing. I understand that completely. What do you do about that? When that happens to you in those contexts, what's your response?

Christina: I have had to ask people to slow their signing down. Or, if I don't know a sign, fingerspell it. But, I'm also not a very good speller, so I don't know, so I've had to ask them how to spell it over and over again just to understand.

Danielle: [Laughs.] Okay, so maybe there's a little bit, it sounds to me like there's a little bit of exposure needed for those kinds of things. As you know with fingerspelling courses, I am sure Ruby talked about this but they look at it as a shape, not letter-by-letter. So, BUS, that's the shape of it. APPLE, they're looking at the shape those letters make in space. Have you heard that before?

[Silence.] 
Can you hear me?

Christina: Yeah.

Danielle: Have you heard that before?

Christina: Not in that type of way. In months, I have heard it.

Danielle: Okay. Yeah, so, in fingerspelling, just in general, when people are signing, when they're fingerspelling, really what it becomes is a shape. They're not looking at each letter like how you and I focus on spelling. The do/Deaf and Deaf culture focuses on fingerspelling with the shape and then you get used to it. So, do you know the sign for JUNK? Have you had to use that before?

\section{Christina: TRASH?}

Danielle: So, no. Well, yes, that's the sign for TRASH. But, if you're saying "Wow! This place is a mess and there's junk everywhere," you sign JUNK, right? But it looks like this to show that the "junk" is everywhere. The sign is moving and in that process . . . so, that means when you sign it so fast you're not catching each letter and spelling the word letter-by-letter. That's not what you're doing but that's what they're looking at. Conceptually, there are pieces that get added; they become adopted signs. The fingerspelling word becomes the sign, and JUNK is a perfect example of that.

There are others like that, but my point is that you don't have to know all the letters to be able to know what the word is. It is a training piece. I'm really glad you brought it up. I think it's something we all struggle with, myself included. I have asked Ruby many times via Marco Polo to spell it again. We all do it. I am a nationally certified interpreter, I have been interpreting for a very long time, but we all do it. It happens to us all. That's okay, but keep that in the back of your mind that it is not about the letters. It is about what it looks like, the context, and training your brain in a way to fill in the blank, to put puzzle pieces together quickly. That's what we are gonna work on. Thank you for telling me that. That's really helpful.

With that as a challenge, do you have any resources now that you use when that happens? I understand, other than when you need to ask someone to slow down or you don't understand, but do you have any other resource like a mentor, $d$ /Deaf people in the community, family members, do you have anybody like that that you utilize or text, or even an online resource, anything like that to overcome that obstacle? 
Christina: My mentor in the spring semester at the preschool; I still keep in contact with her and there's someone I worked with for like three sessions maybe.

Danielle: Cool. Will you talk to her after so you can keep up that rapport and keep working together? Will you still stay in contact?

Christina: Yes, most definitely. I spent about 4 months with her. We became friends.

Danielle: That's awesome. Good. So that means in the future, it sounds like she is a good resource and person to talk to.

Christina: Mm-hmm.

Danielle: Good, I'm glad.

So, this is a weird question but why would anybody would maybe leave the interpreting profession?

Christina: The college part or ...

Danielle: The actual field. Post-graduation, right, you start working, you start interpreting. Would there be any challenge or any obstacle that would be present that you might think you can't do this anymore? Can you imagine a situation like that where something might keep you from continuing your work as an interpreter?

Christina: I have heard of interpreters or Deaf people getting carpal tunnel. So, that might be one reason.

Danielle: Okay, just repetitive strain injury and doing the same thing over and over again. So, physical reasons. Is there any other reason why you might think, "this is not for me?"

Christina: Um . . . I don't think so.

Danielle: Okay. And you said before that you are sometimes confident with your decision to not have gone into vet school. Is that something that you still see yourself doing? When you think 
about your growth as an interpreter thus far in the program, do you think you would ever complete this program and then go back to your original path or original plan?

Christina: Further down the line, I might get a vet degree, but as of right now, I'm going to stick with this.

Danielle: Good.

Christina: I am going to interpret for a while.

Danielle: Okay. So, you want to interpret; you really do want to be an interpreter.

Christina: Mm-hmm.

Danielle: Awesome. Okay, so what's your favorite context to interpret? So, do you really like education? Did you like your preschool experience? Would you rather interpret for an older population? What's your preferred context?

Christina: I preferred the younger, like elementary or middle school.

Danielle: Okay. Why?

Christina: I feel like it's easier to talk to them.

Danielle: Gotcha.

Christina: And, this will probably sound really bad, but, like they won't know the big complicated signs or the big complicated sentences.

Danielle: Right.

Christina: So, I could follow along. I don't know. It is . . the older you get, the more complicated things get so signing words ... 
Danielle: I understand what you are saying. I think there are times when the opposite is true but I understand what you mean because they're using larger words and likely speaking faster but at the same time someone who is, for example, in a post-secondary education setting, they're in college. They're going to use signs. When you're talking to a preschooler, elementary schooler, or a middle schooler, you're going to have to use more classifiers, more of your body language to get them to do something or communicate because they haven't learned that language yet. So, it is a different part of your brain, well, it is a different type of interpreting. You are going to use different pieces of the language depending on the group you are in. If you are comfortable with that, more power to ya. We need good ones. I understand. That's good though. So, younger population is where you want to be. Okay.

Is there a context you would never interpret in?

Christina: Medical. I would never do that. Jasmine had talked about how you can know the sign for something, MEDICINE. But if the doctor asks if you need a refill, you have to sign what is being said. You can't have your own input or anything, even if you know the patient and they take a shot medicine. But, if the doctor does not say "Do you need a refill on your shot medicine?" and just says, "Do you need a refill on your medicine?" then something can get lost in translation. The patient can die or something really can happen and I don't want to be at fault for that.

Danielle: Gotcha. So, my question to you then is are you responsible for someone's education when you are their interpreter?

Christina: Yes.

Danielle: Yes, so you are still responsible for something, you just don't want it to be someone's life, like medical decisions.

Christina: Yes.

Danielle: Okay, cool. I just wanted to make sure I knew the difference, right? That I knew it is not the responsibility factor. It is the fact that it is the medical situation.

Christina: Yes.

Danielle: I used to do video remote interpreting in medical settings, and it definitely takes a nuance. It takes a lot of understanding how to present those sentences without providing any sort of misinformation, right? That I'm not doing MEDICINE, like in my mouth, that I'm just saying 
MEDICINE. That I'm just communicating the fact that he's asking if you want any refills. Most of the time, that ends up looking like a list, and I just say NEED REFILL? Done. Usually, that's what ends up happening. I totally understand what you mean. I get that.

Now, let's talk about your last course experience. Let's talk about what worked. I know you said life happened. I understand that. What worked in the past in order for you to better understand yourself as an interpreter as well as what helped you learn? This is obviously online. It was not always online. Learning a language and then learning how to interpret online are very interesting processes; it's part of why I have a dissertation. So, really, what this ends up being is, what did you find most helpful given the unique situation you are in?

Christina: Like, last fall semester, because I had ASL last fall semester?

Danielle: Yes. So, specifically, this class because you said this is your second time taking it, that you have taken it before. So, given the fact that you have done this once already ... That's true, actually. Any of your classes: ASL or in any of your interpreting stuff, what works for you?

Christina: Well, it is online so it can't be in-person. Face-to-face, that worked. Keeping in contact. Some of my assignments last year that I was there for ... I was putting myself in there for that class at the beginning, at the very beginning. Some of them, I would send an email and ask a question and I would get the answer after the assignment was due. So, I would have to turn it in. So, communicating: that works really well.

Danielle: I love your response. Communication. Yes, I agree. We are interpreters. We should do that a lot better. I'm sorry you didn't get a response. I won't do that to you.

Christina: It's okay. People are busy.

Danielle: No, no, no. If you ask a question about an assignment, within reason, of course. If you ask me a question 15-minutes before the assignment is due, I can't guarantee you a response, but if you ask me before it is due then there should be no reason that I can't get to you and answer your question. That's not fair.

Christina: Yeah, and last semester, or last fall semester my class was really big. I had a lot of people in the class, 12 maybe.

Danielle: Wow! That is big. 
Christina: This year, I think in a few of my classes I think it's just me and Maggie. I think that's her name. Some of the classes there are two other people from last fall semester, so there are either two or four people in my classes. That could possibly be better.

Danielle: Okay, so more opportunities, what I'm hearing, for one-on-one. You want the feedback and information to know how you are doing when you have the question because otherwise how are you supposed to learn. Is that a pretty fair summary?

Christina: Yeah.

Danielle: Okay. That makes perfect sense. I don't want you to think I'm going to say, "Listen, they said you didn't answer." Trust me. The biggest piece about all of it is that I want to know where you felt most challenged and I want to know ... there are ways that we can do quick communication. I don't know if you have heard of something called Flipgrid before, but I usually describe it as educational Snapchat. So, to me, educational Snapchat is a really good way for us to post questions. We can sign our questions and post a video response in sign. So, if you ask me a question about how to interpret something, I can respond to you with my suggestion for an interpretation. I won't do it for an assessment, but there are ways that we can do that where you can get much quicker feedback and you can see what your classmates are asking and what they are doing which helps too. We have a lot of great tools that we can use that I want to introduce because I want that same thing. I want that same communication for all of you guys and I want to figure out how we can do that the best. I appreciate that that's a big thing for you.

Anything other than communication? Well, communication and feedback. Anything else?

Christina: Not that I can think of.

Danielle: Okay. That's fine.

You kind of answered this before, but is there anything you want to see me do in this class to help you be successful, other than answer your emails when you have a question?

Christina: This is the consecutive signing ... I forget what class this one is.

Danielle: It's simultaneous and consecutive interpreting. 
Christina: From English?

Danielle: So, this focuses on interpreting from English into American Sign Language, but we are going to do both. Most of the time, people don't struggle, I mean sometimes, but most of the time, people don't struggle with the English to ASL. Most of the time people struggle with ASL to English because that receptive skill-- we know, it should be easier to go from English -- from American Sign Language to our native language, into English, but we know that that's not always the case so we are going to do a little bit of both simulations interpreting but from ASL to English and from English to ASL. But, it is simultaneous and consecutive. Do you know what that means?

Christina: Simultaneous is-- there's a pause and you interpret in the pause and consecutive is where there's a little time and when the person starts talking and when you start signing.

Danielle: So, you actually have those perfectly backwards.

Christina: Ah.

Danielle: Perfectly backwards. Simultaneous: think at the same time. And it is not that you are talking over somebody, I don't mean it like that, but you are starting, like you said, you have processing time and then you start. And then, you maintain that processing time while the other person is speaking or while the other person is signing. The flipside to that is consecutive where someone maybe gives you a sentence and then you interpret, or someone gives you a sentence in sign and then you start talking. Does that make sense? Okay. Yeah, you have it perfectly backwards. You know what it is but you have it perfectly backwards. So, given that there's a time thing on it does that change anything for what you need? If I am asking you to simultaneously interpret a 15-minute discussion, what would you need from me to feel prepared for an assignment like that?

Christina: Like, with an assignment, you know what it is going to be about, technically, so I don't know. [Chuckles]

Danielle: That's fine. I don't expect you to know right now. For example, some people might feel more comfortable if they have additional time to look up terms. Sometimes that helps, right? Because then, you have understanding of the vocabulary. You might not know how to interpret it yet but you know what is being talked about and you have done your research. You have done all the reading you could possibly do and then you could go into your interpretation or your interpreting experience with some background knowledge that might make you feel more comfortable. Sometimes that gives people the confidence to go in and interpret for something they have never been in before. 
Okay, cool.

So, those are all of my questions. Do you have any questions left for me before we disconnect? I will still be reachable. I'm not saying that once we disconnect that we can never talk again. I am not saying that at all. I will bug you a lot. Is there anything you want to ask me about the course? I know you asked me about the vlog; I appreciate that. Anything else you want to talk about?

Christina: Well, technically, this is not about the course, but I am going to be going out of state soon. I am going to take all of my course stuff with me and do it when I have time, but it's going to be different. So, I will figure out the time zone if there's a Zoom meeting or something, but that's going to make a big difference on when assignments are due. Like, if it is midnight here but it's 9:00 in California.

Danielle: So, given that, it will still have to be EST. I won't be able to do the adjustment so quickly, but if I see something from you three hours after the due date, but if I see something due at 11:59 PM EST and I get something from you at 3:00 in the morning because it is three hours behind, but in that context: First of all, now I know, right?

Christina: I will let my teachers know when I am leaving. We are just playing by ear right now.

Danielle: I understand that. I have more of an issue with you submitting something four days late. A three-hour time difference or time-zone change is not something to submit something three days later without you talking to me first. If something is going on and you are working, but you need more time to sit down with an assignment, but if you have a three hour difference and now you need three days, that's a whole other conversation. You know what I mean? The two are not related. So, I'm good with that just keep me posted on when that happens.

Christina: I will let you know whenever I know something.

Danielle: I understand. Especially since things are remote. I am going to travel too. I am remote so I can take my work and go camping and darn skippy, I'm going to do it because I love it. So, I understand. I know what you mean. Just keep in mind that we are still in school. Three hours is not a reason to have something three days late, but if you have a time zone change, let me know what is happening.

Awesome. If you need something else, you know how to reach out to me. We will be doing lots of these, maybe not calls like this but I will be seeing a lot of your face, you will be seeing a lot 
of my face. My cellphone number is also on the cover letter which is on Blackboard. If you need me, you can use that number to call me. If an emergency or whatever happens, you can always use that. I would much rather you let me know than feel like you can't tell me what's going on because I don't have a way to contact. If something happens, within reason, but if something happens, you can always let me know. That way, I'm not going to not be available. That won't happen.

Okay?

Christina: Alright.

Danielle: We will get started soon. Next week, we are going to start with the thick of it so here we go!

Christina: Alright.

Danielle: Thank you. Stay safe.

Christina: You too.

Danielle: Bye. 
Appendix J (continued)

Interview 2 with Christina

Danielle: Give me one second. I just realized you can't see my face. Now I'm making you dizzy by watching me move the camera around.

Christina: That's fine. My computer wouldn't work so I'm using my phone.

Danielle: I'm sorry. That's the worst. My keyboard decided not to work on me. I spilled something on my keyboard. So, that's how I spent my day yesterday. I did nothing but clean my keyboard up. It was great. Alright. Let's get into these questions. To remind you, these are the interview questions for my research. I'm going to ask you some things about how you feel in the class so far and then in the program. Things like that.

Christina: Okay.

Danielle: They're never where I think they should be. I should just move them. I should put them somewhere else. Actually, I also need another document. I didn't ask you this stuff before, but let me start by asking some demographic questions, like an age range. I will give you a range and you can tell me where you are in that range. 18-21, 22-24, 25-27, or 28+.

Christina: 18-21.

Danielle: Okay. Then, your background. You said you are in West Virginia, right?

Christina: Yes.

Danielle: Are you from West Virginia? Are you a native?

Christina: No.

Danielle: Where are you from?

Christina: That's a good question. I was born in California, but my dad is in the oil field so we moved like every year and a half. 
Danielle: Okay. See, that's really helpful stuff to know because I bet that changed your perspective on life.

Christina: Yeah.

Danielle: Yeah, see those are great things to share with people, well, certain interpreting professors who ask questions, because that's super relevant. I love knowing that. I mean, going from California to West Virginia, first of all, there's a perspective change. I know you didn't spend long there because you moved a bunch but that's a huge environment adjustment just by being on different sides of the coast, of the country. That's really cool. Okay, so what county are you in right now?

Christina: Harrison.

Danielle: Okay. Why West Virginia?

Christina: It was either Texas, where we would spend, I think it was a maximum amount of 3 years, or West Virginia where we'd spend a maximum of 10 years, but the company my dad was with. And since my sister was going into high school at that time, my dad said we'll just go to West Virginia so they can do high school and college and we don't have to move. And after, well, it wasn't a max 10 years. It was a max 5 years. So, my dad just switched companies.

Danielle: Gotcha. Okay. Cool. That's pretty awesome.

Christina: BJ Services shut down.

Danielle: Oh, my gosh. Okay. So, you are currently in state, but initially, that would not have been true. Relationship to the deaf community? You said you made a deaf friend, but do you have any deaf family members?

Christina: No.

Danielle: And then, what year in the program is this for you?

Christina: This is my third year. 
Danielle: Technically, okay. Course attempt? Is this your second?

Christina: Yes, this is my second course attempt.

Danielle: Do you speak other foreign languages or have you learned other foreign languages in school at any point in time in the past?

Christina: I learned Spanish but don't ask me anything in Spanish because I don't remember it.

Danielle: When was that? When did you have to learn Spanish?

Christina: The last two years of high school, so ...

Danielle: High school.

Christina: Three to four years ago.

Danielle: Okay. Perfect. That's all of those. I meant to ask you all those questions previously and I completely spaced it, so thank you. So, let's start with the good stuff.

How do you feel you've grown as an interpreter this semester because if you can believe it, it's almost the end, which to me is crazy. But, how do you feel like you've grown over the last 14ish weeks?

Christina: I feel like I've grown a lot, especially in the vocabulary area and how to put it all together. I don't know how to word it correctly.

Danielle: I know what you mean. Okay. How so? How do you feel like that growth has happened?

Christina: Well, us going over the interpretation process. That one really helped.

Danielle: Awesome. 
Christina: The vocabulary has grown by ... I found another site this year, which was handspeak. I couldn't find that last year. I didn't see it. That one helped me. I mean, this year was kind of hard because of COVID and you can't go nowhere. So ...

Danielle: COVID ...

Christina: So, it was hard to get out into the community.

Danielle: I hear you on that. That was probably the hardest thing for me because there were so many things I wanted to be able to do that we couldn't do. That's a tough one, but that's great that you feel more ... do you feel like you understand how to interpret better? When someone asks you to describe interpreting, could you provide more detail now?

Christina: Yeah.

Danielle: Okay. Is that because of the conversations? What do you think helped you with that?

Christina: The conversations and the exercises.

Danielle: Okay. So, both of those things together.

Christina: Yeah.

Danielle: Awesome. Good to know. Okay. So, there's things that you have learned as an interpreter as far as skill set. Is there anything not, like, so, I would probably define the language skills as more "hard" skills, but I would define the other stuff, like being what we could call "culturally sensitive" as the soft skills. How can you enhance those soft skills in the future?

Christina: So, basically the question is ...

Danielle: Do you think you have those skills, for example, maybe you are more empathetic. That might be a good descriptor of the kinds of skills I'm talking about. Just being understanding of others. Those kinds of skills.

Christina: Yeah, I have those skills. I've always had them. I've always been patient with people. 
I've always tried to understand somebody and be polite. I'm always trying to be polite. Sometimes, I come off rude though.

Danielle: Why do you think you come off rude?

Christina: Well, it's also one of the things I've been trying to work on is my facial expression. I always have a blank face and a lot of people think that that's like, they call it the b-word face.

Danielle: Your RBF. Yeah. Okay. Yeah, and that's a really good thing to know for yourself as an interpreter because of how facial expressions are. So, my facial expressions get me in trouble because I have the opposite problem. Everything I feel is on my face, so I have to do the opposite, but what I've mastered is what I call the pleasant neutral. I am not showing any affirmation, response, or reaction to anything, but I don't look like I'm just being a butt. I don't look like I'm judging. I just have a slight smile. It's not to be bitchy, rude, or disrespectful. It's more to make sure that what I'm communicating is just the message. I am human and I have responses and I have to be aware of what my face could say but I also have to be careful not to turn people away from talking to me. I don't want to seem cold. So, I had to find that balance. That would be my suggestion to you, and it is going to sound really goofy, but when you need to show nothing or just listen to someone, master the ears back, eyebrows up face where you're just alert and paying attention. Then, when someone is talking, or you're just, maybe you are affirming, master the pleasant neutral smile where it's a gentle smile where you're not making anything but there's a slight upturn that at least you know people are not judging or they're not thinking you're cold. That's my suggestion. Practice those in the mirror. As goofy as it sounds, practice those faces because they really do help. They change everything, as silly as that is. That's the theater part of this job. Yeah. So, you said you are an empathetic person. Is that an important part of interpreting? Do you feel like everyone should be empathetic?

Christina: Yes because in the vlog that we're doing, it has different races, different situations and you gotta be understanding about all the races, all the situations that are happening because it does matter.

Danielle: Why does it matter? In what way?

Christina: If you're interpreting at a funeral and it's an Indian funeral, they have customs and you have to be able to adjust to those customs and their word choices, also. I'm not Indian. I don't know anything about Indian culture.

Danielle: You're right though! Good for you. Those are all things I want you to know. You're right: Culture, word choices, maybe even the structure of it. Maybe men speak and women do not. I don't know either, but it could happen. That's not rare. Patriarchy is a thing, so, yeah. 
That's totally something you have to pay attention to. If you think about it ... let's dive for a second. If you are at an Indian funeral and you are interpreting for them and most of the people who are speaking are men, but you're a female, how does that potentially impact your interpretation and the way people receive your interpretation?

Christina: Some might not be paying attention to you while you interpret because you are not a male interpreter. They could ... I mean, they could judge you real hard. That's life. Anyone can judge you real hard. They can also judge you on your attire because a custom Indian, it would be, like, I don't know a funeral would be like but they have real colorful dresses-type things.

Danielle: Yeah, and if you are in black, they might be like, "Hey, that's not appropriate. You're supposed to be in a sari right now."

Christina: They could turn you away; they could turn you away at the door and be like, "No, we're not going to have you as an interpreter."

Danielle: Yes. Good for you. So, there's a lot of things that could happen. There's a lot of pieces that can go into that. A lot of times, in medical settings, I know you don't want to do medical, but so you know, in medical settings that's really common when you have a male client who does not want a female interpreter for a prostate exam. There's also things that men understand because they're men, so when they're interpreting things, like I interpreted a phone call once for a deaf friend talking to another deaf friend and he picked up the phone and was like, "Wassup bitch?" That's what I got to interpret. It was funny but I had to acknowledge, I saw the person I was interpreting for and when I heard the person on the other end, I knew who I had to match, right? I knew that I had to be a boy. I had to take on that persona of such a bro.

Christina: Mmhmm.

Danielle: When you do stuff like that sometimes it's really hard to do when you're in a very culturally-influenced, a high-context situation where there's so much cultural influence that might impact the conversation, like an Indian funeral or whatever, because they're interactions are so heavily based in tradition. So, yeah, for sure. Good job.

So, with that, do you enjoy, overall and with this class too and your experiences this semester in general, interpreting? Do you still feel like this is the right field for you?

Christina: Yeah. I also feel like, even though I'm hoping to graduate in May, I'm not going to go in right away. I have a list of online courses that I can take to get my bachelors. 
Danielle: Awesome.

Christina: Ms. Costo, she sent out schools that can offer bachelors so I'm going to do that because I don't ... I feel comfortable but I don't feel confident enough to do it in the school system and have a child's education on my hands.

Danielle: Good for you. So, do you mean like a bachelors in interpreting?

Christina: Mm-hmm.

Danielle: Oh my gosh! Christina, that's so exciting. I'm excited for you. That's awesome. I totally understand that. I think this is the really hard part and I will tell you this now, even by taking classes, you're going to need to find opportunities to interact with Deaf people in whatever way. Like I suggested before, those little Deaf events. I don't know if you friended Ruby on Facebook since that time but finding those events and finding ways to communicate with Deaf people. I'm trying to talk to Ruby about getting some stuff set up where you all go into the Deaf community and do that, where you have a way to help others connect or help others do something. It doesn't have to be a connection thing but just to do something. That way, you have a chance to be involved with the Deaf community to practice the language, to see what things are like. That's really where, I think, most online programs miss out. So, I love that you're going to practice more and learn more. Just be sure to keep looking for those opportunities to stay in the community because that's the whole reason we do this. It's not the classes. It's not the formal stuff. It's the people we're going to work with. Don't lose sight of that.

Christina: Okay.

Danielle: I was going to ask you ... . well, I'm sorry, I still have a part of that.

What do you enjoy the most about interpreting and then the least?

Christina: Umm ... I enjoy, like, I really don't know. I really don't know, honestly.

Danielle: I mean, like, why do you like it? What makes you want to keep going or even get better at it? 
Christina: I like kids and so, like, the kids.

Danielle: But, you could teach, so then why interpret? If you like children, there's other ways you can be involved with them. Why be involved with them in an interpreting role? Why that?

Christina: Well, I think because when I first saw sign language, that girl and her interpreter in band, it looked real pretty. Just, the movements. It looked real pretty.

Danielle: Just the act of doing it. You just like how it looks and what it is. Okay. That's the sign language part, though. Right? That's the language piece of it. You can say you're not sure, but is there anything with the interpreting process that you enjoy where, for example, if you enjoy finding a "deeper meaning" of a message? Some people who are really into English like those kinds of exercises because they like analyzing literature.

Christina: I hate analyzing.

Danielle: You hate it?

Christina: I hate it. The project was pretty difficult for me.

Danielle: That's important to know. It's also really important for yourself too. That's the whole process of interpreting is analyzing. I'm not saying you have to love it but you have to find a way to somehow enjoy it because you have to do it so much, so that in order for you to really do it ... maybe once you practice it and you realize how much more capable you actually are in doing it, I think you might enjoy it more. Right now, you might think it's awkward and uncomfortable. As humans we're kind of like that. You might feel better as you continue doing it. You might enjoy it more as you get better at it. Just try really hard not to dismiss it because you have to do it in the field.

So, I was going to ask you before, but you kind of told me: After graduation, you will not go right into the field but keep going with your bachelors degree.

Christina: Mm-hmm.

Danielle: Good for you. Which school do you think you're going to go to?

Christina: Umm ... I was talking to my mom about this and she works in the schools as a 
janitor. She's always getting updates and stuff, not even just janitor stuff and Washington Ivory, somewhere in Harrison County, there's a few Deaf kids that have just one interpreter as of right now. They share just one interpreter. And, so, well, I'm going to try to stick in Harrison County so I can still live with my parents and save up money to live somewhere else. So, Harrison County mostly.

Danielle: So, what school?

Christina: A school in Harrison County that I can drive to. I don't have a preference on what school. I've been to three in Harrison County and none of them, I didn't like none of them.

Danielle: Wait, what kind of schools are you talking about? You were saying for your bachelors degree.

Christina: Oh! I thought you meant which school I wanted to interpret at.

Danielle: No, I mean for your bachelors degree. You said you're not going into the school system right after, right?

Christina: Oh, there's . . it started with a B or a C. I can't really remember right now off the top of my head. I have the links but it's the one that Ms. Nealy went to to get her bachelors.

Danielle: Okay. I don't know which one. I will have to look and see. I'm glad. It's online, too. Okay. So, are you going into the school system or no?

Christina: I want to go into the school system.

Danielle: But right after graduation?

Christina: Not right after graduation.

Danielle: Okay. Do you want national certification eventually?

Christina: Eventually, yeah. 
Danielle: Cool. Okay. Do you want to stay in the school system forever or you're just not really sure yet? Get started and see what happens?

Christina: Get started and see what happens.

Danielle: So, if you could, or not, would you pick interpreting all over again?

Christina: I would . . . I would still pick it but I would double major in something else like vet.

Danielle: Okay. How come?

Christina: Because I knew that going into interpreting, not knowing anything besides the ABCs, it was going to be very difficult and it is. And, I knew that. And, I've always wanted to be a vet. I grew up and wanted to be a vet. I wanted to help animals. And then, I was like I want to help people too, but I don't want to be a nurse because I can't do blood. I can't do human blood on me. Animal blood doesn't really matter, but so, I knew I didn't want to do nursing and wanted to help people and also wanted to help animals. And then, I was like, do I really want to spend all this money just so I can cry over an animal that's not mine dying? But, there's also, just, not just the animals dying, I'm also saving an animal so I would like to do that, so I would double major in both. I probably confused you.

Danielle: I know what you mean. I am going to be real with you. You are going to be in situations that are absolutely terrible, so you didn't really escape it. I was like, "Christina, you didn't escape it." That's life. We can't avoid it. People try to do that. Good and bad things happen. That's life, so no matter what, you're going to find it. Now, you're going to find it in interpreting.

Christina: I would cry harder. I know I'm going to cry. I cry a lot but crying over a dead animal is worse than crying in a situation, a child tells me that's happening at home.

Danielle: Gotcha. Okay. Yeah, good to know for yourself, too, right? That's your threshold, which means if you have to interpret something for animals . . . when I was working video remote interpreting, I was interpreting for Petco Hospitals, it's the Banfield brand or company, I guess. So, we would interpret for those vet appointments, the really difficult ones. Even in those contexts, I thought I would interpret human medical interpreting and then some of it turned out to be animal medical interpreting. That was hard. So, I totally know what you mean and it's good for yourself to have those kinds of things in the back of your mind. If you get to the point when you're interpreting anything, human, animal, vegetable, doesn't matter, if you're interpreting for those people you need to understand that you might get overly emotional. You might need some help. I would always put out a call sign. I would put a hi-sign to ask for help 
because I knew I couldn't make it through 2 hours. 20 minutes? Maybe, but more than that, I can't do it. So, I at least could give people a buffer where I could stick it out for a little bit but knowing that about myself is important. Good things to have in the back of your mind.

Okay, so with all of this discussion of having the skills of an interpreter that are language based and then the things that are not language based, like empathy, what does it mean to be an interpreter? If you could summarize it with those little key concepts in mind, what would you say?

Christina: So, describe an interpreter to someone who doesn't know what an interpreter is?

Danielle: Yeah. So, there's two parts: One is the role of the interpreter as far as what's their job and then what's the role of the interpreter in the Deaf community because one is the job that they do, the actual function, and then the other is their position in the Deaf community. Is that more clear?

Christina: Yeah.

Danielle: Okay.

Christina: Their role for the first part, interpreting, would be language. Like, um, I don't want to say language bridge but that's the first thing that comes to my head. I know that's kind of correct but not really correct.

Danielle: So, what do you feel is missing out of that? What's wrong with a bridge?

Christina: The human part.

Danielle: Cool. That's the other side I was talking about. What about the human part? What's involved in that human part?

Christina: It can bring more ... I don't want to say awareness ...

Danielle: Awareness is a good word.

Christina: More knowledge about the community to those who don't understand it. 
Danielle: Yes. Yeah, totally. And that same thing goes too for your ability, if you have that knowledge, then you are better able to communicate it across a barrier, across that bridge, because you understand both cultures then and well enough to make those adjustments where it all makes sense. You can respect both cultures and foster that respect out of both clients, both sides of the interaction. That's an interpretation win. When both people leave the interaction understanding that their languages and cultures were respected, you have done your job as an interpreter because you just showed both people that their languages, neither one is better than the other, and that is our entire purpose. So, like, if you can have that understanding, boo-yah. That's where you want to be. Good answer. Good for you.

So, do you feel like you can do those language things and the non-language things? The humanness? Do you feel like you can do both? Or not yet? Give me a scale: 1-10.

Christina: I feel like I can give the culture side, the human part, but on the language side, the barrier, I can but not as at the level that it should be.

Danielle: Gotcha, okay. That just comes with experience. To be honest with you, that's just an experience thing, but good. Do you feel, now, more than you did at the beginning of the semester that you understand what you're supposed to do as an interpreter? Like, are interpreters and translators the same thing?

Christina: No.

Danielle: Why are they different? I am going to beat this into each one of you.

Christina: An interpreter is one that can-- it's not on paper.

Danielle: Good. It's spoken. That means that language, so, to some people that's the only distinction. To other people, it's also the immediacy of it. So, to some people translation happens on paper and not necessarily in realtime. Or, I've provided sight interpretations before meaning that I've interpreted a document into sign language when a Deaf person was at a doctor's appointment to better understand what the letter said because it was in another language. That's not translation. A it was in their language and it happened in real time. If I recorded that interpretation, it might have been closer to translation. Some people might argue that it's still an interpretation, but others could say that it's closer to a translation because you just translated it into a different language but it's the same meaning that you're communicating. So, there's some nuances in that. 
Anyway, do you feel like you're an interpreter? You're not a translator. What makes you an interpreter? Or maybe you're not there yet. I don't know.

Christina: I feel like I am closer to being an interpreter. I can interpret real-time, like the videos, the exercises. I can do that, but it also takes me 5 days just to look up the vocabulary.

Danielle: I was just going to ask you what you do for those 5 days? And, my brain wants to scream at you that you don't need the vocabulary.

Christina: I know.

Danielle: Okay. I won't lecture you again. I already did that. I won't do it again. So, speaking of lecturing you and telling you all the things I want you to know, do you feel like there's anything in the class that's been really challenging, either in terms of the way you experienced the information, the way it was presented or anything that was really challenging, as far as the type of interpretation? Maybe one is a different register, more formal, one's more for children, that kind of thing. Anything like that that you found really challenging about the class?

Christina: The interpretations where it was stuff that, like the Shakespeare, where she talked about Shakespeare. I never really paid attention in English when we went over Shakespeare so I had no idea what she was talking about. But, then ... schema! That's the word I'm looking for, but the one where we did the interpretation of the California rolls. I know exactly how to make California rolls so that was a lot easier for me.

Danielle: Yeah.

Christina: So, schema and a difficult one was the accent. The indifference where he had the accent.

Danielle: Yes.

Christina: Schema and accent were the ones that were challenging. The schema was not as challenging. If that makes sense.

Danielle: Yes, that makes perfect sense. Yeah, and that happens. That's why interpreters have to be knowledgable about everything. As much as I hate to tell ya, if you're working in the school system, you are going to have to do literature, even if you hate it. You're going to have to do Englsh things again because if you had to go through it then they have to go through it or 
something similar at least and that means you have to know all of those things again. Like, I was never good at math until I became an interpreter and then I interpreted a bunch of math classes and I realized when it wasn't me under the pressure of learning it and not feeling smart, I could learn it and understand it, but going into those classes in the first place, I was terrified because I had no idea how to present it. I didn't know any of the words. I didn't pay attention in math. I forgot it. It was scary. When you get into those positions, you realize it is not about you and you need to have the knowledge, the information. That also means that in those contexts, you prep more, which is fine, you just prep more. If you know you're going to work on Shakespeare that day then before you go, you review some of the words they might use so you're prepared to break them down, and not surprised. The last thing you want to do is spring on miscommunication on a student who is trying to learn the concept. If you miscommunicate, they don't learn, so you have to know where you are, but like I said, that just means a little bit of extra prep. If that's your regular, full-time job, then okay. That's an easy one. That's just something you make part of your day, your preparation for your work. No big deal.

Is there anything you found to be really helpful?

Christina: When you explained the interpretting process and also explained glossing, that was very helpful, especially the glossing part. I did not know how to write in ASL.

Danielle: How do you think learning that helps you interpret? You did the other interpretations. How did you feel like the glossing impacted those interpretations? Or did it? Maybe it didn't at all.

Christina: In our assignments when we had written down the glossing and how to interpret it, I had written it wrong. I didn't get a good grade on it anyways. So, that meant I interpreted it wrong.

Danielle: Gotcha. Like I said before, I wish you guys had said something. I didn't know how little it was discussed. From my understanding, and I wasn't there, it was briefly reviewed; it was not really taught as much as it likely should have been because even though it is a small component it does impact one's ability to prepare an interpretation, so yeah, which is definitely a downside. That's a deficit. I just wish I had known that earlier because I would have explained. I made notes for myself in the future, so you know. I made a list of the descriptions that I need to provide and one of the things I am going to do is the video like you and I had and walk future students through the process so that no matter what they can review it and then we will also meet and discuss it. There's a description along with the first assignment because I realize how helpful those were. I'm going to try to bottle that experience for other people. I want you to know that the fact that you're saying that, and all of your classmates said it because we all worked together in the same way, every single one said that was so helpful so I'm going to try to bottle that so I can do it with other people since it actually did something. 
My last question for you is: How do you expect other interpreting professionals to influence your work in the future?

Christina: Can you dumb that down a little?

Danielle: Sure! As an interpreter, more than likely, as you know right now, there's only one interpreter working with several students in one county. But, there's going to be times when you will work with other interpreters. For example, like if you collaborate or team with the current interpreter in the system. How do you expect people like that, and other people, to influence your interpreting? Or do they not? And how do you plan on interacting with those people? Do you want to join an RID chapter so that you can be involved? Do you not want to do that? How do you want to be placed in the interpreting community? Are you an active member? Maybe not? Where do you want to be?

Christina: I want to be an active member because they do help other interpreters. I don't know how to word it. So, the interpreter that I worked with in the spring at the elementary, I still have her number and throughout the summer, we had stayed in contact. We had FaceTimed and gone over signs and just talked sometimes.

Danielle: Awesome.

Christina: So, I stuck with her. She helped me with my interpreting and that might not be with all interpreters, not all interpreters want to help others. I understand that. So, with my experience, interpreters help others. With the one in the school system right now with multiple students, she could reach out to other interpreters and say, "Hey, this subject. I don't know how to interpret it. How would you interpret it?" Or something like that. Does that answer the question?

Danielle: Kind of. I think what I'm looking for is a little bit more on how you interact with them, not how they interact with others. So, you gave me a little bit of it because you said that interpreters seem helpful. I would imagine you could expect collaboration when you have a chance to celebrate right?

Christina: Yes.

Danielle: So, you want those opportunities? How will you seek them out? You did answer the question. Think about it this way: Some interpreters don't want to talk about it and don't want to interact so what are going to do to seek out that professional relationship when others are not readily available, perhaps? 
Christina: I think it was what you said before, the RID interpreters in the community.

Danielle: A local chapter?

Christina: Yeah.

Danielle: There actually isn't one in West Virginia. I don't know if you know that or not.

Christina: I didn't. I hardly know anything.

Danielle: There isn't one in West Virginia, which is pretty telling in my opinion. It's pretty rough. So, you know, you did answer the question because in order to collaborate with people, what can you do? My suggestion to you would be if there's no way to collaborate with the RID chapter because one doesn't exist; there hasn't been one for like 15 years. It's been a long ... there's too much drama in a small town and way too much drama in a Deaf small town. In the future, when you move out of the state, look for local chapters you can get involved in.

That means that you should focus on the Deaf community. If you can't get involved in the interpreting community, which is okay as far as I'm concerned, get involved with the Deaf community. Having what we call in the profession, "Deaf Heart" is a really great thing and I think that's where you have a great opportunity to grow is in experiencing Deaf people, Deaf culture, Deaf language in natural interactions. You can live that life for a bit. You start to live like they do; the "when in Rome" expression. You start to live like that. I think the more you do that, the better interpreter you are because you pick up habits (good and bad), but you pick up habits of those people which makes you a really good intermediary, a really good bridge of communication between hearing people and Deaf people because you know what both are like instead of you being a hearing interpreter put into a situation where you try to make it work. You know what I mean? So, in the next couple years, since you are going to stay in West Virginia, those virtual events, get in them. Talk to those people. Play those games.

I want to figure out what those links are too. I'm not on social media. I want to play too. I miss that interaction. That literally is the best part. I like teaching interpreting and I like talking to Deaf people. I don't want to actually interpret. I want to talk about it and then I want to talk to people with it. That's the dream. So, like I said, since there's not the RID thing, focus on the Deaf community, which is not a bad thing for your language skills either. So, that's not a bad way to go about it. That's kind of my point: Look for opportunities even when they're not easy. Look for those opportunities. Depending on how you do, you know that you're borderline. The next set of grades are point-dense. I want you to think about what you can do now and in the future. 
When's your final interpretation?

Christina: The 20th at I think 2:00.

Danielle: Yes. Okay.

I will send you the audio for that on Thursday at 2:00. So, I initially said 12 hours but I'm not sending it to you at 2 AM. I'm not doing it so I will send it to you 24 hours prior. I don't want you to go crazy over it and panic about it. That's not the goal. So, I'm sending it to you 24 hours before but that doesn't mean you have to obsess over it. Use the practice, the procedure that we talked about, gloss it a little bit, think about the signs, but you're not going to take 5 days. I'll give you 24 hours to think about it. Take a little time with it and plan your message so that when you start interpreting for me, you know where you're going with it. You know where the audio is going but it is still pretty raw: informed, but raw. I will use the rubric that's on the final project and then the one that's posted. That same rubric. That's the one I'm using to grade so that you know what I'm looking for. Okay?

Cool. If you need anything else, I know you submitted your final project, but if you need me between now and next week, let me know. Same for the vlogs. If you need something, let me know. Okay?

Christina: Okay.

Danielle: Thank you for time. Thanks for moving the meeting up with me. I appreciate that.

Christina: It's fine. I was in the middle of making lunch when you said that.

Danielle: I appreciate that because it means I didn't have to scramble after our meetings to make my last one. This is just a day of meetings. So, here we go. Anyway, have a great day. If you need me, you know where to find me.

Christina: Alright.

Danielle: Thanks. Bye. 
Christina: Bye. 


\section{Appendix K}

Interview 1 with Willow

Danielle: You might see a recording icon in the corner. It is really good to meet you. Do you go by Willow? Kate? Katie?

Willow: Katie, Willow. Either.

Danielle: Sounds good, just making sure. You know this is recorded but this is, as it says in the cover letter online, this is for my dissertation research. If you are not comfortable for any reason, you are more than welcome to contact Jamie and let her know. She will let me know. You don't have to feel uncomfortable reaching out to me. You have someone else you can talk to.

Willow: I am part of student government. We record all the time.

Danielle: Awesome. I want you to know, too, everything I collect, when I am ready to type it up, analyze my data, everything will be anonymized. I will make sure your names are off. It will not say Pierpont. It is stated, but not identified. I know you said you're comfortable but it makes me feel better to know that you know.

Willow: That makes sense.

Danielle: Let me get my questions. Before we start with these, do you have any questions about the way things are set up on Blackboard or any issues with what's there and what's due this week? Anything you want to ask before these questions?

Willow: What do we have to do with the v-log?

Danielle: The instructions should be online now. The first time they weren't. I will show you exactly where you can go but depending on when you looked it might not have been accessible. A student told me it was not available and I had to click a couple buttons.

Willow: I did the survey last night.

Danielle: Okay, awesome. So, here's what you'll do: I will share my screen. Let me know if you can't see it. 
Willow: I can see it.

Danielle: Beautiful. So, here you will see the vlog assignment. You will see the instructions and a submission link. The instructions are right here. This is just a prompt. It is supposed to be a PDF that's taking an eternity. This is what you are answering. Here's the question: Did it change anything? Did it help you understand anything about yourself and as an interpreter, what kinds of implications do these results have? How do these results maybe impact how you see yourself as an interpreter? Maybe they don't. I'm glad it's there.

Willow: Now I know what to do.

Danielle: I apologize for that. I had to make a few clicks. Soon as I clicked it, it showed up. Technology, right? Okay, so what made you decide to be an interpreter?

Willow: I have two Deaf friends. In sixth grade, I actually wanted to learn sign language to communicate with one of my peers. Then we became best friends and since sixth grade until now, I've been best friends with her.

Danielle: Gotcha. So, it's a passion. If you want to connect with friends, that is a deeply rooted feeling then.

Willow: The interpreter that was with her taught me some signs every day.

Danielle: Gotcha. So, you had constant exposure. That's nice and lucky.

Willow: Now, I help with Deaf camps over the summer. This year, they're on Zoom, but it's called Camp in County.

Danielle: Yes. I've heard of that camp. That's awesome and so cool. So, you are confident in what you decided to do. This is your home and where you're supposed to be. That's great that you feel that way.

So, at what point, do you feel like you get to self-identify as an interpreter? What does it mean to be an interpreter? 
Willow: If no one else can communicate, I feel like an interpreter sometimes. If she's in a store and they don't know she's Deaf, I'm helping her communicate, kinda.

Danielle: Yeah. Gotcha. I understand that. So, in those moments you would consider yourself an interpreter.

Willow: Or even if she comes to my church, I stand up there and interpret the whole time to interpret for her.

Danielle: Okay. So you have the exposure with your friend, but in general, are there certain qualities an interpreter should have?

Willow: A lot of practice, I believe.

Danielle: Okay. Do you feel like you need more of that?

Willow: A little bit but not much. I kind of went with my pastor when all the shutting down happened with the Coronavirus. I was signing with him, the message and some songs and stuff.

Danielle: Good, okay. So you've been busy. That's great. So, practice. When someone says or asks about "an interpreter," what would be your answer to that?

Willow: They help the Deaf and the hearing connect with each other. With the Deaf, like if they don't know something, they can ask the interpreter to ask in English to the person that is hearing.

Danielle: Gotcha. Okay. So, communication facilitation, too. That's great. So, as an interpreter, what's your role in the Deaf community? Or just an interpreter in general? What is an interpreter's role in the community?

Willow: To connect with both the hearing and the Deaf.

Danielle: Okay. How do they connect with the Deaf? How does an interpreter connect with the Deaf?

Willow: Can you repeat the question? 
Danielle: How does an interpreter connect to the Deaf community?

Willow: By knowing their language, maybe knowing different things they can connect to with the Deaf. Maybe there's a CODA is an interpreter and they just interact and connect with them.

Danielle: So, comfort with the language and interaction, probably what I would call immersion. Putting yourself in that culture, in that context to interact with the community. I agree with you completely. So, these questions probably sound like I'm repeating myself, but these questions really get to what's your responsibility as an interpreter to the Deaf community?

Willow: To help them communicate in any way they need. If it's the doctor, the lawyer, court. My job is to help them communicate.

Danielle: People are people, no matter where you go. There's going to be human conflict. There's going to be issues with that communication. Things will get in the way of you your job to interpret. Not just that as an issue, but perhaps other issues, too, but what kind of challenges will you experience as an interpreter?

Willow: I have not experienced much but having someone get aggravated with you. Maybe you are doing the wrong sign you were taught but they know it a different way and they might be confused.

Danielle: Anything with the interaction between Deaf and hearing client? Take the interpreter out of it. Let's assume and be optimistic that once you're done with the course you are proficient enough to address those issues, if you're not sure what you're talking about. Hopefully you are comfortable enough to clarify that. Let's assume proficiency. What about between hearing and Deaf clients? Anything you might see or you have experienced as far as conflict? Or issues that get in the way of being able to interpret?

Willow: So, back to my friend: She had a cochlear implant and they disconnect it. She communicates and reads lips and sometimes the miscommunication can get in a big old mess.

Danielle: Yes.

Willow: Look at me, talking with my hands. 
Danielle: Haha you're fine. I'm sitting on my left hand and I am holding the mouse with my right hand because if not, I would flail. You're good.

Willow: I'm sorry.

Danielle: No, I had to teach myself when I went through the program, I had to be taught how to not flail because that's why I have to sit on my left hand and right hand on mouse. I'm playing Twister.

Willow: Yeah, I'm trying to hold my hands and it is not working.

Danielle: Don't fight it. We are interpreters. I don't expect you to stop. In a few minutes, I will get tired of doing this and I will start flailing. But yes, that will cause communication. If your deaf friend is depending on reading lips and speaking, then someone might think she can have a full conversation and then she can't. So, how do you think as an interpreter, right? If you are in that interaction, how can you help that miscommunication? Can you do anything about that?

Willow: Well, if I was with her I could tell the hearing person, "Okay. I need to tell you she is deaf, but she can read lips." So, do not talk slow but make it so she can see your lips.

Danielle: So, providing information for what they can do to work with her. You're willing to communicate what this person is going through and might need from you. Okay.

Willow: A lot of times, if they have a beard or mustache she has a harder time.

Danielle: Yes. That makes perfect sense. Can you imagine that's the only way? There are deaf people who don't have language skills so they depend only on lipreading. Then, you have a person who comes up who has a beard, or a mustache, or both. And they have no idea what's being said? I can't imagine how that feels. I can't imagine obstruction of communication because of facial hair. That seems very sad to then be left without anything.

Willow: My dad has a mustache. It takes her forever. I have to be there to sign to her because of that.

Danielle: Right, yeah. To get around that, or to bypass that fact. Yes, for sure. That's funny though. That's really funny. 
Willow: He won't shave it.

Danielle: [Laughs.] Yeah, so you can't tell hearing people to shave their mustache. You can tell your family members but you probably can't walk up to a client and say, "Listen, this interaction would be twenty times smoother if you just shaved your facial hair off, okay?" Can't really do that part but speaking clearly and not doing one of these [turns around], if someone is depending on reading your lips, not turning around to talk where the person can't see you. Yeah, that makes sense. So, all of that, and I don't know how much you have experienced as far as, diversity of experiences, but is there any reason that you can imagine that someone might leave the interpreting field? Maybe they just decide it's not the right fit.

Willow: Maybe with a client or something, maybe they got into it, and they might want to go into another field. I don't know how they would. I love interpreting.

Danielle: Okay. I'm not suggesting that you should get out. I'm not ever suggesting that. I guess what I'm getting at is there are different experiences that you have as an interpreter that ... what classes have you taken thus far in your program?

Willow: I have done all of first year. I had to take 2202 and 2203 from last year.

Danielle: We will talk about that in a second because I want to hear more about your challenges with that. I definitely want to make sure that you don't have to take it a third time. I don't want that to happen for you. I want you to be really successful.

Willow: That's my goal.

Danielle: Yeah. Okay, so you've taken . . . once you're done with 2202 and this one, 2203, are you graduated and done?

Willow: There's another one that I can't remember what it is.

Danielle: That's okay. So, then you have one more and then you're done.

Willow: I think it was Jasmine Campbell's [inaudible] last semester.

Danielle: That makes sense because it would be a spring session. Okay, yeah. So, all of those pieces ... when you go through, for example, the ethics class, one of the things you probably 
should have learned about is vicarious trauma. Does that mean anything to you? Do you know what that is?

Willow: Can you explain that a little bit more?

Danielle: Yes, sure. So, vicarious trauma is the experience and the feelings that interpreters, not just interpreters but people in other professions, too, but interpreters will feel given your exposure to that situation. So, when you witness a Deaf person going through oppression and being marginalized by whatever the case may be, at some point, interpreters do start to feel that kind of trauma just by living through that experience with their Deaf client. So, vicarious means living through someone. Trauma is trauma. So, vicarious trauma is experiencing trauma by being, basically, by being a bystander, right? As interpreters, our job is not to interfere or intervene. Our job is to bridge communication and make information accessible but sometimes it happens where there are other pieces that affect us and we do get those feelings, right? We do have those sensations of being oppressed just by our mere exposure to that interaction. Does that make sense?

Willow: It's like helping, like . . you want to help them, but you know that it is your job just to sign, but you are with them for so long that you get a connection to be with them.

Danielle: It might not even be that you have to be with the person for very long but just witnessing it sometimes is enough. If you think about, like I said, I don't know if you have experienced situations like this, but I have been in quite a few where the hearing person is just not interesting in accommodating. They think the whole thing is ridiculous. I have interpreted for doctors like that. That's not to say all doctors are like that but I have interpreted for medical professionals who will dismiss the deaf person and talk to the interpreter, or try to talk to the interpreter, which not only is infuriating because how dare you but is also really heartbreaking when you think about, "What if I wasn't here?" What if there wasn't an interpreter to say, "Why are you talking to me? Talk to your deaf client." What if my presence was removed and this person was on their own? Trying to navigate this situation with someone who is not interested in helping, right? So, in those kinds of contexts, that can be really hard for an interpreter.

Sometimes, when those build up, interpreters, we call it "burnout," right? There's only so much of that that people can take before they're exhausted and can't maintain. Have you ever experienced that before?

Willow: Not really.

Danielle: Okay.

Willow: But, I know an interpreter that's here in Raleigh County, well, I think she's still an 
interpreter.

Danielle: [Laughs.] Okay.

Willow: Corolla Beasley, you might now her. She's a CODA. Both of her parents are Deaf.

Danielle: I probably met her at an event. That's probably why I know her name.

Willow: She was telling me experiences like that.

Danielle: Gotcha. Would you ever leave for the same kind of reason? Would you ever leave for the same kind of reasons? Would you ever just say, "Listen, this is . . . not being able to do anything is too much and now I'm done?" Do you think that would ever happen?

Willow: Probably not, I like interpreting too much. I would get aggravated. I might take a little bit off.

Danielle: Fair enough.

Willow: Because sometimes, you can, in general get aggravated with a job or anything.

Danielle: Of course.

Willow: I work at Kohl's right now and it is very aggravating some days.

Danielle: I can't imagine. Being in retail right now cannot be fun.

Willow: It's not. The masks, everything.

Danielle: I can't imagine, so kudos to you for the patience that you have. Kudos to you.

Willow: Everyone is so impatient. 
Danielle: Oh my gosh, yes. They want instant gratification and quick. Faster service than we ever had because no one likes to be inside now. There's too many rules.

Willow: Yeah.

Danielle: Yeah, I hear that.

So, I know you've interpreted for your friend before, but if you have interpreted for other people, how do you feel about that experience? Do you feel like when you graduate you'll be ready to interpret? Are you ready now to interpret?

Willow: I believe I am ready now to interpret, somewhat. I need to refresh my memory.

Danielle: Cool.

Willow: It has been forever, but one of . . . well, she's a Deaf teacher in Raleigh. She does classes like when the pandemic first started. She did like once a day, did signs and stuff. So, it refreshed my memory.

Danielle: Good, good I love that.

Willow: She does them at her church, normally.

Danielle: Oh, okay. Is there a context that you feel most confident or comfortable interpreting?

Willow: I do very good I fingerspelling.

Danielle: Okay. So, that's a big piece of your confidence then when you are interpreting both when you're signing as well as receptive, right? You're good with the receptive part, too?

Willow: Yeah.

Danielle: Cool, me too. It's one of my favorite things. 
Willow: I get fingerspelling right away.

Danielle: Yeah, I hear you on that one. What about where you would want to work? Do you want to work in a school system? Would you rather work not in a school system? Somewhere else? Do you want to do community work and work everywhere? Where do you want be when you're done?

Willow: I don't want be in the school system at first. I want to gradually take myself up to maybe [inaudible.]

Danielle: Gotcha. Is there a context you would never interpret in?

Willow: I don't think so.

Danielle: So, when you're ready, you would do legal?

Willow: How?

Danielle: What do you mean how?

Willow: You glitched for a second.

Danielle: So, once you're graduated you would interpret legal, for example?

Willow: Mm-hmm.

Danielle: Awesome, medical too. You would be okay with that when you are ready, you would be comfortable.

Willow: Yeah.

Danielle: Awesome, good. Okay, cool. What makes you feel like you could take any of those on? Not that you should question that but I'm just curious. You have a lot of confidence. What gives you so much confidence? 
Willow: I guess knowing a lot of the signs and building my confidence up throughout the years.

Danielle: Okay.

Willow: I think that's a big part of anything. You never know, but yeah.

Danielle: [Laughs.] Yeah, there's times you walk into a difficult situation and it's just difficult. I know what you mean but when you have that confidence no matter what situation you walk into, you feel like you can figure it out. That's a good place to be. Good.

Let's talk about what happened in the past. So, let's talk about your successes from the previous time you took this class and then we will talk about the challenges. What did you do really well that you took this class, 2203? What were you really good at?

Willow: I'm trying to remember what we actually did.

Danielle: Okay. Because it's been so long?

Willow: Yeah. The only thing I'm very bad at is if I don't understand it, I will take forever to do it. I need to reach out when I don't understand.

Danielle: Do you mean understand an assignment?

Willow: Yes.

Danielle: Okay.

Willow: That's one of my downfalls.

Danielle: Okay. Do you think that's what led to you needing to retake this class this time? You did not ask for clarification? Did you say yes?

Willow: Yes. 
Danielle: Okay. Sorry. Yeah, so that's definitely a big thing for you. Do you feel like you will reach out when you have those questions? Do you feel like you're more comfortable now doing that?

Willow: I am now more comfortable. I think it was just . . I was up in the dorms and trying to work too. I was trying to do classwork, too. It was too much.

Danielle: Okay. That's fair. I can understand that. So, were there other challenges or other things that maybe got in the way? Or was it really a time management?

Willow: Time management, normally.

Danielle: Okay. That's hard with online classes. That's definitely . . . most people who struggle with online work state that most of the time, they're time management issues. That doesn't mean that you shouldn't try to improve, or people in general, but you should know that what you experienced is something that I think a lot of people go through and that once you get mentally ready to address the concern, then you can address the concern. It sounds like that's what you're going to do.

Willow: Although I feel like ...

Danielle: Is there anything I can help you do to get to that point?

Willow: Yes. I have a question. I had a question: When I need to email you, or could I Zoom you, or?

Danielle: All of the above. You can record a video and send me a YouTube link. You can draw me a picture and give me arrows for things you don't like. Honestly, whatever you need we'll figure that out. If you need a face-to-face, boom. Let me know when. Whatever it is. I am reachable. Whatever you need. That's the beauty of having four students in the class and it being you and three of your classmates, I have the ability to do that, which doesn't always happen. But, I have the chance now, so whatever you need. If it's something that you're asking me about an interpretation, I'm not going to answer that on an email because I can't explain that on an email, right? But if you're asking me to describe an assignment then I can describe an assignment, I can do that.

Willow: I do better face-to-face than in an email. 
Danielle: Gotcha, yes. So, whatever you're comfortable with, which would make online learning and time management difficult if you are not comfortable with an email and you don't feel like you have other options. It makes sense why you would then struggle. That makes sense. I also heard, and I don't know if this is systemic, if this is just what happens, but did you experience where you sent an email but didn't get a response? Did that happen to you?

Willow: Yes. Sometimes. It would be a few days.

Danielle: Okay. So I will answer your emails within 24 hours, which I want you to know that it's probably going to be faster than that but 24 hours is a safe bet. I have a life so over the weekend I might not be immediately responsive, but Monday morning, first thing, I will get back to you. I won't leave you. I had a classmate of yours tell me that after the assignment was due she got a response from the instructor. So, that won't happen.

Willow: Alright. Yeah. The weekend, everyone has a life on the weekend.

Danielle: Right. I just know it makes it difficult then because if you are working, sometimes the weekend is when you can get stuff accomplished. Sometimes, those kinds of . . I will still try to answer because I understand that when you are in an online program your school day does not end on the week day. Your school day carries over. I understand that. I will try to answer but during the week I can guarantee 24 hours. Over the weekend, I can't guarantee but I am willing to say I will answer. If you say, "Hey, I am struggling with this" or "This isn't working like I want it to," I'm pretty sure we could find a minute to have a conversation, if you absolutely were struggling. I won't leave you days after. That's not fair.

Willow: I appreciate that.

Danielle: Yeah, and I'm sorry you experienced that. It was interesting because I had two different students, on two separate occasions, tell me the exact same issue that they ran into. And I was like, "This should not be repeated. One thing is really sad. Two times means it's happening too often. That's not okay. That won't happen.

Willow: Yeah, I've had that happen too. We had a final exam and the whole Blackboard went down and no one could get on to it. Well, she was like "you're going to have a zero." She did not realize it was Blackboard that was down.

Danielle: Oh. Well, two things: (1). I hope Blackboard doesn't go down but it could. So, if those kinds of things do happen, please let me know that something is going wrong so I can look into the issue because that's not fair. If we're online, the systems need to work. If you're going to require people to be online, you have to give them a system that everybody can access. That's 
the point. There's that. I will advocate for all of us.

Willow: The whole Pierpont went down. I was like, okay. I can't do my homework.

Danielle: That's big too. Reaching out to me to let me know Blackboard is down. We don't need Blackboard to work. We need Blackboard because it's a central location where everybody can go but if something like that does happen, I'll send the assignments that way. Or if you can't $\log$ in, I'm more than happy to send you assignments another way. Not every time, I don't have time to submit every assignment that way but I'm happy to help you in those issues. That's . . . yeah. I'm sorry you went through that. We won't do that again because I've communicated with some of your other classmates, too. There are three big things that I'm studying and focusing: one of them is cognitive presence, social presence, and teacher presence in an online classroom. Cognitive presence is being involved with the material where your brain is really thinking about what it means to interpret. Social presence is feeling like you have classmates because especially in this field, we have a great opportunity to collaborate. We often don't have that opportunity; we do a lot of solo work. So, I do want to make sure that you guys understand how lucky we are to have people who we can work with right now. It won't happen always. And then, teacher presence is me being available. That includes responding to emails, that includes meeting whatever you need when you need it within reason, of course, so that we can, so you can be successful. That's really what I will be focusing on. If you feel like at any point, you are disconnected, that's something I want you to mention in your vlog, for example. That way, you don't have to feel like you're telling me directly. That can be a weird conversation. But this way, you have a way to express that kind of aggravation or that disconnection, even if you are not aggravated with it. That disconnect, I need to know that so I can bring it back together? Does that make sense?

Willow: Yes.

Danielle: Okay, cool.

I didn't think it would take long. I'm glad it didn't. Is there anything else you want to ask me?

Willow: No. 
Appendix K (continued)

Interview 2 with Willow

Willow: Let me turn you up a little bit.

Danielle: Okay. Sounds good.

Alright, so, let's just dive right in so that we don't take too long because I want to eat lunch, so . . . [laughs]

Willow: [Inaudible]

Danielle: First things first, do you feel like through the semester that you've grown as an interpreter?

Willow: Yes.

Danielle: Yeah? How so?

Willow: I feel like I have got more skilled throughout, not so much using English and using more ASL.

Danielle: Okay.

Willow: I know in some of my videos there's still a little bit of English but I catch myself.

Danielle: Oh! Nice. You're more self-aware and that's the goal. I'm not expecting you to be perfect but if you're more self-aware then I don't have to be there to correct it because I've made you aware for yourself. And that's the goal because then you don't need me there anymore and that's the dream.

Cool! So, as an interpreter, there's obviously the linguistic skills that are important. Let's put language aside, so not language-related things, what kind of skills does an interpreter need to have to be good at their job? 
Willow: They need to be focused on what the speaker is saying.

Danielle: Okay. What about not language things? They definitely need to focus, so they've focused, they've gotten the message, they understand. Then, what? Okay. I got the message, now what am I doing with it?

Willow: To figure out how they're going to interpret it to their client or student.

Danielle: Okay. And what kinds of things do you have to take into consideration when you're planning your message that way? That reconstruction process. What kind of things do you think about?

Willow: Your facial expressions and how, maybe your body language. If it's a good message or if it's going to be a bad message.

Danielle: Okay. So, conveying affect, depending on the feeling of the message, like you said, good, bad, joke, not joke. That kind of thing. We're still kind of hovering around language things. What about people things? Let's think human-related things. Maybe that will help a little bit. What human-related skills do interpreters need to be good?

Willow: I didn't know it wasn't just the words. It's early in the morning.

Danielle: That's okay. I don't want to just give it to you. I really want you to get this because I want this to be the point, the take away of the conversation. So, people have the language skills and that's great but there's more to the interpretation process, right? There's way more to it. So, what's involved?

Willow: Well, you've got to want to do the interpretation.

Danielle: Okay, so what does that mean? When you "want" to do it? How does someone not want to do it? What do you mean by that? What's the difference?

Willow: If you've been an interpreter for a very long time then having someone who just came out in the field, they are wanting to do it... 
Danielle: Gotcha, so there's a motivation factor for sure. There's definitely motivation. And there's also, so really what I want you to take away is the need for empathy, right? Someone who doesn't have as much motivation likely will have less empathy because they'll be tired, right? They're not as motivated, so they're not as intrigued to have those feelings. They're not as energized to feel some type of way about somebody else or to have that empathy because they're tired because they're not going to have that. Not sympathetic, it's not pity. It's just understanding where someone's coming from. So, do you have empathy? Do you think you're somebody with empathy?

Willow: Yes.

Danielle: Okay. So, what can you do to make your empathy better? Because we can always get better. What can you do to increase your empathy to make you a good interpreter?

Willow: I mean, getting to know maybe words I don't know or to increase my vocabulary.

Danielle: Does that make you more empathetic when you have a better vocabulary?

Willow: Yes and no.

Danielle: Okay, how so?

Willow: How in fingerspelling a word, you would actually know the word than having to fingerspell it.

Danielle: I'm not understanding how that makes you empathetic though. Empathy is really the understanding of somebody else, like the ability, people say, colloquially, just in speech, the ability to walk a mile in somebody else's shoes. That's kind of how I describe empathy. It's a little more than that, but that's a good place to start, at least. So, how does learning signs make you more able to walk a mile in someone else's shoes or see someone else's point of view?

Willow: Maybe, say they know ASL and maybe I'm using English and I'm not understanding them, or I could even use gesture or classifiers to get through what I'm trying to say.

Danielle: Okay, okay.

Now, is empathy an important skill ... I don't know if I asked you this or not, but is empathy 
important for interpreters?

Willow: Yes.

Danielle: Why is it important? I just don't remember what you said.

Willow: To, like, make sure that the people you're working for gets the message.

Danielle: Okay.

So, do you enjoy going through that process of interpreting? Would you pick learning how to do this job all over again? Do you enjoy it enough to say that you would choose it all over again?

Willow: Yes.

Danielle: Good for you. Why do you like it so much?

Willow: Well, because you get to communicate, even with us hearing, if you know it and you are in a room or something and you don't want to speak or you can't speak, you can sign to each other.

Danielle: Mm-hmm.

Willow: I do that in church.

Danielle: For sure.

Willow: Until I don't know a sign and then I'm like, "Uhh . . . I need help."

Danielle: Yes, yes. Exactly.

Okay, so what do you enjoy the most about interpreting and the least about interpreting? There's always good and bad, so what's the best and what's the worst part about interpreting? 
Willow: Um, the best part that I like is, like, getting to know different people and signing, and improving my skills even if I don't know something, they teach me something.

Danielle: Yep.

Willow: That part is, is when someone talks so fast and you can't interpret for them.

Danielle: [Laughs.] Yeah, that quick processing. Yeah, that's a tough one.

Willow: I've had two times like that, trying to interpret for one of my pastors and they talk very fast.

Danielle: Yeah, yeah, it's humbling when those things happen. You're like "oh my gosh, you're so quick," but that's when you focus on the point of the message instead of the words themselves. That's exactly why we do that. We focus on what they're getting at so that you don't have to worry about catching every single word because you could probably say it in 11 signs. What they go "blah blah blah" about because hearing people talk too much, we could put out in 20-25 signs, not that Deaf people aren't chatterboxes. I'm not suggesting that they're not because they totally are, but we can better represent concepts than English words can. Sign language does a much better job of representing concepts.

Okay, so let me ask you some demographic questions. These are super easy. I need like age range, your background, in or out of state, that kind of thing. I'm going to give you an age range, you tell me where you are. 18-21, 22-24, 25-27, or 28+.

Willow: 18-21.

Danielle: Okay. Where are you from?

Willow: Beckley, West Virginia.

Danielle: Is that where you live now?

Willow: Yes.

Danielle: Have you always been there? 
Willow: Yes. I went to Fairmont for college but I have always lived in Beckley.

Danielle: That makes you in-state. What's your relationship to the deaf community? Do you have any deaf family members? Anything like that? Just deaf friend, right?

Willow: Deaf friend, yeah.

Danielle: Yeah.

Willow: I know about 7 people that's deaf.

Danielle: Gotcha. So, you sign a lot, I'm guessing. Yeah, you talk to a lot of deaf people. That's pretty cool. That's good. I'm just writing that down.

Willow: I also help with the deaf camp during summer.

Danielle: Awesome. [Typing on computer.] Which one is that? Is that Gizmo?

Willow: It's Camp Can-Do. Around here, in Beckley.

Danielle: Gotcha.

Willow: She just started it last year? Yeah.

Danielle: Awesome. I'm writing that down, too. That's really cool.

What year is this in the program for you?

Willow: It's my third.

Danielle: And then ... 
Willow: Because I had to take this one over again.

Danielle: So does that mean this is the second attempt on this class?

Willow: Yes.

Danielle: Okay. Have you taken other foreign languages in the past?

Willow: Ahh ... Spanish.

Danielle: Spanish. Do you remember any of it?

Willow: Nope. I had no desire to, I guess, learn it.

Danielle: Gotcha. When did you take it? Was that high school?

Willow: Yes.

Danielle: Yeah. You don't have to worry about specifically. I was just wondering the type of school you were in, so yeah. Okay.

Willow: And I went to vo-tech to do early childhood education.

Danielle: Okay, okay.

Willow: I actually got to see like 4 little ones who did the [inaudible] sign in sign language.

Danielle: Very cool. Very cool. Okay, so with all of that, so, what are your plans after graduation?

Willow: After graduation, I plan to try and maybe ... should I go more into doing more signing at Pierpont? Or should I do more ...? Or should I just look for a job out in the field with just an associate's? 
Danielle: What do you mean by that? Do what with Pierpont?

Willow: Like, should I stay with my associate's or should I go get my abachelor's degree in signing?

Danielle: What do you want to do?

Willow: I don't know which one would be better for me to get a job with.

Danielle: So, do you want to get national certification? Is that something that's in the future for you?

Willow: Yeah.

Danielle: Okay, so then you need a bachelor's degree. If you want national certification then you have to have that, so that kind of answers the question. There's nothing that can replace experience, so yes, you need the bachelor's degree but there's nothing that replaces experience, so I don't have an answer for you. [Laughs.]

Willow: Associates I can do here in WV, right?

Danielle: Well, you'll have an associate's once you're done. Oh! You mean like work with it? $\mathrm{Oh}$, what you'll need is a certification, to pass a quality assurance screening. You will take the EIPA, you'll register for that. Or, you will register for the VQAS, which is the Virginia Quality Assurance Screening, so you'll do the educational one; that's the first one or this one. So, it just depends on which you want to do, go into. But, with an associate degree, you can take both of those screenings and begin to work. You can definitely do that. You'll have to wait for those results, I would imagine, and I would imagine most school systems are going to want to see that. I would argue that you should not go into the school system without at least having somebody there to work with you, just because you're first starting out. Even though you interact with a lot of interpreters, it's helpful to have people who can guide you through it. So, if you have that, if you're already involved in the community and you could potentially have that, I say go right ahead because you'll have a mentor. You'll have somebody there, but when you first start, you need that guidance. So, what I would argue, in my opinion, if you have the guidance, go into the field and slowly earn your bachelor's degree. Gain experience and get the degree and the same time so that you can go into and get that national certification. If you don't have the ability, get the degree because in my opinion, you should not be in the school system yet. There's too much that you, and it's no fault of yours, but just by experience you will get better and when it comes to a child's language and education, I don't mess around with that. That's definitely something that we have to be careful with and acknowledge limitations. So, like I said, that's what I would 
use to decide. I know that doesn't really answer your question but if you have the guidance, I say go right in. If you don't, I say get further education and then . . . because that is akin to guidance. It's like having that kind of in-field experience, sort of. Right? Kind of. There's nothing like interacting with deaf people but you do that so I think you're good either way. I think you just need to figure out where you can get the most support and that's what I would look for when you're deciding.

Willow: Yeah. I was going to do that and see how I do in the field.

Danielle: Yes.

Willow: And then, if not, go get my bachelor's degree.

Danielle: Like I said, you'll need those screenings first. I definitely recommend you working with someone for that period of time and then slowly go through. It's just, like I said, it's all a matter of availability.

Okay, but good to know. And then, do you want to be in education?

Willow: Yes.

Danielle: Is that where you want to interpret?

Willow: Yes.

Danielle: What level?

Willow: Probably elementary.

Danielle: Why elementary?

Willow: They're easier to get along with.

Danielle: Yeah, gotcha. They're way more fun, but sometimes it's hard to get their focus. You're trying to play but if you like doing that, it makes it enjoyable. If you already went to 
school for early childhood education, you probably appreciate that. You're probably like, "this is just fun." Other people ... I would go insane. I just want to talk. Sit down. Stop moving. Sit down. Okay.

So, what does it mean to be a sign language interpreter?

Willow: What do you mean? Give me an example.

Danielle: I don't want to give you too much information but I can describe a little bit. So, what I mean is, there's two different, I would say "jobs" or "roles" that a sign language interpreter takes on. The first role is-- what's their function? Why do you need one? What's the job? What's their purpose? And then the second part of that as far as what does it "mean," is what's the interpreter's position in the Deaf community? How do they relate to other Deaf people? What's their status in, amongst deaf people? And hearing people?

Willow: Well, you help people communicate through ... with the deaf and the hearing.

Danielle: Okay, so that's their function.

Willow: And what was the other one?

Danielle: The other one was the way that the interpreter basically, what their position is with deaf people.

Willow: Making sure that they get the message correctly and make sure they understand. And, if not, you can explain it maybe a different way.

Danielle: Okay, okay. How do you think deaf people see interpreters?

Willow: Um ... like, they are helpful?

Danielle: You think they're helpful? You think deaf people see them as helpful?

Willow: Sometimes not as helpful if the person doesn't know what they're talking about. 
Danielle: Only helpful if they actually know what they're doing? [Laughs.]

Willow: There was one interpreter ... she did not know nothing.

Danielle: That's not an interpreter. We don't call those interpreters.

Willow: She was a "helper." I signed for the deaf student the whole time.

Danielle: That's not what they're supposed to be. They're not supposed to do that. Yeah, no, but it's good to know that you can distinguish that difference between what you should and should not be doing.

How do you feel the course structure impacted your learning? Or did it? Maybe it didn't?

Willow: Well, with doing the videos, doing the first draft and then seeing what I needed to work on with the feedback. And then, the second time. I caught what I did wrong the first time and then could fix it the second time.

Danielle: Nice! Good! Okay, good. Is there anything you found really challenging?

Willow: Not really.

Danielle: Not really? Okay. Was there any specific interpretation that you thought was really hard? Anything that stocks out in your brain that you're like, "Oh, I hated that one?"

Willow: No.

Danielle: Okay! Lastly, how do you expect other interpreting professionals to influence your work in the future?

Willow: Um ... like, are they going to be like certified ones? Or is it like could it be my classmates?

Danielle: Yes. [Laughs.] This is not as an insult, but I don't typically call interpreting students interpreters. What I mean in this case is actual, like, field interpreters. You can still answer the 
question for your classmates, for other students, but I typically don't call interpreting students ... you're interpreting students. You haven't gotten to that point yet. That's my job -- is to get you there. So, I mean more the people in the field, like when you're a practicing interpreter, how do other practicing interpreters maybe or maybe not influencing your work?

Willow: I was just making sure.

Danielle: You're good.

Willow: I know some that's been in the field like 20 years and they help me, influence me to, when I say, "Oh, I can't do this." They're like "Push on. You've got this. You might mess up but try it again."

Danielle: Okay, so there's been some support. Do you know a good number of interpreters? Do you know a good number of people in the field?

Willow: I know about four.

Danielle: So, that definitely helps and if you have that community, hold on to it because there's no local chapter of the Registry of the Interpreters in West Virginia, so that's a really big deal. The fact that you have that community is what RID Local would provide, but since we don't have one, hang on to the connections you have made because you can't really make them through the chapter that doesn't exist. Okay, that's great. Those are all the questions that I have. Do you have anything for me before I let you go with like, final project, final interpretation, or postassessment?

Willow: For the interpreting, I did not see the email you sent for scheduling.

Danielle: That's okay. We can schedule right now while I have you.

Willow: I looked for it last night and I couldn't find it.

Danielle: That's fine. That's part of why I wanted to do these [interviews] this week, the one-onone so that we can schedule for the interpretation if the link didn't happen. You know what I mean? If people didn't sign up that way. Let me take a look. How about Monday?

Willow: I cannot do Monday. 
Danielle: Not Monday.

Willow: Tuesday or 1:00 or after on Wednesday, I can.

Danielle: I can do Tuesday.

Willow: I work 10-5 on Monday.

Danielle: Okay, oh yeah. That's like right in the middle of the day. Okay, so how about Tuesday at . . . can I have you at 11:00?

Willow: Yes. Let me write that down.

Danielle: Okay, me too.

Willow: For some reason, I thought the interpretation was today and I woke up today looking for the email. I was like, "It's not here." When I looked, I saw it was the one-on-one.

Danielle: I am going to add you on the calendar. You will get a Google invite from me. You will get a calendar invite from me this way. Okay. I just did it. It's there.

Willow: I do ... the where we grade ourselves.

Danielle: That's the final project. There's a final project, final interpretation, and then the posttest.

Willow: What's the post-test, again? Can you refresh?

Danielle: Yep. The post-test. If you remember at the beginning of the semester, I had you do the first two videos.

Willow: From the book? 
Danielle: Yes. So, you're going to do those again and then I have a couple questions, basically, like your vlog is basically what it is. It's the two interpretations and then your final vlog prompt is basically what you're doing.

Willow: Okay. So we're signing those two.

Danielle: Yes, you're interpreting those two, yes. And then, that last one, as far as the vlog goes, you don't have to sign it. If you just want to answer it, that's fine. If you want to sign it, that's fine too. It's just an option. I don't really care. That's what that assignment is.

Willow: Do we have a paper where we grade ourselves?

Danielle: That's the project. I'm going to double check that all of this stuff is on Blackboard because if so then I can guide you there and if not, I'll fix that. My idea is this way you'll be able to look at all of this stuff and not try to remember because that makes me nervous. If you try to remember, that wouldn't work.

Willow: I have a piece of paper right here, writing down everything I need.

Danielle: I have been having issues logging into Blackboard so I need to switch browsers so that I can get in.

Willow: My password expired so it took me a while and then I locked myself out so I had to change it again.

Danielle: Awful. I know that feeling. Let's see what I can do here. So . . .

Willow: It's been a rough week altogether.

Danielle: Whew! It's just a rough year, isn't it?

Willow: And it's horrible when an animal you've had passes away.

Danielle: Is that what just happened? I'm sorry. 
Willow: Of 15 years.

Danielle: You expect their little feet to come down the hallway.

Willow: He was an outside dog.

Danielle: Yeah. I know what you mean. You expect them to be there. Yep. Those things get better though, they do.

Willow: They do. This year, I said, it's just been rough all around.

Danielle: Yes, precisely. Hang on, one second. [Talking to self]

If you go into "End of semester assignments," everything is there. Course content > End of semester assignments. There's three assignments and four links. One is the final project instructions. One is the final project assignment template that you're using to actually do it.

Willow: Would I be able to print them off and do them?

Danielle: Totally. Yes. So, what I would recommend for . . . oh you mean . . . what part do you want to print?

Willow: The one that we have to do the instructions.

Danielle: Grading yourself? Your project? I'd rather have it in a Word document. I want everything put together. I break it down simply. I give you the document to use so all you have to do is edit it. You don't have to make it. I gave you something to copy and paste. You will have to do it twice because there's two interpretations; you will have to copy and paste it two times, but I gave it to you so all you have to do is delete my example and then put in your own thing. I tried to make it as easy as possible. And then, with the interpretation assignment is there. That's really short. That's just -- you will schedule with me and then we'll meet and then you'll interpret. That's very simple. And then, the post-test assessment is there too. That prompt is in those instructions.

Willow: Okay. 
Danielle: That way, you don't have to look for it in the emails. It's right there.

Willow: So, the one we just have to delete your example?

Danielle: Exactly. It's a table, so you'll see the term and then next to it is where you'll see my example. You'll delete my example, put in your own thing, and then keep going.

Willow: I was just making sure because I was confused and wanted to ask.

Danielle: You're good. That's where you're looking for that.

Let me just double check that everything is there where I need it. Yeah, everything is there.

Willow: Okay.

Danielle: So, if you need anything, let me know between now and whenever.

Willow: Everything needs to be in by the 20th?

Danielle: Yeah. If you can, I would appreciate it if it's in earlier but the drop-dead time is on the 20th because I have to get grades in by Sunday. That gives me 48 hours to do it. And, that way too, it helps because if you have questions, you can ask me questions. Because after the 20th, I can't change anything. The 20th is my dead date to accept any changes. That means, if you want to re-record videos to get more points, that has to be in by the 20th because at that time I'm not accepting anything else. I have to have time to grade it and then post it and then finish the processes on my end.

Willow: I was going to work on it right after our meeting.

Danielle: Perfect. That way, you have time, I have time. If there's issues, you and I can talk about it. That way, it's not a mad scramble to try to figure something out. And you're not like, "Oh, if I only had more time, I could have passed," right? There's such heavy points that I don't want you to have issues and not be able to ask questions so don't wait until the last minute.

Willow: I am going to work on it today. I have the weekend too. 
Danielle: Good!

Willow: I'm going to try and get it done-- what day is Wednesday?

Danielle: Of next week? I have no idea. I'll look at the calendar. I have no clue. That's the 18th.

Willow: What day is it?

Danielle: Next Wednesday is the 18th.

Willow: The 18th. I want to get everything done by the 18 th.

Danielle: Yeah. And if you have questions between now and then, too, I will be available. I still have my office hours. You can always text me. My number's on the syllabus. It's the Google Voice. It's not my actual phone number; it's one I created, but then you can ... whatever you need you can contact me, okay?

Willow: Okay. And then, there's the final draft thing and it still has a 0 on it.

Danielle: So, you have to submit the link to me. You have to let me know what you've submitted so I know where to look because otherwise, I'm not going through each one and try to figure out where you are. There's a submission link on Blackboard under Assignments where it says "re-interpretations," or re-recordings of interpretations, or something like that. You'll tell me what you did so I know what to look at and what grades to adjust. I'm more than happy to. You just have to tell me where to look. I don't have time to go through all of it.

Willow: I feel ya. Okay. Making sure because I wasn't sure.

Danielle: Yep! I'm glad you did. That's exactly why I want you to get those things in now so that you have time to ask those questions and submit those links so that you have time to get your . . . to boost your grade to see where you are before these last three projects come in or come due, I should say.

Willow: And, then we have a meeting with the EIPA tomorrow from 10-2? 
Danielle: Yes. You have that training, the workshop, whatever you want to call it tomorrow. Yep.

Willow: I was making sure I got that in.

Danielle: Yeah. I'm not sure exactly how the EIPA registration or VQAS go. Especially with COVID, I don't know what the details are with that so I would reach out to Jamie and see what's being done and what the program is doing about that. I'm not sure but I would reach out to her because she'll have more information than I do.

Willow: Okay.

Danielle: Okay?

Willow: What location are you in?

Danielle: I'm in Morgantown.

Willow: You're in Morgantown.

Danielle: Mm-hmm.

Willow: Because I know Jennifer and Jasmine are both in Charleston.

Danielle: Yes. They're in the southern part. So, Jamie is in Pittsburgh area. They're at the southern part. I'm kind of in the middle-ish. Closer to Jamie, but yeah.

Willow: I'm like 45 minutes from them.

Danielle: Gotcha.

Willow: Close to Charleston.

Danielle: Like I said, I'm in Morgantown, but I've worked in every single part of this stinkin' 
state. I swear to goodness. Been all over. Alright, cool. So, like I said, if you need anything, let me know and I will let you go. Okay?

Willow: Well, you have a good rest of your evening.

Danielle: Thank you! Yeah, I'm going to go get some food. I'm hungry.

Willow: I know. When I saw you send me a message, I just had to shovel food into my mouth to hurry up and go.

Danielle: [Laughs.] Good for you. Alright, I'll talk to you later.

Willow: Alright. Have a good day! Bye.

Danielle: You too. 


\section{Appendix L}

\section{Interview 1 with Reba}

Danielle: First things first, let me get you-- actually, did you read the cover letter on Blackboard?

Reba: Yes.

Danielle: Okay, awesome. I have a copy for you. I will send it in an email. I want to make sure you have that just in case everywhere, right? If there's ever a time you don't want to be included in the study, whatever it might be, you can always opt out, email Jamie, she will email me. It does not impact anything as far as grading goes. That will not happen. Additionally, when it is time for me to write anything, everything will be anonymized: Your name, the name of the institution. As much information that I can take away to identify anybody, it will be done. The name and location is not relevant. The way we interact and work through this class together in this context of being online and learning a skill like this, that's really what I am trying to study. I don't want you to think I am going to go out and say, "Hey! Reba did this!" [Laughs.] That's not going to happen. I won't do that. Just so you have a heads up, and if anything makes you uncomfortable, you can let Jamie know and then she will let me know. Then, you don't have to worry that we will have any weird things or think that maybe I will hold it against you. That won't happen either. Okay?

Reba: Okay.

Danielle: First things first, what made you decide to major in Sign Language interpreting? Why this program?

Reba: I had been considering going to college for a good 5 to 6 years. I was still living in North Carolina at the time and when the Deaf West production of Spring Awakening came to

Broadway, and I saw Allie Stroker, who was the first person in a wheelchair on Broadway in that production, I cried. I straight up cried.

Danielle: I just got chills. I know exactly what you're talking about. I just got chills. Yeah.

Reba: I balled my eyes out, and I went "wait, hold on a minute." Theater is my second greatest passion in life, behind professional wrestling. So, seeing somebody like me on a Broadway stage 
and it being because of a production that included sign language, and having grandparents who are partially deaf in at least one if not both ears, I was like, "Okay. Maybe this is something I can do." I started looking into interpreting at wrestling events because again, my biggest thing is wrestling. I actually talked to someone who owns one of my favorite companies, and he was telling me, "I always have interpreters when I do stand-up comedy. I don't know why there's not interpreters at these events for when the guys are giving promos and things like that, you know? Why is there not somebody here, interpreting these things for people?" And I went, wait, maybe this is my door into the business that I love so much.

Danielle: I appreciate that. That's awesome. Do you like your decision? Are you happy with your choice? You had so much time to think about it. Are you still okay with your decision?

Reba: In the beginning I struggled. I literally almost dropped out on day one because I was the only person in the beginning of my program when I started in 2018 who had no sign language experience in the beginning whatsoever. Everyone else in my class was communicating really easy with Jamie, they could at least fingerspell to tell her things. I had nothing and I had a mental breakdown outside Hardway Hall, and was like "Wait, maybe I made a mistake here." You know? I still have my moments. I do feel like I'm slower at picking things up than everyone else; I do feel like I'm struggling.

Danielle: That's scary. Okay.

Reba: I technically was supposed to graduate this past spring, but had a breakdown over some different things and didn't graduate, but I was like, you know what, this gives me another year to be around the language, around people who can help me. You know, I was not ready to be an interpreter last spring had I graduated. I would not have been a successful interpreter. So, I made the decision finals week. I messaged all of my professors and told them I am not taking the finals but I am going to retake the entire semester. I am not ready. I can't do this.

Danielle: I am glad you knew that for yourself. I'm glad they worked with you for all of those reasons. That makes me very happy, and given all of that you are still here. Good for you. That's a good mentality to take a step back and rethink, if you need to.

Reba: I had to look at it, again, my grandparents being hard of hearing, I was like if they needed an interpreter, would I want somebody that barely passed? That barely made it through and was not ready to be interpreting for my family? No, no I would not.

Danielle: Good for you. I appreciate that. That is something that a lot of people don't have the mentality or perspective to do. Most people are like, "Yeah, I can do it" because they want to do it. And, I am not saying you don't want to, by any means, but I appreciate that you also 
acknowledge what your abilities are because that's essential. When you can say, "Listen, I'm not ready and this is what I need to do again." And, like you said, you are around the language, which ... awesome; you have more exposure to it which you not having previous exposure, now is essential, and then everything else that you do going forward just builds on that. Okay. To me, that sounds great. So, I appreciate all of that. Given that, I think that goes perfectly into my next question. What does it mean to be a sign language interpreter? How will you know when you are ready?

Reba: I think for me I have a different perspective because I am a person with a disability myself. I know what my own needs are and how I would feel comfortable with somebody being able to help me, so I can kind of look at it as, if I were this deaf person that they want me to interpret for, would I want myself to interpret for me?

Danielle: Gotcha, okay. So, then, when do you feel like someone is ready? Is it someone who is really good at the language? Is it someone who is really good at maybe just at interaction? What things or markers do "skilled" (*air quotes*) interpreters have that you are still developing? What does it mean to be an interpreter?

Reba: I think being absolutely perfect at the language is $100 \%$ essential because you can still get your point across without being absolutely perfect.

Danielle: Perfect. Okay.

Reba: The language is constantly changing; all languages are constantly changing. So, you are not going to know every single thing, every single minute. It's not going to happen.

Danielle: Yes, agreed.

Reba: But, if you're able to get your point across without too many stumbling blocks, I think then at least you are ready to start at like a base level.

Danielle: Okay, so it's the ability to convey a concept. Whatever that concept is, whatever the context is, it is being able to communicate a concept. Okay, okay. I agree with that. That's a good differentiation. And, do you think you're there yet or do you not think you are there yet?

Reba: I think when it comes to ASL as a structure, no. I think if I were going to work in signsupported English, yes, absolutely. I think I could. I'm there as far as that goes, but the actual ASL grammar, no. Mm-hmm. No. I can't process. 
Danielle: What makes you feel like you can't do that? Is that because of your ability to understand the language? Is that a fear? You understand but you freak out on stage? What piece of that makes you uncomfortable?

Reba: I think the biggest thing that trips me up is when things get really fast, I can't process.

Danielle: Okay.

Reba: My brain can't process that as quickly. And being one of the older students in the group, I was the second oldest in the group when we started, and I am literally missing a chunk of my brain, processing is occasionally difficult when it comes to certain things.

Danielle: Okay.

Reba: Remembering to flip words around, like this goes here even though it goes here in English.

Danielle: Gotcha. And we will work through all of that stuff. That makes perfect sense. I'm hearing that you are very insightful. Does that mean that you understand what your role as an interpreter would be in the Deaf community? Whatever the context is. Goodness, I hope it's in wrestling for your own dream to come true, I really do, but whatever the context, do you understand what your role is as an interpreter in the Deaf community?

Reba: I think, again, because I have, that sort of as-a-person-with-a-disability thing. I know what it's like to not have the world accessible to me, so I can help somebody else have the world a little more accessible to them. That's important to me because like, the disabled community as a whole, Deaf people, people in wheelchairs, we are all equally ignored on a certain level.

Danielle: Awful.

Reba: If people in wheelchairs aren't going to stand up for the Deaf community, and the Deaf community won't help the Blind community, we have to stand with each other if the able-bodied world isn't going to stand up with us. You know what I mean?

Danielle: Yeah. And I think so much of the misperception what happens in a lot of these contexts is interpreters go into the situation thinking, "I'll fix it for ya, honey," "I'll make it 
better."

Reba: No.

Danielle: It is a very important self-concept to have to better understand the fact that first of all, you shouldn't be walking in thinking you can fix it because (A) you not gon' fix it and (B) you should not walk into it thinking you are anything better or whatever. It is more of a function of bridging communication and providing access to information. Period. That's it. I don't want to say that's it like it's nothing, like it's such an easy process and anybody can do it. This is hard. If it was easy, everyone would do it.

Reba: Right.

Danielle: This is a hard thing to learn, but it is also important to know once you do reach that point, because you are gonna reach that point, once you are there, then how do you behave? Then, what? Right? Because there's a difference between being in school and being in the profession. So, good. I'm glad you have that that is your perception of your role in the Deaf community because otherwise I have to work to fix it. [Laughs] I will. When there are classmates and colleagues that have differences in perspectives and I have an opportunity, we'll work on it; we'll fix it, but I'm very glad that your perspective is much more "let's do it together." We typically now call it-- not the advocate or ally ... I can't think of the word. I sign SUPPORT, but it is more like Bonnie and Clyde. That's how I always think of it. Like, the interpreter with the d/Deaf person, going to do something together, ride or die, we are going to go into this together. I think that's important. So, that's great.

Now, going forward, when we think post-graduation, all of that stuff, when you are in your interpreting career, what kind of challenges and I'm sure you can think of a few, what kind of challenges do you foresee and things that you might have to address in order to be successful in your career?

Reba: My biggest thing is I'm going to have to get over the speed issue. The speed issue has been a thing from the beginning. I know that that's going to be a problem.

Danielle: Okay. Do you have a reason why you think that is? I mean, is that like because of processing? Or is that because of being overwhelmed? Which part of it?

Reba: I think it's a little bit of both. I think I get overwhelmed because I can't process and then I get overwhelmed because I'm overwhelmed and. . . 
Danielle: [Laughs] I understand.

Reba: I have anxiety.

Danielle: Trust me. I live with it. I am an anxious human. I have had a lot of things happen in my life that when you start to interpret and information comes at you so fast, there's a pit in your stomach. It's going to be there. I'm going to tell you right now; you're going to feel it. That anxious feeling is going to sit there. You will learn how to use it. That's what's going to happen. You will learn how to focus it because listen, it is not going to go away, but you will figure out, okay, that anxiety is telling me this. Let me address it appropriately by doing this and that's my job is to teach you how to do that.

Reba: Right.

Danielle: Because that's what you need to know. You are who you are. I don't want to change you. I just want you to strengthen those skills, utilizing everything about who you are as a person. That's what I want.

So, other than being, not that it's a small thing, other than being overwhelmed or feeling like the speed is a problem, how are you going to address that? What do you think you can do about something like that?

Reba: I think practice is going to be the most important thing.

Danielle: Okay.

Reba: Even when I'm done, I'm going to have to sit down and, let's say I do end up working in wrestling like I want to because I already have a company where I've met some of their talent and they're like, "Hey, when you get your degree, we will put a word in. Just let us know."

Danielle: Awesome.

Reba: I have sat down and literally made a list of like, these are the people who I think are going to be easy to interpret for. And these are the people that are going to be nightmares and I'm going to have to work on that. [Laughs]

Danielle: Okay! No, but that's great though! You're acknowledging what you want to do, as 
well as limitations and potential things that you can do to overcome those limitations. That's awesome.

Reba: Like, there's some of the guys on the roster that I'm telling you, I'm going to corner in a hallway somewhere and go, "Listen, can you take a breath for 30 seconds because I can't do this?" [Laughs]

Danielle: I will tell you. I'm not sure how much you know about how quickly other people talk, right, but I speak other languages. I will tell you this: I have interpreted from Spanish to Sign Language before. Let me tell you: That population. They speak so fast. Especially from Puerto Rico, they speak so fast. It is unreal and it will make you want to bang your head against a wall, every time. Every time, it's like breathe, compose your thought, and then talk.

\section{[Laughs]}

Instead of rushing, just breathe for a second, so, yes, I understand. What we can work on, too, is really honing those skills to be able to chunk your information because a lot of times what they're doing is, though the information that they're putting out, they might think is all essential, you might be able to grab that and instead of signing each word, you could grab the message, process quickly, I understand that part is still new, but process, and then give a couple signs to help yourself, not that you're missing the message. I don't mean that, but you're really getting the concept then and not worrying about the specific words because I think sometimes that's where we struggle. We think we have to catch and interpret every single word that comes out instead of us taking a minute, breathing, thinking about what they are saying, and then perhaps getting it out. Whatever that is. I always think of, "you have the right to remain silent." That's a lot of words. Typically I would just sign HAVE RIGHT MOUTH-CLOSED. Basically, you have the right to shut your mouth. That's three signs for "You have the right to remain silent." I understand that things are quick but I also think that we can work on your ability to process concepts which then will help you when you are afraid you missed everything because then you are not missing everything so that's great.

Now, this kind of seems like an off-the-wall question, but I do find it related: Do you think there's any reason that people would leave the interpreting profession? Can you think of any reason why that might be? And would you ever leave for the same problem?

Reba: I would say one of the biggest ones, and this is actually something we have talked about over the summer, because we thought that I had carpal tunnel for a few months over the summer.

Danielle: Gotcha. 
Reba: I know that's a big thing that happens in interpreting because of the repetitive movement and things like that. So, I could see that taking somebody out. I can see burnout, just having done it for so many years and just getting tired and overwhelmed and just done after a while because that happens in anything that you do for years and years and years.

Danielle: Yeah. It happens a lot. It happens. That's why I raised my hand. It happens all the time. I think it's important to acknowledge that burnout is a real thing. Especially, too, I also want to draw attention to, and you understand this, as a person with a disability, you understand as well that when you are in a situation when you are repeatedly seeing someone else's oppression, it's going to take a toll.

Reba: Yeah.

Danielle: And, you will become tired of the fight. I train martial arts; I train Muay Thai. I don't do the ground stuff; I do the stand-up stuff. I'm trying to do ground stuff. I love wrestling; I'm just scared of it. It's not really wrestling; it's more jiu Jitsu, but same kind of concept, but I love fighting. I love it. The big thing for me, I realized the more I interpreted, the more I needed martial arts. And, that's okay, right? Because taking care of yourself is important but what you realize is at a certain point, you are so burnt out emotionally, physically, psychologically, physiologically, that then you need a break.

Reba: Right.

Danielle: I think you are right that burnout does happen doing the same thing over and over. And, yeah. $100 \%$. I'm with you.

Reba: That's something that me and my family talk about a lot because like I started school at 18 months old, so I started fighting for myself and my own rights before I was old enough to remember and it gets to a point when you are just tired of having to fight for your right to exist.

Danielle: Yes, and I think that's a really hard thing to communicate to somebody who hasn't had to do that for a long period of time. So, I'm glad that you understand it because I think that happens as an interpreter. I don't say this to discourage you from the profession. I say this to make sure that you understand it is not any better when you are an interpreter. It is not. Hearing people don't understand what you are there for. It does not make sense. They do not understand why you exist. And then when you are there, you have to demonstrate this is my purpose. This is why I am helpful. Period. End of discussion. This is what it is. Period. Don't ask me anything else, but I feel like that is something that happens frequently. It is part of what exhausted me. It is literally where I could not take it anymore because at a certain point, you just get tired. You are just done. It is just the process has gone on long enough. You are right 
though. That burnout is definitely a good reason. Like you said, your right to exist. I love that expression. I'm sad about it. I don't love that it is real, but I love the image of that. I think that's very accurate.

So, when you do interpret, when you do have the opportunity to record yourself or interpret for Jamie, for example, how do you feel about it? Do you feel comfortable? Are you uncomfortable?

Reba: It depends on normally the length of the assignment for me because the longer something goes because of my physical limitation, I get to where I am in pain. That's my biggest thing that after a while, my hands just lock and I can't. It really depends on what I'm doing because if it is something that maybe takes me 5 to 10 minutes, then okay, I'm good. It might take me a couple of times to restart or redo the video, but I can get through it. There's been times I've been asked to interpret on a video for 30 minutes on a video without stopping and I've had to message my professor and say, "I can't." My hands shake. I can't do this. It is too much.

Danielle: Okay. But, that means that you have to understand the contexts in which you can interpret. It doesn't mean that you can't do it, right? But it's understanding then that a 2-hour presentation is not going to be Reba's jam. That's not going to be what Reba does. Nope. Not going to happen. That's fine. Understanding and acknowledging that that's your limitation and role. That was going to be my next question: where would you want to interpret and where would you never interpret. And I know you kind of answered the first one but it sounds to me like the other side of that question is really anything that could be more than, I'd say, 15 minutes or so, of a speech or a communication that you'd have that kind of time frame and anything longer would be uncomfortable and painful.

Reba: That definitely-- I think I would do, if I wasn't going to get where I wanted to get because a lot of wrestling promos and things like that are 5 to 10 minutes, at max. They're out there, they're talking, they're talking their smack and they're hitting each other. I'm good. I'm done. We're set. We are there.

Danielle: Right.

Reba: But, other than that, I think community interpreting for me would be better than seminars and presentations and ...

Danielle: Okay.

Reba: Just, smaller things where I have a couple of minutes to stop and breathe and stretch my hands, you know? Maybe put some gloves on. Maybe take some pain medication. I know what 
I need so I know what I can kind of do to keep myself going if things are too bad.

Danielle: Good. No, and that's great and having that opportunity also means you have a chance then to say, if you are working with an agency, "In this assignment, I absolutely require a team." In those contexts, 15 minutes on, 15 off, 20 on, 20 off, whatever it is, having something like that, gives you that opportunity. You then can still process without hurting your hands. You can process the information and do all those things to take care of yourself, especially since you know what you require. That's very helpful. That opens up a lot of opportunities for you.

Reba: And, I know, I learned through doing the internship over the summer and the internship last semester-- I cannot do educational interpreting.

Danielle: Why's that?

Reba: I am too emotional a person. I can't-- I am way too emotional. Way too empathetic. I will get attached to my kids and then not be working with those kids anymore. I worked with kids the summer before last for a week and I still remember and talk about those kids.

Danielle: Gotcha.

Reba: I can't emotionally prepare myself for, "Okay. I get this kid for three years and then ..." no. I can't do it.

Danielle: Then they'll be gone. Yeah. That's a really good thing to know about yourself. There's other contexts where educational interpreting is not like that, like in post-secondary education, for example, because you are then working with an adult, but if you are doing something in the public school system, especially because it really could just be you and your d/Deaf student, then that's gonna make a really big difference. You are going to be connected. That person is sitting there and if you have a hard time distinguishing boundaries of interpreter versus helper or friend or whatever it is, then that's important for you to know for yourself. That's not a bad thing. That was going to be my next question: Is there a context in which you would never interpret? And it sounds like that's the one.

Reba: Again, that's another thing that makes me want to get in to interpreting at wrestling shows because I might interpret for somebody at one event, at one arena, and never see them again because they may not come back to another show, you know? I may be at a completely different arena two weeks from now.

Danielle: Yes. 
Reba: I am not going to get attached to people that I am interpreting for consistently. For me, that is important. I am a very, very emotional person. I think that distance for me is very important.

Danielle: I will say no matter how many times I meet different or new people, I never forget them. I interpreted video relay calls. I have interpreted video remote medical. I have interpreted video remote legal. I have interpreted in-person. I have interpreted in a myriad of contexts all over the place. I remember every person. So, I will tell you this. I'm not saying don't do it. I'm not saying it's not a good fit. I am saying you will remember everybody and everyone will be near-and-dear to your heart and all of those experiences will make your brain happy. And you will feel sad that you can't relive that experience exactly as it was, especially when they are awesome experiences. It is just going to happen. We are human. That happens. I don't want you to think that going into wrestling means that you won't get connected to people or never be upset because that's not the case. I have interpreted calls where it's Sorenson Video Relay service and you don't know what you're getting when the call comes through, and I'll never forget certain calls that I've answered with profanity. I click that button, person came up, started signing profanity, and that's how I started interpreting. I'll never forget those moments. That was fun. [Laughs.] Those people were awesome. So, I think that is really good though for you to have the insight of the repeated presence, though. That being a barrier for you is a good thing to know.

Now, let's talk about your previous interpreting experiences. I have two questions left for you. So, you have taken this course before and I understand life happened so I'm not saying that it's a function of an instructor, but it could have been. What course experiences, and I'm not going back to anyone to tattle about what you said. I just want to understand what helps you versus what doesn't help you learn; that's all I'm trying to get at. So, what experiences that you've had in this class that you've taken previously or in other interpreting courses, that helped you be successful?

Reba: I think the biggest thing for me was having somebody to be able to go back to that I was like, "Okay. I know that I know this sign but I can't think of what it is. I can't get it out of my brain, like the word is there and I can't."

Danielle: Okay. No, that's good. So, having a resource, having somebody to talk to to work out that connection between concept and sign, having somebody to talk to. Is there anything else?

Reba: I know I've had professors in the past that I would message them about a concern and then never hear from them. I have literally had to go directly to the Dean to get an answer to my question before because they would not get back to me. 
Danielle: So, I had a meeting with a colleague of yours just prior to our conversation who told me the exact same thing so I want you to know-- I don't want that to be a bash on an instructor, but I want you to know that you're not alone in that. I will tell you the same thing I told your colleague, which is I respond, you have seen how I respond, like that. *snaps*. Within reason, right? If you email me at 11:58 and the assignment is due at 11:59, you're not getting an answer. I'm in bed. Or if I'm not in bed, I'm not answering my email. It's 11:59 and I have a life. So, given rationale, right? Being reasonable as people, I will always respond but it is interesting that you guys shared the exact same experiences. Your colleague was saying they would not get a response until after the assignment was submitted. They would not hear anything from the instructor until after the assignment was sent and not hear anything back about it until goodness knows when. I won't do that. I promise not to do that. If I do do that, you can refer to this recorded conversation. You can say, "Professor South, you told me you wouldn't do this." I won't do it to you. Is there anything else other than communication and having a resource? Both of those seem legitimate.

Reba: I think the biggest thing for me, and I think this goes back to what happened to me last semester when I had my breakdown. I was in the interpreting internship for last semester. And I got kicked out because of my disability. They asked me to leave. Because of my disability and my religious views, I was asked to leave. Because I answered a question that I knew because of my religion and apparently it made people uncomfortable and I was asked to leave and they tried to mask it as because I could not go to bathroom on my own, I was an issue, I needed to leave.

Danielle: Okay, okay.

Reba: So, that's what's the person coming into this.

Danielle: Wow. Thank you for telling me. I appreciate you telling me. Here's what I will tell you about me: I have very strong views but I don't push them on people. So, really, as far as anything else goes, and I don't mean this to sound crass, but your views are not important to me because you are who you are as a person and that's all I need to know. So, as long as you are respectful, you can communicate and have a conversation of differing opinions but I don't think a lot of people are equipped to manage those conversations quite often.

Reba: Right.

Danielle: So, I can't speak for what happened. I wasn't there, but I can tell you about how I handle things like that. I am more than open to listening. I don't know if you watch certain things on YouTube, but there's a man named Steven Crowder who talks on "Change my Mind" and he sits down with people about really touchy subjects about things that are very "hot topics" right now. And has conversations, and real conversations with people where otherwise it would just be a blowup they would just go at each other and bicker and not really get anywhere. I kind 
of take this stance that he does in which it's more about having the conversation and working something out than it is about me saying "I'm right and you are wrong," for example. Or, "This makes me uncomfortable." Okay, but why does it make you uncomfortable? Does it make you uncomfortable because you disagree? Or does it make you uncomfortable because someone is hurting you? That's different.

Reba: Right.

Danielle: Just because you disagree, keep your mouth shut or have a conversation and understand. But, if you are uncomfortable, you should talk about your discomfort. Either way, you should have a conversation and not just push somebody out. So, I'm sorry that happened to you. I really am. That's not fair but I want you to know that there's, within reason, right? We can always have those conversations.

Reba: I think it is important for everyone I'm working with because outside of you, I am working with professors that have worked with me in previous courses throughout the last two years I've been at Pierpont, and I think it is important for everybody to know, they're not dealing with the same person because that was straight up traumatic for me. That's straight up part of the reason why I didn't pass last spring. I could not cope with that. I could not deal with that. I already have PTSD. I am a person with PTSD. Something like that was not good for my mental health.

Danielle: It would be hard for everybody, especially when you have layers. It's painful. Thank you for telling me. I'm glad you said something. I hope that in the future you feel like you have a home in talking to me in the program, in the field. I really hope that you feel like that that you get that sense of being able to be your true self. That is part of me asking in what context you want to interpret. Some people really fit the educational interpreter box. Not a stereotype but that profession, they really work well within that system.

Reba: Right.

Danielle: If I was in public education, I don't like when people don't like me, but not enough for me to keep my mouth shut. I have a hard time with that. In public education, there's a lot of playing a game and I am not good at it in terms of doing it quietly. I do not do it silently. I will play but you are going to hear every time that I have an issue, you are going to hear that. I think you have to find your home. That may just be that your home is not with, well, it might not be in this area, this state, this geographic location. It might be somewhere else. It might be that your home is with wrestling. Your home is with fighters, you know? You end up being within that circuit. I think you have great opportunities to do something you love. I think you have to find the place that accepts you for you. That's the point of what we are doing here. I want to figure out what that piece is and identifying that, and figuring out where you belong within that to be 
accepted.

Reba: Right.

Danielle: Yeah. I totally am sorry that happened. Especially when someone lies about it, that's hard. That's hard. Just tell me the truth. If there's an issue, just tell me the truth.

Reba: Like I said to you in my email yesterday, I have two over-arching goals for the semester. And that's managing my stress better because that was a lot of the big panic last semester. I let myself get dug into a hole and then didn't tell anybody that I was in that hole. That leads into the second bit which is I need to be better about telling people what I need and when I need it. For a lot of years, I was very much treated as, "We will handle it. You just shush and deal with it." No.

Danielle: That's what happens to $\mathrm{d} /$ Deaf people. I don't know how many people you have been around. I know you have your grandparents. I don't mean to say they're not a good representation, but in the community, it happens across the board. It's like a, "It's okay, little Deafie. We will take care of it." That's the role of the interpreter: Empowerment. Ability. I just got chills thinking about the role of the interpreter. Seriously. I wish you could see it. I have chicken skin. I have chills thinking about the role of the interpreter and that empowerment that you can provide for someone by being their access to language because otherwise, that's what they would have to do is sit down and keep their mouth shut because how can they understand or be part of the process without language access? Same way for you. How can you be part of a process if you are not brought into it to make a decision? I appreciate that. I'm glad you're saying something. I'm glad you're telling me. I think it's also a really significant piece for growth and you, as an interpreter, will need these kinds of skills. I hate to say it like this, but to survive. You will have to be able to tell people what you need. You need to be able to tell someone to move over if your client cannot see you. Say it nicely, not rudely, but you can have a conversation to understand others and be courteous and polite while disagreeing with someone and correcting them. I think that you have a really good mindset for that. I don't think you can't do it. I think you need an opportunity. I'm sorry someone took away your opportunity. That's not cool. I don't like that.

So, given all of that, I think you have answered this, but is there anything else you would want to make sure happens in the class to make sure you are successful? You talked about it a little but is there anything else?

Reba: I think more than anything, because, yes, I have taken this class before, I am only taking this class because I got a D instead of a C. I technically passed this class, but not well enough. That goes back to just making sure that if I can't get something done that I think is going to get me a good enough grade to get where I need to be, then I do need to come forward and say, "I 
don't think I can do this. How can we work on that to make sure that I can?" It just goes back to making sure that I can express when I need something whether it be having to adjust an assignment or whatever it be. Being able to know that I can lean on people. A lot of times, I'm scared to tell people when I need help.

Danielle: Probably out of fear that they'll tell you you just can't do it, so go away.

Reba: I had an art teacher in high school who got tired of having to cut things because I can't with my hand. It would not and she got frustrated and just sat a stack of art magazines in front of me. She said, "this is what you're going to do for the rest of the semester. Just sit there and read them."

Danielle: No?

Reba: [Laughs]

Danielle: You sit there and read them. Yeah, no, inappropriate. I understand. Inappropriate. That's cruel and unusual punishment. That's not cool. We're not playing those games.

Those are all of the questions I have for you. 
Appendix L (continued)

Interview 2 with Reba

Danielle: Hi! Sorry about that. Can you hear me okay?

Reba: Yeah, we're good.

Danielle: Yay! Sorry, I went downstairs for a second. Hi kitten. Here's a kitty cat.

Reba: Cat!

Danielle: How are you, by the way? I saw your email and I just wanted to check in on ya, make sure you're okay too.

Reba: Honestly, not doing that great right now.

Danielle: Oh, I'm sorry.

Reba: This is one of those days I wouldn't have gotten out of bed if I didn't have to get out of bed, but I'm here.

Danielle: Gotcha.

Reba: Like...

Danielle: Well, I will make this go fast so you can do what you need to do. Let's get right to it then. Okay?

So, we're recording and we're good. Okay.

So, let's start with the easiest stuff, I think. So, do you feel like you've, throughout the semester, because, can you believe it, we're 9 days away from the end? Holy moly! Um, do you think you've experienced any growth in your interpreting abilities for the last, whatever it's been, 12, 13 weeks? 
Reba: I definitely do, and, like, not only that, but I know better how to figure out, like, okay, where am I making issues and where do I need to continue to improve.

Danielle: Oh! I love that. Good. So, you feel like you can identify that stuff now.

Reba: Because I think, like, in the beginning, I was very stressed about how much improvement can I make in this one semester.

Danielle: Gotcha.

Reba: But, I understand now that it's more important that I know how to improve myself in the long run versus over the course of 14 weeks.

Danielle: Girl, I love that! Okay. First of all, I also love your shirt.

Reba: [Laughs.] This is the first time I've worn this shirt so . .

Danielle: I think you'd appreciate this, too. This is my blanket.

Reba: [Laughs]

Danielle: Yeah, no. I love that. I think that's really great and really true, and I'm glad that you understand that now going forward. That's awesome.

Reba: Right.

Danielle: So, okay. Let me frame this: The question is very direct but let me frame this a little bit. So, as an interpreter, are there any characteristics that you think stand out as far as being important? Anything that you think, in order to be an interpreter, I have to be really good at ... or someone, anybody has to be really good at this, or have this emotion, whatever? Anything like that?

Reba: I think empathy is a really important thing, at least in my mind. If you can't empathize with the situation someone is in when you're interpreting for them, then you can't understand the exact message because something somebody says out of anger, you're going to interpret 
differently than something that they're going to say while they're sitting there, bawling their eyes out.

Danielle: Yeah. Exactly! Okay, so this is awesome. This is why I love you because my question was, "how can you continue to grow your empathy as an interpreter?" So without even prompting, when I asked you what you thought was important, you answered with my question and I love that. So, boom. I love that. So, that's exactly what I want, right? I want you to understand that interpreting requires that give and take and it requires the connection, and like you said before, over the long run. Right? So, over the long run, though, because I know that yourself with disabilities, especially ambulation, there's been limitations that you've experienced, right? You can't physically stand up and go do it. Like, you just ... it's just the case, right? So you've experienced that, too, so how do you relate without crossing that line, right? Maintaining that professional boundary. How do you do that but also create empathy and connect with your clients, both of them? How do you do that? What do you think you could do?

Reba: I think for me when we did Deaf culture in my first semester, that was something that really helped me click as far as, like, I've never known another person with CP.

Danielle: Gotcha.

Reba: But, going through the Deaf culture textbook and things like that, I was like, "Wait. I've been in this exact situation, just slightly different."

Danielle: Right.

Reba: So, like, having the life experiences that I've had, being able to bring that to the table and, like, not even necessarily have to tell the other person, but just kind of knowing sort of what it's like to be there, then you kind of know, like, what you might have to do to advocate for that person because you've had to advocate for yourself.

Danielle: Yes.

Reba: In my scenario.

Danielle: Yes. Okay. I love that. No, I totally agree with you. Um, and, that's definitely, as you experience more time with Deaf people, you'll also see more of that connection. I think that empathy, to answer that question, I think what really comes out of that is your empathy can grow that way because you'll be able to do more of exactly that: Your empathy, your understanding of their potentional experiences will broaden because you will see more, you will experience more 
so then you can be involved in that. Good. Good for you.

Reba: Right.

Danielle: So, I know you said the message might not be exact, right? If a person does not have the empathy that they need as an interpreter, but what kind of other issues, other than that one, are there any other issues you can think of that could arise from someone not having the empathy that they need in the profession?

Reba: I don't know necessarily if it would be quite the same with interpreting, but going back to some of my own experiences, some of the professionals that I've worked with in like my own life, as far as like doctors and things like that, if you aren't an empathetic person, sometimes you can come across as very rude and like, you're blowing the person off. And, maybe you don't believe what they're saying. I feel like that could also, like, if you're not empathetic, and you're not understanding what's being said or whatever, your facial expression may show that like maybe you don't believe what this person is saying or you don't trust what's being said.

Danielle: Yeah. Gotcha. Yeah! I totally agree with you. There's a definitely a trust factor that gets developed when two people have empathy for each other. That, they can, yes. I totally agree with that. I think that's a really good assessment.

So, I have a couple questions I wanted to ask. They're very basic, demographic kind of things before I forget. Let me get you. I have age ranges, so I'm going to ask you to pick one: 18-21, 19-22, 23-27, and then 28 and older.

Reba: 28 and older.

Danielle: Okay. And then, you said you're from North Carolina. Is that right?

Reba: Yes.

Danielle: That's where you were born?

Reba: Well, no. I was born here in West Virginia and then I moved there and then I came back, but I was raised in North Carolina.

Danielle: I was just going to ask you that. So, raised in North Carolina. And then, when did 
you move back to West Virginia? Was that recent?

Reba: 2014.

Danielle: Okay. Okay, thank you. So, that means you are currently in-state.

Reba: Mmm-hmm.

Danielle: So, you said before that your grandparents are deaf? Hard of hearing?

Reba: Hard of hearing, yeah. My grandpa has Maneer's Disease and my grandmother suffered several mini strokes that caused loss in at least one of her ears, but my grandfather is completely deaf in one ear and losing the hearing in the other.

Danielle: So, my question to you: Do they use sign language?

Reba: No.

Danielle: So, do you feel like that connects you more to the deaf community or not really because they don't use sign language? Or no impact at all, that's your other option?

Reba: I would say yes and no. Even though my grandfather does not use sign language, he was exposed to it. He knows someone who went to the West Virginia School for the Deaf when he was younger. When I started the program, that was somebody he used to talk about all the time. He said, you know, I didn't understand it but I watched them.

Danielle: Yeah. So, there was exposure there, okay. Okay. And then, technically, is this your third year in the program?

Reba: Yes, technically, yes.

Danielle: Okay. Course attempt? Second?

Reba: Yeah. 
Danielle: Yeah? Okay. And then, do you have any other foreign language experience?

Reba: I took two semesters of Spanish and a semester of Latin in high school.

Danielle: Okay, and I'm sure you don't remember that because it was forever ago.

Reba: I remember bits and pieces of Spanish but I was actually take a second semester of Latin, but we got like a week in and as soon as we started and I realized I couldn't understand what was going on, I was like, I didn't learn enough from the first semester to stay in this course, so I got out.

Danielle: Gotcha. Yeah. I hear you. That makes perfect sense. Okay. That's done. I just had to ask those questions for my own records. I know, silly stuff.

Okay, so after graduation. I know you have talked about this before a little bit. It is in here but I just have to ask it so that I have it recorded. Your plans after graduation. Do you want to interpret in the schools? You said no, right?

Reba: No.

Danielle: No. And you said that was pretty much because of the connection there, that's just something that you weren't interested in investing in?

Reba: Sometimes, people say that I'm overly empathetic and I can definitely kind of agree I would get too attached and I can't ... .

Danielle: Okay.

Reba: Working with the same person long-term is not something I could emotionally invest myself in.

Danielle: Gotcha, okay. So, hold on ... in the future, would you ever work toward a bachelor's degree to try to get national certification?

Reba: That's the plan when I finish this program is to start my bachelors. 
Danielle: Good for you, okay. And then, is that just to have it? And then get started working, hopefully with the companies you've been in-touch with?

Reba: What I'm going to do, is I'm doing my bachelors in English with a minor in journalism, is what my plan is.

Danielle: Okay.

Reba: So that even if, like, I go to a show that I'm going to interpret at or even if I'm not interpreting at a show, I can go home, write an article about that show, and then still . . . it's like a double, like, even if I'm interpreting at a show I can come home and write an article about the show I was just interpreting at.

Danielle: Just be careful that it doesn't come out that you're the interpreter.

Reba: Right.

Danielle: Because that is like proprietary information. Well, not really because you are involved in the community, too. You pay attention to wrestling so that's something you would have otherwise gone to. The only thing to be careful of, is in certain situations, if you wouldn't have otherwise been there, you can't talk about it.

Reba: Right.

Danielle: Right? Because you can't publicize; however, it's a public event and more than likely, if you weren't interpreting in, you would have gone in and written about it. You know what I mean? You would have been there anyway.

Reba: Even if I was watching it at home, I probably still would have written results or my thoughts on it, or whatever.

Danielle: I think that's a great idea. I also appreciate that because I think there could be some, realistically, looking at the market, I don't know how much will happen because if you can't get a bunch of people together because of COVID, then that takes down the need for that, so at least you have an opportunity to use what you love to still do something and make money with it. You know what I mean? To still survive and be in the field that you like because I know how much you love wrestling. 
Reba: That was kind of my plan, was to have a backup for my backup for my backup for my backup.

Danielle: Good for you. That's awesome. I think that's really smart. I don't think it is supposed to be offensive, like when someone says, "Make sure you have a backup." It's more like, "Hey, make sure you have thought about this creatively and can turn this into something you can enjoy." It sounds like that's what you did. Like I said, just be careful with the proprietary stuff because if you would not have otherwise been there, and it's something that you're only privy to because you're interpreting, you can't talk about it.

Reba: Right.

Danielle: But, like I said, you probably would have been there anyway either watching it at home, watching it physically, or whatever. Yeah. And, having an understanding of other people, like Deaf people, for example, isn't a bad thing. Right? So, even if you don't interpret and you only do journalism things, having the background isn't terrible, so like, you've kind of helped yourself in a lot of ways. I think that's really great. Yeah.

Okay. Would you pick interpreting all over again? If you had a choice?

Reba: I would, absolutely.

Danielle: Awesome. Why is that?

Reba: I planned, like, four or five separate times in North Carolina before we moved here, to go to college. I was going to go for musical theater. That was my plan. We were getting me ready to live in a dorm in North Carolina when we ended up moving because of life situations down there, and when I started to realize that I had the interest in Sign Language, it was kind of, like always there, but I hadn't really ever thought I could take it anywhere. I was like, "Wait. Let me look into this."

Danielle: [Laughs.] Yeah, let me actually expand on this. Yes, for sure. Oh! Wait a second. What county are in right now?

Reba: Umm ... Marion County. 
Danielle: You're in Marion, you said?

Reba: Yeah.

Danielle: I meant to ask you that before. Sorry about that.

Reba: You're fine.

Danielle: I love to hear that. That's awesome.

Okay, so, I asked you a similar question when we started and I just want to see if anything's changed. So, can you define or describe the role and job of an American Sign Language interpreter?

Reba: It's all, like, bridging that communication gap. Like, there's definitely, like, not only bridging communication but access. Access is like the most important thing.

Danielle: Okay. And then, how do you fit into that access opportunity as the interpreter?

Reba: I think in my specific situation given, like, my specific view on things, because I've had to fight for my own access, I kind of know where there are access issues and can help someone fight for those a little bit better than somebody who maybe has never had to fight for their right to be somewhere, for their right to do something.

Danielle: Yeah. Yeah, I appreciate that. So, in sign language, I don't know if you've ever heard it before. I'm sorry. In the Deaf community, people talk about something called Deaf Heart. Have you ever heard that before?

Reba: Mmm-hmm.

Danielle: Deaf Heart is, to me, if I can teach anybody anything, it would be the fact that you should have Deaf Heart. Because, I can't always provide the opportunities but if I can make you curious, I can make you want to go look for opportunities, right? So, if I can teach anybody anything, that's what I would teach them. So, what you're talking about right now, what I understand that to me is like Deaf Heart. It's like understanding that major component. Not the linguistic part. Not having the communication access, but more so being restricted from information, or being blocked from information because of your ... I don't even want to call 
what theirs is a disability. I don't even want to compare it. But, you know what I mean. Because of experiences and because of how you're situated in society, that's what happens. And it sucks, right? But, you understand that. You've lived it and you can then provide that insight which also makes you a really good, what I would call, "warrior." Not in the Social Justice Warrior-type, not like that, but the champion ... that's the better term. The champion for those people who can't otherwise, who don't otherwise have the connection. As someone who is hearing, when you communicate with other people who are hearing, they will, no pun intended, listen to what you have to say because you are like them in that way. So, if you're sharing that information because you understand it, that makes you awesome because they better understand that it's a perspective that other people can obtain. People like them can have too so they start to think, "Oh. That's the right perspective and I can have that one instead." That's a really cool perspective. I hope that makes sense. I'm trying to describe it. It's like the ability to call shenanigans. I don't think there's any smart way to say it. You can call shenanigans of that type, where most people can't because they don't notice it because they haven't lived it.

Reba: It's one of those things that like got me started in the beginning because it was, like, when it comes to able-bodied people in general, whether it be hearing people, ambulatory people, whatever, a lot of times they don't fight for people with a disability or whatever and it's like, if those of us with CP or some other condition don't fight for other people in the community with other conditions, nobody is going to fight for us because nobody has.

Danielle: Right. If it's not you, then who? Right? If it's not the person standing next to you, or me, then who's going to do it? I appreciate that and I think that's where the empathy piece comes in, right? That's a big piece of that. And, that's what, like I said, drives Deaf Heart. I think the only component you're missing is the linguistic thing. That comes with experience. I don't think that's because of any fault of your own. I think what you've been able to harness is your experiences and then apply them in a new context. And, no matter what you end up doing as a profession, I think that's a really good trait because then you can see other people's perspectives and communicate from those. No matter what you're doing, writing or interpreting or talking. You know? Whatever it is.

Reba: Right.

Danielle: For sure.

Okay, so throughout the course, and listen, this is not a plug, a shameless plug at myself at all. I'm really just asking because I really want your feedback. So, throughout the course, was there anything that you found really helpful? Any specific -- it could be an activity. It could have been a practice that we did. Whatever. Whatever component or piece of the course. Anything you might have found helpful? 
Reba: When we started doing, like, the weekly meetings and things like that, and even just like getting weekly emails and things like that, I have a course that I did this semester that, like, we got a syllabus that was like, "Hey! Here's the entire semester laid out for you." And we basically, never heard from her after that. We were on our own. We would get occasional emails, if half the class missed a quiz we were supposed to do where she had to reopen it, we would get an email because of that but we never really heard from her other than that, so having that actual connection of like, we can reach out and make sure that, you know, we're on the same page, we're getting things done, like, I hate being completely on my own and feeling like I have nobody to turn to.

Danielle: Yeah. And, you should not have to. That's not really teaching if someone just says, "Here's the course" and doesn't provide you with anything after that. You could do that with Google. You don't need to pay money with that. That's Google that can do that for you, yeah. No, I understand that, and I'm sorry. I want you to know you're not the only person who said that and I-- how can I say this? I am doing things about it. I have a responsibility as an educator to be a gatekeeper. I don't take that lightly.

Reba: Right.

Danielle: Because I control-- I have back-end control on who goes into the Deaf community and how they get impacted. I can't take that lightly. I'm not there. I can't be there in the future, but I can be here right now. So, people shouldn't just brush that off and I don't think that's cool, for you guys either because that's a waste of your money. From that perspective, even if you don't care about the profession, which I'm not saying is the case for you, but it's not right because they paid money and that's not ethical. You don't just take money from people and not give them what they paid for.

Reba: Right.

Danielle: That's not right. So, yeah.

So, is there anything that you felt challenging? So, I'm really glad that regular communication was helpful. I heard from somebody else that they wanted more regular weekly calls. Would you agree with that?

Reba: See, it's one that that's kind of difficult for me to answer in my specific situation because with my health, I don't know if I could have been there every single time.

Danielle: Gotcha. 
Reba: So, as great as it would have been, there were definitely times when I was like, "I would not be getting up for this if I didn't have to."

Danielle: Right.

Reba: Like, you remember there were meetings where I was like, "I'm going to lay here. I can't even sit up." I'm here but I can't sit up.

Danielle: Yes. I understand that. So, yeah, I think that's a good point and the class itself, or the program itself is not technically-- there's no scheduled classtime, so it's not like I can ever require. I can say they're required, but I can't really require the meetings because that's not what was agreed upon when y'all signed up for the course, so it's like going into a contract. I'm not going to change that but I understand what you mean. I just, I liked the ability to provide direct feedback and I remember you saying that was pretty much the biggest downside of going online was the fact that that immediate response wasn't available anymore.

Reba: Yeah.

Danielle: I really liked that opportunity but I understand what you mean because I also wasn't prepared for that, for those weekly things. I mean, I got prepared, right, but I was not planning on that. So, that also changes things, too because it becomes different for everyone. Everyone is dealing with the shift in how the class is being structured.

Reba: Right.

Danielle: So, yeah, I think that makes sense. But anyways, anything you felt challenging?

Reba: Other than like, physical challenges, I think a lot of the things that challenged me most were doing the feedback for others because I have a hard time criticizing other people unless you really screw up and upset me.

Danielle: [Laughs.] Okay. That's good to know. So, did it make you feel awkward?

Reba: Definitely. 
Danielle: Okay.

Reba: Not only giving the criticism, but there were definitely times in the beginning, and I think you and I talked about it, where I would get the same criticism for one everybody, over and over and over again, and I'm like, I'm trying my best to fix it but I don't know what else to do because that was something that yeah, in other classes, we were required to respond to our peers but it was more like, talking about the subject and agreeing on thoughts and adding to conversation. It was not feedback in the sense that we were doing.

Danielle: Yeah. And I think that's where -- so, let me ask you this: Do you feel that you know what to do better now? Do you feel like you understand the interpreting process and what should be done instead of feeling so stuck?

Reba: I do now, yeah. There were definitely times in the beginning where it was like, kind of disheartening but once I got out of my own head and was like, "Okay. It's not what I think it is. This can actually be done."

Danielle: Yes. Okay. Good. I'm glad you made the progress because that's really where I want you to be. And it's supposed to be hard, right? If it was easy, everybody would do it so it's supposed to be hard. I don't expect it to come naturally to every single person who steps in. That's just not normal. Okay.

So, and really, my last question then: How do you expect -- oh my gosh-- other interpreters to influence your work in the future, if at all? Maybe they don't influence your work, but what kind of relationship do you expect to have with other interpreters in the future?

Reba: I think communicating with other interpreters is going to be a little bit easier now because we've had to sit and assess each other and things like that, so if I go get pulled to the side by somebody I'm working with later, I'm going to know how to handle that a little bit better.

Danielle: Oh! Good.

Reba: I can remember doing my summer internship and our student wasn't there. So, the interpreter I was working with, we sat and we looked at the book we would have been interpreting and talked about how we would have interpreted it had he been there.

Danielle: Right. 
Reba: And, I think that's something that like, at the time, I was able to do a little bit because I knew the story, but now I'd be able to look at it a little bit differently and maybe provide a little bit more than I could at the time having not taken this course yet.

Danielle: Yes! Yes! That's exactly what I want. So, yeah. Getting to the process, and that's awesome! And, you're right: The more you do, the more situations like that you're in, the better you'll get at it because now you've done it so many times, SO many times, and then the more you do it the better you'll get and that's really why we did so much practice.

Reba: Right.

Danielle: But, no! That's awesome. Oh, my gosh. I'm so glad. Yay! So, those are all my questions. Super quick.

Is there anything-- I won't keep you unless there's anything that I can help you with for final project. I know we talked about that a little bit. You're good there. I'm good with the audio stuff. Like I said, just make sure it's all together so I don't have to go to a million places to find it.

Reba: I know you were talking about PowerPoint, having audio and adding it to Word and things like that. What if I just made it a PowerPoint so I could record it that way?

Danielle: The only thing I was thinking, I'm not against that, but I was thinking about bringing the template over might be difficult. But, if you can do it, I am more than willing -- don't hand me stuff I don't understand. If I don't understand it, I can't grade it. So, make sure it is wellorganized, but if you are comfortable doing that and you can make it make sense and complete it, by all means, I don't care. As long as you complete the assignment, like I said, just let me know what I'm opening. Let me know what is there so that when I go in I'm not, not that I'll forget, but that I'm not confused of like --

Reba: I'm trying to like, in my notes as I'm writing them, write down exact timestamps of like, at this moment is this error. At this moment is this error and try to do it that way.

Danielle: Good. Good. And, definitely make sure that you comment. So, define it but also give me a little description, right? So, give me the type of error, like illocutionary force, paralinguistic feature, blah blah blah, words I can't pronounce, and then include, "I did xyz" and whatever. It does not have to be a big description but a couple words to give me more information than just the type. 
Reba: Right.

Danielle: Like, is it a production error, in which case, did you put your hand on your forehead for dry instead of putting it on your chin?

Reba: Right.

Danielle: Right? You signed SUMMER instead of signing DRY. Fine, whatever. You might have done something like that and those are the kinds of things that I want you to note for me so I can still have that, but yes, to straight up answer your question: You can do it in PowerPoint, just make it clear. Don't care.

Reba: But, I think as long as I can keep it short and I don't have to have, like, these long explanations of exactly what I did, I might be able to type it out, but that was my biggest worry.

Danielle: Yeah.

Reba: I also have a six-to-eight-page research paper I'm working on right now, so there's a lot of typing going on right now

Danielle: Yeah, no, and that's fine. And, you can also ... just make sure for the description or the justification, be sure still, I do need you to document some things in there, so even if you have notes, I do need in that piece your, um, I need things to at least be summarized in that area, even if you give me a more descriptive oral essay. That's fine. I just need some things written down so that I know where you're placing me, right? So, like I said, a summary so that when I go in, I'm like, okay, I know what I'm looking at. For example, the titles of the two interpretations, be sure to include that so when I click on it, I know where I'm going.

Reba: I think what I'm going to do when I sit down to put everything into the template is do one page with like the name of the first interpretation on it and then a second page with the template again and the name of the second interpretation on it.

Danielle: Yep. Perfect. And, like I said, just, yeah, you can totally record those audio pieces there and put them right in there because as long as it's all integrated in the same spot, that's easy for me and I don't care. Just make sure you are still responding to the questions completely.

Reba: Mmm-hmm. 
Danielle: Just because it's an oral response doesn't mean it should just be sloppy, not that yours are. I'm not saying that but I don't want you to be like, if you don't do that completely, I don't want you to be surprised because my expectation is that you're still giving me complete thoughts and still thinking about what I'm asking you, not just like "uhh . . . And filling your time with that because that's not an answer. "Uhhh" doesn't work.

So, no, that's great. Let me know if you have other questions, but yeah. I will see you-- do you and I have your final interpretation scheduled?

Reba: We do. I think so, yeah.

Danielle: Awesome. Let me just look. I want to double-check where it is on my calendar before you go so I don't mess this up. [To self] So, next week. That's just the day, silly Danielle. I have you Thursday at 2. Yes?

Reba: Mmm-hmm.

Danielle: Okay, so I will send you the interpretation. I will not send it to you at 2 AM. I will send it to you the day before at 2 PM. I said 12 hours but when I realized what that would mean, I would have to either schedule it, which I don't trust because I don't trust it would actually go out. Something would get messed up, so I'll just send it the day before. You'll get it on the 18th at 2. Don't panic over it. Just listen to it a couple times. Get an idea. Think about it a little bit. Don't obsess over it. I will notice if you have already planned it all out. It should look like, not like a first draft, but a good draft. That's what I'm looking for. And, I'll use that rubric. That's what I'm grading, using to grade it, the rubric that you guys have. It's posted. Okay?

Reba: I do want to let you know because I want to kind of let you know where my heads at when it comes to re-recording things because I had originally planned to sit down and rerecording every single interpretation we had done and go for that point and a half on everything, but at this point, I don't know if I'm going to physically be able to do that with all of the other assignments that I have.

Danielle: That makes perfect sense.

Reba: And with the weight of the assignments that are left, I think that it is more important to show you where I am now versus going back and trying to do something that I've already done. 
Danielle: Yes. I agree.

Reba: I don't think that's it's worth it of putting myself through the stress of doing something that might not even turn out better. I may not even get the extra points for--

Danielle: You're totally right. The weight of the assignments going forward is way more significant. It just looks weird right now because all of our assignments have been these little ones. I'll break down and I will send it out, um, so, what I'm going to do so you know, is once you've sent me-- sorry, you're going to do your final interpretation on Thursday. Once that's done, I will have your grade to you by 4 PM so you'll know your grade with our without, depending on where you are with the post-test, with or without that assignment included but you will know where you are. I think it's 25 or 30 points, something like that. But, you'll know quickly so if there's anything you need to talk to me about at any point in time there, let me know, unless, the only other thing I would say is unless you want to move your final interpretation earlier in the week. I know it wasn't initially in the link, so if you need time to hand in anything else you have more time, if you need it. If something happens, I don't want it to be a scramble that on Thursday, we have to do something on Friday, but physically you can't. Do you have time earlier in the week?

Reba: I don't know, is the thing, honestly.

Danielle: That's fine. We will leave it. That's cool.

Reba: When you and I talked at midterm and we talked about where I was there and everything, I think I have come to realize that the most important thing for me is not getting this perfect so I can get through. It's just making sure that you know that I'm making improvements, even if I'm not perfect at the end of the semester, I have a whole other semester I'm still learning.

Danielle: I don't expect you to be perfect. That's not what I'm expecting. I'm glad you realized that too because I hope it shifted the pressure. You know what I mean? I hope you realized what the pressure should actually be. It should not be on being perfect; it should be on making sure that you're actually getting better because that's all I care about. If you're improving-- there are thresholds, right? If you go from 0 to 5, and I need you at 1,000, I don't care about that 5point jump. That doesn't help me, but if you're at a 10 and you make it to a 6 or a 5 , whatever number I said first. That's exactly what I need to see. The rest of the half, you still have time. I feel like there's good, um, I feel like you understand what you need to focus on toward the end of the semester which should take the pressure off of it just being a mad dash to the end. And good for you for not worrying about those interpretations, good for you.

Reba: Like, I know I still have linguistic issues, I know I do, but linguistic issues are something 
that I can work on throughout the entire rest of the program. They don't have to be perfect right now.

Danielle: They won't be, but you're right, I want to see that you know what to improve so that you can improve it. The first step is identifying, you know? If you don't know it's a problem, you can't fix it. So, identify the issues so that you can solve it. That's what I want you to be able to do: Figure it out for yourself and help other people identify their problems, too, and then figure out how to communicate it because what we need in this world is the ability to hold mirrors up to other people, so if I can teach you a little bit of that skill to be like, "Hey, listen, here's what you need to work on," I'll take that too; that's a victory in my book too. I understand what you mean. And, good for you, because it's not about being perfect.

Reba: I know you probably remember, like, our midterm discussion. I was very upset that my interpretation issues were what they were at that point, but I'm realizing now, even if they've improved a little, at least I know how to improve them and that's more important than fixing them every single time.

Danielle: Yes. And it doesn't mean that you don't try every single time but it means that every time you try, you're not just shooting in the dark and hoping that it works.

Reba: Right.

Danielle: That's a lot harder for me to teach somebody where to point than when you're trying to shoot in the dark. I can't help you. I'm sorry. It's easier for me to teach you where to point, than shooting in the dark and figuring out if you can get it or not.

Reba: Right.

Danielle: So, yeah, no. I'm so glad. I'm really glad. That's the entire point.

Reba: Imperfect does not equal bad.

Danielle: Right, exactly.

Reba: That's something that I've had to teach myself as a major perfectionist. Just because my interpretation was not perfect does not mean it was bad. 
Danielle: So, think about the term "ambiguous." And I'm going to leave you with that and how it relates to interpreting and why I might care, and I'll ask you tomorrow what you think. I'll make a note for myself. Think about those two things together: Ambiguous and interpreting and how, if at all, they're related. And I'll bug you about it later, but feel better.

Reba: Thank you. Bye.

Danielle: Bye. 


\section{Appendix M}

Teaching Journal 


\section{Journal}

Page 


\section{Danielle's Teaching Journal Home Journal Video Journal}

loday was tne ilrst aay or conege courses. I Innany nau tne opportunity to sign into biackdoara to set up my course on August 16, 2020. I did not have a username, nor did I know how to log into the system. I finally got assistance and signed on.

I noticed that several of the features with which I have become familiar were not present. I do not, for example, have the ability to use Collaborate Ultra with the Blackboard systems currently used at the College. I have meetings with the students the first week of class and I will have to utilize Zoom. Not a problem, but it is an additional step for these students all to connect with me.

Additionally, I have an interesting student case. She reached out to me indicating that she felt concerned about the essential functions listed on the syllabus. She worried that she would not be able to accomplish the tasks of the course, given her need for accommodations. She self-identified with a musculoskeletal disorder. After speaking with the Program Coordinator, I learned that, frankly, she should not be an interpreter. She told me to allow her to remain in the course, but to fail her again if necessary. She said that the course's Essential Functions were updated to protect the program from this student stating that her failure was due to discrimination. Rather, we have documentation via the syllabus that a student agreed to be able to complete the unique Essential Functions (by staying in the course).

There are currently two students (out of four) that stand out to me. Both are cognizant of their coursework and contact me frequently. I am intrigued to see how well they fare in the course, given that $3 / 4$ of these students are "repeats." I learned just before the start of classes that I had a student outside of the three students who did not pass their initial course attempts.

REFLECTION: I am under the impression that allof these students failed the class because they did not have the skills to pass. When I asked about why the students failed, the Program Coordinator, Jamie, told me it was because the students were lazy and because one has a severe disability.

Page 


\section{Danielle's Teaching Journal Home Journal Video Journal}

I spoke witn two or my students today! it was nice to see tnelr Iaces. ivy, now tneır personallues aliter. I wonder how their personality test results impact the students' perception of who they are as people and as interpreters.

It was interesting: my students today mentioned two things. (1) Their previous instructors were terrible communicators. (2) They both stated how they "lost their way" last semester.

Each of these students is a unique case. They truly are.

Both students today told me that previous instructors have failed to reply to communication. One would return correspondence about an assignment after the assignment was due. While I assured the student that I would never delay to respond to an email, I also informed her that she should not expect a reply from me at 11:58 PM for an assignment due at 11:59 PM. The other student told me that previous instructors refused to answer her emails, and she ultimately had to escalate to the Dean to get a response.

While I was not there for the Instructor's side of this situation, I really do hope that I never miss an email for more than 24 hours. I hope that I am able to maintain access to my computer, internet, and the web to facilitate quick communication (email or otherwise!) throughout the entire semester. I hope I never have to leave a student for that long.

Additionally, both students stated how they "fell off" at the end of the Fall 2019 semester. These students stated that they stopped working on coursework altogether. One stated that now she has a planner to write down her tasks, since she did such a poor job at staying abreast of her work during that semester.

Initial assessments:

- Christina: Very shy. It was very painstaking to interview this student. I would ask a question hoping for more information. Or, share a little more about myself in hopes of getting her to open up. She never did. I perceive a lack of self-confidence and self-efficacy. I do not know if she feels that she should interpret. She believes interpreting in elementary or secondary (middle school, specifically) will be easiest for her because she is not comfortable when information comes at her quickly. I fear that she does not understand the amount of creativity required for interpreting at those younger levels. I hope to shed light on her internal conversation and help determine if she is capable of handling such a position. She mentioned that her last semester, she stopped working on all of her courses. She bought a planner and seemed motivated to utilize it to organize her semester. I hope she utilizes it to its full potential! I will be sure to follow-up with her in a few weeks and see how she is doing with it. Perhaps we can work together if she is struggling.

- Reba: Very outgoing and perceptive. Frankly, the antithesis of Rachel. We spoke at length about her

Page đability, her experiences, her perspective, her goals, and her struggles (for nearly two hours, rnmnared to lescthan $\Delta 5$ minutes writh Sturdent $\Delta$ ) She is verv inciohtfill ahnu it the neaf 


\section{Danielle's Teaching Journal Home Journal Video Journal}

allow her to add speech-to-text features to nurture her academic and professional careers. She seems to need additional support and self-advocacy encouragement. I communicated to this student that while I am willing to work with her to adjust assignments (e.g. responding via voice rather than typing or handwriting), the essential functions of the course will not change. I do hope that she understands how true this fact is. Throughout the semester, I am interested to see how she approaches her work. I was told by the Program Coordinator that she should not be an interpreter. I do not know what to expect.

REFLECTION: I feel very disheartened by the approach taken by the College. This student has been identified as one who should not be an interpreter, but I am supposed to encourage her through the program. I feel like I am in a very difficult situation, one where I am set up to be the hatchet man, but I don't want to get cut (Thanks, Dr. B, for the verbiage here). I also acknowledge the drive to keep as many dollars in the College system as possible. But, by allowing a student who may not meet the essential functions of the course to continue in the program, are we setting her up for failure? I was told by the_College Psychologist_that I was only supposed to tell the student if she passed the class, not if she would be successful in the professional field. This statement is heartbreaking to me! Is this the future of education? Take their money, but don't help them find their passion? Push them through the system. Don't help them find their internal motivators. Just add them to the Conveyor Belt of Non-Thinkers. (Date: September 3, 2020)

Additionally, the students did not fail for the reasons to which I was previously alluded. These students struggled with time management, self-discovery, and self- actualizations. These students seemed to struggle more with their identity than they did with their coursework, at least by their own description.

I speak with one other student tomorrow. I speak with my final student on Thursday morning. I am excited to meet them both! :)

August 19,2020

I spoke with my third student today, Maggie. She has a much different background and set of experiences than the other students.

Page

She is a CODA, or a Child of a Deaf Adult. In the interpreting profession, these individuals are typically 


\section{Danielle's Teaching Journal Home Journal Video Journal}

I Spoke today witn tne rsycnologist in tne Lonege visadilty services Uince. sne was extremely neipiuı! We spoke about options, and she reminded me of the space for notes in the Accommodation Letter Agreement. I made notes about the kinds of available accommodations for the student. I sent it to the student for her to look over. She responded that it looked good! I hope that we have a successful semester together!

I am curious to see what happens/changes when the students start to interpret. They all seem very confident now, but are they truly capable of interpreting? I'm intrigued to find out!

Truthfully, I find it intriguing that this student is allowed to be in the interpreting program. I spoke with the Program Coordinator, Renee, about this situation. When I told her

I have my final conversation with my student tomorrow, Willow! I am interested to talk to her. She is the least talkative via email, so I am curious to see how she does in a face-to-face meeting.

Page 


\section{Danielle's Teaching Journal Home Journal Video Journal}

I spoke witn my inda stuaent yesteraay, vvıllow. sne is Irom kaleign county, vv v. sne seemea very confident in her abilities. She was well-versed in interpreting, and passionate about the field. She even said, "I can see why some people might leave the field, but I won't. I love it." I hope she is right! :) She also informed me that she prefers face-to-face discussions than email. She said that often, she feels more capable of expressing herself in a face-to-face conversation. This preference could explain the minimal communication I received from her. I wonder if she has been punished because she is not comfortable with email. Is there a way to find these students quickly (other than speaking with them) to provide them with access to communication alternatives? I don't want them to fall through the cracks!

She mentioned to me that I am the first instructor she has had who actually wanted to speak with her the first week of classes. I am glad there are only four students in a class, but I am sorry that allof these students had such poor communication with their previous instructors. Additionally, my third interviewee, Student C, emailed me this afternoon and said: "Thank you for actually answering emails. I'm still getting use to having a teacher that responds back to me and does it in an actual timely manner." I will be informing my Program Coordinator. I don't know details, but I think she should know when a pattern exists.

I have not yet started grading assignments but will the beginning of next week. I am interested to see how feedback goes.

Currently, I am interested in creating the following for my course:

- A voice discussion board, perhaps on FlipGrid, or a software of the kind.

- A sign language resource bank, where answers to commonly asked questions (about a sign, about interpreting, etc.) are available.

August 25, 2020

I feel extremely disconnected from my students after meeting with each of them last week. I am currently investigating methods by which I can more regularly connect with them or at let see their faces asynchronously. I may use Flipgrid to do this, but I am still not sure about the structure of how I can make this work.

August 26, 2020

I met with Dr. Sherfinski today regarding my prospectus work. We are going to start with the Methodology section (Chapter 3) for my dissertation.

*Page 
Danielle's Teaching Journal

Home Journal Video Journal

I was speaking witn a Iew veaI Irıenas via ivarco yolo (video communıcation app/ ana startea asking them about how they were taught to be Deaf interpreters. The process of Deaf interpreting (and then becoming certified) is intriguing. A lot of what they interpret is experiential. As a hearing certified interpreter, I am utilizing an L2 skill to process information. They are native language users. (Truthfully, their skills are a research interest of mine all on their own, but that's a study for another time.)

Interestingly, one of them was not diagnosed as Deaf (medically AND/OR culturally) until later in life. He is amazingly brilliant. He was able to mimic those around him and make sense of auditory stimuli without his ears actually "hearing" what was said. So, he grew up (for about 12 years) as a Child of a Deaf Adult (CODA). He learned English and American Sign Language. In this case, I would call both his L1: Neither was really differentiated when he was a child. He spoke to his mother in American Sign Language (single-parent home) and to his siblings in English (most are hearing). He also went to a mainstream public school, where he spoke English. He still was not identified as deaf (medical diagnosis) until he was in secondary school.

Nevertheless, both of these men are natives of American Sign Language. Like one of these Deaf interpreters, I have a student who is a CODA, too. I do feel like she could better empathize with the Deaf population than my other students. I should note that one of my other students is in a wheelchair, so she does have an accessibility understanding that many other interpreters have to learn. She was also not exposed to the language until she arrived in the program. My other two students are friends with Deaf individuals. One of the two speaks regularly with field/community interpreters. These students are able to empathize with the Deaf community to understand the cultural nuance required of interpreters. However, how can I provide students with these experiences in the classroom?

\section{Under pinning:Dewey and Experiential Learning}

Page 
Danielle's Teaching Journal Home Journal Video Journal I ne more I tnink adout it, I Delleve I snouid write situationa iniormation ror tne interpreting cips that students will be completing. I will ask students to reflect and suggest potential interpreting accommodations they need to make given the contextual information shared/understood /acknowledged about the Deaf/Hearing clients. I think students too often practice interpreting in a vacuum (I know I did in my program) and need to understand that they have a responsibility to accommodate their audience. In the past, interpreters were asked to be robotic and emotionally remove themselves from the situation. However, complete disconnect from the situation is impossible. Seeing, hearing, understanding, processing, and actualizing hurtful messages takes a toll on individuals. Interpreters are not only communication facilitators. keywords: situational, roleplay, situationalroleplay

I decided today that I was going to hold regular office hours, rather than only meeting with students by appointment. I honestly missed speaking with my students and am genuinely concerned about them losing contact with me and the content. I want to make sure I am available. If they choose not to use me, that's okay.

Additionally, I created a Flipgrid to share with students for this course. I am going to create space for students to collaborate on their upcoming assignments and projects, in addition to a spot for me to respond to questions students might have. I am not sure how else I will use Flipgrid, but I am excited to have it in play as a communicative tool.

I tried to utilize some Google features, though not my favorite, because the College students have Google accounts. However, some of the tools that are available on Google are limited to specific College administrators or IT personnel. This limitation is very frustrating. I wanted to have all systems connected, instead of trying to layer. I initially considered creating a Google Classroom. While I may in the future for this program, I did not want to take students all over the internet of hosting sites.

Page 


\section{Danielle's Teaching Journal Home Journal Video Journal}

so mucn nappened today.

- I restructured a bit of my course. Instead of organizing my course by weeks, I am going to organize my course by interpreting process. This way, students know on which part we are focusing this week. Students can also review content more easily when they need to review. I contemplated switching over completely to Google Classroom, but at this point, I want to utilize Blackboard at least for assignment submission. In the future, I will have to figure out what I want to do. I'm pretty sure this dilemma is that "stacking platforms" dilemma I learned about in IDT 610 with Dr. B.

- I decided to upload documents onto Google Drive (students have Google accounts) to get students most up-to-date information.

- I sent Dr. Beasley several drafts of my email to perfect it before Week 3 starts. I believe it is almost ready to go!

August 30-September 1, 2020

Did not work directly on course. On August 31, I sent out my weekly introductory email to students. I received one response from a student shortly after about this week being difficult for her due to personal reasons. Other than that correspondence, I did not hear from any students about this week's assignments. I am focusing on my methodology section for my dissertation currently. Will continue with coursework tomorrow, September 2, 2020. I will also check that students have posted first drafts of their video.

- Responded to several emails from students: Asking about grades, asking about assignments (clarification for how to record, where to post different assignments)

- Two out of four students have contacted me, stating that they posted the first draft of their first interpretations.

September 2,2020

I spoke with Dr. Sherfinski today about my Methodology section, as well as the overall theoretical framework for my dissertation. In speaking with her, I realized that my focus has been on teaching the process of interpreting to students, rather than allowing students to experience interpreting. ${ }^{* *}$ I made a note in an earlier journal posting (August 27,2020) that this focus is highly Deweyan. Going forward, I am looking at how I can structure the course to hand educational responsibility over to the student. This way, students are learning "how to fish for life," rather than just being handed a fish. Students can learn how to find relevant information in the interpreting field: at this point, fortunate enough to be with colleagues, but likely independently in the future!

Page 


\section{Danielle's Teaching Journal Home Journal Video Journal}

yestercay, viaggle reacnea out to me ior auditional as sistance witn ner otner clas ses. Honestiy, 1 am honored. I did inform the Program Coordinator, but also reassured her that I don't want it to stop and it does not bother me to be the point of contact for a student. I am sad for her, though. What about the other students in my class? Do they experience the same issues/struggles and not say anything? I'm glad I'm here for her, though! I hope others know/understand the same thing.

Big questions: Do students reach out to each other for assistance? Do they look for their instructors to provide answers?

UPDATE FROM INITIAL POST: ${ }^{* *}$ I got a response from Jamie, the Program Coordinator. Her response was fascinating. Initially, she seemed to support the student. She followed the information up with an email to all the adjunct instructors, telling them to be available for students. However, after I told her who it was (though she kept calling her Millie, rather than Maggie), she referred to her as a "liar." The tone of the conversation shifted from "The instructor will no longer work here" to "The student is a liar and I'm sure that if Maggie actually reached out, the instructor would respond." I feel very conflicted. I think this student seemed very genuine in her concerns, especially considering that many other students informed me that their other instructors did not respond to written correspondence. Jamie even said, "Oh, and those other three are lazy." In other words, I have "lazy" and "lying" students in my class! I definitely don't see them like that, at least not as of yet!

September 8, 2020

- Graded assignments

- Provided feedback

- Set up assignment for next week

September 14,2020

I created a Google Voice phone number (forwards to my personal cellphone) for students. I have not received questions from my students. They received their first assignment grade, but I not one reached out to me to discuss. The highest grade was 18/25, so they should have all had questions about their results. However, no one asked. Perhaps this is because of the method of communication. I added office hours, but maybe I need to make it even more accessible. I'll try it!

Students were asked to attend a workshop over the weekend. Some of the students were required as part of their other courses. I want to speak with each of them to see what they got out of the experience. I have contacted all four to set up meetings to discuss their experiences. I have heard now from three students and have just one meeting schedule.

Page 


\section{Danielle's Teaching Journal Home Journal Video Journal}

1 met witn two or my students today to alscuss tneir wedinar experience.

The first, Willow, did not have much to say about the classifiers workshop. However, she did seem curious about planning her interpretations. She told me that she often has mismatches between her facial expressions and her signs. She remarks that her face shows how her brain is "searching" for the right sign to match the speaker. She also told me that in her interpretations, she needs to look up signs, rather than fingerspelling words. My feedback to her centered around two things:

1. I want her to think about interpreting as a contextual process, rather than expecting a 1:1 ratio of English word to ASL sign. Not all signs will be the same for each concept. For example, I "run" to the store is different than my refrigerator is "running."

- Interestingly, when I asked this student to sign, "My refrigerator is running," she used the sign WORK to replace RUN. While this makes sense in English, in ASL, WORK is associated with a job, not an object that functions. She and I worked through this sentence until she arrived at the word OPERATIONAL, which would be more appropriate in this context.

2. I want her to consult with all of her peers to gain more understanding of what the source language message is and how best to communicate that into an ASL interpretation.

After, I met with Reba. Willow told me that she and Reba speak while they are working on interpretations, and often collaborate on their assignments. I was ecstatic to hear this! Reba said that she was only able to attend a portion of the workshop, as she thought that it started at 11 AM EST, just as I did. The organization (or lack thereof) for this event did contribute to a lot of confusion for all students.

I recorded as much of both conversations as technology would allow; I did have some issues recording with Willow.

I meet tomorrow with Maggie and Christina at 3 PM.

Page 


\section{Danielle's Teaching Journal Home Journal Video Journal}

1 recoraea tne entire conversation with ivaggie ana christina.

Speaking with Maggie and Christina was more than interesting. The two feel like complete opposites.

Christina seemed overwhelmed by the workshop experience. She stated that she depended on the members of her breakout group to catch her up to speed with what was going on. In speaking with her, she brought up how it "is hard for [her] to show emotion." This fact makes me curious. Christina has told me that she wants to be an educational interpreter, preferably in primary school. Typically, primary school interpreters should be more emotive than others! Children at a young age soak in emotions. An interpreter with minimal emotion could be detrimental to an interpreter's success (and a Deaf student's learning, comprehension, and overall development!).

Christina immediately suggested pen and paper, which again made me very concerned. I probed her and she did finally come up with gestures and classifiers (two VERY visual) systems in American Sign Language.

Maggie, on the other hand, did not get to attend the conference. However, she seemed to better understand more effective and efficient alternative practices for interpreters when "standard ASL" isn't working. While I did not ask Maggie at this time, she nodded reassuringly when I made my probes to Christina.

I informed Maggie and Christina that I would like to meet with them to better teach them interpreting than I feel the asynchronous content has done.

I have set up a Google Sheet to get students' inputon dates and times that work to begin meeting more regularly.

September $18-20,2020$

I am going camping this weekend and will not have access to my computer. However, I have been handwriting some journal entries. I will post images/scans of these pages soon to complement this digital blog.

Page 


\section{Danielle's Teaching Journal Home Journal Video Journal}

vvnle cnatung witn my mom (yes, really), 1 started to taik out some or tne issues 1 experience regurarly with this course.

1. I have no idea what the expected prior knowledge scope is. While I know not all students will comprehend all necessary information, I am not sure what has been covered thus far. I think working together with the Program Coordinator and the other adjunct instructors for interpreting (especially if I teach other classes in the future) would be beneficial! We should better connect our courses to make sure that we all know what the other is covering. I hope that all instructors would understand that this process is not to "check" if people are doing their jobs. I want to make strong interpreters and knowing where they've been will help plan where they need to go to be successful interpreting professionals.

2. The ethics course should come earlier in the Plan of Study. Students would benefit from understanding the impact of interpreting on the Deaf and Hearing communities, as well as the interpreter herself. Students should grasp the weight of a misinterpretation on the Hearing and Deaf clients. Additionally, interpreters should understand how the environment (emotionally triggering, for example) could impact an interpreter's ability to interpret. I will likely make this suggestion to Jamie at the end of the semester.

3. I am only a week ahead of my students (barely) in planning. I'm busy. I can barely keep up. Future iterations of this course (if I get to teach it) will be better in the future.

I made some adjustments to the class:

1. I added video explanations to the assignments in Flipgrid. While they're not anything stellar, it's different than writing out the descriptions. I'm curious to see if the students (a) watch the videos and (b) perform "better" as a result.

2. I have been flexible accepting late assignments, but students are failing to turn work in. I am now enforcing the $10 \%$ deduction policy in my syllabus.

3. I made adjustments to the syllabus, including a focus on the interpreting process rather than the weekly breakdowns as it previously was. I posted this new syllabus to Blackboard for students to reference. I also updated the assignment schedule. I took out the suggested due dates; they are misleading to students.

I am curious about how this week's vlog goes! I asked students to answer the following ten questions:

1. What is something that no one would guess about you?

2. What do you believe in? (NOTE: The response to this question is open to wide interpretations and should not be perceived in any specific light, other than the vast spectrum of the world of "things.")

3. If you could be doing anything, anywhere right now, what and where would it be?

4 dghat do you wish you had done differently in your life?

5. What are you doing to improve yourself? 


\section{Danielle's Teaching Journal Home Journal Video Journal}

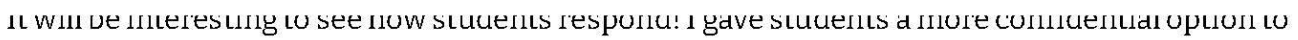
respond, as well, if they're self-conscious about their peers seeing their vlog posts on Flipgrid.

September 23,2020

\section{Lack of student interaction with content and each other.}

I asked students to participate in a brainstorming activity via Google Draw. While not ideal, and Christina stated that she would have done better collaborating in a Zoom call, only two students even partook in the exercise. Their lack of participation is both frustrating and disconcerting. I am curious whether it is my interaction with these students that has led them to disengage, or if this was the center of their demise during their previous iterations of this course. At what point does their lack of involvement become my issue? At what point can I help them? When can't I?

Reba did contact me last week to tell me that she was going out of town this week. However, she did not keep up with assignments this week. I want to be flexible with her (and all students) but there is a line that must be drawn between when work can still be accepted. I do need students to work together on assignments and failure to turn work in on time does affect others.

Again, I can make schedules and plans very clear, but if students don't want to invest the time and energy into becoming an interpreter, I cannot make them... It is hard to watch people fail, even if they only fail temporarily.

Page 


\section{Danielle's Teaching Journal Home Journal Video Journal}

I nave deen working on my metnodology section ior tne past montn. une or tne recurring tnemes is the development of empathy: for myself and for my students. At the core of deconstruction is the ability to put yourself in someone else's shoes. In doing some research about this notion, looking for scientific proof of this idea, I stumbled across this video:

https://www.youtube.com/watch?time_continue=1248v=fpl84D-uNmY\&feature=emb_logo

Truthfully, I am in tears. This video was created by/for World Relief.

\section{ABOUT WORLD RELIEF:}

"Every second of every day children are orphaned by disease, women are widowed by conflicts, families are devastated by natural disasters and refugees are relocated to new countries. These are the heartbreaking stories of the vulnerable.

We believe God has equipped the church - the most diverse social network on the planet to be at the center of these stories, leveraging time, energy and resources to join the vulnerable in their time of need.

We practice principles of transformational development to empower local churches in the United States and around the world so they can serve the vulnerable in their communities. With initiatives in education, health, child development, agriculture, food security, antitrafficking, immigrant services, micro-enterprise, disaster response and refugee resettlement, we work holistically with the local church to stand for the sick, the widow, the orphan, the alien, the displaced, the devastated, the marginalized, and the disenfranchised.

In our own backyard and around the globe, we stand with individuals and communities through the process of healing, reconciliations, transformation and empowerment.

Whatever it takes, and wherever it takes us, we are faithful to our call."

In the video, the narrator states, "It's one thing to wonder if someone else is worth fighting for, but when you begin to identify with someone else, commune with them, that's when the question is no longer worth asking. That's when it becomes offensive even. [...] I don't care how long it takes. I don't care how many times we fail. [...] You never stop fighting for your own."

While I am by nomeans a pious woman, I certainly appreciate the message from World Relief, narrated by a Mr. Micah Bournes. The core of the final statement, "You never stop fighting for your own" is the crux of having Deaf Heart as an interpreter: become part of the Deaf community (as an interpreter) and you become more capable of rendering interpretations that are culturally, socially, Page
and conceptually accurate. 


\section{Danielle's Teaching Journal Home Journal Video Journal}

1 oday was awesome. 1 nad an opportunity to meet witn all or my students togetner at tne same time to complete an activity for this week's work. I was able to record the session. I cannot wait to rewatch the video to transcribe it, making note of the capabilities of each student.

The students were mostly participative, though I noticed that Reba was not interested in saying much. Truthfully, I am concerned about her ability to synthesize information. She has physical limitations, yes, but more namely, her cognitive abilities to deconstruct (and then reconstruct) concepts in English or American Sign Language greatly worries me.

I found it intriguing to watch students deconstruct (the assignment this week) a passage.

Hello, come in. Nice to meet you. I understand that you wish to talk to me about your daughter's schooling. Now she's hearing impaired, too, isn't she? And she's currently at Cherry Tree Juniors, and you want her to be transferred to the old Deaf and Dumb school? Actually, you know, my great aunt was hard of hearing, and I learned some of the sign language myself when I was in the Brownies. Of course, that's quite a few years ago now, but I still remember a bit of it... That's A, isn't it? Yes, very good. Can you lipread me all right?

Students were QUICK to judge this individual as disrespectful. I actually found the assignment in an Interpreting Pedagogy book (from the early 2000s). While the information in the book is certainly outdated, this assignment was absolutely perfect. In the text, they discuss the process of Critical Discourse Analysis, what I perceive as the application of deconstruction. The author writes that her class also saw the speaker as rude, at first, then realized that she is an individual who is uneducated in the appropriate terminology (i.e. utilizing Deaf and Dumb). However, my students were quick to judge this individual for being an inconsiderate female. In fact, students initially believed the speaker was male. When I pointed to the Brownies reference (a group for young girls), students remarked, "that changes things. Females are so judgmental."

I plan to provide students with additional activities like this one, guiding them through it via Zoom. I do not want students to be left to their own judgments at this time to misinterpret a situation. Until they are competent in empathy, I plan to guide students through other deconstruction and reconstruction activities. 


\section{Danielle's Teaching Journal Home Journal Video Journal}

I oday, I sudmittea miaterm grades. I pian to make silgnt aujustments to tne grauing ior assignments:

\section{ASSIGNMENT EXAMPLE}

- Each portion of the assignment (typically 4-5 components) is worth 3 points

- Students who successfully complete each portion of the assignment will receive full credit

- Success is measured by students' ability to respond to relevant questions

- Success is measured by students' ability to synthesize concepts into American Sign Language and English (utilizing rubric)

I do not like making this adjustment, but I was finding the ability to assess students' progress difficult. I plan to update the gradebook later today in order to give students sufficient information while they receive a letter value for their course work thus far.

Page 


\section{Danielle's Teaching Journal Home Journal Video Journal}

It has deen some time since I wrote in my journal, duc not decause or tne Iack or events.

- I posted midterm grades two weeks ago. I have one student with a B, one with a C, and two with a D. Only the student with the B reached out to me for quite some time. One of the students with a D, Reba, reached out to me yesterday for us to speak today.

Our conversation was fascinating.

Reba is an intriguing case. At the beginning of the semester, I was told that this student was not "cut out" to be an interpreter. In fact, she had communicated at some point to Jamie that she didn't want to interpret; she wanted to act using Sign Language. Since I met her, she has often surprised me. Though, like all students, she has her moments (i.e. failing to turn in any assignments for an entire week). However, I spoke with Reba today about her standing and was impressed by her response. She told me that she wanted to address the issue now and take action with 6 weeks left, rather than waiting until the end of the semester when nothing can be done. Despite my perspective that Reba is capable, she does not always give me content to assess her competence. She showed me today, however, that she is willing to take responsibility for her work.

In speaking with Reba, she added that she has had to unlearn many habits in taking my class. She informed that even during her formative classes (e.g. American Sign Language courses), she was passed for completing the assignment... and not even always completion! Often, Reba was awarded 100\% for an assignment she completed $70 \%$ of. In other words, Reba was passed for a lame attempt. Reba told me that I am the first instructor to actually address the issues in her interpretations.

Reba took this course again, from what she said, "to improve" (even though she would not have passed the course the first time because she earned a $\mathrm{D}$, and the program requires all course to be completed with a C). However, she was not expecting the feedback she has received.

Ultimately, Reba and I talked about several things she can do to improve her interpretations. I offered to work through an interpretation with her. With her suggestion, I wrote down that I should record one of my own interpretations to show students what it looks like to see me work... and mess up! Much of what Reba said was a fear of being "wrong." I want them to see that being skilled does not mean being perfect. I think having someone with National Certification show them what it's like to mess up is a great idea. I'm working on creating this video, if not for this semester, then definitely for a future iteration of this course.

I had made a comment during our call today about how hard it is to walk students through the process I want them to understand while not meeting consistently, hence my requirement of

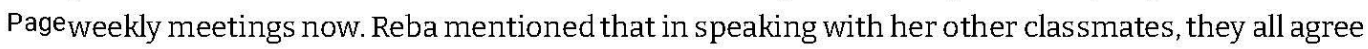
that switching from in-person to online was hard due to the loss of interaction and immediate 


\section{Danielle's Teaching Journal Home Journal Video Journal}

an interpretation. I feel a lot better that I'm actually making sure students understand how to interpret before I "time them" doing so.

- Currently on the final "section" of the interpreting process (Self-Evaluation and Reflection) that I want to cover with students. In the last 6 weeks, we will complete the following:

- Source of Error (Week 9, this week)

- Self-monitoring and Correction (Week 10)

- Transfer; One-on-one with Prof. South (Week 11)

- Final Project \& Final Interpretation (Weeks 12-14)

- Final project should include post-assessment

- Perhaps incorporate reflection between pre- and post-assessment in a reflective section of students' course portfolio

- I offered one of my students (Willow) the opportunity to earn partial credit for the vlogs she has not submitted. I offered her $2.5 / 5$ points for each of them (5) that she did not yet complete. I (1) want her data and (2) do not want her to fail again! I currently have $3 / 4$ students failing (after updating grades from the last two weeks' assignments). I offered another student (Christina) insight into my grading, hoping that she will see what elements of an interpretation I find essential and reflect on what she can do to work on her skills and pass the course. I hope that I do not have to fail anyone, especially those who have already taken the course. However, if I do, I can do so knowing that I tried to give them a way to pass, offered them additional assistance, and provided them with opportunities to make up the work they needed to complete. If they do not pass, it is for fault of their own.

I still have the following to do:

1. Write self-monitoring and correction lesson plan

2. Write transfer lesson plan

3. Write final project \& final interpretation

- Write post-assessment interpretation (assignment and instructions)

Page
October 20,2020 


\begin{abstract}
Danielle's Teaching Journal Home Journal Video Journal the same piece of advice: she needs to do a better job of "embodying" the message. In ASL interpreting, interpreters have to become the voice, whomsoever it may be. Maggie could benefit from additional practice with children's stories, focusing on how she can think about the message, rather than each word. Additionally, I had to address another (VERY AWKWARD) concern with Maggie: her appearance. While I support freedom of expression, in interpreting, your hands and your face are constantly watched. Maggie has two very large piercings in her nose and her lip/cheek area, and wears large rings on almost every finger. I could barely focus on what she was saying. I had to address it. I did, and Maggie handled it well (via email). She thanked me for the feedback. Um.... does this mean that no one else said anything? I cannot be the only one who saw it as an issue.
\end{abstract}

- I created and sent out final interpretation information, final project, and the scheduling for the one-on-one with me.

October 27,2020

Today, I realized that I still had to write and send out post-test information, so I did. I included several vlogs in this post-test. I asked students to complete the assignment before the end of the semester, $11 / 20 / 2020$. I figured giving them enough time now would allow them to schedule their time appropriately... or... well... not.

October 28,2020

Today, I met with Maggie and Christina about the final project, interpretation, and more! I sent them a barrage of emails (not really, just for the assignments). Maggie said she didn't like that I sent her one email per assignment and Christina said that she appreciated it because of how her email searches on her computer by default. Perfect example of why we have to accept that we can't make everyone happy all the time.

While talking with both students, I had a few ideas and wrote them down.

- Group/team interpreting assignment (then final): I was thinking about doing a teamed interpreting assignment so that students have to feed off of each other. While talking to Maggie and Christina, Maggie was direct with me and said, "Not everyone in this class is ready for that." Definitely a real issue/concern that I need to consider in the future, but something I want to consider. I think it would be a great assignment idea.

${ }^{* *}$ Any suggestions for how to organize different assignments? Do y'all create assignments when you think about them and then save them for when you need them? Would love your perspective/insight here!**

Page 


\section{Appendix N}

Pre-assessment: Maggie

\section{Performance Rubric for ASL Interpreting}

\begin{tabular}{|c|c|c|c|c|c|}
\hline CATEGORY & $\begin{array}{l}\text { Sign } \\
\text { production \& } \\
\text { vocabulary }\end{array}$ & Grammar & Use of Space & Affect & $\begin{array}{l}\text { Pacing and } \\
\text { Pausing }\end{array}$ \\
\hline $\begin{array}{l}\text { Excellent } \\
\text { control }\end{array}$ & $\begin{array}{l}\text { High level of } \\
\text { equivalence between } \\
\text { SL and TL; produces } \\
\text { signs accurately, both } \\
\text { structurally and } \\
\text { conceptually; wide } \\
\text { range of well-chosen } \\
\text { vocab }\end{array}$ & $\begin{array}{l}\text { ASL syntax } \\
\text { successfully conveys a } \\
\text { wide range of } \\
\text { grammatical structures } \\
\text { (T/C, conditionals, } \\
\text { RHQs, etc.); ability to } \\
\text { use complete and } \\
\text { complex sentences }\end{array}$ & $\begin{array}{l}\text { Signing space is } \\
\text { appropriate; clear } \\
\text { establishment and use } \\
\text { of referents; excellent } \\
\text { use of spatial aspects } \\
\text { of expansion features }\end{array}$ & $\begin{array}{l}\text { High level of } \\
\text { equivalence between } \\
\text { source text and target } \\
\text { text }\end{array}$ & $\begin{array}{l}\text { Sr Joth and fluid } \\
\text { roduction; few to } n \\
\text { hesitations; pausing } \\
\text { where appropriate }\end{array}$ \\
\hline Good control & $\begin{array}{l}\mathrm{Pr} \text { uuces most } \mathrm{si}_{2} \text {. } \\
\text { ccurately, both } \\
\text { structurally and } \\
\text { conceptually; good } \\
\text { range of vocabulary }\end{array}$ & $\begin{array}{l}\text { ASL syntax conveys a } \\
\text { range of grammatical } \\
\text { structures (T/C, } \\
\text { conditional, RHQs, } \\
\text { etc.); mostly complete } \\
\text { sentences that are } \\
\text { complex, with few } \\
\text { errors }\end{array}$ & $\begin{array}{l}\text { Clear establishment } \\
\text { and use of referents } \\
\text { with few errors; } \\
\text { limited command of } \\
\text { spatial aspects of } \\
\text { expansion features }\end{array}$ & $\begin{array}{l}\text { M stly successt.; } \\
\text { epresentation of } \\
\text { source text affect }\end{array}$ & $\begin{array}{l}\text { Production is relatively } \\
\text { smooth but contains } \\
\text { some hesitation and } \\
\text { unevenness. }\end{array}$ \\
\hline $\begin{array}{l}\text { Adequate } \\
\text { control }\end{array}$ & $\begin{array}{l}\text { Produces signs } \\
\text { inaccurately, } \\
\text { structurally and/or } \\
\text { conceptually; limited } \\
\text { range of vocabulary; } \\
\text { source text is } \\
\text { retrievable } \\
\end{array}$ & $\begin{array}{l}\text { Sor ce text renc red } \\
\text { f thfully with } \\
\text { occasional lapses ano } \\
\text { elisions }\end{array}$ & $\begin{array}{l}\text { Es } s^{+} \text {olishment ano ise } \\
\text { c. referents are not } \\
\text { lear, but meaning of } \\
\text { source text is } \\
\text { etrievable }\end{array}$ & $\begin{array}{l}\text { Offers fair } \\
\text { representation of } \\
\text { source text }\end{array}$ & $\begin{array}{l}\text { Production is } \\
\text { frequently hesitant and } \\
\text { jerky }\end{array}$ \\
\hline $\begin{array}{l}\text { Weak (or no) } \\
\text { control }\end{array}$ & $\begin{array}{l}\text { Structural and/or } \\
\text { conceptual clarity of } \\
\text { signs is lacking; } \\
\text { limited } \\
\text { vocabulary....rendering } \\
\text { the source text } \\
\text { irretrievable }\end{array}$ & $\begin{array}{l}\text { Lim d ranger } \\
\text { grammatical } \\
\text { structures; incomplete } \\
\text { sentences that obscure } \\
\text { meaning }\end{array}$ & $\begin{array}{l}\text { Estabind use } \\
\text { of referents are not } \\
\text { clear and rendered } \\
\text { message is not } \\
\text { retrievable }\end{array}$ & Affect is largely absent & $\begin{array}{l}\text { Production is slow and } \\
\text { choppy; excessive } \\
\text { pauses make } \\
\text { comprehension of the } \\
\text { source text difficult }\end{array}$ \\
\hline
\end{tabular}

Comments: Maggie's interpretation is incredibly expressive. I can see that Maggie has a significant amount of experience in signing because of her comfort putting signs together. However, her message is literal and lateral: she utilizes word meanings rather than speaker or message intent. 


\section{Appendix N (continued)}

Post-assessment: Maggie

\section{Performance Rubric for ASL Interpreting}

\begin{tabular}{|c|c|c|c|c|c|}
\hline CATEGORY & $\begin{array}{l}\text { Sign } \\
\text { production \& } \\
\text { vocabulary }\end{array}$ & Grammar & Use of Space & Affect & $\begin{array}{l}\text { Pacing and } \\
\text { Pausing }\end{array}$ \\
\hline $\begin{array}{l}\text { Excellent } \\
\text { control }\end{array}$ & $\begin{array}{l}\text { High level of } \\
\text { equivalence between } \\
\text { SL and TL; produces } \\
\text { signs accurately, both } \\
\text { structurally and } \\
\text { conceptually; wide } \\
\text { range of well-chosen } \\
\text { vor-1 }\end{array}$ & $\begin{array}{l}\text { ASL syntax } \\
\text { successfully conveys a } \\
\text { wide range of } \\
\text { grammatical structures } \\
\text { (T/C, conditionals, } \\
\text { RHQs, etc.); ability to } \\
\text { use complete and } \\
\text { complex sentences }\end{array}$ & $\begin{array}{l}\text { Signing space is } \\
\text { appropriate; clear } \\
\text { establishment and use } \\
\text { of referents; excellent } \\
\text { use of spatial aspects } \\
\text { of expansion features }\end{array}$ & $\begin{array}{l}\text { High level of } \\
\text { equivalence between } \\
\text { source text and target } \\
\text { text }\end{array}$ & $\begin{array}{l}\text { Sm vith and flui } \\
r \text { oduction; few to } 1 \text {, } \\
\text { hesitations; pausing } \\
\text { where appropriate }\end{array}$ \\
\hline Good control & $\begin{array}{l}\text { roduces most s. Tns } \\
\text { accurately, both } \\
\text { structurally and } \\
\text { conceptually; good } \\
\text { range of vocabular }\end{array}$ & $\begin{array}{l}\text { ASL syntax conveys a } \\
\text { range of grammatical } \\
\text { structures (T/C, } \\
\text { conditional, RHQs, } \\
\text { etc.); mostly complete } \\
\text { sentences that are } \\
\text { complex, with few } \\
\text { errors }\end{array}$ & $\begin{array}{l}\text { Clear establishment } \\
\text { and use of referents } \\
\text { with few errors; } \\
\text { limited command of } \\
\text { spatial aspects of } \\
\text { expansion features }\end{array}$ & $\begin{array}{l}\text { Mr ay successt.: } \\
5 \text { presentation of } \\
\text { source text affect }\end{array}$ & $\begin{array}{l}\text { Production is relatively } \\
\text { smooth but contains } \\
\text { some hesitation and } \\
\text { unevenness. }\end{array}$ \\
\hline $\begin{array}{l}\text { Adequate } \\
\text { control }\end{array}$ & $\begin{array}{l}\text { Produces signs } \\
\text { inaccurately, } \\
\text { structurally and/or } \\
\text { conceptually; limited } \\
\text { range of vocabulary; } \\
\text { source text is } \\
\text { retrievable }\end{array}$ & $\begin{array}{l}\text { Sr arce text render d } \\
\text { aithfully with } \\
\text { occasional lapses and } \\
\text { elisions }\end{array}$ & $\begin{array}{l}\text { Es } \text { olishment and } \mathrm{t} \text {. } \\
\mathrm{c} \text {.referents are not } \\
\text { lear, but meaning of } \\
\text { ource text is } \\
\text { trievable }\end{array}$ & $\begin{array}{l}\text { Offers fair } \\
\text { representation of } \\
\text { source text }\end{array}$ & $\begin{array}{l}\text { Production is } \\
\text { frequently hesitant and } \\
\text { jerky }\end{array}$ \\
\hline $\begin{array}{l}\text { Weak (or no) } \\
\text { control }\end{array}$ & $\begin{array}{l}\text { Structural and/or } \\
\text { conceptual clarity of } \\
\text { signs is lacking; } \\
\text { limited } \\
\text { vocabulary....rendering } \\
\text { the source text } \\
\text { irretrievable }\end{array}$ & $\begin{array}{l}\text { Limitec of } \\
\text { grammatical } \\
\text { structures; incomplete } \\
\text { sentences that obscure } \\
\text { meaning }\end{array}$ & $\begin{array}{l}\text { Establisnmumit and use } \\
\text { of referents are not } \\
\text { clear and rendered } \\
\text { message is not } \\
\text { retrievable }\end{array}$ & Affect is largely absent & $\begin{array}{l}\text { Production is slow and } \\
\text { choppy; excessive } \\
\text { pauses make } \\
\text { comprehension of the } \\
\text { source text difficult }\end{array}$ \\
\hline
\end{tabular}

Comments: Maggie seems to be more competent in her ability to think about another person's message, but she depends heavily on English-language structures still, rather than dropping form to adopt ASL ones, as requested. I think that Maggie's dependence on English stems from her use of the language with her family, as well as her other language exposure experiences. 


\section{Appendix O}

Pre-assessment: Christina

\section{Performance Rubric for ASL Interpreting}

\begin{tabular}{|c|c|c|c|c|c|}
\hline CATEGORY & $\begin{array}{l}\text { Sign } \\
\text { production \& } \\
\text { vocabulary }\end{array}$ & Grammar & Use of Space & Affect & $\begin{array}{l}\text { Pacing and } \\
\text { Pausing }\end{array}$ \\
\hline $\begin{array}{l}\text { Excellent } \\
\text { control }\end{array}$ & $\begin{array}{l}\text { High level of } \\
\text { equivalence between } \\
\text { SL and TL; produces } \\
\text { signs accurately, both } \\
\text { structurally and } \\
\text { conceptually; wide } \\
\text { range of well-chosen } \\
\text { vocab }\end{array}$ & $\begin{array}{l}\text { ASL syntax } \\
\text { successfully conveys a } \\
\text { wide range of } \\
\text { grammatical structures } \\
\text { (T/C, conditionals, } \\
\text { RHQs, etc.); ability to } \\
\text { use complete and } \\
\text { complex sentences }\end{array}$ & $\begin{array}{l}\text { Signing space is } \\
\text { appropriate; clear } \\
\text { establishment and use } \\
\text { of referents; excellent } \\
\text { use of spatial aspects } \\
\text { of expansion features }\end{array}$ & $\begin{array}{l}\text { High level of } \\
\text { equivalence between } \\
\text { source text and target } \\
\text { text }\end{array}$ & $\begin{array}{l}\text { Smooth and fluid } \\
\text { production; few to no } \\
\text { hesitations; pausing } \\
\text { where appropriate }\end{array}$ \\
\hline Good control & $\begin{array}{l}\text { Produces most signs } \\
\text { accurately, both } \\
\text { structurally and } \\
\text { conceptually; good } \\
\text { range of vocabulary }\end{array}$ & $\begin{array}{l}\text { ASL syntax conveys a } \\
\text { range of grammatical } \\
\text { structures (T/C, } \\
\text { conditional, RHQs, } \\
\text { etc.); mostly complete } \\
\text { sentences that are } \\
\text { complex, with few } \\
\text { errors }\end{array}$ & $\begin{array}{l}\text { Clear establishment } \\
\text { and use of referents } \\
\text { with few errors; } \\
\text { limited command of } \\
\text { spatial aspects of } \\
\text { expansion features }\end{array}$ & $\begin{array}{l}\text { Mostly successful } \\
\text { representation of } \\
\text { source text affect }\end{array}$ & $\begin{array}{l}\text { Production is relatively } \\
\text { smooth but contains } \\
\text { some hesitation and } \\
\text { unevenness. }\end{array}$ \\
\hline $\begin{array}{l}\text { Adequate } \\
\text { control }\end{array}$ & $\begin{array}{l}\text { Prod-Ces signs } \\
\text { in ccurately, } \\
\text { s ructurally and/or } \\
\text { onceptually; limited } \\
1 \text { inge of vocabulary; } \\
\text { sc urce text is } \\
\text { retri -able }\end{array}$ & $\begin{array}{l}\text { Source text rendered } \\
\text { faithfully with } \\
\text { occasional lapses and } \\
\text { elisions }\end{array}$ & $\begin{array}{l}\text { Estal.snment a. d use } \\
\text { of eferents are not } \\
\mathrm{c} \text { ear, but meaning o. } \\
\text { s surce text is } \\
\text { I trievable }\end{array}$ & $\begin{array}{l}\text { Offers fair } \\
\text { representation of } \\
\text { source text }\end{array}$ & $\begin{array}{l}\text { Production is } \\
\text { frequently hesitant and } \\
\text { jerky }\end{array}$ \\
\hline $\begin{array}{l}\text { Weak (or no) } \\
\text { control }\end{array}$ & $\begin{array}{l}\text { Structural and/or } \\
\text { conceptual clarity of } \\
\text { signs is lacking; } \\
\text { limited } \\
\text { vocabulary...rendering } \\
\text { the source text } \\
\text { irretrievable }\end{array}$ & $\begin{array}{l}\text { Lim d range u. } \\
\text { gr mmatical } \\
\text { ructures; incomple } \\
\text { entences that obscus } \\
1 \text { leaning }\end{array}$ & $\begin{array}{l}\text { Establishment and use } \\
\text { of referents are not } \\
\text { clear and rendered } \\
\text { message is not } \\
\text { retrievable }\end{array}$ & Affe . is largely a'ssent & $\begin{array}{l}\text { Pro'uction is s. W and } \\
\text { toppy; excessive } \\
\text { fauses make } \\
\text { comprehension of tl } \\
\text { ource text difficult }\end{array}$ \\
\hline
\end{tabular}

Comments: Christina struggles with putting the message together in ASL. It seems like she is aware of this challenge because her interpretation did not exude confidence. I believe Christina has missed a significant amount of learning from previous semesters on how to structure ASL. 


\section{Appendix O (continued)}

Post-assessment: Christina

\section{Performance Rubric for ASL Interpreting}

\begin{tabular}{|c|c|c|c|c|c|}
\hline CATEGORY & $\begin{array}{l}\text { Sign } \\
\text { production \& } \\
\text { vocabulary }\end{array}$ & Grammar & Use of Space & Affect & $\begin{array}{l}\text { Pacing and } \\
\text { Pausing }\end{array}$ \\
\hline $\begin{array}{l}\text { Excellent } \\
\text { control }\end{array}$ & $\begin{array}{l}\text { High level of } \\
\text { equivalence between } \\
\text { SL and TL; produces } \\
\text { signs accurately, both } \\
\text { structurally and } \\
\text { conceptually; wide } \\
\text { range of well-chosen } \\
\text { vocab }\end{array}$ & $\begin{array}{l}\text { ASL syntax } \\
\text { successfully conveys a } \\
\text { wide range of } \\
\text { grammatical structures } \\
\text { (T/C, conditionals, } \\
\text { RHQs, etc.); ability to } \\
\text { use complete and } \\
\text { complex sentences }\end{array}$ & $\begin{array}{l}\text { Signing space is } \\
\text { appropriate; clear } \\
\text { establishment and use } \\
\text { of referents; excellent } \\
\text { use of spatial aspects } \\
\text { of expansion features }\end{array}$ & $\begin{array}{l}\text { High level of } \\
\text { equivalence between } \\
\text { source text and target } \\
\text { text }\end{array}$ & $\begin{array}{l}\text { Smooth and fluid } \\
\text { production; few to no } \\
\text { hesitations; pausing } \\
\text { where appropriate }\end{array}$ \\
\hline Good control & $\begin{array}{l}\text { Prodn mus rigns } \\
\text { ac urately, both } \\
\text { ructurally and } \\
\text { onceptually; good } \\
\text { ange of vocabulary }\end{array}$ & $\begin{array}{l}\text { ASL syntax conveys a } \\
\text { range of grammatical } \\
\text { structures (T/C, } \\
\text { conditional, RHQs, } \\
\text { etc.); mostly complete } \\
\text { sentences that are } \\
\text { complex, with few } \\
\text { errors }\end{array}$ & $\begin{array}{l}\text { Clear establishment } \\
\text { and use of referents } \\
\text { with few errors; } \\
\text { limited command of } \\
\text { spatial aspects of } \\
\text { expansion features }\end{array}$ & $\begin{array}{l}\text { Mostly successful } \\
\text { representation of } \\
\text { source text affect }\end{array}$ & $\begin{array}{l}\text { Production is relatively } \\
\text { smooth but contains } \\
\text { some hesitation and } \\
\text { unevenness. }\end{array}$ \\
\hline $\begin{array}{l}\text { Adequate } \\
\text { control }\end{array}$ & $\begin{array}{l}\text { Produces signs } \\
\text { inaccurately, } \\
\text { structurally and/or } \\
\text { conceptually; limited } \\
\text { range of vocabulary; } \\
\text { source text is } \\
\text { retrievable }\end{array}$ & $\begin{array}{l}\text { Sor ce text reno ed } \\
\text { f thfully with } \\
\text { ccasional lapses an } \\
\text { lisions }\end{array}$ & $\begin{array}{l}\text { Est - Jishment an }{ }^{\text {' use }} \\
\text { of referents are not } \\
\text { ' ear, but meaning o. } \\
\text { ource text is } \\
\text { I trievable }\end{array}$ & $\begin{array}{l}\text { Offer alir } \\
\text { rep esentation of } \\
\text { sc irce text }\end{array}$ & $\begin{array}{l}\text { Prodv-uon is } \\
\text { fre aently hesitant a d } \\
\text { je ky }\end{array}$ \\
\hline $\begin{array}{l}\text { Weak (or no) } \\
\text { control }\end{array}$ & $\begin{array}{l}\text { Structural and/or } \\
\text { conceptual clarity of } \\
\text { signs is lacking; } \\
\text { limited } \\
\text { vocabulary...rendering } \\
\text { the source text } \\
\text { irretrievable }\end{array}$ & $\begin{array}{l}\text { Limited range of } \\
\text { grammatical } \\
\text { structures; incomplete } \\
\text { sentences that obscure } \\
\text { meaning }\end{array}$ & $\begin{array}{l}\text { Establishment and use } \\
\text { of referents are not } \\
\text { clear and rendered } \\
\text { message is not } \\
\text { retrievable }\end{array}$ & Affect is largely absent & $\begin{array}{l}\text { Production is slow and } \\
\text { choppy; excessive } \\
\text { pauses make } \\
\text { comprehension of the } \\
\text { source text difficult }\end{array}$ \\
\hline
\end{tabular}

Comments: Christina demonstrated an ability to "figure it out" in this interpretation. While she did not know every sign, she managed to utilize language more efficiently to adequately communicate the source message. I think that Christina would benefit from more exposure to the Deaf community, but I recommend that to everyone. 


\section{Appendix P}

Pre-assessment: Willow

\section{Performance Rubric for ASL Interpreting}

\begin{tabular}{|c|c|c|c|c|c|}
\hline CATEGORY & $\begin{array}{l}\text { Sign } \\
\text { production \& } \\
\text { vocabulary }\end{array}$ & Grammar & Use of Space & Affect & $\begin{array}{l}\text { Pacing and } \\
\text { Pausing }\end{array}$ \\
\hline $\begin{array}{l}\text { Excellent } \\
\text { control }\end{array}$ & $\begin{array}{l}\text { High level of } \\
\text { equivalence between } \\
\text { SL and TL; produces } \\
\text { signs accurately, both } \\
\text { structurally and } \\
\text { conceptually; wide } \\
\text { range of well-chosen } \\
\text { vocab }\end{array}$ & $\begin{array}{l}\text { ASL syntax } \\
\text { successfully conveys a } \\
\text { wide range of } \\
\text { grammatical structures } \\
\text { (T/C, conditionals, } \\
\text { RHQs, etc.); ability to } \\
\text { use complete and } \\
\text { complex sentences }\end{array}$ & $\begin{array}{l}\text { Signing space is } \\
\text { appropriate; clear } \\
\text { establishment and use } \\
\text { of referents; excellent } \\
\text { use of spatial aspects } \\
\text { of expansion features }\end{array}$ & $\begin{array}{l}\text { High level of } \\
\text { equivalence between } \\
\text { source text and target } \\
\text { text }\end{array}$ & $\begin{array}{l}\text { Smooth and fluid } \\
\text { production; few to no } \\
\text { hesitations; pausing } \\
\text { where appropriate }\end{array}$ \\
\hline Good control & $\begin{array}{l}\text { Produces most signs } \\
\text { accurately, both } \\
\text { structurally and } \\
\text { conceptually; good } \\
\text { range of vocabulary }\end{array}$ & $\begin{array}{l}\text { ASL syntax conveys a } \\
\text { range of grammatical } \\
\text { structures (T/C, } \\
\text { conditional, RHQs, } \\
\text { etc.); mostly complete } \\
\text { sentences that are } \\
\text { complex, with few } \\
\text { errors }\end{array}$ & $\begin{array}{l}\text { Clear establishment } \\
\text { and use of referents } \\
\text { with few errors; } \\
\text { limited command of } \\
\text { spatial aspects of } \\
\text { expansion features }\end{array}$ & $\begin{array}{l}\text { Mostly successful } \\
\text { representation of } \\
\text { source text affect }\end{array}$ & $\begin{array}{l}\text { Pro'. Tion 1s. latively } \\
\text { s looth but conta. is } \\
\text { some hesitation an } \\
\text { unevenness. }\end{array}$ \\
\hline $\begin{array}{l}\text { Adequate } \\
\text { control }\end{array}$ & $\begin{array}{l}\operatorname{Pr} \text { uces } \$ 1 g_{1} \\
\text { naccurately, } \\
\text { structurally and/or } \\
\text { conceptually; limit d } \\
\text { range of vocabular } ; \text {; } \\
\text { ource text is } \\
\text { re. revable }\end{array}$ & $\begin{array}{l}\text { Source text rendered } \\
\text { faithfully with } \\
\text { occasional lapses and } \\
\text { elisions }\end{array}$ & $\begin{array}{l}\text { Establishment and use } \\
\text { of referents are not } \\
\text { clear, but meaning of } \\
\text { source text is } \\
\text { retrievable }\end{array}$ & $\begin{array}{l}\text { Off s fair } \\
\text { r'presentation } \\
\text { ource text }\end{array}$ & $\begin{array}{l}\text { Production is } \\
\text { frequently hesitant and } \\
\text { jerky }\end{array}$ \\
\hline $\begin{array}{l}\text { Weak (or no) } \\
\text { control }\end{array}$ & $\begin{array}{l}\text { Structural and/or } \\
\text { conceptual clarity of } \\
\text { signs is lacking; } \\
\text { limited } \\
\text { vocabulary....rendering } \\
\text { the source text } \\
\text { irretrievable }\end{array}$ & $\begin{array}{l}\text { Lim ed range of } \\
g \text { ammatical } \\
\text { tructures; incompl te } \\
\text { sentences that obsct e } \\
\text { neaning }\end{array}$ & $\begin{array}{l}\text { Est?' } 1 \text { shment ad use } \\
\text { of referents are no. } \\
\text { lear and rendered } \\
\text { nessage is not } \\
\text { etrievable }\end{array}$ & Affect is largely absent & $\begin{array}{l}\text { Production is slow and } \\
\text { choppy; excessive } \\
\text { pauses make } \\
\text { comprehension of the } \\
\text { source text difficult }\end{array}$ \\
\hline
\end{tabular}

Comments: Willow is clearly passionate about interpreting, but seems to lack the ability to formulate ASL interpretations from English utterances. She expressed significant access to the Deaf community, but I'm curious as to her language exposure experiences (i.e. communication variance). 


\section{Appendix P (continued)}

Post-assessment: Willow

\section{Performance Rubric for ASL Interpreting}

\begin{tabular}{|c|c|c|c|c|c|}
\hline CATEGORY & $\begin{array}{l}\text { Sign } \\
\text { production \& } \\
\text { vocabulary }\end{array}$ & Grammar & Use of Space & Affect & $\begin{array}{l}\text { Pacing and } \\
\text { Pausing }\end{array}$ \\
\hline $\begin{array}{l}\text { Excellent } \\
\text { control }\end{array}$ & $\begin{array}{l}\text { High level of } \\
\text { equivalence between } \\
\text { SL and TL; produces } \\
\text { signs accurately, both } \\
\text { structurally and } \\
\text { conceptually; wide } \\
\text { range of well-chosen } \\
\text { vocab }\end{array}$ & $\begin{array}{l}\text { ASL syntax } \\
\text { successfully conveys a } \\
\text { wide range of } \\
\text { grammatical structures } \\
\text { (T/C, conditionals, } \\
\text { RHQs, etc.); ability to } \\
\text { use complete and } \\
\text { complex sentences }\end{array}$ & $\begin{array}{l}\text { Signing space is } \\
\text { appropriate; clear } \\
\text { establishment and use } \\
\text { of referents; excellent } \\
\text { use of spatial aspects } \\
\text { of expansion features }\end{array}$ & $\begin{array}{l}\text { High level of } \\
\text { equivalence between } \\
\text { source text and target } \\
\text { text }\end{array}$ & $\begin{array}{l}\text { Smooth and fluid } \\
\text { production; few to no } \\
\text { hesitations; pausing } \\
\text { where appropriate }\end{array}$ \\
\hline Good control & $\begin{array}{l}\text { Produces most signs } \\
\text { accurately, both } \\
\text { structurally and } \\
\text { conceptually; good } \\
\text { range of vocabulary }\end{array}$ & $\begin{array}{l}\text { ASL syntax conveys a } \\
\text { range of grammatical } \\
\text { structures (T/C, } \\
\text { conditional, RHQs, } \\
\text { etc.); mostly complete } \\
\text { sentences that are } \\
\text { complex, with few } \\
\text { errors }\end{array}$ & $\begin{array}{l}\text { Clear establishment } \\
\text { and use of referents } \\
\text { with few errors; } \\
\text { limited command of } \\
\text { spatial aspects of } \\
\text { expansion features }\end{array}$ & $\begin{array}{l}\text { Most succes sil } \\
\text { re resentation of } \\
\text { s surce text affect }\end{array}$ & $\begin{array}{l}\text { Produrt... } \\
\text { sm oth but conta. 's } \\
\text { s me hesitation ano } \\
\text { nevenness. }\end{array}$ \\
\hline $\begin{array}{l}\text { Adequate } \\
\text { control }\end{array}$ & $\begin{array}{l}\operatorname{Pr} \text {-uces S1g- } \\
\text { uaccurately, } \\
\text { structurally and/or } \\
\text { conceptually; limit d } \\
\text { range of vocabulay; } \\
\text { ource text is } \\
\text { re revable }\end{array}$ & $\begin{array}{l}\text { Sour text rence ed } \\
\text { fai Afully with } \\
\text { o casional lapses anc } \\
\text { e isions }\end{array}$ & $\begin{array}{l}\text { Est olishment a. I use } \\
\text { o. referents are no } \\
\text { lear, but meaning c } \\
\text { source text is } \\
\text { otrievable }\end{array}$ & $\begin{array}{l}\text { Offers fair } \\
\text { representation of } \\
\text { source text }\end{array}$ & $\begin{array}{l}\text { Production is } \\
\text { frequently hesitant and } \\
\text { jerky }\end{array}$ \\
\hline $\begin{array}{l}\text { Weak (or no) } \\
\text { control }\end{array}$ & $\begin{array}{l}\text { Structura and/or } \\
\text { conceptual clarity of } \\
\text { signs is lacking; } \\
\text { limited } \\
\text { vocabulary....rendering } \\
\text { the source text } \\
\text { irretrievable }\end{array}$ & $\begin{array}{l}\text { Limited range of } \\
\text { grammatical } \\
\text { structures; incomplete } \\
\text { sentences that obscure } \\
\text { meaning }\end{array}$ & $\begin{array}{l}\text { Establishment and use } \\
\text { of referents are not } \\
\text { clear and rendered } \\
\text { message is not } \\
\text { retrievable }\end{array}$ & Affect is largely absent & $\begin{array}{l}\text { Production is slow and } \\
\text { choppy; excessive } \\
\text { pauses make } \\
\text { comprehension of the } \\
\text { source text difficult }\end{array}$ \\
\hline
\end{tabular}

Comments: Willow demonstrated appropriate rhythm and affect for this interpretation. She seemed obsessed with the presentation of words, rather than the illustration of ideas. 


\section{Appendix Q}

Pre-assessment: Reba

\section{Performance Rubric for ASL Interpreting}

\begin{tabular}{|c|c|c|c|c|c|}
\hline CATEGORY & $\begin{array}{l}\text { Sign } \\
\text { production \& } \\
\text { vocabulary }\end{array}$ & Grammar & Use of Space & Affect & $\begin{array}{l}\text { Pacing and } \\
\text { Pausing }\end{array}$ \\
\hline $\begin{array}{l}\text { Excellent } \\
\text { control }\end{array}$ & $\begin{array}{l}\text { High level of } \\
\text { equivalence between } \\
\text { SL and TL; produces } \\
\text { signs accurately, both } \\
\text { structurally and } \\
\text { conceptually; wide } \\
\text { range of well-chosen } \\
\text { vocab }\end{array}$ & $\begin{array}{l}\text { ASL syntax } \\
\text { successfully conveys a } \\
\text { wide range of } \\
\text { grammatical structures } \\
\text { (T/C, conditionals, } \\
\text { RHQs, etc.); ability to } \\
\text { use complete and } \\
\text { complex sentences }\end{array}$ & $\begin{array}{l}\text { Signing space is } \\
\text { appropriate; clear } \\
\text { establishment and use } \\
\text { of referents; excellent } \\
\text { use of spatial aspects } \\
\text { of expansion features }\end{array}$ & $\begin{array}{l}\text { High level of } \\
\text { equivalence between } \\
\text { source text and target } \\
\text { text }\end{array}$ & $\begin{array}{l}\text { Smooth and fluid } \\
\text { production; few to no } \\
\text { hesitations; pausing } \\
\text { where appropriate }\end{array}$ \\
\hline Good control & $\begin{array}{l}\text { Produr... signs } \\
\text { ac urately, both } \\
\text { sucturally and } \\
\text { onceptually; good } \\
\text { ange of vocabulary }\end{array}$ & $\begin{array}{l}\text { ASL syntax conveys a } \\
\text { range of grammatical } \\
\text { structures (T/C, } \\
\text { conditional, RHQs, } \\
\text { etc.); mostly complete } \\
\text { sentences that are } \\
\text { complex, with few } \\
\text { errors }\end{array}$ & $\begin{array}{l}\text { Clear establishment } \\
\text { and use of referents } \\
\text { with few errors; } \\
\text { limited command of } \\
\text { spatial aspects of } \\
\text { expansion features }\end{array}$ & $\begin{array}{l}\text { Mostly successful } \\
\text { representation of } \\
\text { source text affect }\end{array}$ & $\begin{array}{l}\text { Produ. } \\
\text { sn Joth but contat s } \\
\text { s me hesitation and } \\
\text { nevenness. }\end{array}$ \\
\hline $\begin{array}{l}\text { Adequate } \\
\text { control }\end{array}$ & $\begin{array}{l}\text { Produces signs } \\
\text { inaccurately, } \\
\text { structurally and/or } \\
\text { conceptually; limited } \\
\text { range of vocabulary; } \\
\text { source text is } \\
\text { retrievable } \\
\end{array}$ & $\begin{array}{l}\text { Source text rendered } \\
\text { faithfully with } \\
\text { occasional lapses and } \\
\text { elisions }\end{array}$ & $\begin{array}{l}\text { Est vlishment a. d use } \\
\text { c. referents are no. } \\
\text { lear, but meaning c } \\
\text { source text is } \\
\text { etrievable }\end{array}$ & $\begin{array}{l}\text { Offers fair } \\
\text { representation of } \\
\text { source text }\end{array}$ & $\begin{array}{l}\text { Production is } \\
\text { frequently hesitant and } \\
\text { jerky }\end{array}$ \\
\hline $\begin{array}{l}\text { Weak (or no) } \\
\text { control }\end{array}$ & $\begin{array}{l}\text { Structural and/or } \\
\text { conceptual clarity of } \\
\text { signs is lacking; } \\
\text { limited } \\
\text { vocabulary....rendering } \\
\text { the source text } \\
\text { irretrievable }\end{array}$ & $\begin{array}{l}\mathrm{Li} \text { - }- \text { ted range os } \\
\text { rammatical } \\
\text { structures; incomplc e } \\
\text { sentences that obsct :e } \\
\text { neaning }\end{array}$ & $\begin{array}{l}\text { Establishment and use } \\
\text { of referents are not } \\
\text { clear and rendered } \\
\text { message is not } \\
\text { retrievable }\end{array}$ & Aff $t$ is largely . 'sent & $\begin{array}{l}\text { Production is slow and } \\
\text { choppy; excessive } \\
\text { pauses make } \\
\text { comprehension of the } \\
\text { source text difficult }\end{array}$ \\
\hline
\end{tabular}

Comments: Reba struggles with rendering vocabulary and constructing conceptually accurate messages. It seems that Reba is unsure of the purpose of interpreting, the processes that guide the practice. I'm curious about her previous training/experiences. 


\section{Appendix Q (continued)}

Post-assessment: Reba

\section{Performance Rubric for ASL Interpreting}

\begin{tabular}{|c|c|c|c|c|c|}
\hline CATEGORY & $\begin{array}{l}\text { Sign } \\
\text { production \& } \\
\text { vocabulary }\end{array}$ & Grammar & Use of Space & Affect & $\begin{array}{l}\text { Pacing and } \\
\text { Pausing }\end{array}$ \\
\hline $\begin{array}{l}\text { Excellent } \\
\text { control }\end{array}$ & $\begin{array}{l}\text { High level of } \\
\text { equivalence between } \\
\text { SL and TL; produces } \\
\text { signs accurately, both } \\
\text { structurally and } \\
\text { conceptually; wide } \\
\text { range of well-chosen } \\
\text { vocab }\end{array}$ & $\begin{array}{l}\text { ASL syntax } \\
\text { successfully conveys a } \\
\text { wide range of } \\
\text { grammatical structures } \\
\text { (T/C, conditionals, } \\
\text { RHQs, etc.); ability to } \\
\text { use complete and } \\
\text { complex sentences }\end{array}$ & $\begin{array}{l}\text { Signing space is } \\
\text { appropriate; clear } \\
\text { establishment and use } \\
\text { of referents; excellent } \\
\text { use of spatial aspects } \\
\text { of expansion features }\end{array}$ & $\begin{array}{l}\text { High level of } \\
\text { equivalence between } \\
\text { source text and target } \\
\text { text }\end{array}$ & $\begin{array}{l}\text { Smooth and fluid } \\
\text { production; few to no } \\
\text { hesitations; pausing } \\
\text { where appropriate }\end{array}$ \\
\hline Good control & $\begin{array}{l}\text { Prc ices mo signs } \\
\text { ccurately, both } \\
\text { structurally and } \\
\text { conceptually; goor } \\
\text { range of vocabula }\end{array}$ & $\begin{array}{l}\text { ASL syntax conveys a } \\
\text { range of grammatical } \\
\text { structures (T/C, } \\
\text { conditional, RHQs, } \\
\text { etc.); mostly complete } \\
\text { sentences that are } \\
\text { complex, with few } \\
\text { errors }\end{array}$ & $\begin{array}{l}\text { Clear establishment } \\
\text { and use of referents } \\
\text { with few errors; } \\
\text { limited command of } \\
\text { spatial aspects of } \\
\text { expansion features }\end{array}$ & $\begin{array}{l}\text { Mostly successful } \\
\text { representation of } \\
\text { source text affect }\end{array}$ & $\begin{array}{l}\text { Prodivelatively } \\
\text { sn joth but conta. 's } \\
\text { ome hesitation and } \\
\text { inevenness. }\end{array}$ \\
\hline $\begin{array}{l}\text { Adequate } \\
\text { control }\end{array}$ & $\begin{array}{l}\text { Produces signs } \\
\text { inaccurately, } \\
\text { structurally and/or } \\
\text { conceptually; limited } \\
\text { range of vocabulary; } \\
\text { source text is } \\
\text { retrievable }\end{array}$ & $\begin{array}{l}\text { Sou-ce text rench red } \\
\text { f? hfully with } \\
\text { ccasional lapses an } \\
\text { lisions }\end{array}$ & $\begin{array}{l}\text { Est-11shmenı. nd use } \\
\text { c. referents are nc } \\
\text { lear, but meaning if } \\
\text { source text is } \\
\text { etrievable }\end{array}$ & $\begin{array}{l}\text { Offe sair } \\
\text { re presentation o } \\
\text { ource text }\end{array}$ & $\begin{array}{l}\text { Production is } \\
\text { frequently hesitant and } \\
\text { jerky }\end{array}$ \\
\hline $\begin{array}{l}\text { Weak (or no) } \\
\text { control }\end{array}$ & $\begin{array}{l}\text { Structural and/or } \\
\text { conceptual clarity of } \\
\text { signs is lacking; } \\
\text { limited } \\
\text { vocabulary...rendering } \\
\text { the source text } \\
\text { irretrievable }\end{array}$ & $\begin{array}{l}\text { Limited range of } \\
\text { grammatical } \\
\text { structures; incomplete } \\
\text { sentences that obscure } \\
\text { meaning }\end{array}$ & $\begin{array}{l}\text { Establishment and use } \\
\text { of referents are not } \\
\text { clear and rendered } \\
\text { message is not } \\
\text { retrievable }\end{array}$ & Affect is largely absent & $\begin{array}{l}\text { Production is slow and } \\
\text { choppy; excessive } \\
\text { pauses make } \\
\text { comprehension of the } \\
\text { source text difficult }\end{array}$ \\
\hline
\end{tabular}

Comments: Reba faithfully rendered the message in this interpretation. She seems more confident and chooses signs based on conceptual representation, rather than literal meaning. I feel that Reba could benefit from more language exposure to expand her perspective on ASL communication. 